\title{
ANÁLISE NUMÉRICA DA ANCORAGEM EM LIGAÇÕES DO TIPO VIGA-PILAR DE EXTREMIDADE
}

\author{
Edson Costa de Assis Júnior
}

Dissertação apresentada à Escola de Engenharia de São Carlos da Universidade de São Paulo, como requisito para a obtenção do Título de Mestre em Engenharia de Estruturas.

Orientador: José Samuel Giongo 
Ficha catalográfica preparada pela Seção de Tratamento da Informação do Serviço de Biblioteca - EESC/USP

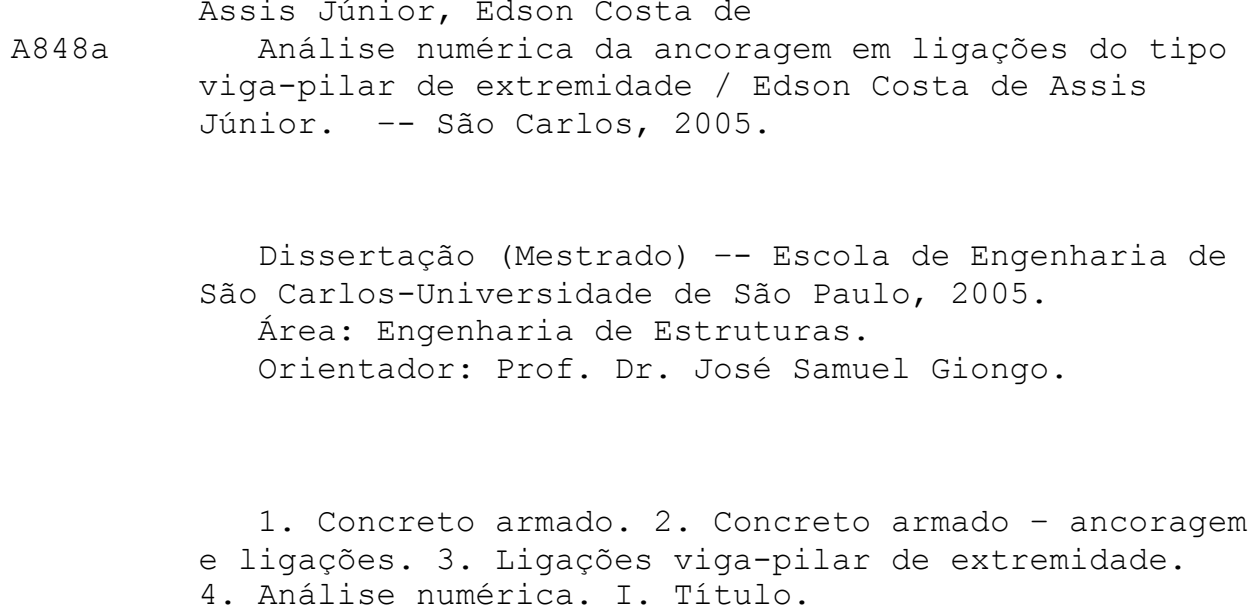

1. Concreto armado. 2. Concreto armado - ancoragem e ligações. 3. Ligações viga-pilar de extremidade. 4. Análise numérica. I. Título. 
Candidato: Engenheiro EDSON COSTA DE ASSIS JÚNIOR

Dissertação đefendida e julgada em 14-10-2005 perante a Comissão Julgadora:

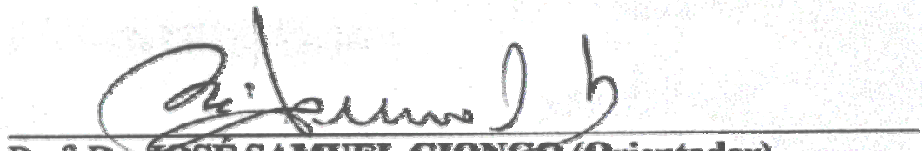

Prof. Dr IOSÉ SAMUEL GIONGO (Orientador)

(Escola de Engenharia de São Carlos/USP)

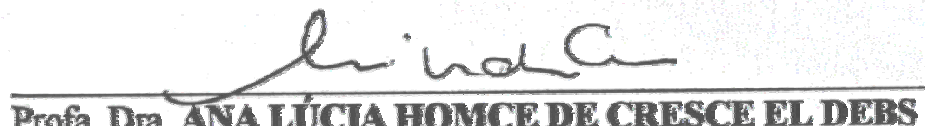

(Escola đe Engenharia de São Carlos/USP)

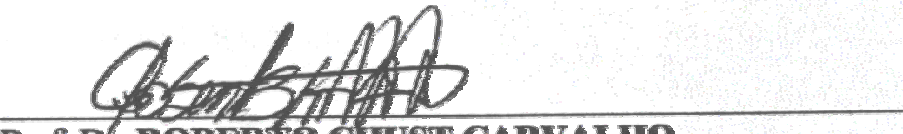

Prof. DE. ROBERTO CHUST CARVALHO

(Universidade Federal de São Carlos/UFSCar)
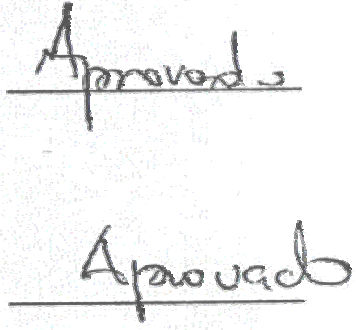

Apromedo

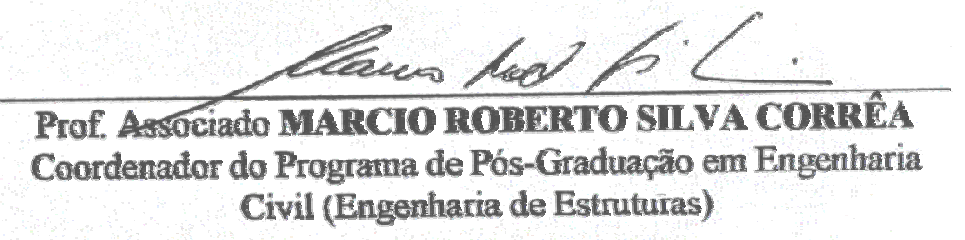

Civil (Engenharia de Estruturas)

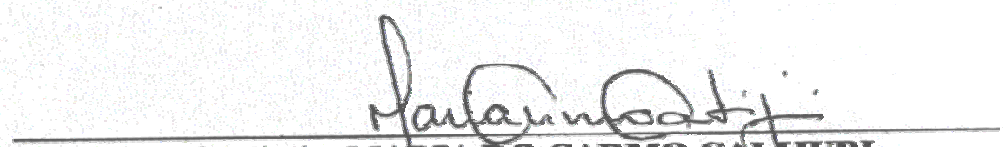

Profa. Titular MARIA DO CARMO CANJJURI

Presidente da Comissão de Pós-Graduação 
As pessoas que mais amo, meus pais, Edson e Anésia e meus irmãos, Danilo e Irla. 


\section{AGRADECIMENTOS}

A Deus pela saúde, força, resignação, paciência e determinação para enfrentar e superar mais um desafio na minha vida.

A minha família, em especial, meus pais, Edson Costa de Assis e Maria Anésia de Jesus Assis e meus irmãos, Danilo Bruno de Jesus Assis e Irla Bruna de Jesus Assis, pelo incentivo, amor e compreensão.

Ao professor José Samuel Giongo, pela orientação e amizade construída ao longo desses anos.

Aos professores, Mounir Khalil El Debs e Roberto Chust de Carvalho pelas contribuições dadas no exame de qualificação.

Aos engenheiros da empresa AEOLUS Engenharia e Consultoria Ltda, Marco Antônio Nagliati e Edmilson Roberto Gavioli, pela colaboração e fornecimento do projeto que viabilizou as análises desenvolvidas no estudo de caso.

Aos colegas e companheiros de departamento, Rodrigo Gustavo Delalibera, Selma Hissae Shimura da Nóbrega e Petrus Gorgônio Bulhões da Nóbrega, pelo auxílio no entendimento das análises numéricas.

A bibliotecária Elena Luzia Palloni Gonçalves da biblioteca central da Escola de Engenharia de São Carlos pelas correções das referências.

Aos professores e funcionários do Departamento de Engenharia de Estruturas pelo apoio dado direta ou indiretamente para a realização deste trabalho.

Aos amigos e companheiros de república, Geilson Márcio Albuquerque de Vasconcelos e Jefferson Lins da Silva, pelos aprendizados de convivência, companheirismo e amizade.

Aos amigos, Jerônymo Peixoto Athayde Pereira e Walter Luiz Andrade de Oliveira, pelo acolhimento, amizade e ajuda indispensável durante este período.

Aos demais conterrâneos da minha querida Alagoas, terra que me adotou, Alexandre (Topó), Márcio Félix, Valber Pedrosa, Fábio Lopes, Eduardo Toledo, Gustavo Codá, Rafael Piatti, André Dória, Saulo Almeida, Eduardo Lucena e Antônio Netto.

Aos colegas de departamento e aqueles que fizeram parte da turma de mestrado 2003, Claudius Barbosa, Wesley Wutzow, Sandra Almeida, Daniane Vicentini, Michel Macedo, Kenneth Borja, Caio Gorla, Fernando Fontes, César Ataíde, Vladimir Haach, dentre outros que eu não citei, pela amizade selada no decorrer deste tempo e pelos momentos de descontração e alegria vivenciados a cada dia.

Ao CNPq, Conselho Nacional de Desenvolvimento Científico e Tecnológico, pelo suporte financeiro. 


\section{SUMÁRIO}

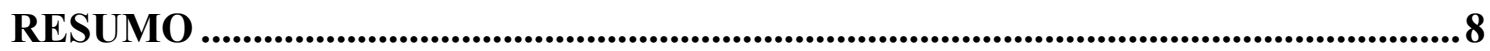

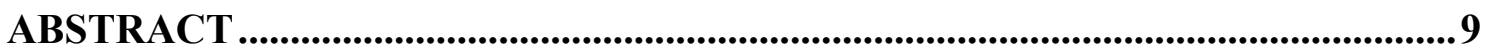

LISTA DE FIGURAS ....................................................................................10

LISTA DE TABELAS ..................................................................................14

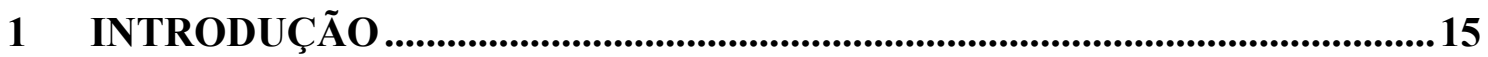

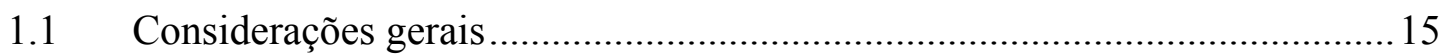

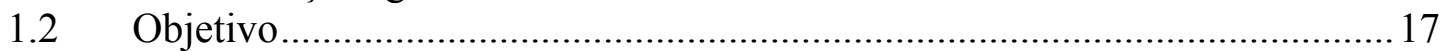

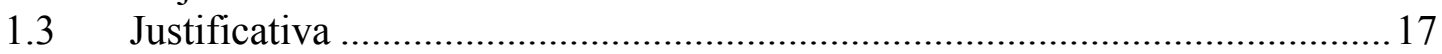

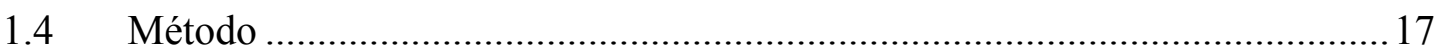

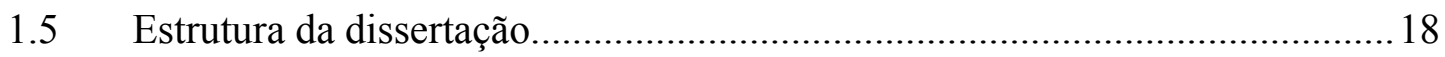

2 ASPECTOS BÁSICOS DA ANCORAGEM ...................................................19

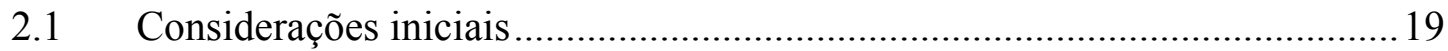

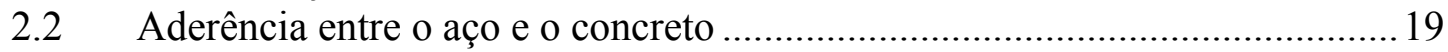

2.3 Ancoragens usuais das armaduras longitudinais de flexão ..........................26

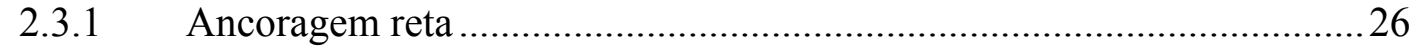

2.3.2 Ancoragem com gancho de extremidade ............................................28

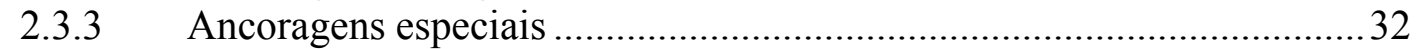

2.3.3.1 Ancoragem em laço....................................................................... 32

2.3.3.2 Placa de ancoragem.................................................................... 33

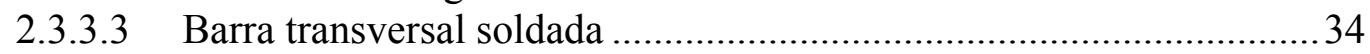

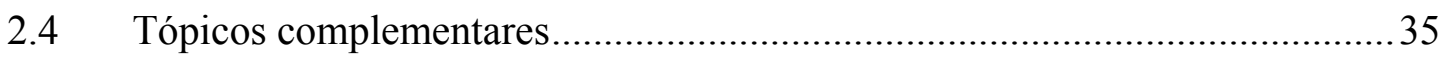

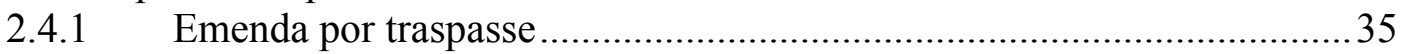

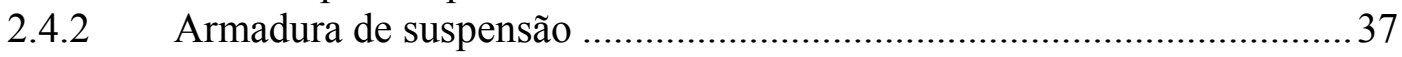

3 ARRANJOS CONSTRUTIVOS DAS ANCORAGENS EM LIGAÇÕES DE ELEMENTOS ESTRUTURAIS..................................................................................38

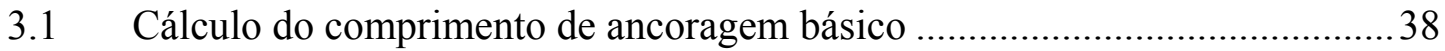

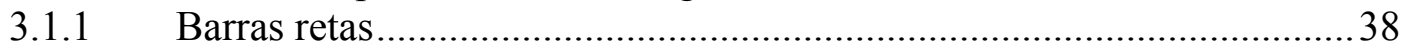

3.1.2 Barras com ganchos de extremidade......................................................4 43

3.2 Decalagem do diagrama de forças nas armaduras ........................................4 44

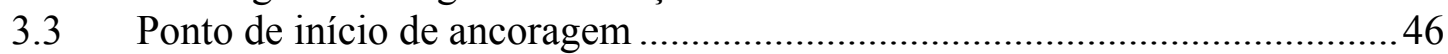

3.4 Ancoragem das armaduras de tração nas seções de apoio ..............................51

3.5 Ligações entre elementos estruturais de concreto armado ..............................53

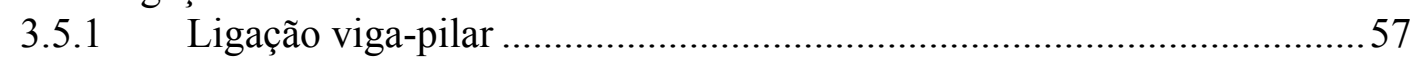

3.5.1.1 Ligação viga de cobertura-pilar extremidade ...................................57

3.5.1.2 Ligação viga de cobertura-pilar intermediário ..................................62

3.5.1.3 Ligação viga intermediária-pilar de extremidade..............................63

3.5.1.4 Ligação viga intermediária-pilar intermediário................................6 67

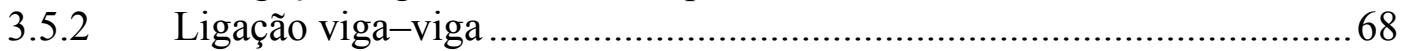

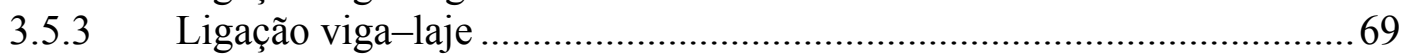

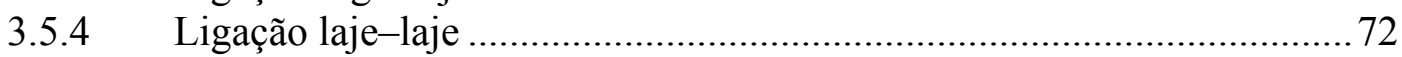




\section{CRITÉRIOS ADOTADOS NA AVALIAÇÃO NUMÉRICA DAS}

ANCORAGENS NAS LIGAÇÕES ...............................................................................76

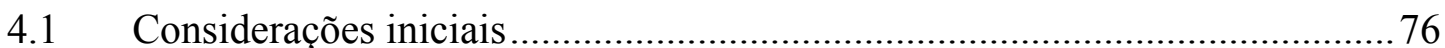

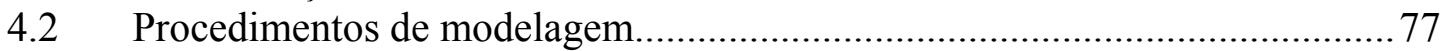

4.2.1 Modelos constitutivos dos materiais ....................................................... 77

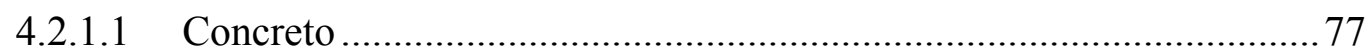

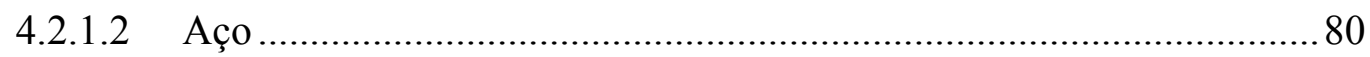

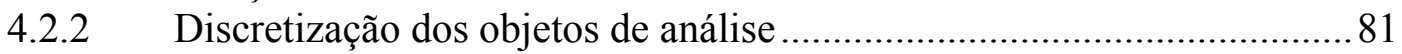

4.2.2.1 Seleção dos elementos .................................................................... 81

4.3 Simulação preliminar para aferição do programa ADINA (2002).................. 82

4.3.1 Descrição do modelo experimental de Ortiz (1993) ................................. 82

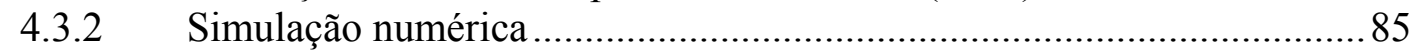

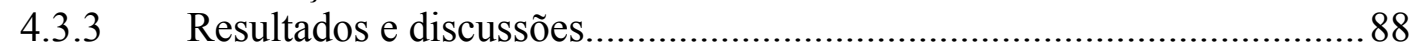

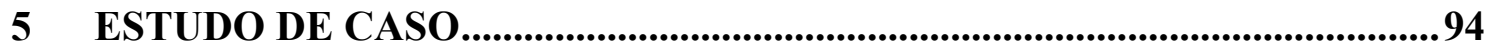

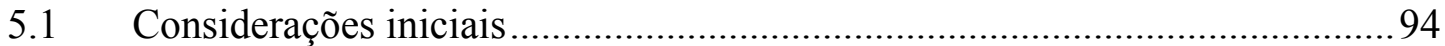

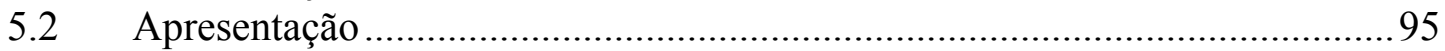

5.3 Descrição dos modelos físicos das ligações viga-pilar ................................... 96

5.4 Procedimentos de concepção e análise dos modelos numéricos.................... 101

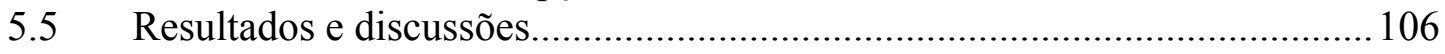

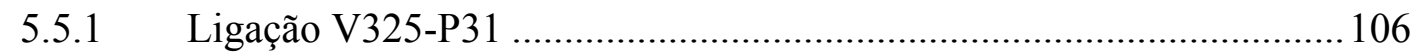

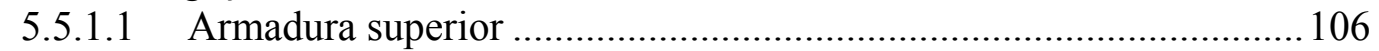

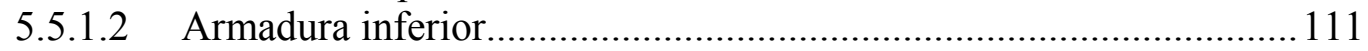

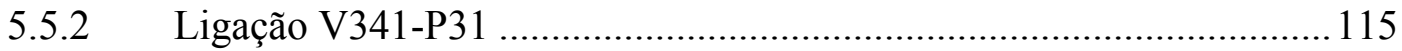

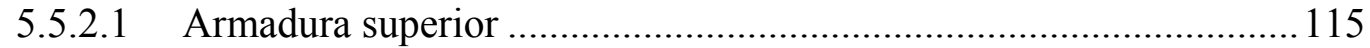

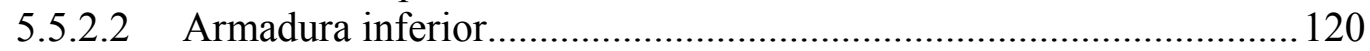

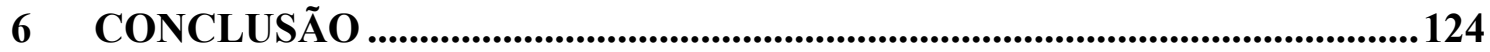

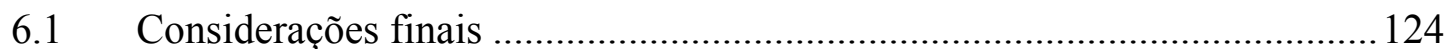

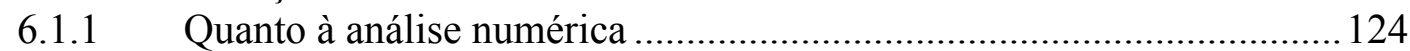

6.1.2 Quanto aos parâmetros de análise ...................................................... 125

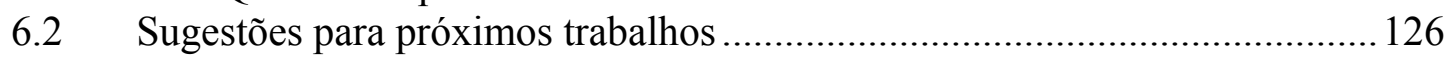

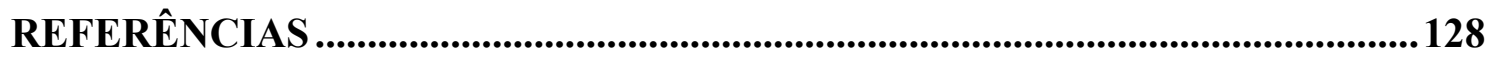




\section{RESUMO}

ASSIS JÚNIOR, E. C. (2005). Análise numérica da ancoragem em ligações do tipo viga-pilar de extremidade. Dissertação (Mestrado) - Escola de Engenharia de São Carlos, Universidade de São Paulo, São Carlos.

Este trabalho é uma contribuição ao estudo da ancoragem de barras de aço da armadura longitudinal em ligações de elementos fletidos de concreto armado em edifícios usuais. São investigadas importantes pesquisas que mostram os avanços em relação ao entendimento do tema nas últimas décadas. É proposto um método de aferição dos modelos constitutivos dos materiais, concreto e aço, no programa de elementos finitos ADINA para verificações de projeto seguindo recomendações da NBR 6118:2003 e MC CEB-FIP 1990. São realizadas análises numéricas de modelos bidimensionais em ligações viga-pilar de extremidade os quais são comparados a modelos experimentais e retirados de projetos já existentes. Os parâmetros de análise são o momento de fissuração e a força de tração a ancorar na seção mais solicitada da viga, conferidos com valores calculados por métodos analíticos e/ou expressões normativas, as tensões e deformações máximas em pontos ao longo do trecho ancorado das armaduras de longitudinais da viga e a influência da força normal. Os resultados revelam que as simplificações e hipóteses assumidas para a concepção dos modelos numéricos são consistentes.

Palavras-chave: concreto armado, concreto armado - ancoragem e ligações, ligações viga-pilar de extremidade, análise numérica. 


\begin{abstract}
ASSIS JÚNIOR, E. C. (2005). Numerical analysis of the anchorage in the exterior beam-column connections. Master's degree dissertation - Engineering School at São Carlos, São Paulo University, São Carlos.

This work contributes to the study of anchorage of longitudinal reinforcement steel bars in connections of flexural elements in reinforced concrete buildings. Some important researches are investigated showing the advances of the subject in the last decades. An evaluation method of material's constitutive models, steel and concrete, using the Finite Element Analysis in the software ADINA is proposed, to project verifications according to NBR 6118:2003 and MC CEB-FIP 1990 recommendations. Comparisons between numerical analysis by using a two-dimensional model of exterior beam-column connections and experimental analysis and using existing projects are made. The analysis parameters are the cracking moment and the anchored steel bar tension force in the most requested beam section, compared to the values calculated by analytical methods and/or design expressions, the maximum stresses and strains in points along to anchored steel bar of the beam longitudinal reinforcement and the influence of the normal force. The results show that the assumed simplifications and hypothesis for the numerical model conception are consistent.
\end{abstract}

Keywords: reinforced concrete, reinforced concrete - anchorage and connections, exterior beam-column connections, numerical analysis. 


\section{LISTA DE FIGURAS}

Figura 2.1 - (a) Aderência por adesão; (b) Aderência por atrito; (c) Aderência mecânica

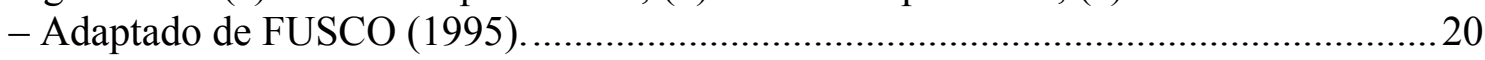

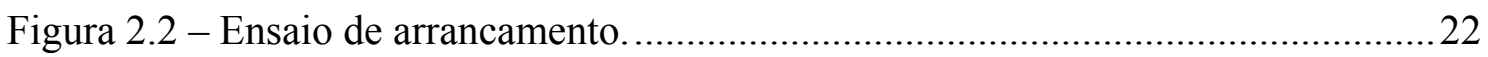

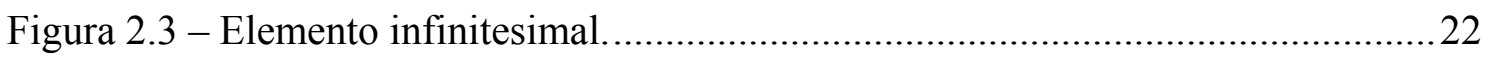

Figura 2.4 - Situações de boa e má aderência - PROMON (1976)................................25

Figura 2.5 - Esforços reais de ancoragem - Modificado de FUSCO (1995). ................22

Figura 2.6 - Fendilhamento cônico (barras tracionadas) - Modificado de FUSCO (1995).

Figura 2.7 - Fendilhamento lateral do concreto (barras comprimidas) - Modificado de FUSCO (1995).

Figura 2.8 - Distribuição das pressões no interior do gancho gradual e semicircular -

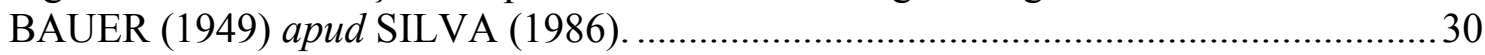

Figura 2.9 - Ancoragem em laço - Adaptado de SÜSSEKIND (1981)......................... 33

Figura 2.10 - Ancoragem mecânica com placas soldadas - Modificado de FUSCO (1995).

Figura 2.11 - Ancoragem com barras transversais soldadas - NBR 6118:2003 ............ 35

Figura 2.12 - Emenda por traspasse de barras tracionadas............................................ 36

Figura 2.13 - Tirante de suspensão - Modificado de FUSCO (1995)............................ 37

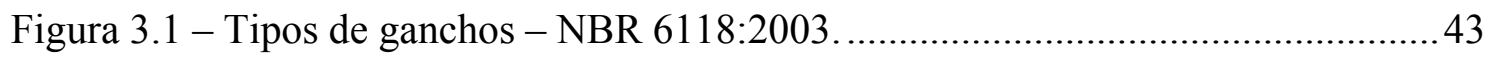

Figura 3.2 - Decalagem do diagrama de momento fletor deslocado:............................ 44

Figura 3.3 - Zona de compressão transversal - Modificado de FUSCO (1995)............ 46

Figura 3.4 - Detalhe construtivo para barras retiradas de serviço - FUSCO (1995)......47

Figura 3.5 - Cobertura do diagrama de força de tração solicitante pelo diagrama resistente - Modificado da NBR 6118:2003 ........................................................ 48

Figura 3.6 - Diagrama de momentos fletores de cálculo estratificado..........................49

Figura 3.7 - Ancoragem de barras em apoios intermediários - (a) prolongamentos das barras até os apoios; (b) interrupção das barras antes dos apoios.

Figura 3.8 - Procedimento prático para detalhamento das barras das armaduras positivas

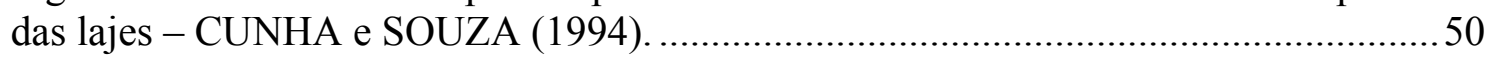

Figura 3.9 - Procedimento prático para detalhamento das barras das armaduras negativas das lajes - CUNHA e SOUZA (1994) ....................................................... 51

Figura 3.10 - (a) Barra em ponta reta; (b) Barra em gancho - PROMON (1976). ........53

Figura 3.11 - Ligação viga de cobertura-pilar de extremidade submetida a momento fletor positivo - Modificado de LEONHARDT e MÖNNIG (1978). 
Figura 3.12 - Resultados da verificação da eficiência de nós de pórticos e estado fissurado das ligações para os arranjos adotados - Adaptado de NILSSON e LOSBERG (1976).

Figura 3.13 - Ligação viga de cobertura-pilar de extremidade submetida a momento fletor negativo - Modificado de LEONHARDT e MÖNNIG (1978).

Figura 3.14 - a) Espaçamento entre as barras e b) Detalhamento adequado - Modificado de LEONHARDT e MÖNNIG (1978).

Figura 3.15 - Emenda por traspasse no nó - Modificado de LEONHARDT e MÖNNIG (1978).

Figura 3.16 - Arranjo de armaduras proposto para $h_{v}>1,5 h_{p}-$ MC CEB-FIP 1990_...66

Figura 3.17 - Panorama do fluxo de tensões elásticas na ligação viga de cobertura pilar intermediário e detalhamento recomendado - LEONHARDT e MÖNNIG (1978).

Figura 3.18 - Viga engastada elasticamente em pilar de extremidade - Modificado de LEONHARDT e MÖNNIG (1978).

Figura 3.19 - Mecanismos de transferência de tensões - Adaptado de ORTIZ (1993). 65

Figura 3.20 - Arranjos de armaduras propostos para a ligação viga intermediária - pilar

de extremidade - Modificado de LEONHARDT e MÖNNIG (1978). 66

Figura 3.21 - Modelos e arranjos de armaduras para ligação viga intermediária - pilar intermediário - Modificado de LEONHARDT e MÖNNIG (1978).

Figura 3.22 - Fluxo de tensões na ligação viga-viga - LEONHARDT e MÖNNIG (1978).

Figura 3.23 - Zona de distribuição da armadura de suspensão - Adaptado de LEONHARDT e MÖNNIG (1978).

Figura 3.24 - Engastamento parcial da ligação viga-laje - Modificado de LEONHARDT e MÖNNIG (1978).

Figura 3.25 - Engastamento na viga de apoio - Modificado de LEONHARDT e MÖNNIG (1978).

Figura 3.26 - Laje em balanço pendurada em uma viga invertida - LEONHARDT e MÖNNIG (1978).

Figura 3.27 - Momentos fletores e forças normais de tração - Modificado de FUSCO (1995).

Figura 3.28 - Arranjos típicos das armaduras para reservatório elevado - CUNHA e SOUZA (1994).

Figura 3.29 - Arranjos típicos das armaduras para reservatório enterrado - CUNHA e SOUZA (1994).

Figura 4.1 - Relação uniaxial tensão-deformação do concreto - Adaptado de ADINA (2002).

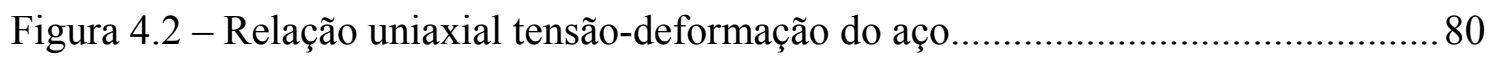

Figura 4.3 - Elemento finito 2-D SOLID - Modificado de ADINA 8.0 (2002)............. 81

Figura 4.4 - Elemento finito TRUSS - Modificado de ADINA 8.0 (2002)..................... 82 
Figura 4.5 - Ligação viga-pilar BCJ2 (Dados geométricos) - Adaptado de ORTIZ (1993).

Figura 4.6 - Instrumentação da barra da armadura longitudinal da viga - Adaptado de ORTIZ (1993).

Figura 4.7 - Detalhe das barras da armadura longitudinal superior da viga na região do

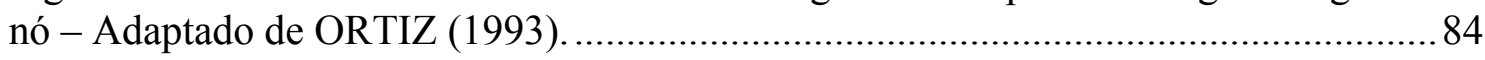

Figura 4.8 - Disposição geométrica do modelo numérico da ligação BCJ2 . ..................85

Figura 4.9 - Disposição da malha de elementos finitos da ligação BCJ2 ....................... 86

Figura 4.10 - Diagrama força aplicada versus deformação no ponto E-1 ..................... 89

Figura 4.11 - Diagrama força aplicada versus deformação no ponto E-2 ......................90

Figura 4.12 - Diagrama força aplicada versus deformação no ponto E-3..................... 90

Figura 4.13 - Diagrama força aplicada versus deformação no ponto E-4 ......................91

Figura 4.14 - Diagrama força aplicada versus deformação no ponto E-5 ..................... 91

Figura 5.1 - Quarta parte da forma estrutural do pavimento-tipo................................. 95

Figura 5.2 - Detalhamento das armaduras longitudinais e transversais das vigas na ligação com o pilar P31: (a) V325; (b) V341; (c) Seção transversal. .............................. 97

Figura 5.3 - Disposição das armaduras longitudinal e transversal do pilar P31: ......... 100

Figura 5.4 - Simplificações quanto à disposição das armaduras longitudinais das vigas.

Figura 5.5 - Pontos de medição na armadura longitudinal da viga: .....

Figura 5.6 - Diagrama momento fletor no eixo do apoio da viga V325 versus deformação no ponto P-1.

Figura 5.7 - Diagrama momento fletor no eixo do apoio da viga V325 versus deformação no ponto P-2.

Figura 5.8 - Diagrama momento fletor no eixo do apoio da viga V325 versus deformação no ponto P-3.

Figura 5.9 - Diagrama momento fletor no eixo do apoio da viga V325 versus deformação no ponto P-4.

Figura 5.10 - Diagrama momento fletor no eixo do apoio da viga V325 versus deformação no ponto P-5.

Figura 5.11 - Diagrama momento fletor no eixo do apoio da viga V325 versus deformação no ponto P-6.

Figura 5.12 - Diagrama momento fletor no eixo do apoio da viga V341 versus deformação no ponto P-1.

Figura 5.13 - Diagrama momento fletor no eixo do apoio da viga V341 versus deformação no ponto P-2.

Figura 5.14 - Diagrama momento fletor no eixo do apoio da viga V341 versus deformação no ponto P-3.

Figura 5.15 - Diagrama momento fletor no eixo do apoio da viga V341 versus deformação no ponto P-4. 
Figura 5.16 - Diagrama momento fletor no eixo do apoio da viga V341 versus deformação no ponto P-5.

Figura 5.17 - Diagrama momento fletor no eixo do apoio da viga V341 versus deformação no ponto P-6.

Figura 5.18 - Diagrama momento fletor no eixo do apoio da viga V341 versus deformação no ponto P-7.

Figura 5.19 - Diagrama momento fletor no eixo do apoio da viga V341 versus deformação no ponto P-8. 


\section{LISTA DE TABELAS}

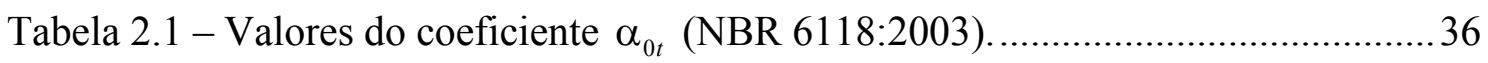

Tabela 3.1 - Coeficientes para os fatores redutores do comprimento de ancoragem

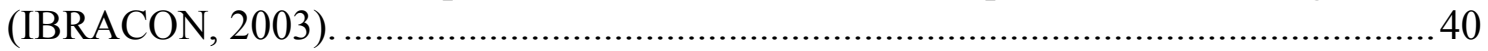

Tabela 3.2 - Valores de $c_{d}, k$ e $\lambda$ (IBRACON, 2003).............................................. 40

Tabela 3.3 - Fatores de majoração e/ou minoração do comprimento de ancoragem.....42

Tabela 3.4 - Diâmetros dos pinos de dobramento - NBR 6118:2003 ............................43

Tabela 4.1 - Valores do coeficiente $\alpha_{F}$ (MC CEB-FIP 1990).................................... 80

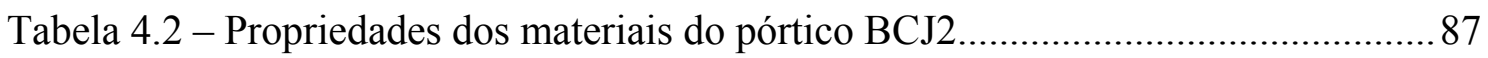

Tabela 4.3 - Valores máximos das tensões e deformações nos pontos verificados. ......92

Tabela 4.4 - Valores da força de tração por barra nos pontos E-2 e E-3 ....................... 92

Tabela 5.1 - Momento resistente de cálculo, força última correspondente e força aplicada nas vigas.

Tabela 5.2 - Valores da força normal e da pressão aplicada nos modelos das ligações.

Tabela 5.3 - Propriedades dos materiais das ligações V325-P31 e V341-P31.............. 104

Tabela 5.4 - Valores máximos das tensões e deformações nos pontos analisados na

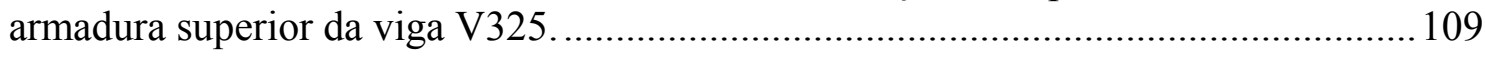

Tabela 5.5 - Valores últimos da força de tração por barra da armadura superior da viga V325 na seção na face do apoio........................................................................... 110

Tabela 5.6 - Valores máximos das tensões e deformações nos pontos analisados na

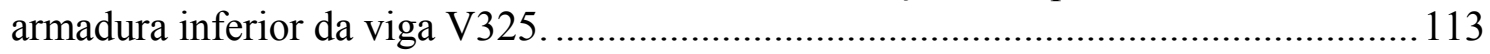

Tabela 5.7 - Valores últimos da força de tração por barra da armadura inferior da viga V325 na seção na face do apoio.

Tabela 5.8 - Valores máximos das tensões e deformações nos pontos analisados na armadura superior da viga V341.

Tabela 5.9 - Valores últimos da força de tração por barra da armadura superior da viga V341 na seção na face do apoio.

Tabela 5.10 - Valores máximos das tensões e deformações nos pontos analisados na armadura inferior da viga V341.

Tabela 5.11 - Valores últimos da força de tração por barra da armadura inferior da viga V341 na seção na face do apoio. 


\section{Introdução}

\subsection{Considerações gerais}

No advento do concreto armado como alternativa para concepção de estruturas em geral, as ligações eram tidas como simples "prolongamentos" dos elementos suportados nos apoios, pois, acreditava-se que o comportamento estrutural ao longo de toda peça fosse invariável e uniforme. Ao passar do tempo percebeu-se que, embora a estrutura estivesse corretamente dimensionada, ocorriam sérios problemas ou até mesmo a ruína das edificações geralmente na região de encontro das peças.

Esse problema motivou o surgimento de estudos para o pleno entendimento do fluxo de tensões nas ligações a fim de se obter arranjos ótimos das armaduras que garantissem a sua funcionalidade e exeqüibilidade. Com o avanço das pesquisas, observou-se que a ancoragem inadequada das armaduras é uma das possíveis causas para a ruína das ligações.

Nos elementos estruturais de concreto armado, a ancoragem tem como finalidade assegurar a solidarização de dois materiais, barras ou fios de aço e concreto, que é a própria justificativa da existência do concreto armado como material estrutural. É oportuno lembrar que o concreto absorve as deformações de compressão, sendo que as de tração, por conseguinte, são absorvidas por barras de aço nas regiões onde elas ocorrem.

A eficiência da ancoragem não está vinculada às tensões longitudinais, mas sim às tensões atuantes na seção transversal da barra a ser ancorada. Visando melhores condições de aderência, essas tensões devem ser de compressão. Portanto, é preferível 
que as barras ancoradas estejam situadas em zonas de compressão perpendiculares ao eixo das barras, conforme Fusco (1995).

As pontas das barras ancoradas podem ser retas ou curvas. Fusco (1995) relatou que nas ancoragens retas, as forças são transmitidas por solicitações tangenciais. Nas ancoragens curvas, parte da força a ancorar é transmitida para o concreto por compressão (solicitações normais) e não apenas por solicitações tangenciais. Contudo, essas tensões são acompanhadas por tensões transversais de tração que tendem a provocar o fendilhamento do concreto. Nos trechos curvos, onde estão concentradas as tensões normais, há um aumento na capacidade de ancoragem por atrito.

Os fatores relevantes para a determinação do comprimento de ancoragem das barras em elementos fletidos de concreto armado são: conformação superficial das barras, qualidade e resistência do concreto, posição da armadura em relação às etapas de concretagem, as forças de tração nas barras e o arranjo da própria ancoragem.

De acordo com os critérios de dimensionamento e detalhamento das armaduras de tração ancoradas por aderência, estabelecidos pela NBR 6118:2003, apenas parte das barras das armaduras dos elementos suportados devem ser levadas aos apoios. As barras prolongadas até os apoios, em elementos estruturais lineares e bidimensionais, para serem convenientemente ancoradas necessitam, não só do que foi exposto nos parágrafos anteriores, mas também de condições geométricas, isto é, dimensões dos elementos de apoio na direção do elemento estrutural analisado, suficientes para transferir a força a ancorar.

Já as ancoragens das barras tiradas de serviço (decalagem do diagramas de momentos fletores) antes dos apoios são verificadas com as condições de resistência do concreto e do aço, definindo o comprimento de ancoragem necessário para transferir as forças atuantes nas barras para o concreto que as envolve.

A razão deste estudo enfoca uma questão claramente abordada na norma brasileira aqui tratada, sobre as condições que devem ser satisfeitas pelas armaduras longitudinais destinadas a absorver as forças de tração junto aos apoios. Em grande parte dos casos de projetos de edifícios, as vigas têm larguras determinadas em função das espessuras das paredes de alvenaria, que na maioria das situações leva o projetista a adotar valores entre $10 \mathrm{~cm}$ e $20 \mathrm{~cm}$. Por isso, verifica-se que em determinadas situações, a área de aço das barras das armaduras longitudinais prolongadas até vigas estreitas e pilares com a menor dimensão paralela ao eixo da viga, não atende ao critério quanto à 
área de aço necessária para garantir a ancoragem da diagonal de compressão e resistir à força de tração $\left(R_{s t}\right)$.

Por causa das pequenas espessuras disponíveis para ancoragem das barras podem ser necessários ganchos nas extremidades, os quais em alguns casos, também são insuficientes conforme a verificação da força a ancorar nos apoios. Com isso, supõe-se que outros mecanismos colaborem significativamente para garantir uma ancoragem segura das armaduras dos elementos suportados.

\subsection{Objetivo}

Os objetivos do trabalho foram avaliar numericamente ligações do tipo vigapilar de extremidade e aprofundar os conhecimentos a respeito do comportamento das ligações entre elementos estruturais de concreto armado, principalmente com relação as ancoragens das barras das armaduras longitudinais.

\subsection{Justificativa}

A limitação das dimensões dos elementos estruturais e a necessidade de se atender aos critérios de ancoragem podem ocasionar o congestionamento das armaduras que concorrem na região de encontro das peças. Por causa da taxa de armadura nas ligações, essas regiões oferecem condições mais difíceis de concretagem. Por isso, é imprescindível averiguar o comportamento das ligações.

\subsection{Método}

O método empregado se fundamentou em revisão bibliográfica acerca de trabalhos já desenvolvidos e disponíveis na literatura técnica a respeito do tema e algumas análises numéricas com base em modelos teóricos.

Posteriormente, foram conduzidas simulações em modelos bidimensionais, no programa Automatic Dynamic Incremental Nonlinear Analysis - ADINA (2002), de ligações do tipo viga-pilar de extremidade de projetos estruturais já existentes.

A avaliação numérica teve como propósitos, a verificação do comportamento das armaduras longitudinais da viga em termos das tensões e deformações em pontos 
localizados na região do nó, do momento de fissuração e da força de tração a ancorar na seção mais solicitada e a análise da influência da força normal atuante nos elementos de apoio nas regiões nodais.

\subsection{Estrutura da dissertação}

A dissertação foi estruturada em seis capítulos resumidamente apresentados a seguir:

- O capítulo 1 expõe uma breve introdução a respeito do tema proposto, o objetivo e a justificativa que motivaram a pesquisa, e o método empregado para o desenvolvimento do trabalho;

- O capítulo 2 apresenta os aspectos básicos relativos à ancoragem como, sua relação com a aderência entre o aço e o concreto e outras variáveis que interferem no seu comportamento adequado, e os tipos de ancoragem comumente empregados nas ligações entre elementos estruturais de concreto armado de edificações usuais;

- O capítulo 3 trata de uma abordagem das prescrições normativas sobre ancoragem e o desenvolvimento das pesquisas que revelam sua participação no comportamento das ligações;

- O capítulo 4 traz toda discussão sobre o método utilizado para análise numérica, bem como as considerações e hipóteses assumidas, e um exemplo preliminar para aferição do programa ADINA (2002);

- O capítulo 5 mostra um estudo de caso real de ligações do tipo viga-pilar de extremidade de um edifício residencial em concreto armado;

- O capítulo 6 apresenta as conclusões deste estudo e as propostas para os próximos trabalhos. 


\section{Aspectos básicos da ancoragem}

\subsection{Considerações iniciais}

O princípio da ancoragem é assegurar que as forças atuantes de tração e/ou de compressão sejam transferidas na massa de concreto adjacente as barras da armadura. Essa transferência só existe por causa das tensões de aderência geradas a partir do deslocamento relativo entre o concreto e o aço. Partindo dessa consideração, neste contexto são apresentados os diversos tipos de sistemas de ancoragem comumente empregados na construção civil para obras em concreto armado.

O texto deste capítulo apresenta os tipos de ancoragem que são usados apenas nas ligações entre elementos estruturais de concreto armado, por isso, o levantamento bibliográfico privilegia os tópicos relacionados a essas regiões havendo, consequentemente, algumas limitações.

Nessa etapa são apresentadas às idealizações dos mecanismos de transferências das tensões, em especial das barras nervuradas, e a evolução nos estudos das ancoragens e dos parâmetros inerentes.

\subsection{Aderência entre o aço e o concreto}

A concepção de elementos estruturais de concreto armado consiste na intrínseca união entre o aço e o concreto. A relação entre esses dois materiais de naturezas diferentes se estabelece por meio da aderência que funciona como um mecanismo de transferência de tensões, que garante a compatibilidade de deformações entre a armadura e as fibras circunvizinhas de concreto. 
A aderência pode ser dividida esquematicamente em três segmentos: aderência por adesão, por atrito e mecânica (Figura 2.1). Embora conste na literatura, na realidade, não se pode determiná-las experimentalmente em separado.

A aderência por adesão funciona como uma colagem entre a nata de cimento e a armadura oriunda das ligações físico-químicas existentes entre ambos. Tal propriedade depende, basicamente, da aspereza e da limpeza superficial das barras. Contudo, apenas esse efeito é insuficiente para resistir a pequenos escorregamentos o que propiciam a destruição dessa ligação entre os materiais. Para fins usuais, considera-se essa parcela seja destruída pelas ações de serviço ou retração do concreto.

Ao passo que haja um pequeno deslocamento relativo e seja destruída a ligação por adesão, surge o efeito de atrito inerente à rugosidade das armaduras e das pressões transversais às quais as barras são submetidas. Essas pressões são provenientes das tensões de compressão transversais causadas pelas ações, pela retração ou expansão do concreto.

Com a relação à aderência mecânica, essa parcela torna-se evidente quando as barras da armadura são nervuradas, pois as saliências propositais, nas denominadas "barras de alta aderência" atuam como peças de apoio, mobilizando tensões de compressão no concreto. Entretanto, nas barras lisas, esse efeito mecânico também está presente em virtude das irregularidades superficiais no processo de fabricação do aço.

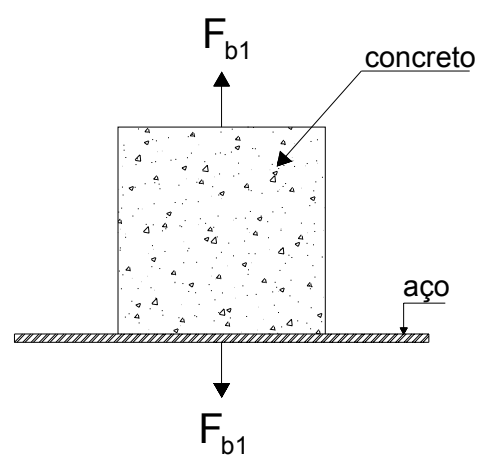

(a)

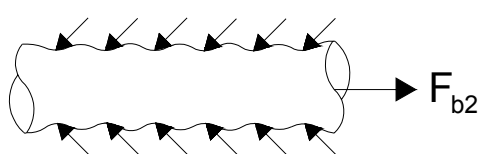

barras lisas

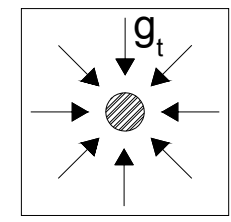

$F_{b 2}$

(c)

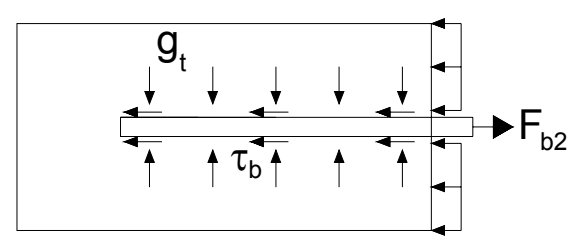

(b)

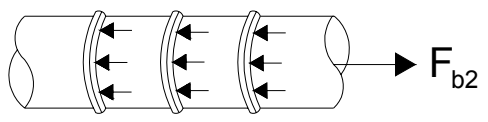

barras nervuradas

Figura 2.1 - (a) Aderência por adesão; (b) Aderência por atrito; (c) Aderência mecânica - Adaptado de FUSCO (1995). 
Sob o aspecto prático, a ligação entre os elementos constituintes do concreto armado é considerada por meio da definição da tensão de aderência e sua distribuição ao longo da superfície de contato cuja eficiência é quantificada mediante a relação tensão de aderência versus deslizamento, a qual representa a variação da tensão que surge na interface do aço com o concreto, relacionada ao deslocamento relativo entre a barra da armadura e o concreto envolvente. Valores máximos desse deslizamento podem ser usados para definir a perda da aderência, geralmente associados a um certo estado de deformação e fissuração.

O surgimento das tensões de aderência está vinculado à variação das tensões no aço ao longo do segmento de barra. Para isso, Leonhardt e Mönnig (1977) citaram as seguintes causas:

a) Ações: as quais estão atribuídas às alterações das tensões de tração e compressão no aço;

b) Fissuras: propiciam o surgimento de elevadas concentrações de tensões de aderência;

c) Forças de ancoragem nos extremos das barras: deve-se garantir a transferência da força atuante na barra para o concreto por meio das tensões de aderência;

d) Variações de temperatura: sabendo-se que a condutibilidade térmica do aço é maior e mais acelerada que a do concreto, nas situações em que os elementos de concreto estão sujeitos a altas temperaturas, como num incêndio, as tensões de aderência impedem que as barras se dilatem livremente até que se atinja o valor máximo dessas tensões ocasionando a ruptura do cobrimento de concreto;

e) Retração do concreto: conceitua-se como deformação volumétrica causada pela perda de água do concreto em contato com o ar em que, dada a expulsão da água inicialmente nas fibras externas, surgem deformações diferenciais entre a periferia e o núcleo, ocasionando tensões auto-equilibradas que provocam a fissuração do concreto;

f) Deformação lenta em peças comprimidas de concreto: trata-se de um acréscimo de deformação ao longo do tempo em que, mantido o carregamento constante, ocorre uma migração da água quimicamente inerte para regiões do concreto onde a mesma já tenha evaporado proporcionando o encurtamento do elemento estrutural e o acréscimo nas tensões de compressão atuantes nas barras de aço.

Dada à complexidade que envolve a determinação da aderência, o ensaio de arrancamento (Pullout test), padronizado pela RILEM/CEB/FIP, tornou-se o mais tradicional método para avaliação da resistência de aderência (Figura 2.2). 
Considerando uma força de tração $F_{t}$ na extremidade saliente da barra, essa provoca o surgimento de tensões de aderência em todo o perímetro da barra que está em contato com o concreto. Escrevendo a relação de equilíbrio das forças atuantes num elemento infinitesimal conforme a Figura 2.3, encontra-se o seguinte valor de $\tau_{b}$ (tensão de aderência):

$$
\begin{aligned}
& A_{s} \cdot \sigma_{s}+\pi \cdot \phi \cdot \tau_{b} \cdot d x=A_{s} \cdot \sigma_{s}+A_{s} \cdot d \sigma_{s} \\
& \tau_{b}=\frac{A_{s}}{\pi \cdot \phi} \cdot \frac{d \sigma_{s}}{d x} \rightarrow \tau_{b}=\frac{\phi}{4} \cdot \frac{d \sigma_{s}}{d x}
\end{aligned}
$$

Onde:

$A_{s}$ : área da seção transversal da barra de aço;

$\phi$ : diâmetro da barra;

$u=\pi \cdot \phi:$ perímetro da barra.
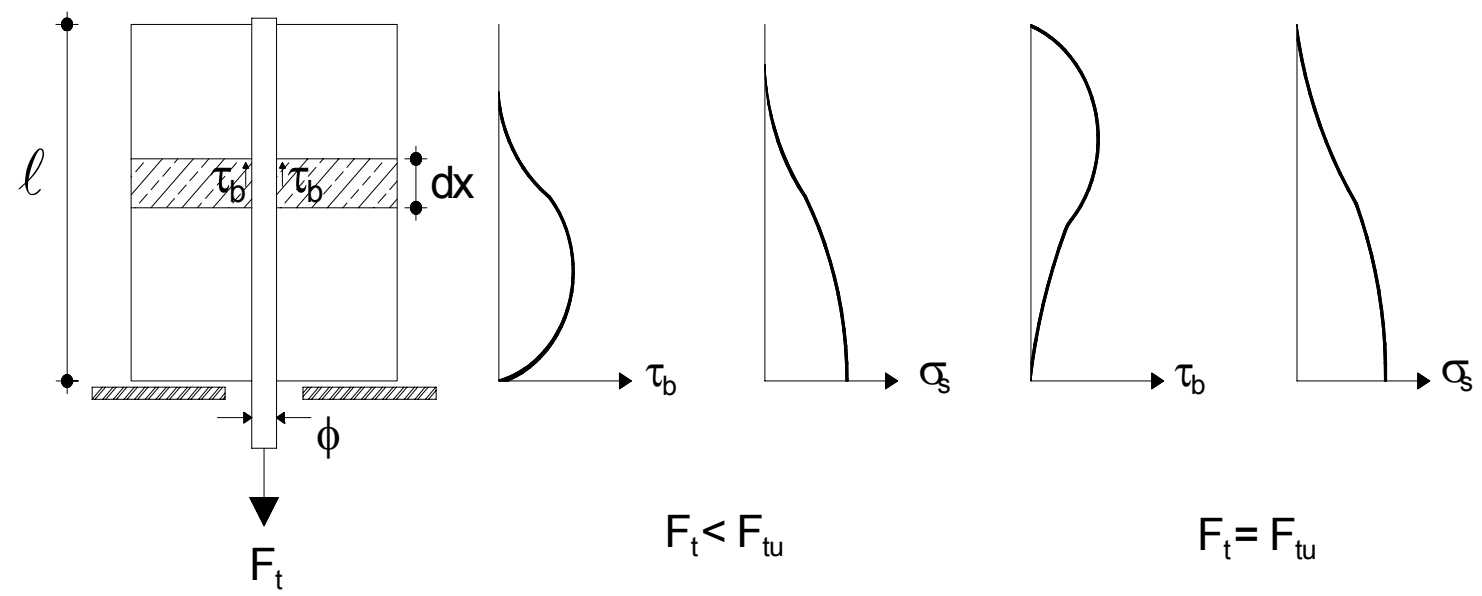

Figura 2.2 - Ensaio de arrancamento.

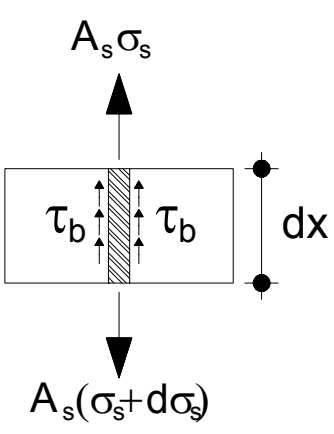

Figura 2.3 - Elemento infinitesimal. 
Em relação ao comportamento teórico das tensões, (Figura 2.2), há duas condições as quais relacionam a força de tração $\left(F_{t}\right)$ e a força última $\left(F_{t u}\right)$. Quando $F_{t}<F_{t u}$, a aderência é mobilizada em todo comprimento da barra. Para $F_{t}=F_{t u}$, ocorre o arrancamento da barra, perdendo toda a solidarização existente entre os materiais e a capacidade última de aderência é atingida. Entretanto, para os fins do ensaio, a força última de arrancamento é determinada mediante o deslocamento convencional da extremidade oposta à aplicação da força visto que antes do arrancamento da barra há uma propagação continuada das fissuras no concreto que enfatiza o fim da ligação entre os elementos constituintes.

Todavia, alguns pesquisadores observaram quanto à validade do ensaio de arrancamento para a avaliação da capacidade de ancoragem das barras. A questão é que a distribuição de tensões obtida nesse ensaio diverge da realidade nas regiões de ancoragem das armaduras de concreto armado, pois existe uma compressão longitudinal do concreto a qual não há nas zonas de ancoragem da armadura de tração de vigas fletidas. Logo, é recomendado que a capacidade de ancoragem das barras seja verificada por meio do ensaio com modelo tipo viga (SILVA, 1986; FUSCO, 1995).

A descrição minuciosa desse ensaio foi apresentada por Moreno Júnior e Rossi (2002) que estudaram o fluxo de tensões na região de ancoragem de uma barra numa viga de concreto armado com concreto de alta resistência a fim de avaliar a influência da resistência à compressão do concreto e o comportamento da resistência de aderência.

Para a determinação da resistência de aderência de cálculo $\left(f_{b d}\right)$, o MC CEBFIP 1990 e a NBR 6118:2003 adotam uma expressão que representa a média da resistência uma vez que sua variação não é uniformemente distribuída ao longo da barra. Assim,

$$
f_{b d}=\eta_{1} \cdot \eta_{2} \cdot \eta_{3} \cdot f_{c t d}
$$

Sendo:

$f_{c t d}=f_{c t k, \text { inf }} / \gamma_{c}$

$\eta_{1}=1,0$ para as barras lisas;

$\eta_{1}=1,4$ para barras entalhadas; 
$\eta_{1}=2,25$ para barras nervuradas;

$\eta_{2}=1,0$ para situações de boa aderência;

$\eta_{2}=0,7$ para situações de má aderência;

$\eta_{3}=1,0$ para $\phi \leq 32 \mathrm{~mm}$;

$\eta_{3}=(132-\phi) / 100$ para $\phi>32 \mathrm{~mm}$.

Onde:

$\phi$ é o diâmetro da barra, em mm.

Como se percebe, a resistência de aderência de cálculo depende diretamente da conformação superficial da barra, da localização da barra no elemento estrutural, considerando as zonas de boa ou má aderência, do diâmetro das barras e da resistência à tração de cálculo do concreto $\left(f_{c t d}\right)$.

A determinação dos fatores relativos aos coeficientes de conformação superficial é feita segundo as prescrições da NBR 7477:1982 que por meio dos ensaios de tração simétrica (tirantes) estabelecem os valores de conformação superficial mínimo para cada categoria de aço, obedecendo às recomendações da NBR 7480:1996 relacionadas a esse aspecto.

Soroushian e Choi (1989) verificaram que o diâmetro das barras exerce pouca influência na variação da resistência última de aderência e na curva tensão de aderência versus deslizamento. Segundo os autores, a tensão última de aderência e o diâmetro das barras são inversamente proporcionais. Na região pré-pico da curva, as tensões de aderência tendem a ser maior quão menor for o diâmetro da barra. Contudo, essa tendência é menos significativa na região pós-pico onde ocorrem grandes deformações.

Quanto às zonas de ancoragem, essas regiões estão especificadas na Figura 2.4, sendo que as regiões I são de boa aderência e as regiões II são as de má aderência. A NBR 6118:2003 estabelece em boa situação quanto à aderência os trechos que se enquadrem em uma das seguintes posições:

a) com inclinação maior que $45^{\circ} \mathrm{em}$ relação a horizontal;

b) para o caso de barra horizontal ou com inclinação menor que $45^{\circ} \mathrm{com}$ a horizontal, desde que localizadas no máximo a $30 \mathrm{~cm}$ acima da face inferior da peça ou junta de concretagem mais próxima;

c) quando a peça tiver altura máxima de $30 \mathrm{~cm}$; 
d) quando a altura da peça for menor do que $60 \mathrm{~cm}$, a região que dista $30 \mathrm{~cm}$ a partir da face inferior;

e) exceto nos $30 \mathrm{~cm}$ superiores de peças com espessura maior que $60 \mathrm{~cm}$;

f) nos casos de lajes e vigas concretadas simultaneamente, a parte inferior pode estar em uma região de boa aderência e a superior em região de má e a laje, se tiver espessura menor do que $30 \mathrm{~cm}$ estará em uma região de boa aderência.

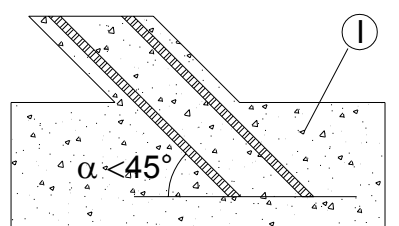

a)

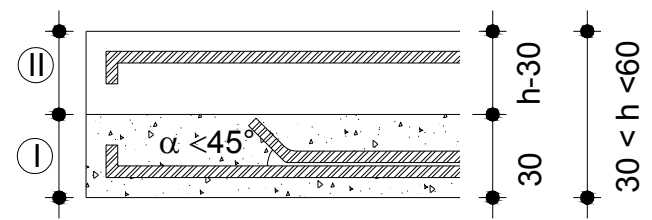

c)

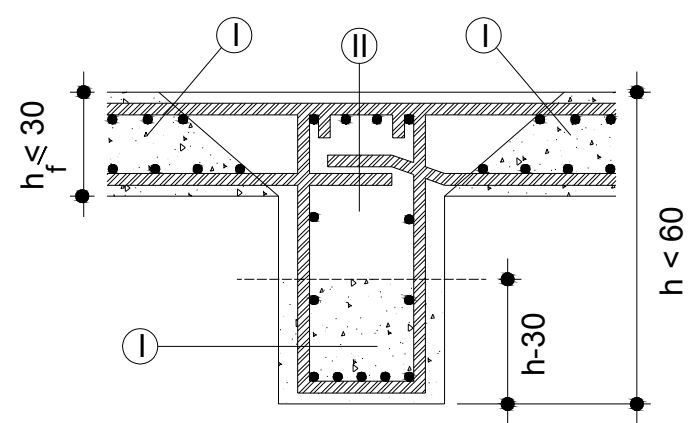

e)

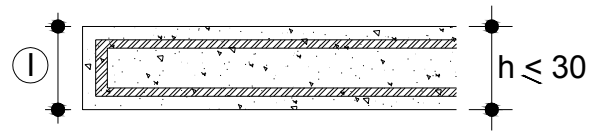

b)

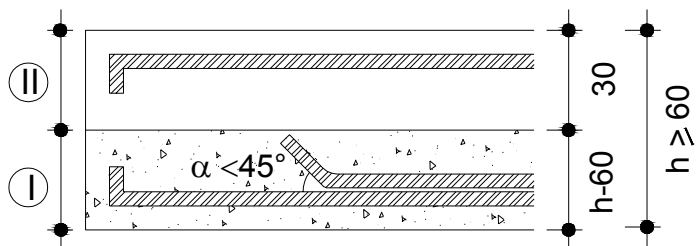

d)

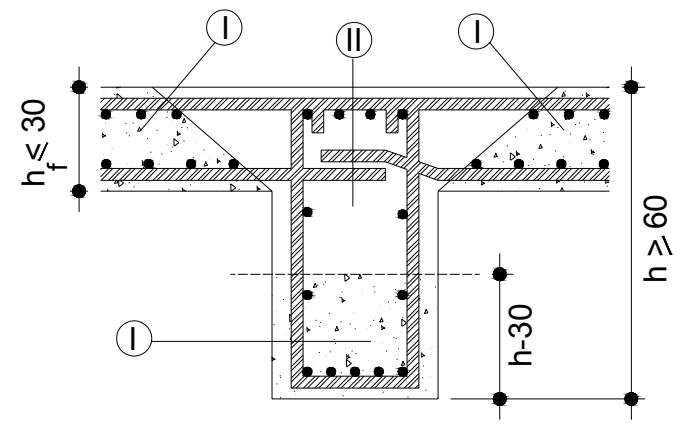

f)

Medidas em centímetros (cm).

Figura 2.4 - Situações de boa e má aderência - PROMON (1976).

A classificação dos elementos em zonas de aderência se deve ao fenômeno da exsudação que acontece mesmo em concretos bem compactados. Observa-se que há um acréscimo de $43 \%$ no comprimento de ancoragem de barras posicionadas em zonas consideradas de má aderência.

A resistência à tração de cálculo do concreto $\left(f_{c t d}\right)$, tendo como base a resistência característica do concreto à tração na flexão $\left(f_{c t k \text {,inf }}\right)$, pode ser definida após algumas simplificações das expressões fornecidas pela NBR 6118:2003 em função da resistência característica à compressão do concreto, conforme se apresenta na eq.(2.3). 
Considerando o coeficiente de minoração da resistência do concreto, $\gamma_{c}=1,4$, tem-se o valor dado na eq.(2.4).

$$
\begin{gathered}
f_{c t d}=0,21 \cdot \frac{f_{c k}^{2 / 3}}{\gamma_{c}} \\
f_{c t d}=0,15 \cdot f_{c k}^{2 / 3}
\end{gathered}
$$

Uma abordagem ampla sobre o comportamento da aderência em estruturas de concreto armado, assim como a influência de fatores os quais não são tratados com maiores detalhes, como, classe do aço; resistência de escoamento do aço; número de barras em uma mesma camada; armadura transversal; tipo, velocidade e duração da ação; número de ciclos e amplitude da ação cíclica, dentre outros, podem ser encontradas em Fernandes (2000) e Castro (2002).

\subsection{Ancoragens usuais das armaduras longitudinais de flexão}

\subsubsection{Ancoragem reta}

Nas barras nervuradas ancoradas com extremidade reta, as reais tensões de ancoragem são apresentadas na Figura 2.5 considerando o estado de fissuração do concreto. Ao passo que seja alcançada a resistência última de aderência, a transferência de tensões é feita a partir de bielas comprimidas de concreto delimitadas pelas fissuras causadas pelas tensões transversais de tração as quais podem ocasionar o fendilhamento do concreto paralelamente ao eixo da barra de aço. Para que essas tensões sejam atenuadas ou anuladas, deve existir uma compressão transversal ao eixo da barra que favoreça a aderência e garanta a manutenção da integridade das bielas diagonais comprimidas. Por isso, não se justificam as antigas regras de ancoragem, preconizadas nos primórdios do concreto armado, pelas quais as barras longitudinais deveriam ser ancoradas em zonas de compressão longitudinal da peça (FUSCO, 1995). 


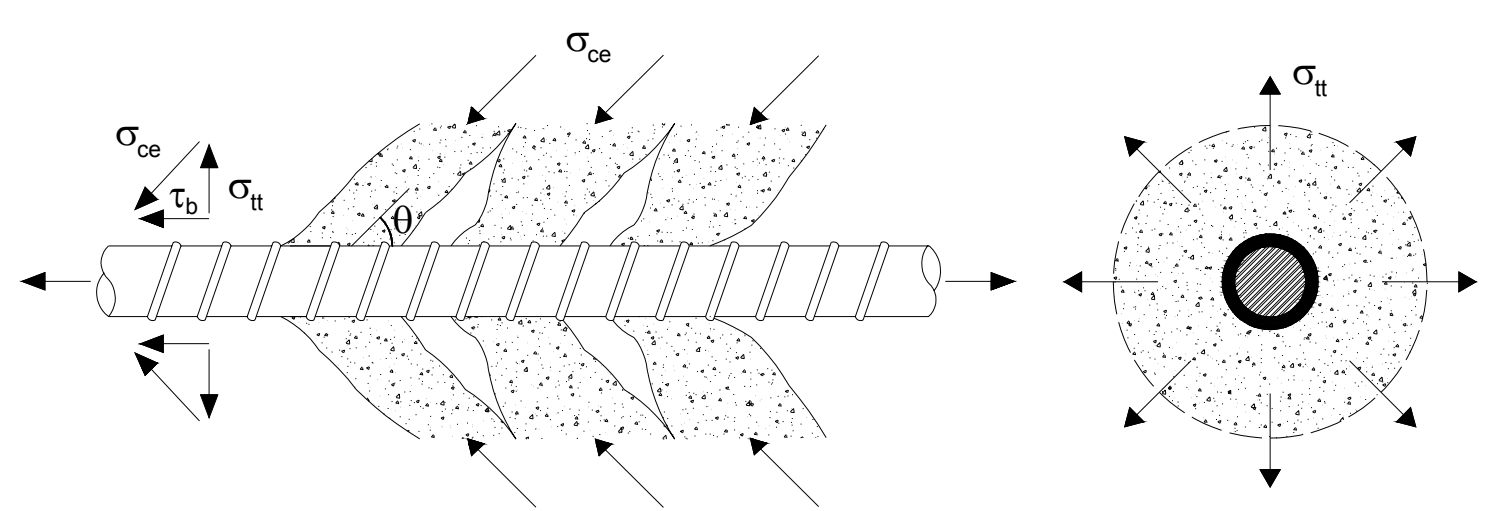

Figura 2.5 - Esforços reais de ancoragem - Modificado de FUSCO (1995).

As ancoragens retas das armaduras longitudinais de flexão podem se apresentar sob compressão ou tração. As barras tracionadas têm o comportamento semelhante ao das barras comprimidas.

No entanto, Fusco (1995) relacionou duas diferenças básicas entre as barras nessas duas situações. Nas ancoragens tracionadas, as tensões longitudinais de tração produzem fissuração da peça acompanhada da microfissuração que rompe o concreto ao longo de um determinado comprimento e reduz em parte a capacidade de ancoragem da barra. No caso da ancoragem de barras comprimidas, o efeito da compressão longitudinal da peça proporciona maior integridade do concreto e, além disso, a existência de uma compressão direta do topo da barra produz um efeito de ponta da ancoragem que eleva sua eficiência.

Esse efeito permite a ancoragem reta de barras lisas nas quais é obrigatório o uso de gancho nas ancoragens tracionadas. Mesmo que parte da força resistida pela ancoragem seja absorvida pelo efeito de ponta nas barras sob compressão, que possibilita uma redução no comprimento de ancoragem, é recomendável a adoção dos mesmos critérios para determinação do comprimento de aderência das barras tracionadas, uma vez que, em virtude da deformação lenta do concreto situado na região de extremidade da barra, esse efeito pode ser muito reduzido.

Embora seja favorável à ancoragem, a concentração de tensões existente na ponta da barra possibilita o surgimento de um fenômeno local de ruptura (Figura 2.6 e Figura 2.7). Uma maneira usual de se evitar esse fenômeno é a utilização de armaduras transversais em maior quantidade na extremidade da barra tracionada e além do trecho de ancoragem, para o caso de barras comprimidas. Sugere-se que, quando existir uma camada de cobrimento de pequena espessura, uma das barras da armadura transversal 
seja colocada além da zona de extremidade da ancoragem, numa distância até de $4 \phi$ dessa extremidade (FUSCO, 1995).

Todavia, Glanville (1930) ${ }^{1}$ apud Allwood e Bajarwan (1996) demonstrou que o melhor desempenho das barras comprimidas se deve, em parte, ao efeito Poisson causado pelo aumento do diâmetro da barra que, por conseguinte, eleva a tensão radial, mobilizando uma parcela relevante das tensões de aderência por atrito.

Extremidade da barra tracionada

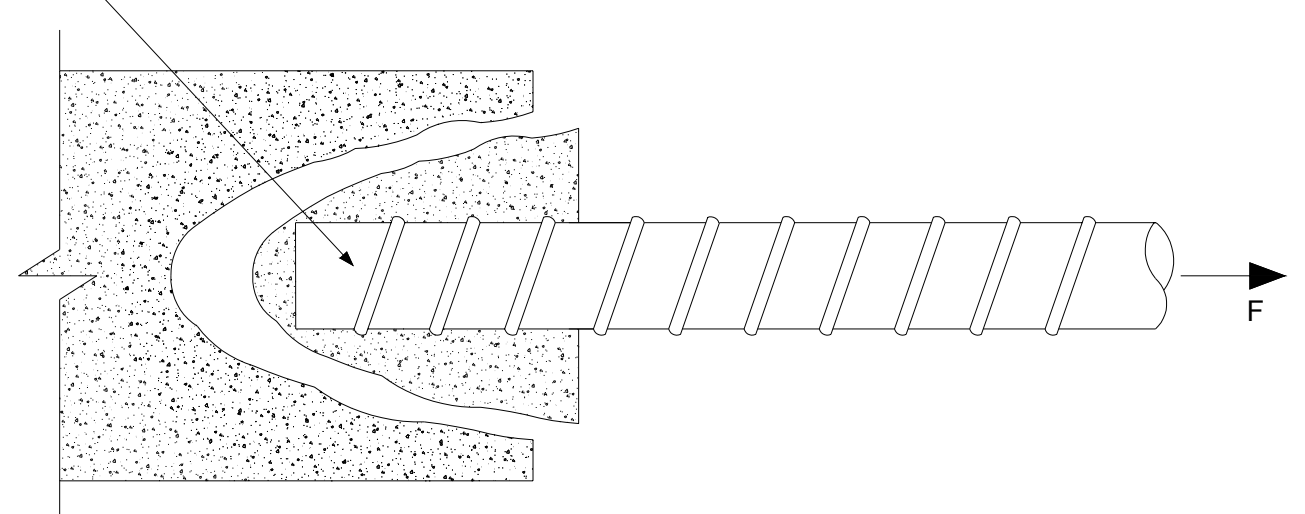

Figura 2.6 - Fendilhamento cônico (barras tracionadas) - Modificado de FUSCO (1995).

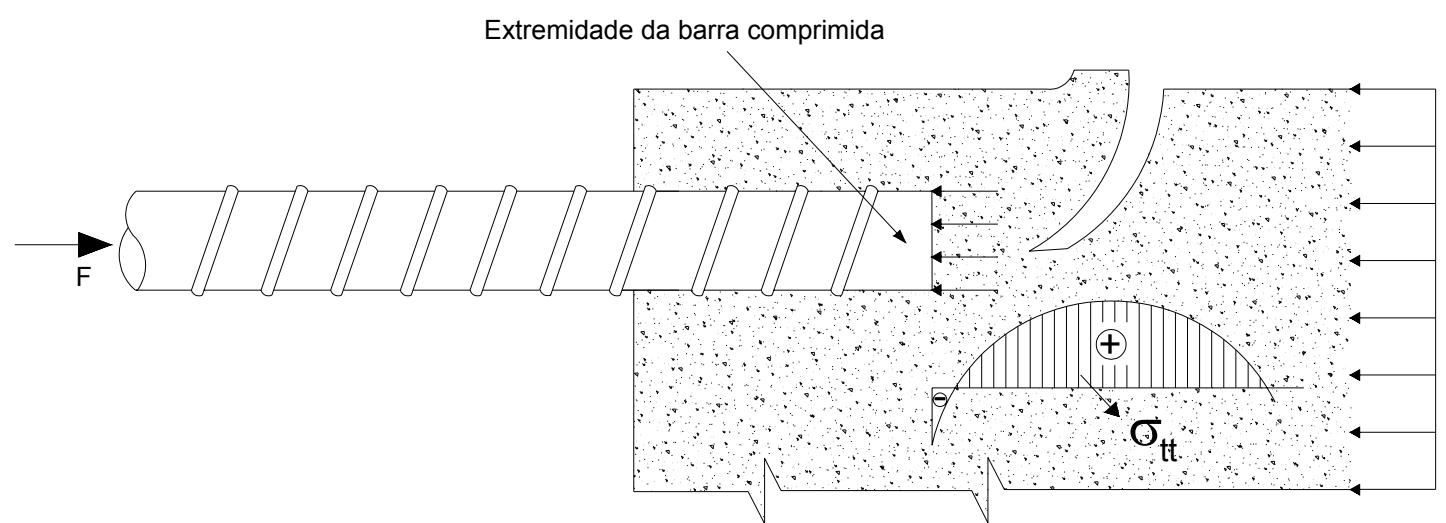

Figura 2.7 - Fendilhamento lateral do concreto (barras comprimidas) - Modificado de FUSCO (1995).

\subsubsection{Ancoragem com gancho de extremidade}

Desde meados do século XX, tem-se discutido a ancoragem com o uso de gancho haja vista a complexidade e diversidade de fatores intervenientes na sua

\footnotetext{
${ }^{1}$ GLANVILLE, W. H. (1930). Studies in reinforced concrete-bond resistance. Building Research Technical Paper, n.10.
} 
capacidade de suporte. O avanço da tecnologia dos materiais e o desenvolvimento de projetos promoveram consideráveis reduções nas dimensões dos elementos estruturais e, conseqüentemente, a necessidade de elevar a capacidade resistente das ancoragens se fez necessário.

A regra básica da ancoragem com gancho é a combinação ideal de trechos retos e curvos de maneira tal que a parcela reta situada antes do início da curvatura, permita ou não apenas pequenos escorregamentos no início do gancho que representa uma segurança adicional da ancoragem à carga de ruptura.

Conforme se constata no meio técnico, a avaliação da ancoragem de barras com ganchos na extremidade se deu, predominantemente, mediante ensaios de arrancamento. Esses ensaios consistiam na retirada de barras de aço de blocos de concreto cujo comprimento aderente era apenas o gancho, sendo o trecho reto precedente isolado por meio de dispositivo plástico ((BAUER, 1949²; REHM, 1969³ ${ }^{3}$ MÜLLER, s.d. $\left.{ }^{4}\right)$ apud SILVA, 1986; HRIBAR e VASKO, 1969; MINOR e JIRSA, 1975; MARQUES e JIRSA, 1975).

Em princípio, a eficiência dos ganchos era estimada em razão apenas da aderência entre o concreto e o aço ao longo do comprimento do trecho curvo.

Entretanto, verificou-se no âmbito das pesquisas que esses elementos trabalham à flexão no concreto. Bauer (1949) apud Silva (1986) estudou o comportamento das tensões internas em ganchos de forma gradual (curvatura secundária na extremidade) e semicircular conforme ilustrado na Figura 2.8. O gancho gradual apresentou uma distribuição mais uniforme das tensões de compressão, traduzida em melhores condições de segurança.

No gancho semicircular, a tensão máxima (ocorrida no início da curva) foi superior à mínima (atuante no final da curvatura) de 3 a 4 vezes, enquanto, no gancho gradual, essas tensões foram aproximadamente iguais. A eficiência dos ganchos graduais foi da ordem de $20 \%$ a $30 \%$ superior a dos semicirculares. Contudo, a desvantagem dos ganchos graduais reside na difícil construção de sua forma a qual exigiria uma produção quase artesanal que elevaria o custo das peças de concreto armado.

\footnotetext{
${ }^{2}$ BAUER, R. (1949). Der Haken im Stahlbetonbau. Berlin, Wilhelm Ernst.

${ }^{3}$ REHM, G. (1969). Kriterien zur Beurteilung von Bewehrungsstäben mit hochwertigem Verbund. Berlin, Wilhelm Ernst.

${ }^{4}$ MÜLLER, H. H. (s.d.). Versuche zur erforderlichen geraden Endlänge von Hakenverankerungen.
} 

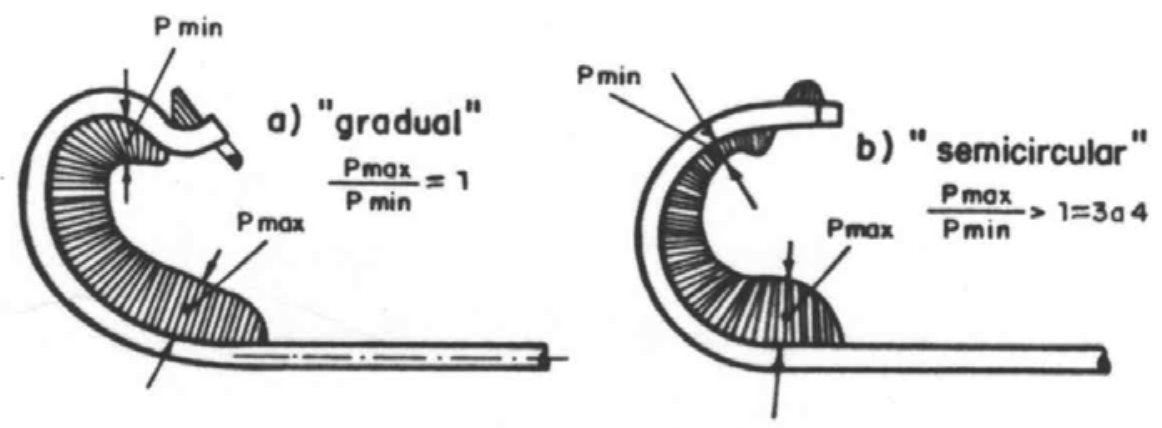

Figura 2.8 - Distribuição das pressões no interior do gancho gradual e semicircular BAUER (1949) apud SILVA (1986).

Rehm (1969) apud Silva (1986) verificou a influência da posição do gancho durante a concretagem e do ângulo de dobramento na capacidade resistente final da ancoragem. Suas conclusões atestaram que a capacidade relativa à força última de um gancho depende da disposição conveniente dos ganchos na seção de concreto e do diâmetro de curvatura, de modo que, quanto maior for esse parâmetro, maior será a possibilidade de fissuração das camadas laterais do concreto envolvente.

Minor e Jirsa (1975) avaliaram outros fatores pertinentes à capacidade resistente de ancoragem de barras nervuradas com gancho. Tratou-se de uma avaliação essencialmente experimental em que foram produzidos 80 prismas de concreto contendo barras curvas com diferentes configurações geométricas. O comprimento de aderência, o ângulo de dobramento, o raio de curvatura e o diâmetro da barra foram as variáveis em questão. Os mecanismos de análise utilizados foram às curvas de tensão versus deslizamento. Esses gráficos foram obtidos a partir do monitoramento do deslizamento de alguns pontos ao longo da barra ancorada durante o período de aplicação da carga. Nesse trabalho, concluiu-se que:

- Para igual razão entre o comprimento de ancoragem e o diâmetro da barra, quanto maior for o ângulo de dobramento e/ou menor a relação raio de curvatura e diâmetro da barra $\left(r / d_{b}\right)$, maior será o deslizamento numa dada barra sob tração;

- Numa ancoragem que possui tanto trecho reto como curvo, o maior escorregamento se dá na parte curva;

- Há uma pequena diferença na resistência entre ancoragens retas e curvas exceto para comprimentos de ancoragem muito pequenos os quais são impraticáveis na construção civil. 
Esses resultados indicaram que no detalhamento do nó em que as barras com gancho são exigidas, curvas de $90^{\circ}$ são preferíveis as de $180^{\circ}$.

Marques e Jirsa (1975) avaliaram a capacidade de ancoragem da armadura da viga em ligações com pilar sujeita a vários graus de confinamento no nó, buscando as condições encontradas em nós de pórticos. Variáveis, como, os efeitos da força axial no pilar, o cobrimento e a armadura transversal na ligação, foram estudadas e consideradas na análise do comportamento das barras com dobras padronizadas. Com bases nos resultados, os pesquisadores atestaram que:

- A influência da força axial, que foi avaliada apenas para ligações com ganchos a $90^{\circ}$, foi dada como desprezível. As forças axiais produzem deformações laterais que causam fendilhamento no mesmo plano com que é produzido por barras curvas. Assim, a força axial não oferece restrição quanto ao fendilhamento do cobrimento e pode reduzir a resistência por causa das deformações laterais na mesma direção;

- No que se refere ao confinamento lateral, a presença de armadura transversal, representada por laços pouco espaçados, são especialmente benéficos no caso de grandes barras ancoradas. A diminuição do cobrimento reduz a capacidade resistente do nó.

As verificações de Minor e Jirsa (1975), no que tange ao raio de curvatura e ângulo de dobramento, foram ratificadas em Fusco (1995). Conforme este, as tensões de transversais de tração podem ser absorvidas pelo próprio concreto e o risco de fendilhamento é minorado, desde que o raio de dobramento da barra seja suficientemente grande e os diâmetros mínimos especificados pela norma vigente sejam respeitados. Caso o raio de curvatura supere o limite especificado, eleva-se o risco de fendilhamento e com isso, obriga-se a colocação de uma armadura adicional.

Essa armadura deve ser transversal e composta por barras retas dispostas perpendicularmente ao plano de dobramento, dimensionada para a absorver $25 \%$ da maior das forças existentes na ancoragem e constituída por pelo menos duas barras de $\phi=6,3 \mathrm{~mm}$, do lado da concavidade da barra. Essa armadura, além de absorver as tensões transversais de tração e diminuir o risco de fendilhamento do concreto, também pode servir como apoio direto à parte curva da barra ancorada e assim reduzir a intensidade das tensões de compressão do concreto. Seu emprego é limitado aos casos especiais em que se faz a ancoragem simultânea de várias barras em posições muito 
próximas. Em situações usuais, sua presença é desnecessária, pois, presume-se que essa função seja cumprida pela armadura transversal das peças estruturais.

Em vistas aos trechos retos que compõem a ancoragem com ganchos na extremidade, é justificável a presença do trecho reto anterior à curva. A função desse segmento é evitar que o gancho atue à plena carga, criando risco de fendilhamento do concreto. Caso seja solicitado, o gancho absorve toda a força a ser ancorada, isto é, nada passa adiante para prolongamentos da barra.

No que se refere ao prolongamento reto após o gancho, há um consenso quanto à sua funcionalidade na transferência de forças atuantes nas barras para o concreto circunvizinho. Esse segmento serve apenas para colaborar na resistência do gancho à flexão sob grandes deslizamentos, impedindo assim que esses ganchos se abram quando solicitados o que permite melhor apoio do concreto sobre a parte côncava do gancho ((MÜLLER, s.d.) apud SILVA, 1986; FUSCO, 1995). Os ensaios de MÜLLER (s.d.) apud SILVA (1986) mostraram que o comprimento reto ao final dos ganchos, de acordo com os padrões da DIN 1045, poderia até ser encurtado. Contudo, é recomendável sua manutenção pelo fato da inexatidão das medidas e dobramentos.

Vale ressaltar que os ganchos de extremidade podem ser aplicados apenas para ancoragens tracionadas. Os ganchos não são aconselháveis em barras comprimidas, uma vez que, introduzem tensões de flexão na barra as quais acentuam ao fendilhamento do concreto.

\subsubsection{Ancoragens especiais}

\subsubsection{Ancoragem em laço}

O uso do laço como dispositivo de ancoragem é uma solução cabível quando se dispõe de exigüidade de comprimento e pouca largura na ligação. A transferência da força proveniente da barra ancorada acontece, em sua predominância, pela resistência ao esmagamento do concreto, em torno do laço, deixando a aderência como um efeito favorável secundário. Conforme Süssekind (1981), para o dimensionamento do laço basta averiguar a condição pela eq.(2.5) tendo como referência a Figura 2.9.

$$
r \geq\left(0,35+0,7 \cdot \frac{\phi}{a}\right) \cdot \phi \cdot \frac{f_{y k}}{f_{c k}} \cdot \frac{\ell_{b}-\ell_{b e}}{\ell_{b}}
$$


Em que:

$f_{c k}:$ resistência característica à compressão do concerto;

$f_{y k}:$ resistência característica à tração do aço;

$\ell_{b e}:$ comprimento de ancoragem efetivo, medido a partir da face do apoio;

$a$ : menor dos dois valores $a_{1}$ e $a_{2}$ indicados na Figura 2.9.

O valor de $r$ é prefixado uma vez que o diâmetro do laço é obtido descontando a largura da viga o cobrimento mínimo em cada lado. Para esse caso, a questão consiste na escolha do diâmetro $\phi$ adequado e do espaçamento entre os laços.

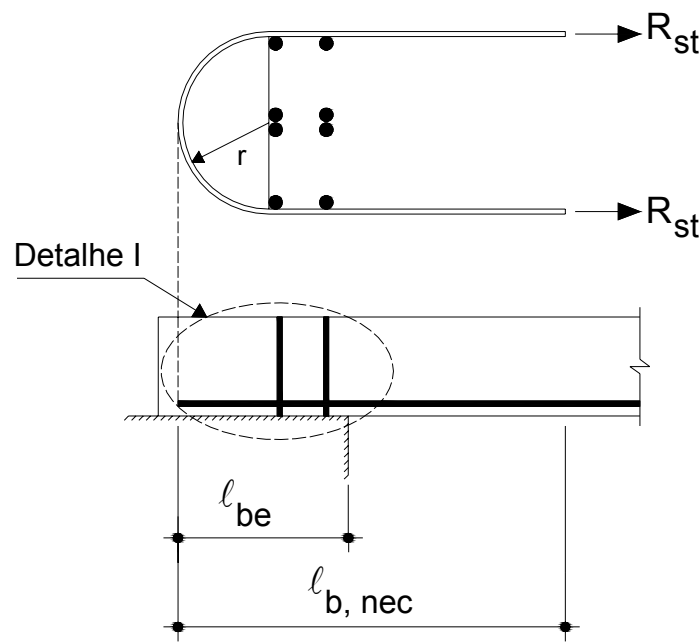

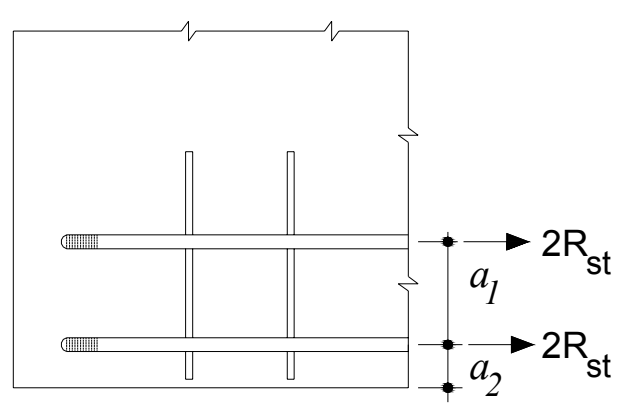

Detalhe I

Figura 2.9 - Ancoragem em laço - Adaptado de SÜSSEKIND (1981).

Já em Fusco (1995) é recomendado que se adote, para o dimensionamento dos laços, o diâmetro de dobramento igual ao empregado nos ganchos, ou seja, $d_{b}=5 \phi$.

\subsubsection{Placa de ancoragem}

A placa de ancoragem é recomendável quando não há possibilidade de ancoragem adequada adotando os meios usuais disponíveis (ancoragem por aderência, gancho e laço). Geralmente, essa situação ocorre quando se tem limitação das dimensões das peças de apoio (apoios estreitos).

Segundo Leonhardt e Mönnig (1978), a placa deve ser dimensionada para uma tensão admissível em áreas parcialmente carregadas. Caso seja ultrapassada essa tensão, a capacidade resistente da ancoragem deve ser verificada por meio de ensaios. No que diz respeito ao tipo de carregamento, quando o mesmo não for predominantemente 
estático, recomenda-se utilizar $70 \%$ da amplitude de oscilação ou $50 \%$ da resistência à ruptura estática e avaliar a capacidade resistente por meio de ensaios.

De acordo com Fusco (1995), o emprego de barras com ancoragens mecânicas, feitas com placas de aço soldadas nas extremidades das barras da armadura, é uma solução conveniente, nos casos de apoio de extremidade ou de extremidades de balanço que recebem cargas concentradas excepcionalmente elevadas e situações de vigas de transição em balanço, em cujas extremidades se apóiem pilares da estrutura. Essas placas podem ser ligadas à barra de acordo com a Figura 2.10.

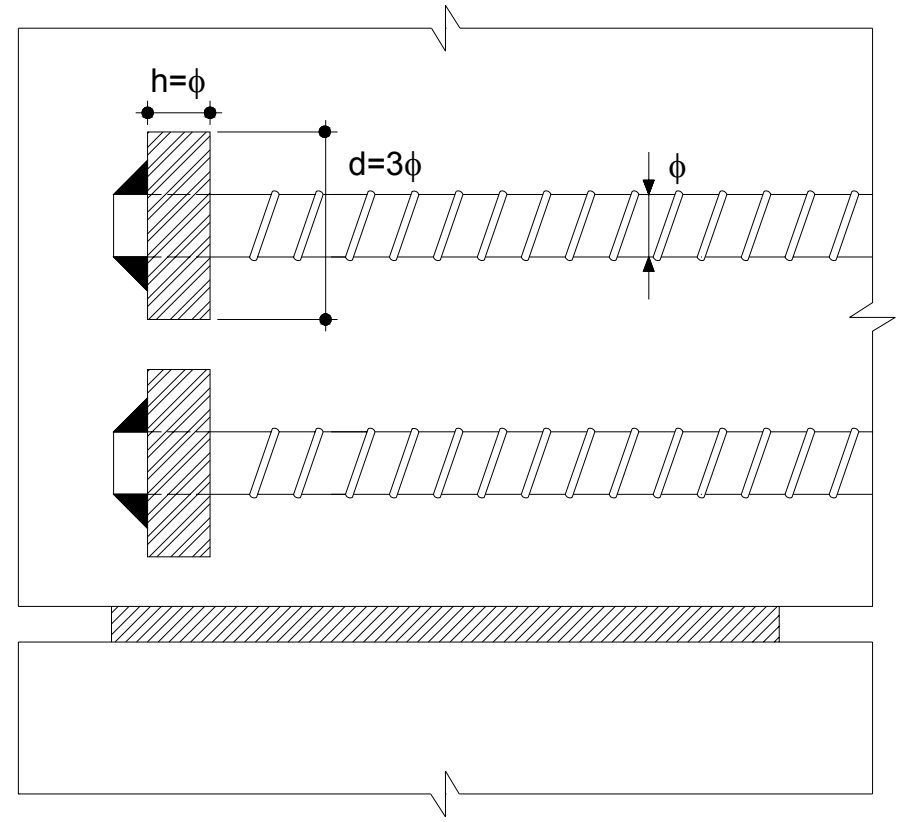

Figura 2.10 - Ancoragem mecânica com placas soldadas - Modificado de FUSCO (1995).

Hegger, Sherif e Roeser (2003) concluíram que a resistência das ligações ancoradas unicamente com placas de ancoragem é cerca de $20 \%$ maior que as ancoradas com ganchos.

\subsubsection{Barra transversal soldada}

As barras transversais soldadas são usadas como um complemento da ancoragem por aderência das barras longitudinais. Conforme Leonhardt e Mönnig (1978), a parcela da força suportada por uma barra transversal é função do deslizamento local da barra longitudinal e, portanto, a razão da localização da barra transversal no trecho de ancoragem. Quanto aos pequenos deslocamentos, a disposição das barras 
transversais no início do trecho de ancoragem é mais favorável. Dispostas no fim do trecho de aderência, essas barras colaboram com mais intensidade sob grandes deslocamentos.

A inclusão de barras transversais soldadas no sistema de ancoragem de armadura de flexão é prevista pela NBR 6118:2003 desde que sejam atendidas as seguintes prescrições (Figura 2.11):

a) diâmetro da barra soldada $\phi_{t} \geq 0,60 \phi$;

b) a distância da barra transversal ao ponto de início da ancoragem seja $\geq 5 \phi$;

c) a resistência ao cisalhamento da solda deve superar à força mínima de $0,3 \cdot A_{s} \cdot f_{y d}$ (30\% da barra ancorada).
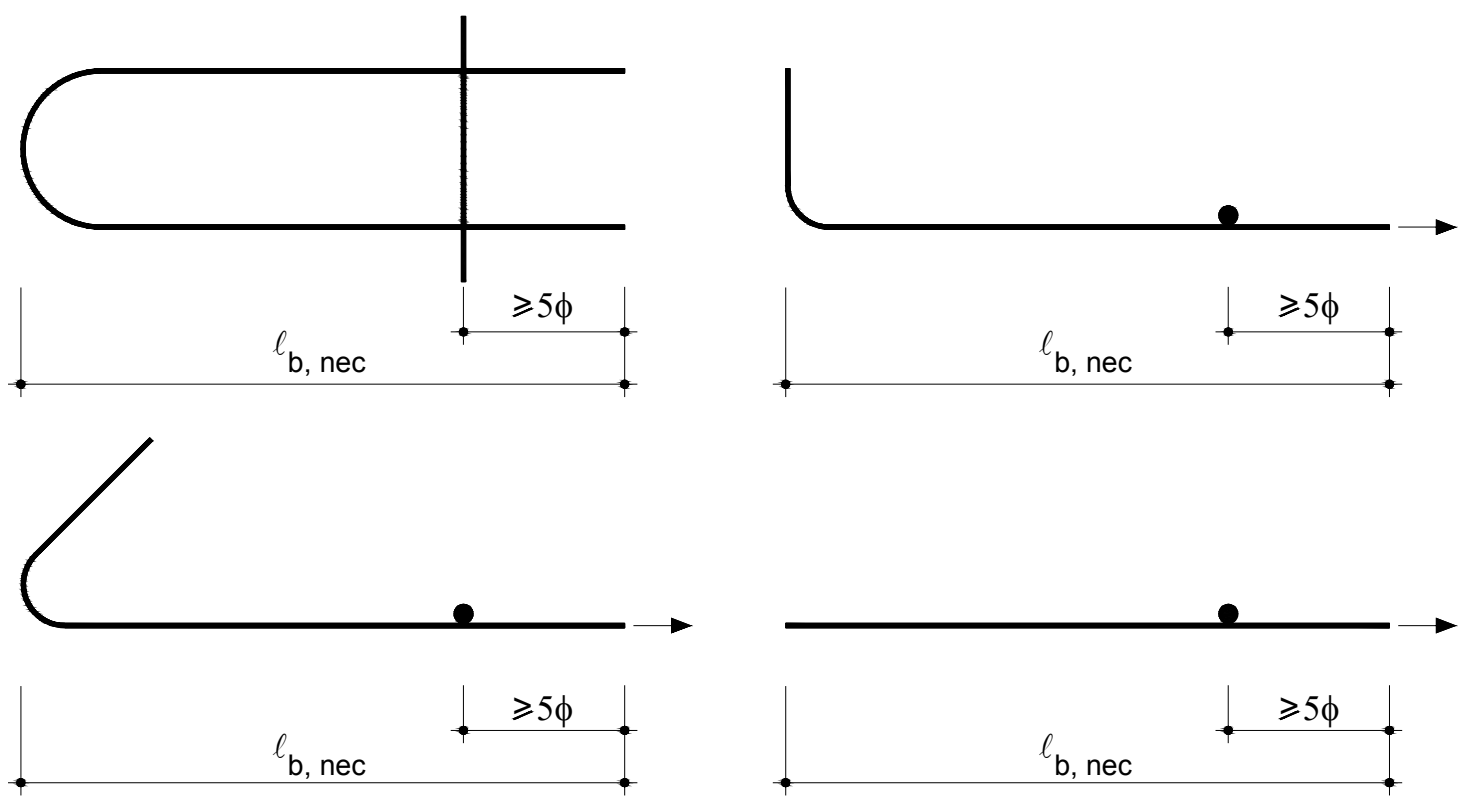

Figura 2.11 - Ancoragem com barras transversais soldadas - NBR 6118:2003.

\subsection{Tópicos complementares}

\subsubsection{Emenda por traspasse}

A presença da emenda por traspasse é verificada quando se tem uma alternância significativa no panorama das linhas de tensões na região das ligações entre elementos estruturais de concreto armado. Para tanto, faz-se oportuno entender e esclarecer como se estabelece à transferência de tensões entre as barras emendadas, em especial, as nervuradas. 
A essência da transferência de tensões por traspasse está na transmissão de forças da uma barra para outra por meio de bielas de concreto inclinadas em relação ao eixo da barra, na qual, parte dos perímetros das barras participa. Assim como funciona a ancoragem das barras retas, a formação das bielas comprimidas ocasiona o surgimento de tensões de transversais de tração as quais elevam o risco de rompimento do cobrimento de concreto.

A limitação da ancoragem em parte do perímetro das barras leva a suposição de que apenas o comprimento de ancoragem básico $\left(\ell_{b, \text { nec }}\right)$ seria insuficiente para garantir a emenda por traspasse e, por isso, as normas prescrevem um coeficiente de majoração para o comprimento da barra a ser ancorado.

Segundo a NBR 6118:2003, $\alpha_{0 t}$ é um coeficiente em função da porcentagem de barras emendadas na mesma seção, conforme a Tabela $2.1 \mathrm{e} \ell_{0 t, \min }$ é o maior valor entre $0,3 \alpha_{0 t} \ell_{b}, 15 \phi$ e $200 \mathrm{~mm}$, para o caso de barras tracionadas isoladas, (ver Figura 2.12).

Tabela 2.1 - Valores do coeficiente $\alpha_{0 t}$ (NBR 6118:2003).

\begin{tabular}{lcccccc}
\hline $\begin{array}{l}\text { Porcentagem } \\
\text { emendadas na mesma seção }\end{array}$ & $\leq 20$ & 25 & 33 & 50 & $>50$ \\
\hline Valores de $\alpha_{0 t}$ & 1,2 & 1,4 & 1,6 & 1,8 & 2,0 \\
\hline & \\
$\mathrm{R}_{\mathrm{st}}$ & $\mathrm{d}$
\end{tabular}

Figura 2.12 - Emenda por traspasse de barras tracionadas.

Caso as barras emendadas estejam comprimidas, a norma brasileira estabelece que o cálculo do comprimento de traspasse deve ser feito segundo a eq.(2.6):

$$
\ell_{0 c}=\ell_{b, n e c} \geq \ell_{0 c, \min }
$$

Sendo, $\ell_{0 c, \min }$ o maior valor entre $0,6 \ell_{b}, 15 \phi$ e $200 \mathrm{~mm}$. 


\subsubsection{Armadura de suspensão}

$\mathrm{O}$ uso das armaduras de suspensão se justifica nos chamados apoios indiretos nos quais funcionam como um tirante interno que transfere a força aplicada pela viga suportada ao banzo inferior da viga suporte, até o seu banzo superior (Figura 2.13).

Esta armadura é constituída por estribos verticais e deve distribuída ao longo de uma distância $d / 2$, sendo $d$ a altura útil da viga suporte medida a partir do centro do nó. No que se refere a sua distribuição, recomenda-se que seja colocada $70 \%$ da $A_{\text {susp }}$ na viga suporte e o $30 \%$ restante na viga suportada. No detalhamento de estribos, em caso de cruzamento de vigas, é usual que os estribos da viga principal, interrompam aqueles de vigas secundárias (LEONHARDT E MÖNNIG, 1978; SÜSSEKIND, 1981).

A área da armadura de suspensão é dada segundo a eq.(2.7), sendo, $V_{d}$, força cortante no apoio da viga suportada e $f_{y d}$, resistência de cálculo ao escoamento do aço. Mais detalhes sobre esse tópico é abordado no item que trata sobre ligações viga-viga.

$$
A_{\text {susp }}=\frac{V_{d}}{f_{y d}}
$$

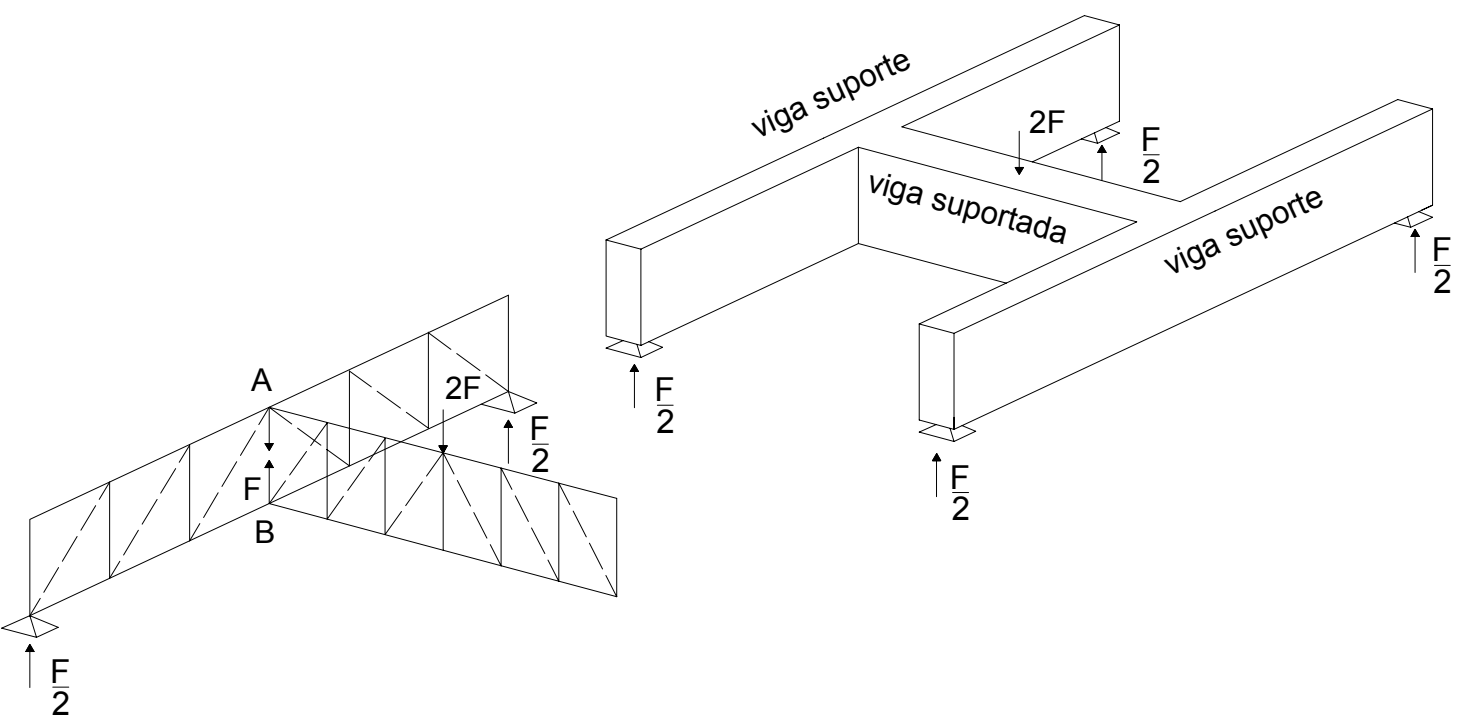

Figura 2.13 - Tirante de suspensão - Modificado de FUSCO (1995). 


\section{Arranjos construtivos das ancoragens em ligações de elementos estruturais}

\subsection{Cálculo do comprimento de ancoragem básico}

\subsubsection{Barras retas}

De acordo com o MC CEB-FIP 1990 e a NBR 6118:2003, o comprimento de ancoragem básico de uma barra reta de armadura passiva $\left(\ell_{b}\right)$ é definido como sendo o segmento de barra necessário para ancorar a força na barra igual a $A_{s} \cdot f_{y d}$. O valor do comprimento é calculado pelo equilíbrio entre as forças resistente $\left(R_{d}\right)$ e solicitante $\left(S_{d}\right)$, medido a partir do ponto considerado de início da ancoragem e estabelecido conforme eq.(3.1):

$$
\begin{aligned}
S_{d} & =R_{d} \\
A_{s} \cdot f_{y d} & =f_{b d} \cdot \ell_{b} \cdot \pi \phi^{2} \\
\frac{\pi \phi^{2}}{4} \cdot f_{y d} & =f_{b d} \cdot \ell_{b} \cdot \pi \phi \\
\ell_{b} & =\frac{\phi}{4} \cdot \frac{f_{y d}}{f_{b d}}
\end{aligned}
$$

Onde:

$\phi$ : diâmetro da barra;

$f_{y d}$ : resistência ao escoamento de cálculo à tração do aço;

$f_{b d}$ : resistência de aderência de cálculo da armadura passiva. 
$\mathrm{Na}$ maioria dos casos práticos, verifica-se que a área de barras de aço adotada é costumeiramente maior que a área de armadura calculada. Com isso, a tensão nas barras diminui e permite que o comprimento de ancoragem seja reduzido na mesma proporção.

Assim, introduz-se o comprimento de ancoragem necessário conforme eq.(3.2) cujo valor depende da razão entre as áreas efetiva e calculada e do parâmetro $\alpha_{1}$ relacionado ao uso de gancho adotado na extremidade.

$$
\ell_{b, \text { nec }}=\alpha_{1} \cdot \ell_{b} \cdot \frac{A_{s, \text { calc }}}{A_{s, e f}} \geq \ell_{b, \text { min }}
$$

Onde:

$\alpha_{1}=1,0$ para barras sem gancho;

$\alpha_{1}=0,7$ para barras tracionadas com gancho, com espessura do cobrimento $\geq 3 \phi$, medida no plano normal ao do gancho;

$A_{s, c a l c}:$ área calculada das barras de aço;

$A_{s, e f}:$ área efetiva das barras de aço;

$\ell_{b}:$ comprimento de ancoragem básico;

$\ell_{b, \text { min }}:$ maior valor entre $0,3 \ell_{b}, 10 \phi$ e $100 \mathrm{~mm}$.

Para casos especiais, as normas anteriormente citadas prevêem a inclusão de outros fatores de redução do comprimento de ancoragem necessário. Segundo o MC CEB-FIP 1990 e o Instituto Brasileiro do Concreto - IBRACON (2003), esses parâmetros adicionais são representados pelos coeficientes $\alpha_{2}, \alpha_{3}, \alpha_{4}$ e $\alpha_{5}$, e podem ser obtidos conforme exposto na Tabela 3.1 e na Tabela 3.2. Logo, o comprimento de ancoragem necessário passa a ser calculado segundo eq.(3.3).

$$
\ell_{b, \text { nec }}=\alpha_{1} \cdot \alpha_{2} \cdot \alpha_{3} \cdot \alpha_{4} \cdot \alpha_{5} \cdot \ell_{b} \cdot \frac{A_{s, \text { calc }}}{A_{s, e f}} \geq \ell_{b, \text { min }}
$$

Onde:

$\alpha_{1}$ : considera a eficiência do gancho;

$\alpha_{2}$ : considera a eficiência de barras transversais soldadas;

$\alpha_{3}$ : considera a eficiência de um bom cobrimento; 
$\alpha_{4}$ : considera a eficiência da armadura transversal não soldada, conforme a posição relativa à armadura ancorada;

$\alpha_{5}$ : considera a eficiência de pressão transversal à ancoragem.

Tabela 3.1 - Coeficientes para os fatores redutores do comprimento de ancoragem (IBRACON, 2003).

\begin{tabular}{|c|c|c|c|}
\hline \multirow{2}{*}{ Fator } & \multirow{2}{*}{ Tipo de ancoragem } & \multicolumn{2}{|c|}{ Armadura } \\
\hline & & tração & compressão \\
\hline$\alpha_{1}$ & $\begin{array}{l}\text { Barras retas, sem } \\
\text { gancho }\end{array}$ & $\alpha_{1}=1$ & $\alpha_{1}=1$ \\
\hline Forma das barras & $\begin{array}{l}\text { Barras retas, com } \\
\text { gancho ou laços }\end{array}$ & $\begin{array}{l}\alpha_{1}=0,7 p / c_{d}>3 \phi \\
\alpha_{1}=1 p / c_{d} \leq 3 \phi\end{array}$ & $\alpha_{1}=1$ \\
\hline $\begin{array}{c}\alpha_{2} \\
\text { Barras transversais } \\
\text { soldadas }\end{array}$ & Qualquer & $\alpha_{2}=0,7$ & $\alpha_{2}=0,7$ \\
\hline$\alpha_{3}$ & $\begin{array}{l}\text { Barras retas, sem } \\
\text { gancho }\end{array}$ & $\begin{array}{c}\alpha_{3}=1-0,15\left(c_{d}-\phi\right) / \phi \\
0,7 \leq \alpha_{3} \leq 1\end{array}$ & $\alpha_{3}=1$ \\
\hline $\begin{array}{l}\text { Cobrimento das } \\
\text { armaduras }\end{array}$ & $\begin{array}{l}\text { Barras retas, com } \\
\text { gancho ou laços }\end{array}$ & $\begin{array}{c}\alpha_{3}=1-0,15\left(c_{d}-3 \phi\right) / \phi \\
0,7 \leq \alpha_{3} \leq 1\end{array}$ & $\alpha_{3}=1$ \\
\hline $\begin{array}{c}\alpha_{4} \\
\text { Barras transversais } \\
\text { não soldadas }\end{array}$ & Qualquer & $\begin{array}{l}\alpha_{4}=1-k \lambda \\
0,7 \leq \alpha_{4} \leq 1\end{array}$ & $\alpha_{4}=1$ \\
\hline $\begin{array}{c}\alpha_{5} \\
\text { Pressão transversal p } \\
\mathrm{MPa}\end{array}$ & Qualquer & $\begin{array}{l}\alpha_{5}=1-0,04 p \\
0,7 \leq \alpha_{5} \leq 1\end{array}$ & $\alpha_{5}=1$ \\
\hline
\end{tabular}

Tabela 3.2 - Valores de $c_{d}, k$ e $\lambda$ (IBRACON, 2003).

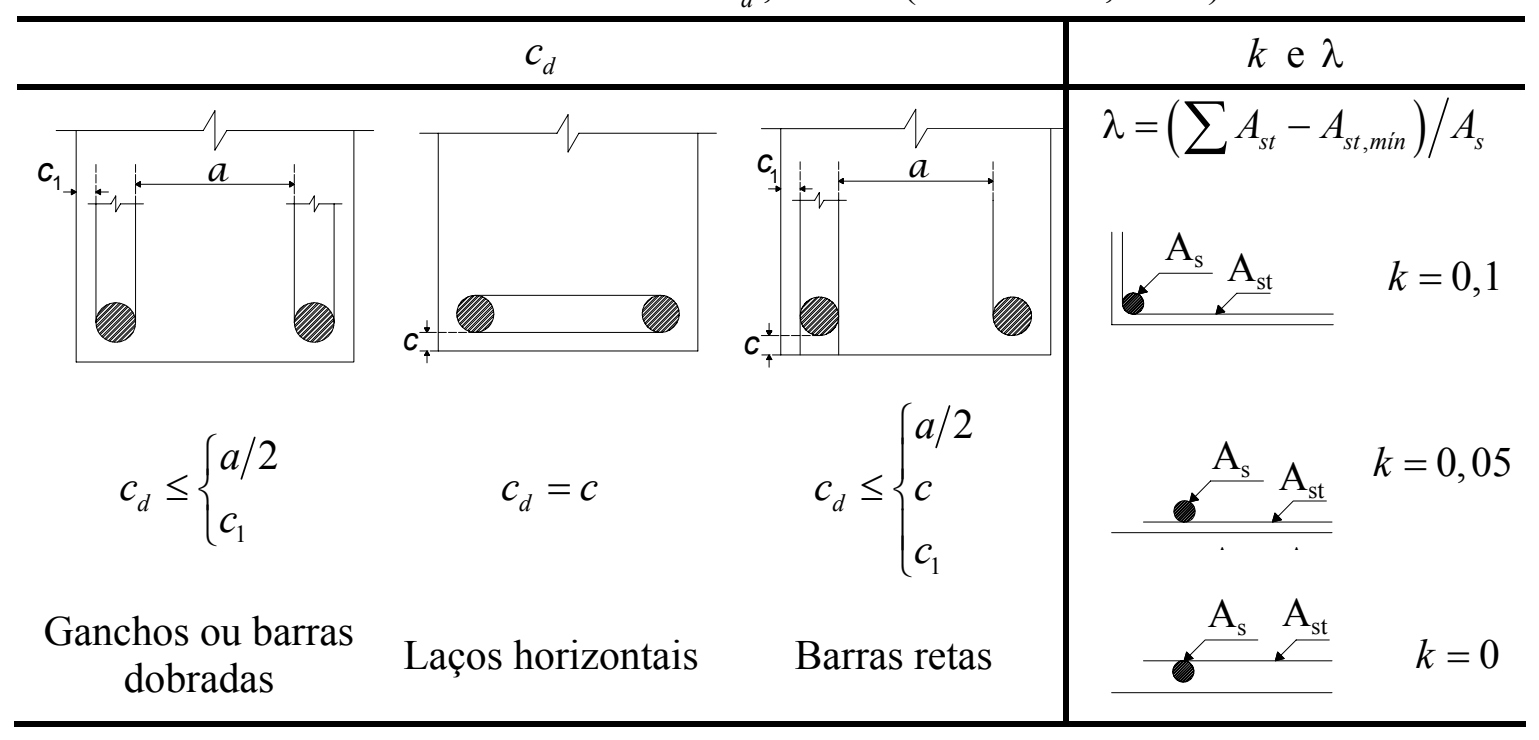


Para o caso do comprimento de ancoragem de barras comprimidas, não se recomenda o uso de ganchos, e o comprimento pode ser determinado pelas mesmas expressões que o das barras tracionadas.

As prescrições do ACI 318:2002 estabelecem expressões distintas para o cálculo do comprimento de ancoragem de barra reta tracionada e comprimida.

Para as barras longitudinalmente tracionadas, o comprimento de ancoragem de uma barra reta pode ser obtido conforme a eq.(3.4):

$$
\ell_{d b}=0,91 \cdot \frac{f_{y}}{\sqrt{f_{c}^{\prime}}} \cdot \frac{\alpha \cdot \beta \cdot \gamma \cdot \lambda}{\left(\frac{c+K_{t r}}{d_{b}}\right)} \cdot d_{b}
$$

Onde:

$\ell_{d b}$ : comprimento de ancoragem básico de barras tracionadas, segundo ACI 318:2002 $(\mathrm{mm})$;

$d_{b}$ : diâmetro nominal da barra $(\mathrm{mm})$;

$f_{y}$ : resistência ao escoamento do aço $(\mathrm{MPa})$;

$f_{c}^{\prime}$ : resistência à compressão do concreto em MPa, para um quantil de $1 \%$;

$\alpha, \beta, \gamma, \lambda$ : fatores de majoração e/ou minoração do comprimento de ancoragem, apresentados na Tabela 3.3;

$c$ : distância entre as barras ou cobrimento;

$K_{t r}:$ índice de armadura transversal.

Para o caso de ancoragem reta em barras longitudinalmente comprimidas, o comprimento de ancoragem é dado pela eq.(3.5). Essa distinção é justificada para que seja reduzido o comprimento de ancoragem, já que não há os efeitos de tração por flexão que provocam a fissuração.

$$
\ell_{d c}=0,24 \cdot d_{b} \cdot \frac{f_{y}}{\sqrt{f_{c}^{\prime}}}
$$


Em que $\ell_{d c}$ é o comprimento de ancoragem de barras comprimidas (mm), segundo ACI 318:2002, cujo valor não pode ser menor que $0,044 \cdot d_{b} \cdot f_{y} e 200 \mathrm{~mm}$.

Tabela 3.3 - Fatores de majoração e/ou minoração do comprimento de ancoragem.

\begin{tabular}{|c|c|c|}
\hline Fator $^{\dagger}$ & Condição & Valor \\
\hline \multirow{2}{*}{$\begin{array}{c}\alpha \\
\text { relativo à localização } \\
\text { da armadura }\end{array}$} & $\begin{array}{l}\text { para armadura horizontal localizada mais que } \\
300 \mathrm{~mm} \text { da face superior da peça }\end{array}$ & $\alpha=1,3$ \\
\hline & para outros casos & $\alpha=1,0$ \\
\hline \multirow{3}{*}{$\begin{array}{l}\beta \\
\text { relativo ao } \\
\text { revestimento }\end{array}$} & para armaduras sem revestimento & $\beta=1,0$ \\
\hline & $\begin{array}{l}\text { para todas as outras situações de armaduras } \\
\text { revestidas com epóxi }\end{array}$ & $\beta=1,2$ \\
\hline & $\begin{array}{l}\text { para barras revestidas com epóxi com o } \\
\text { cobrimento menor que } 3 d_{b} \text { ou com um } \\
\text { espaçamento livre menor que } 6 d_{b}\end{array}$ & $\beta=1,5$ \\
\hline \multirow{2}{*}{$\begin{array}{l}\gamma \\
\text { relativo ao diâmetro } \\
\text { da armadura }\end{array}$} & $\begin{array}{l}\text { para barras com diâmetro menor ou igual a } \\
20 \mathrm{~mm}\end{array}$ & $\gamma=0,8$ \\
\hline & $\begin{array}{l}\text { para barras com diâmetro maior ou igual a } \\
25 \mathrm{~mm}\end{array}$ & $\gamma=1,0$ \\
\hline \multirow{3}{*}{$\begin{array}{l}\lambda \\
\text { relativo a densidade } \\
\text { do concreto }\end{array}$} & $\begin{array}{l}\text { para concreto de baixa densidade (concreto } \\
\text { leve) }\end{array}$ & $\lambda=1,3$ \\
\hline & $\begin{array}{l}\text { para concreto com densidade abaixo da normal } \\
\text { (semi-low-density concrete) }\end{array}$ & $\lambda=0,56 \cdot \frac{\sqrt{f_{c}^{\prime}}}{f_{c t}}$ \\
\hline & para concreto com densidade normal & $\lambda=1,0$ \\
\hline
\end{tabular}

$\dagger$ Não é necessário adotar para o produto de $\alpha$ e $\beta$ um valor maior que 1,7 ;

* Esse valor não pode ser menor que 1,0 quando $f_{c t}$ é especificada.

No que se refere ao parâmetro relativo à distância entre as barras ou cobrimento (c), seu valor é o menor encontrado dentre as situações descritas abaixo:

a) à distância entre o centro da barra ancorada e a superfície de concreto mais próxima;

b) a metade do espaçamento entre os centros das barras ancoradas.

Por fim, o índice de armadura transversal é obtido de acordo com eq.(3.6):

$$
K_{t r}=\frac{A_{t r} \cdot f_{y t}}{10,5 \cdot s \cdot n}
$$


Sendo:

$A_{t r}$ : área total de armadura transversal disposta ao longo de uma distância $s$ que atravessa o plano potencial de fendilhamento na armadura ancorada;

$f_{y t}$ : resistência ao escoamento da armadura transversal;

$s$ : espaçamento máximo da armadura transversal, entre os estribos dispostos ao longo do comprimento da armadura principal, medido de centro a centro;

$n$ : número de barras ancoradas ao longo do plano de fendilhamento.

Para que as falhas por arrancamento sejam evitadas, pode-se estabelecer um valor limite de 2,5 para $\left(\frac{c+K_{t r}}{d_{b}}\right)$.

O ACI 318:2002 também permite a redução do comprimento de ancoragem das barras para os casos em que a armadura calculada seja menor que a armadura efetiva, mediante a razão entre ambas, respectivamente.

\subsubsection{Barras com ganchos de extremidade}

A NBR 6118:2003 estabelece três tipos de ganchos nas extremidades das barras longitudinais à tração, que são: os semicirculares, com ponta reta de comprimento não inferior a $2 \phi$; em ângulo de $45^{\circ}$ (interno), com ponta reta não inferior a $4 \phi$; em ângulo reto, com ponta reta não inferior a $8 \phi$ (ver Figura 3.1).
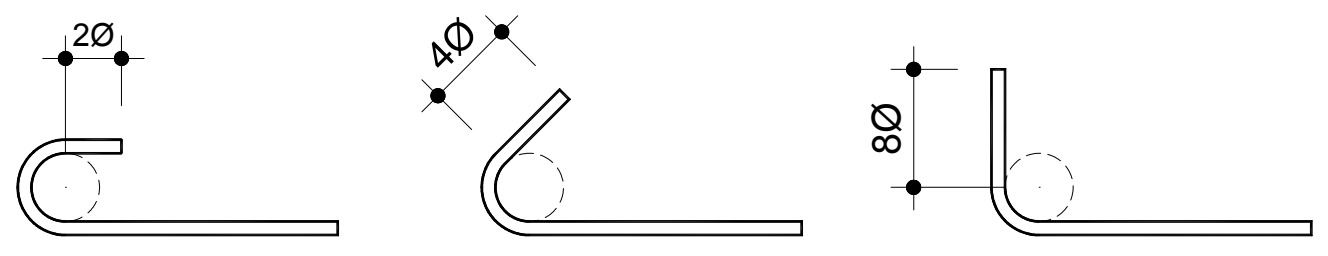

Figura 3.1 - Tipos de ganchos - NBR 6118:2003.

Os diâmetros internos mínimos para dobramento dos ganchos em função do tipo de aço adotado são apresentados na Tabela 3.4.

Tabela 3.4 - Diâmetros dos pinos de dobramento - NBR 6118:2003.

\begin{tabular}{c|c|c|c}
\hline \multirow{2}{*}{ Bitola (mm) } & \multicolumn{3}{|c}{ Tipo de aço } \\
\cline { 2 - 4 } & CA-25 & CA-50 & CA-60 \\
\hline$\phi<20$ & $4 \phi$ & $5 \phi$ & $6 \phi$ \\
$\phi \geq 20$ & $5 \phi$ & $8 \phi$ & - \\
\hline
\end{tabular}


Com relação às recomendações do ACI 318:2002, o comprimento da ponta reta deve ser no mínimo $12 \phi$, para os ganchos a $90^{\circ}$, e de $4 \phi$, para os ganchos a $180^{\circ}$.

\subsection{Decalagem do diagrama de forças nas armaduras}

A prática freqüente para retirada de serviço de barras da armadura de flexão se dá pelo deslocamento do diagrama de forças $R_{s t}\left(M_{d} / z\right)$, no sentido mais desfavorável e paralelo ao eixo da peça, de um valor $a_{\ell}$, o qual é corriqueiramente substituído pela decalagem aproximada do diagrama de momentos fletores (Figura 3.2).

De acordo com a NBR 6118:2003, esse valor de $a_{\ell}$ é inerente ao modelo de cálculo adotado para a determinação da armadura transversal destinada a absorver as tensões de tração oriundas da ação da força cortante e representa um valor de segurança conveniente para se contabilizar os efeitos provocados pela fissuração oblíqua. A diferença básica entre ambos é que para o modelo I, admite-se que as bielas diagonais de compressão tenham inclinação de $\theta=45^{\circ}$ em relação ao eixo longitudinal da peça e que $V_{c}$ tem valor constante, ao contrário do modelo II, o qual permite uma escolha arbitrária do ângulo de inclinação das bielas comprimidas $(\theta)$ variando no intervalo $30^{\circ} \leq \theta \leq 45^{\circ}$ e o valor de $V_{c}$ é considerado com valores menores.

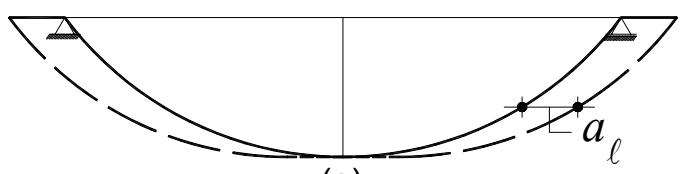

(a)

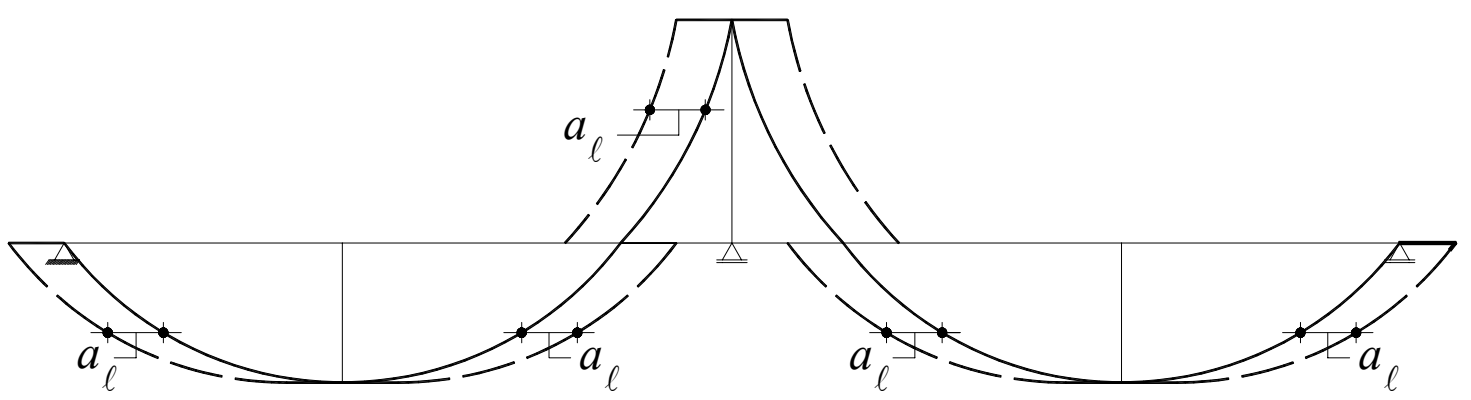

(b)

Figura 3.2 - Decalagem do diagrama de momento fletor deslocado:

(a) Viga biapoiada; (b) Viga contínua com dois tramos. 
Os valores de $a_{\ell}$ e seus respectivos modelos de cálculo são expressos de acordo com eq.(3.7) e eq.(3.8):

$$
\begin{aligned}
& a_{\ell}=d \cdot\left[\frac{V_{S d, \text { máx }}}{2 \cdot\left(V_{S d, \text { máx }}-V_{c}\right)} \cdot(1+\cot g \alpha)-\cot g \alpha\right] \quad \text { (modelo I) } \\
& a_{\ell}=0,5 \cdot d \cdot(\cot g \theta-\cot g \alpha)
\end{aligned}
$$

Onde:

$\theta$ : ângulo de inclinação das bielas de compressão do concreto;

$\alpha$ : ângulo de inclinação da armadura transversal em relação ao eixo longitudinal da peça, variando $45^{\circ} \leq \theta \leq 90^{\circ}$;

$d$ : distância entre o centróide da armadura de flexão tracionada e a fibra de concreto comprimida mais afastada;

$V_{S d, m a ́ x}$ : força cortante solicitante máxima de cálculo;

$V_{c}$ : parcela da força cortante resistida por mecanismos complementares ao modelo em treliça;

$a_{\ell} \geq 0,5 \cdot d$, no caso geral;

$a_{\ell} \geq 0,2 \cdot d$, para estribos inclinados a $45^{\circ}$.

Uma alternativa para a decalagem do diagrama de força é aumentar a força de tração em cada seção, pela eq.(3.9):

$$
R_{S d, c o r}=\frac{M_{S d}}{z}+0,5 \cdot\left|V_{S d}\right| \cdot(\cot g \theta-\cot g \alpha)
$$

Onde:

$\mathrm{z}$ : braço de alavanca;

$M_{S d}:$ momento fletor solicitante de cálculo. 


\subsection{Ponto de início de ancoragem}

Para que se garanta uma boa ancoragem, é razoável que a mesma seja feita, preferencialmente, em zonas de compressão transversal às barras. Logo, numa peça fletida, desde que se assegure o comprimento necessário de ancoragem $\left(\ell_{b, \text { nec }}\right)$, se uma das barras de tração puder ser eliminada, ela pode ser interrompida na própria zona de tração.

Na maioria dos casos, as zonas de compressão transversal são introduzidas pelas bielas de concreto resistentes à força cortante cuja eficiência e uniformidade ao longo do comprimento da barra ancorada está diretamente ligada ao espaçamento dos estribos (Figura 3.3).

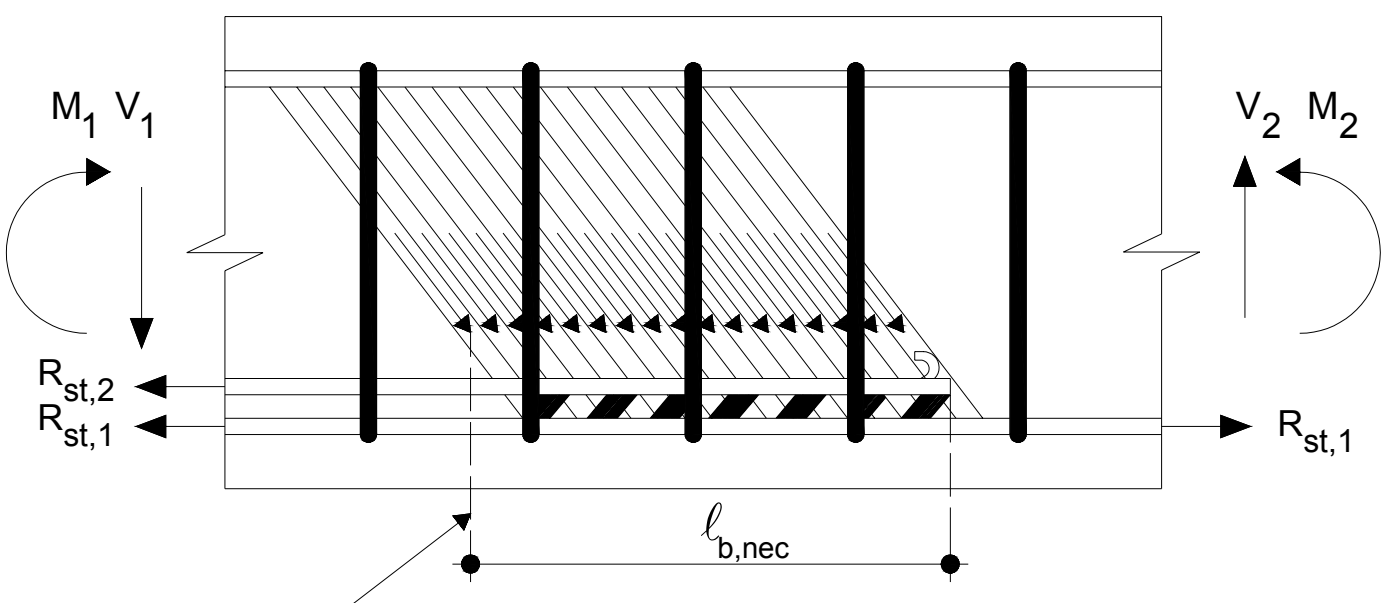

Seção de início da ancoragem

Figura 3.3 - Zona de compressão transversal - Modificado de FUSCO (1995).

Um detalhe construtivo para barras retiradas de serviço em elementos sujeitos à flexão é apresentado na Figura 3.4. Nas barras lisas é obrigatório o gancho na extremidade uma vez que sua presença inibe o escorregamento inicial da barra. Já nas barras nervuradas, pode-se adotar uma ancoragem reta sem gancho justificada pelas nervuras e mossas que mobilizam essencialmente a ancoragem mecânica, a qual resiste bem aos efeitos da deformação lenta e do escorregamento longitudinal. Entretanto, nos trechos de grande solicitação de flexão em que são elevadas as tensões na armadura sob as ações de serviço, o gancho de extremidade das barras lisas ou a simples interrupção das barras de alta aderência deve ser evitado, pois, pode provocar o surgimento de uma 
fissura de grande abertura. Por isso, sugere-se que as barras sejam ligeiramente levantadas para dentro da peça (FUSCO, 1995).

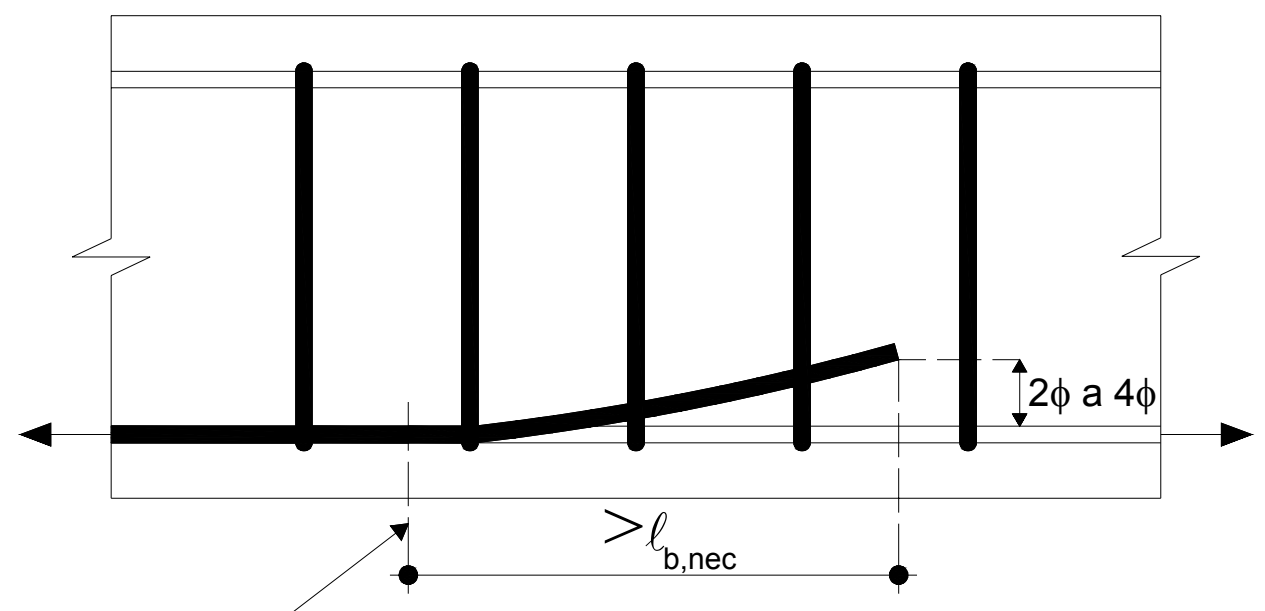

Seção de início da ancoragem

Figura 3.4 - Detalhe construtivo para barras retiradas de serviço - FUSCO (1995).

Seguindo as prescrições da NBR 6118:2003, o segmento da barra tracionada a ser ancorado tem início na seção teórica onde sua tensão $\sigma_{s}$ começa a diminuir (a força de tração nas barras da armadura começa a ser transferida para o concreto). Com isso, prolonga-se pelo menos $10 \phi$ além do ponto teórico de tensão $\sigma_{s}$ nula, não podendo em nenhum caso ser inferior ao comprimento de ancoragem necessário $\left(\ell_{b, \text { nec }}\right)$.

Uma vez que seja determinada a armadura longitudinal e escolhido o diâmetro das barras que a compõe, o problema passa a residir na escolha dos comprimentos ótimos e dos arranjos ao longo do elemento estrutural. O critério adotado no detalhamento das armaduras de tração consiste na divisão do diagrama em segmentos cujas distâncias entre si equivalem ao momento fletor capaz de ser absorvido pela barra da armadura unitária de área $A_{s}$. Portanto, os pontos de interseção do diagrama de momento fletor decalado com os feixes de linhas indicam em que seção as barras da armadura podem ser retiradas de serviço e ancoradas.

Conforme se constata na Figura 3.5, a partir do ponto A do diagrama de forças decalado de um valor $a_{\ell}$, inicia-se o comprimento de ancoragem da barra da armadura longitudinal de tração dos elementos estruturais solicitados por flexão simples dependendo do modelo de cálculo. Este diagrama equivale ao diagrama de forças corrigido $R_{S d, c o r}$. Para barra reta, o trecho de ancoragem deve ser prolongado além de B, 
no mínimo de $10 \phi$. Nas seções intermediárias entre A e B, o diagrama resistente linearizado deve cobrir o diagrama solicitante.

Para o caso das lajes, a NBR 6118:2003 recomenda que se adote $a_{\ell}=1,5 d$.

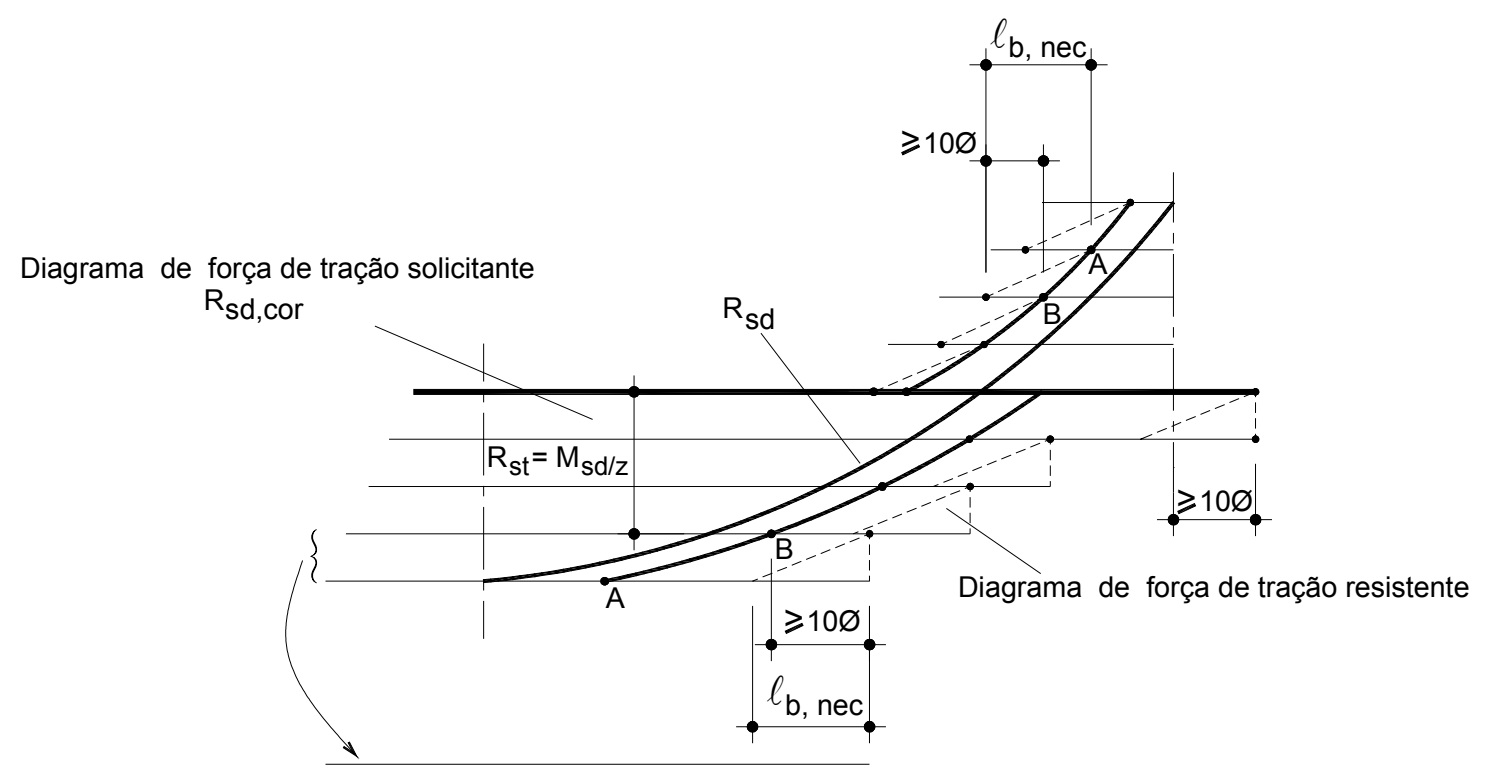

Figura 3.5 - Cobertura do diagrama de força de tração solicitante pelo diagrama resistente - Modificado da NBR 6118:2003.

Para facilitar o uso da decalagem, pode-se aplicar um procedimento simplificado que consiste em envolver o diagrama de momento fletor já deslocado de $a_{\ell}$, por uma “escada" de degraus verticais, determinada conforme indicado na Figura 3.6, retirandose de serviço e ancorando as correspondentes barras, degrau por degrau. É evidente que esse procedimento é semelhante ao proposto pela NBR 6118:2003, entretanto, ligeiramente a favor da segurança. Contudo, a proposição se torna bastante conveniente dada a sua simplicidade (SÜSSEKIND, 1981; CARVALHO e FIGUEIREDO FILHO, 2004). 


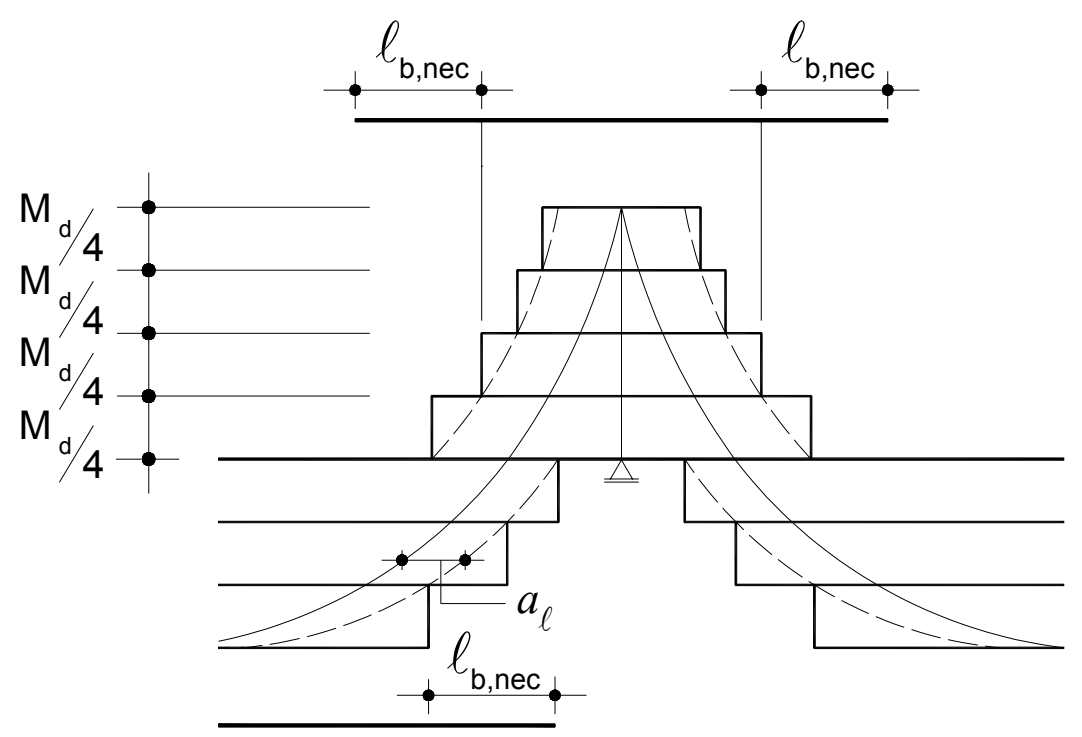

Figura 3.6 - Diagrama de momentos fletores de cálculo estratificado.

No que tange aos apoios internos, há duas situações a se considerar acerca do ponto de início de ancoragem:

- Quando o comprimento de ancoragem da barra se iniciar na face do apoio ou além dela e a força a ancorar na armadura $\left(R_{s t}\right)$ diminuir em direção ao centro do apoio, recomenda-se que esse seja medido a partir dessa face;

- Se o diagrama de momentos fletores de cálculo não atingir a face do apoio, as barras prolongadas até o apoio devem ter o comprimento de ancoragem necessário $\left(\ell_{b, \text { nec }}\right)$ marcado a partir do ponto no qual o eixo da barra intercepta o diagrama deslocado e, obrigatoriamente, deve ultrapassar $10 \phi$ da face de apoio.

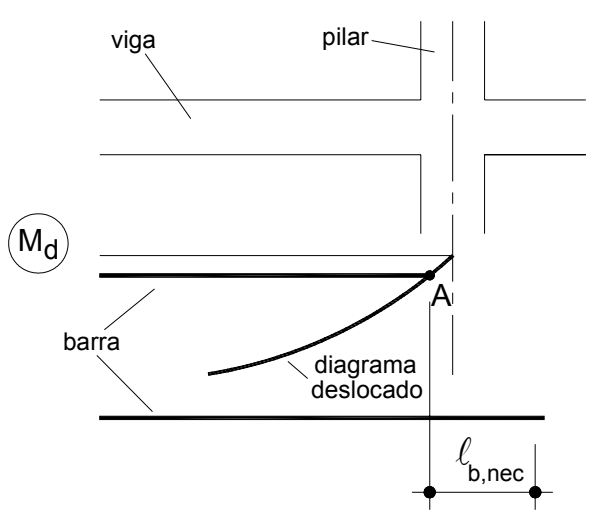

(a)

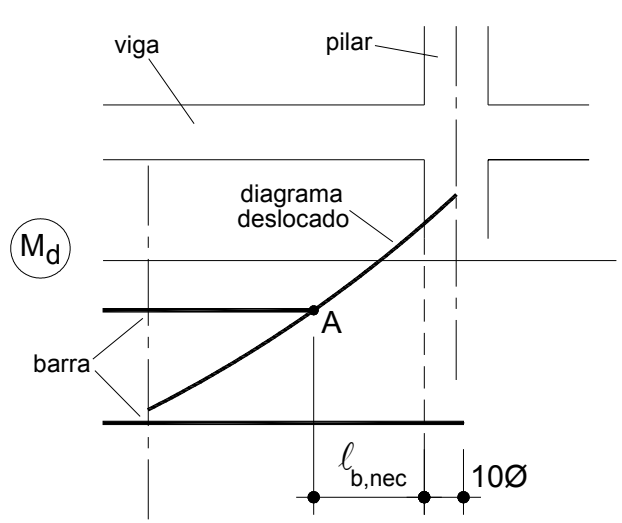

(b)

Figura 3.7 - Ancoragem de barras em apoios intermediários - (a) prolongamentos das barras até os apoios; (b) interrupção das barras antes dos apoios. 
Nas ligações entre vigas, o ponto de início de ancoragem deve ser considerado a partir de 1/3 da largura do apoio, sendo o comprimento total da barra a ancorar igual a $\ell_{b, \text { nec }}+(1 / 3) \cdot b_{w}$.

Segundo Cunha e Souza (1994), a decalagem do diagrama de momento fletor para as lajes é bastante trabalhosa. Por isso, na prática, costuma-se detalhar as barras das armaduras de flexão positiva, traspassadas uma da outra conforme a Figura 3.8.

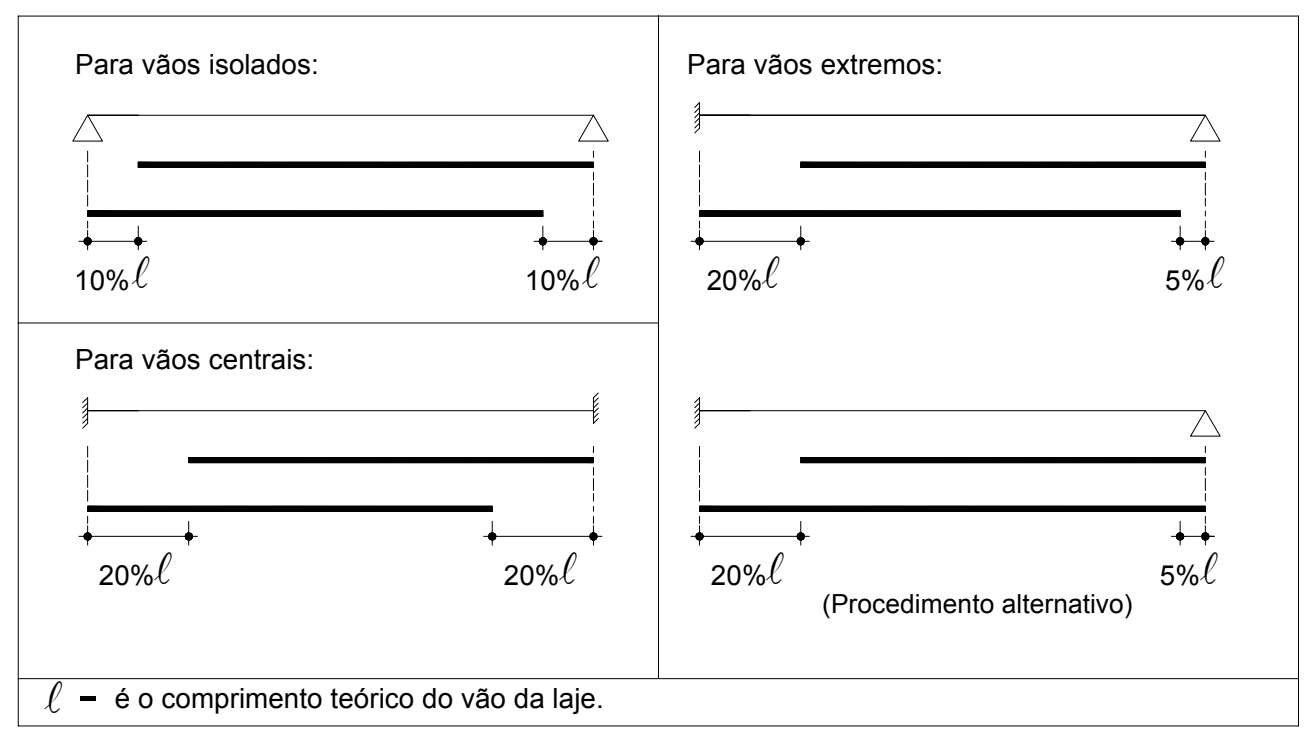

Figura 3.8 - Procedimento prático para detalhamento das barras das armaduras positivas das lajes - CUNHA e SOUZA (1994).

Com relação às armaduras de flexão negativa das lajes, Cunha e Souza (1994) apresentaram seis possíveis disposições das barras em função dos espaçamentos comumente empregados (ver Figura 3.9). 
$\phi$ c. 20

$\phi$ c. $10 ;$ c. 12,$5 ;$ c. 15

$\phi$ c.7,5; c.6,7; c.5
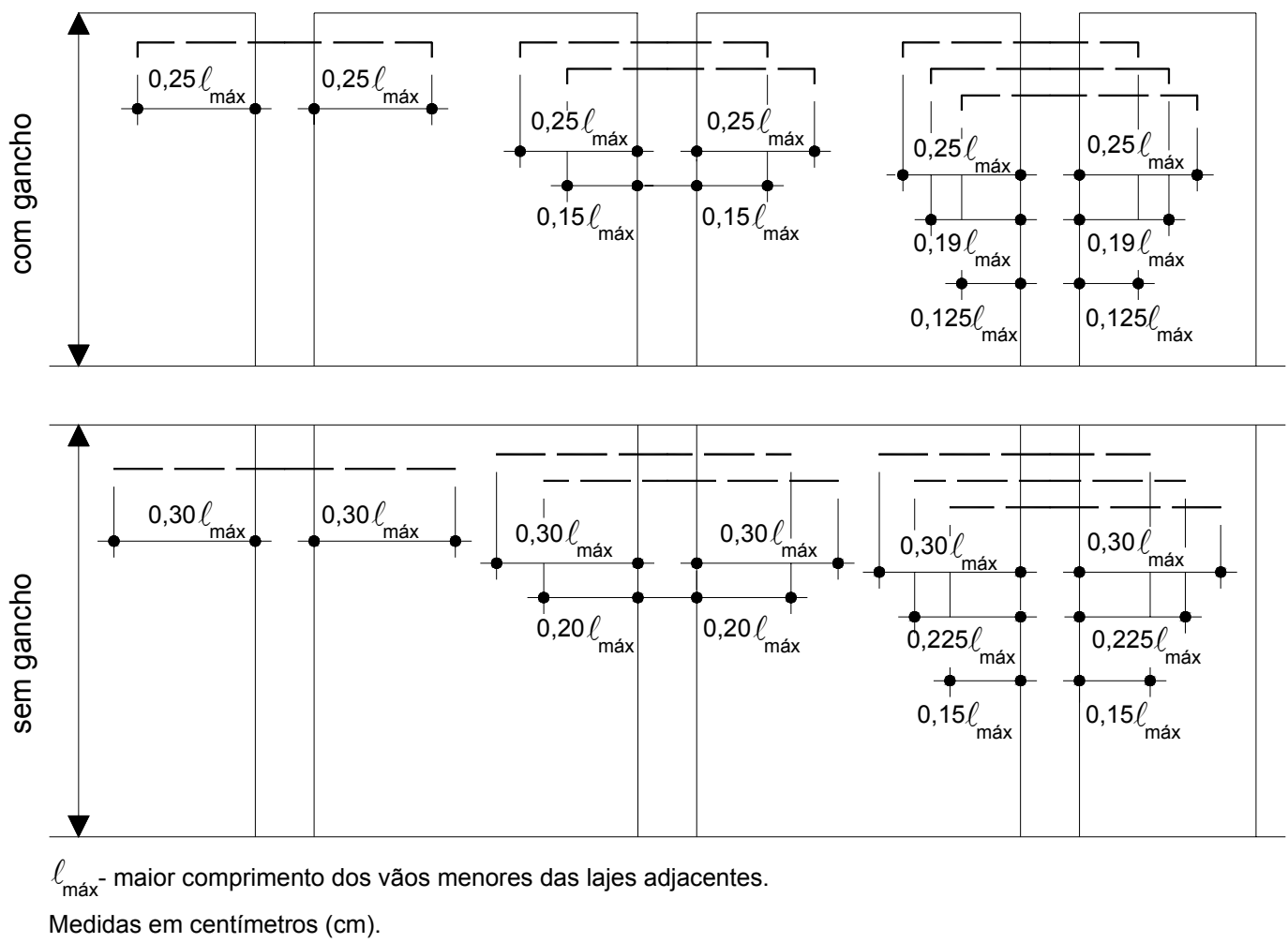

Figura 3.9 - Procedimento prático para detalhamento das barras das armaduras negativas das lajes - CUNHA e SOUZA (1994).

Para Carvalho e Figueiredo Filho (2004), a possibilidade de racionalização do processo de fabricação deve preceder aos critérios de detalhamento a serem utilizados. Em alguns casos, é mais rentável sob o aspecto econômico a extensão das barras da armadura ao longo de todo elemento estrutural a cortá-las como sugere a NBR 6118:2003. Segundo os autores, se o custo do trabalho despendido no projeto e no corte e dobra da armadura for superior ao custo do material economizado, é preferível optar pelo uso das barras com comprimento igual ao do elemento.

\subsection{Ancoragem das armaduras de tração nas seções de apoio}

A ancoragem das armaduras de tração nas seções de apoio está prevista na NBR 6118:2003 sob três condições cujo entendimento é essencial para o desenvolvimento do trabalho. Essas recomendações atestam que as forças de tração junto aos apoios de vigas simples ou contínuas devem ser resistidas pelas armaduras longitudinais, atendendo a mais severa dentre elas, a saber: 
a) na ocorrência de momentos fletores positivos, as armaduras obtidas por meio do dimensionamento da seção;

b) em apoios extremos, para garantir ancoragem da diagonal de compressão, armaduras capazes de resistir a uma força de tração $R_{s t}=\left(a_{\ell} / d\right) \cdot V_{d}+N_{d}$, onde $V_{d}$ é a força cortante no apoio e $N_{d}$ é a força de tração eventualmente existente;

c) em apoios extremos e intermediários, por prolongamentos de uma parte da armadura de tração do vão $\left(A_{s, v a ̃ o}\right)$, correspondente ao máximo momento fletor positivo do tramo $\left(M_{\text {vão }}\right)$ de modo que:

- $A_{s, \text { apoio }} \geq 1 / 3 \cdot\left(A_{s, v a \tilde{o}}\right)$ se $M_{\text {apoio }}$ for nulo ou negativo e de valor absoluto $\left|M_{\text {apoio }}\right| \leq 0,5 M_{\text {vão }}$

- $A_{s, \text { apoio }} \geq 1 / 4 \cdot\left(A_{s, v \tilde{a} o}\right)$ se $M_{\text {apoio }}$ for negativo e de valor absoluto $\left|M_{\text {apoio }}\right|>0,5 M_{\text {vão }}$.

Para as condições descritas em $b$ e $c$, no caso de apoio extremidade, as barras devem ser ancoradas a partir da face do apoio, com comprimentos iguais ou superiores ao maior dos seguintes valores:

$\ell_{b, \text { nec }}$

$(r+5,5 \phi)$, com $r$ igual ao raio efetivo do gancho;

$60 \mathrm{~mm}$.

Comumente se adota no meio técnico, os detalhamentos apresentados na Figura 3.10 para apoios extremos. A questão é que nos apoios estreitos e extremos de ligações monolíticas, a largura da peça de apoio pode ser insuficiente para alojar o comprimento de ancoragem necessário, mesmo considerando gancho na extremidade da barra. Portanto, quando se tem $\ell_{b, e f}<\ell_{b, \text { nec }}$ no apoio é necessário diminuir a tensão $\left(\sigma_{s}\right)$ nas barras estendidas até o apoio, aumentando-se, proporcionalmente, a área calculada de armadura no apoio $\left(A_{s, \text { calc,apoio }}\right)$, que o resulta em:

$$
A_{s, e f, \text { apoio }}=\frac{\ell_{b, \text { nec }}}{\ell_{b, e f}} \cdot A_{s, \text { calc,apoio }}
$$


Sendo, $\ell_{b, e f}=b_{w}-c, \operatorname{com} b_{w}$ igual a largura do apoio na direção do eixo da viga e $c$ é o cobrimento da armadura.

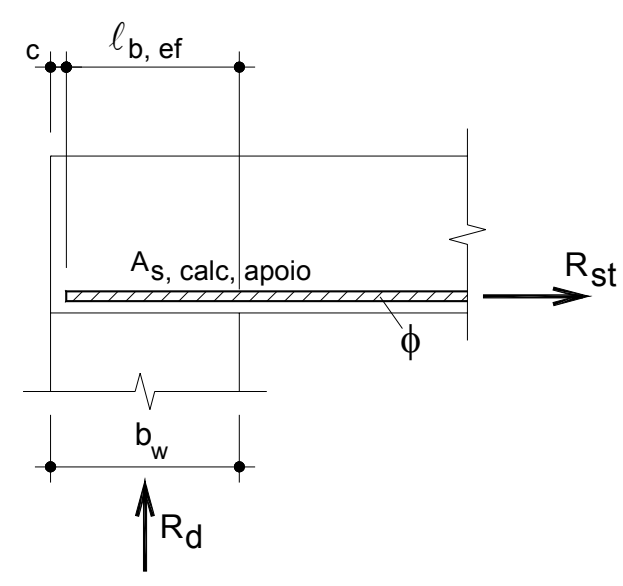

(a)

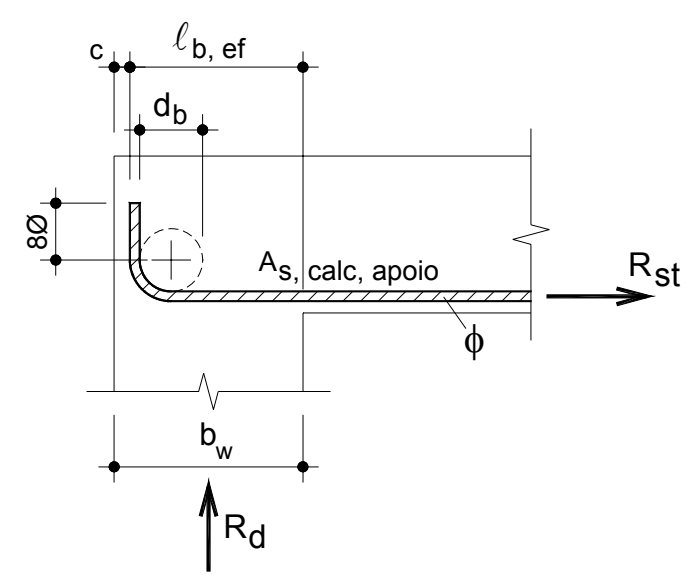

(b)

Figura 3.10 - (a) Barra em ponta reta; (b) Barra em gancho - PROMON (1976).

Em apoios intermediários, o comprimento de ancoragem pode ser igual a $10 \phi$, desde que não haja qualquer possibilidade da ocorrência de momentos positivos nessa região. Caso não se possa garantir essa condição, as barras devem ser contínuas ou emendadas sobre o apoio.

\subsection{Ligações entre elementos estruturais de concreto armado}

Durante algum tempo, o posicionamento das barras das armaduras nos encontros entre peças estruturais era feito de acordo com a experiência do projetista em função de obras anteriores. Contudo, a racionalização dos materiais com vistas à contenção de custos e o desenvolvimento de programas computacionais que fornecem resultados mais precisos quanto à análise estrutural, provocaram uma otimização de dimensões das peças e, com isso, possibilitou a disposição mais racional.

As ligações entre os elementos estruturais são denominadas como regiões especiais visto que sua descontinuidade geométrica não permite a validade das hipóteses de Bernoulli quanto à variação linear das deformações ao longo da seção transversal. Alguns estudos que tratam da verificação do fluxo de tensões nesses trechos revelam 
que há uma mudança no direcionamento das forças internas que, conseqüentemente, alteram a distribuição das tensões.

A complexidade no que tange ao comportamento dessas regiões obriga que as mesmas tenham uma resistência superior em relação aos elementos que nelas convergem. Essa resistência está associada a diversos fatores que vão desde as propriedades intrínsecas aos materiais até aos aspectos relativos à geometria das peças.

Em vistas à concepção estrutural, a eficiência dos arranjos das armaduras nas ligações não está apenas associada a sua capacidade de absorção dos esforços solicitantes, mas também, ao controle de fissuração, sem que para isso, ocasione o congestionamento de barras nos trechos em questão. Uma possibilidade de escolha do arranjo adequado é pela utilização do modelo de bielas e tirantes cujos aspectos básicos podem ser encontrados com detalhes em Silva e Giongo (2000).

Os trabalhos que estão relacionados abaixo tratam do desenvolvimento de parte das pesquisas que se têm desenvolvidos ao longo das últimas décadas, dando uma idéia parcial do estado-da-arte referente ao estudo das ligações:

- Nilsson e Losberg (1976) realizaram um abrangente estudo sobre o panorama do fluxo de tensões elásticas em nós de pórticos de concreto armado e a adequação dos arranjos das armaduras.

- Ueda, Lin e Hawkins (1986) desenvolveram um modelo computacional capaz de prever a força axial última e a deformação nesse estágio, e o comprimento de ancoragem necessário das barras de armaduras de vigas ancoradas em pilar de extremidade. O modelo incorpora a relação tensão de aderência versus deslizamento, relação tensão versus deformação para o aço, condição de continuidade entre o aço e o concreto, modificação para concreto confinado, critério de falha e um procedimento para o comprimento de ancoragem equivalente para barras com gancho.

- Soroushian et al. (1988) analisaram o desempenho de barras de viga ancoradas com curvas a $90^{\circ}$ em pilar de extremidade para aferição de um modelo analítico para simulação de ensaio de arrancamento. Nos trabalhos experimentais foram extraídos os efeitos do diâmetro das barras, do grau de confinamento e da resistência do concreto. A relação força de arrancamento versus deslizamento foi obtida mediante expressões empíricas. Posteriormente, Soroushian e Choi (1991) aprimoraram o modelo para ligações ancoradas com barras retas. 
- Leon (1989) investigou a influência do comprimento de ancoragem das barras das armaduras nas ligações viga-pliar intermediários.

- Andreasen (1991) descreveu uma investigação de cunho experimental para verificar o comportamento da ancoragem de barras de armaduras de vigas dispostas em múltiplas camadas.

- Luo et al. (1994) avaliaram a eficiência dos arranjos de armaduras constituídas por barras ancoradas mediante emendas por traspasse em ligações do tipo viga de cobertura-pilar de extremidade. O mecanismo de ruína e fissuração, a distribuição das deformações ao longo das barras, a capacidade de carga, a resistência e a ductilidade foram as variáveis discutidas.

- Barbosa e Almeida (2001) apresentaram uma discussão sobre os nós de pórtico de concreto que abrangeram aspectos relativos aos modos de ruína, aos modelos de bielas e tirantes e aos arranjos das armaduras.

- Lundgren e Magnusson (2001) avaliaram a ancoragem de barras nervuradas em apoios diretos e indiretos, variando a resistência do concreto e a taxa de armadura transversal. Constataram que a capacidade de ancoragem aumenta substancialmente com a presença de estribos e, é tão maior quanto for à resistência do concreto. Entretanto, para concretos de alta resistência a ruína da ligação aço-concreto ocorre de maneira frágil em conseqüência da dificuldade de redistribuição de forças de tração entre as barras ancoradas.

- Lundgren (2002) fez uma análise comparativa numérico-experimental sobre a o comportamento de barras ancoradas por emendas de traspasse em nós de canto. Suas avaliações numéricas foram conduzidas por meio do método dos elementos finitos e foi considerada a não-linearidade dos materiais.

- Alva e El Debs (2002) observaram os fenômenos não-lineares que ocorrem nas ligações viga-pilar de concreto armado, submetidas às ações cíclicas, via análise numérica, incorporando modelos que utilizam conceito de dano e plasticidade.

- Barbosa e Almeida (2003) fizeram um estudo acerca de ligações viga-pilar para verificar o comportamento das barras longitudinais no nó submetido a carregamento cíclico reverso, a ancoragem das barras e o processo de transferência de esforços.

- Hegger, Sherif e Roeser (2003) realizaram um trabalho investigativo em relação aos parâmetros que influenciam a resistência ao cisalhamento de ligações externas e internas entre vigas e pilares. A eficiência do comprimento de 
ancoragem foi atribuída à relação entre o momento de fissuração e o momento teórico, seguindo a mesma lógica empregada por Nilsson e Losberg (1976). Esse estudo forneceu conclusões interessantes acerca das vantagens referentes ao uso de placas de ancoragem sobre os ganchos de extremidade.

- Atta et al. (2003) realizaram uma extensa pesquisa experimental sobre o desempenho das ligações monolíticas viga-pilar feitas com concreto de alta resistência. Em Atta et al. (2004) foram conduzidas análises numéricas para complementar os estudos sobre a influência do concreto de alta resistência nos nós de pórtico. Em ambos os trabalhos foram averiguados o efeito da força axial no pilar, da presença de estribos e os mecanismos de confinamento na região nodal.

Dentre os trabalhos acima citados e os disponíveis na literatura, é notável a predominância do enfoque das pesquisas, em sua grande parte, nas ligações do tipo viga-pilar.

Nos itens a seguir é apresentado o comportamento estrutural previsto para as ligações ora tratadas, quando submetidas a ações monotônicas, e alguns possíveis arranjos propostos para as barras das armaduras de tração e cisalhamento nas referidas regiões. 


\subsubsection{Ligação viga-pilar}

\subsubsection{Ligação viga de cobertura-pilar extremidade}

O comportamento estrutural da ligação entre viga de cobertura - pilar extremo pode ser avaliado em duas situações nas quais, tem-se o momento fletor ora tracionando as fibras internas ora as fibras externas.

Nilsson e Losberg (1976) reproduziram, mediante o método dos elementos finitos, a trajetória das tensões elásticas principais em nós de pórticos ortogonais submetidos a momento fletor positivo (tração nas fibras internas). De acordo com o que se apresenta na Figura 3.11, elevadas tensões diagonais de tração originam as fissuras que conduzem ao risco de fendilhamento da zona comprimida na flexão.

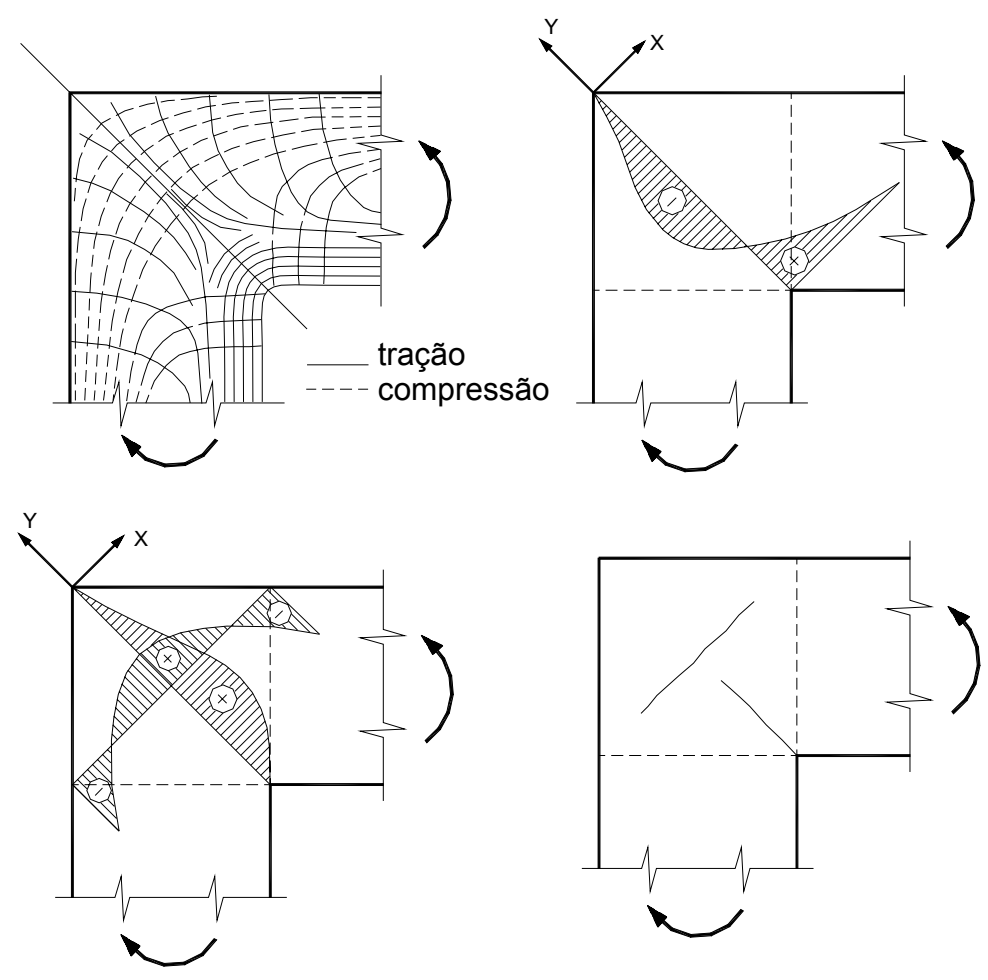

Figura 3.11 - Ligação viga de cobertura-pilar de extremidade submetida a momento fletor positivo - Modificado de LEONHARDT e MÖNNIG (1978).

O objetivo dessa pesquisa foi verificar a eficiência dos possíveis arranjos de armaduras, sendo essa definida pela relação entre o momento fletor de ruína do nó $\left(M_{u, \exp }\right)$, determinado experimentalmente, e o momento fletor de ruína teórico $\left(M_{u, t e o}\right)$ da seção na face da ligação, da barra mais desfavorável. Conforme os resultados dispostos na Figura 3.12, a eficiência máxima foi obtida para o nó com armadura em 
laço, que dispunha de barras inclinadas adicionais no vértice interno cuja área total deve ser maior ou igual à metade da área da armadura longitudinal de flexão da viga.
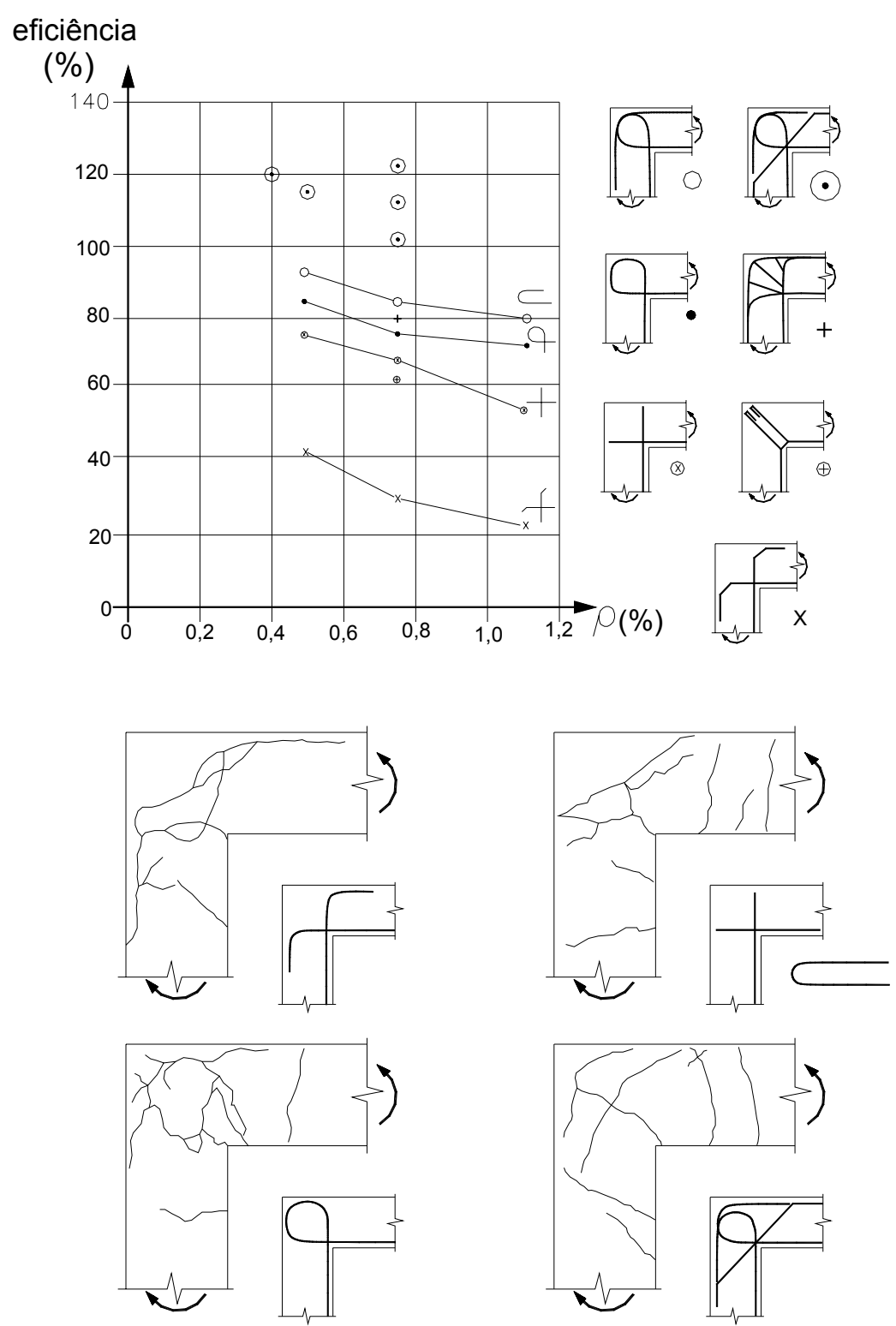

Figura 3.12 - Resultados da verificação da eficiência de nós de pórticos e estado fissurado das ligações para os arranjos adotados - Adaptado de NILSSON e LOSBERG (1976).

Em seguida, os próprios Nilsson e Losberg (1976) determinaram o fluxo de tensões elásticas nessa ligação submetida a momento fletor negativo (tração nas fibras externas). Segundo se constata na Figura 3.13, as fissuras principais surgiram ao longo do perímetro da ligação e em uma das diagonais. O risco de ruína desse tipo de nó se deve a um provável esmagamento do concreto na região do vértice interno. 


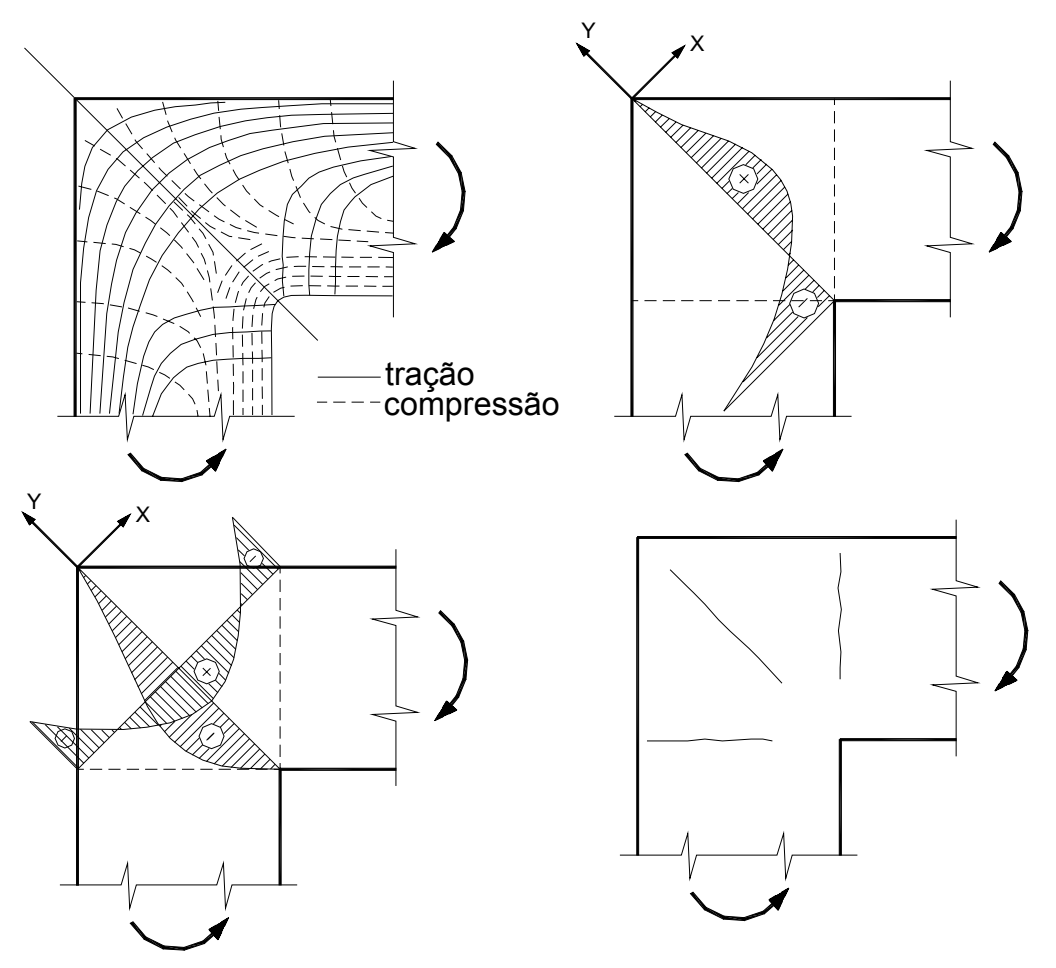

Figura 3.13 - Ligação viga de cobertura-pilar de extremidade submetida a momento fletor negativo - Modificado de LEONHARDT e MÖNNIG (1978).

Para a situação acima exposta, Leonhardt e Mönnig (1978) sugeriram que, para se evitar que a pressão relativa à mudança de direção cause o fendilhamento do concreto, a barra da armadura colocada no perímetro externo da ligação deve ser dobrada com um raio razoavelmente grande. Essa possibilidade é mais evidente quando à distância ao bordo ou entre as barras for muito pequena. $\mathrm{O}$ diâmetro necessário para a dobra é obtido pela eq.(3.11).

$$
d_{b, \text { nec }} \geq 2,48 \cdot \sqrt{\frac{\phi}{e}} \cdot \frac{f_{y k}}{f_{c k}}
$$

Sendo:

$\phi$ : diâmetro das barras da armadura;

$d_{b}$ : diâmetro da dobra;

$e$ : espaçamento entre as barras. 
Conforme a Figura $3.14 a$, recomenda-se adotar $e=e_{r}$ quando $e>2 e_{r}$, e, caso contrário, adota-se $e$, desde que $e_{r}=3 \phi \geq 3 \mathrm{~cm}$, sendo $e_{r}$ a distância do eixo da barra mais externa ao bordo.

O detalhamento mais adequado é apresentado na Figura $3.14 \mathrm{~b}$ para o qual se observa que a armadura de fendilhamento colocada no interior da dobra deve ser utilizada somente quando $d_{b}<d_{b, \text { nec }}$. Além do mais, em nós estreitos, o com dimensões pequenas, para diminuir as tensões de compressão no concreto, o vértice interno deve ser chanfrado ou curvo.

a)
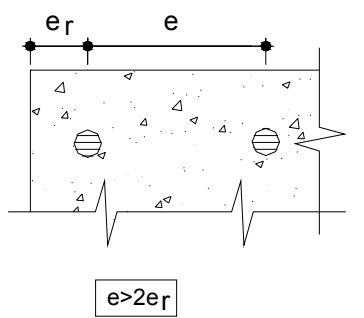

armadura de fendilhamento

b)
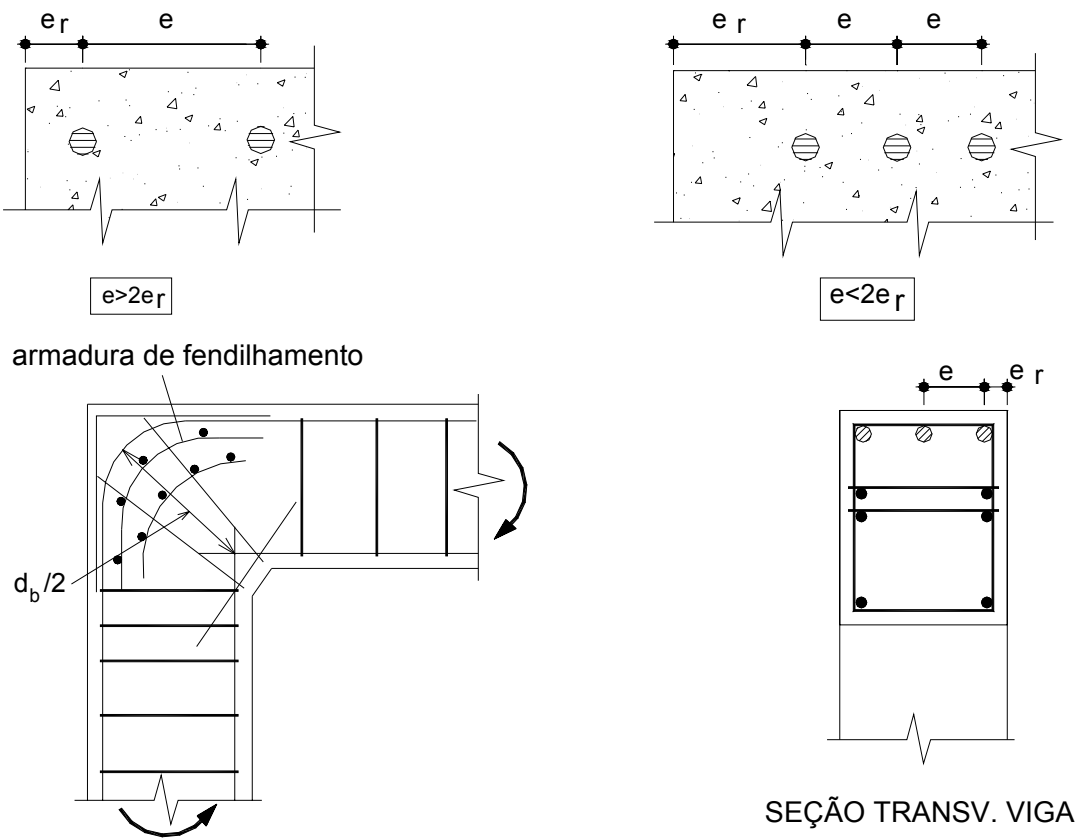

Figura 3.14 - a) Espaçamento entre as barras e b) Detalhamento adequado - Modificado de LEONHARDT e MÖNNIG (1978).

Em função do processo construtivo, quando se utilizam juntas de concretagem entre os pilares e as vigas, Leonhardt e Mönnig (1978) recomendaram que fossem utilizadas emendas por traspasse de laços em gancho e, com o intuito de limitar as aberturas de fissuras, devem-se colocar quatro barras adicionais no interior dos ganchos (ver Figura 3.15). 


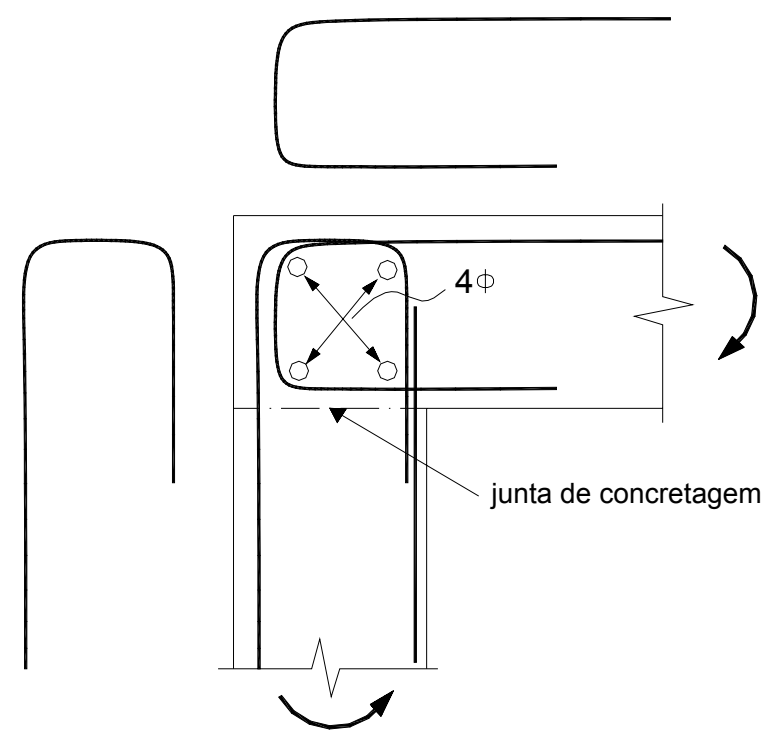

Figura 3.15 - Emenda por traspasse no nó - Modificado de LEONHARDT e MÖNNIG (1978).

Quando a relação $\frac{h_{v}}{h_{p}}>1,5$ for verificada, o MC CEB-FIP 1990 propôs um arranjo caracterizado pela presença de estribos horizontais com a função de resistir às tensões de tração horizontais que porventura possam surgir. Neste modelo, os comprimentos de ancoragem devem ser garantidos por $\ell_{b 1}$ para a força $R_{s t}=R_{s t 1}-R_{s t 2}$ da barra tracionada externa e $0,6 \ell_{b 1}$ para a barra comprimida interna.
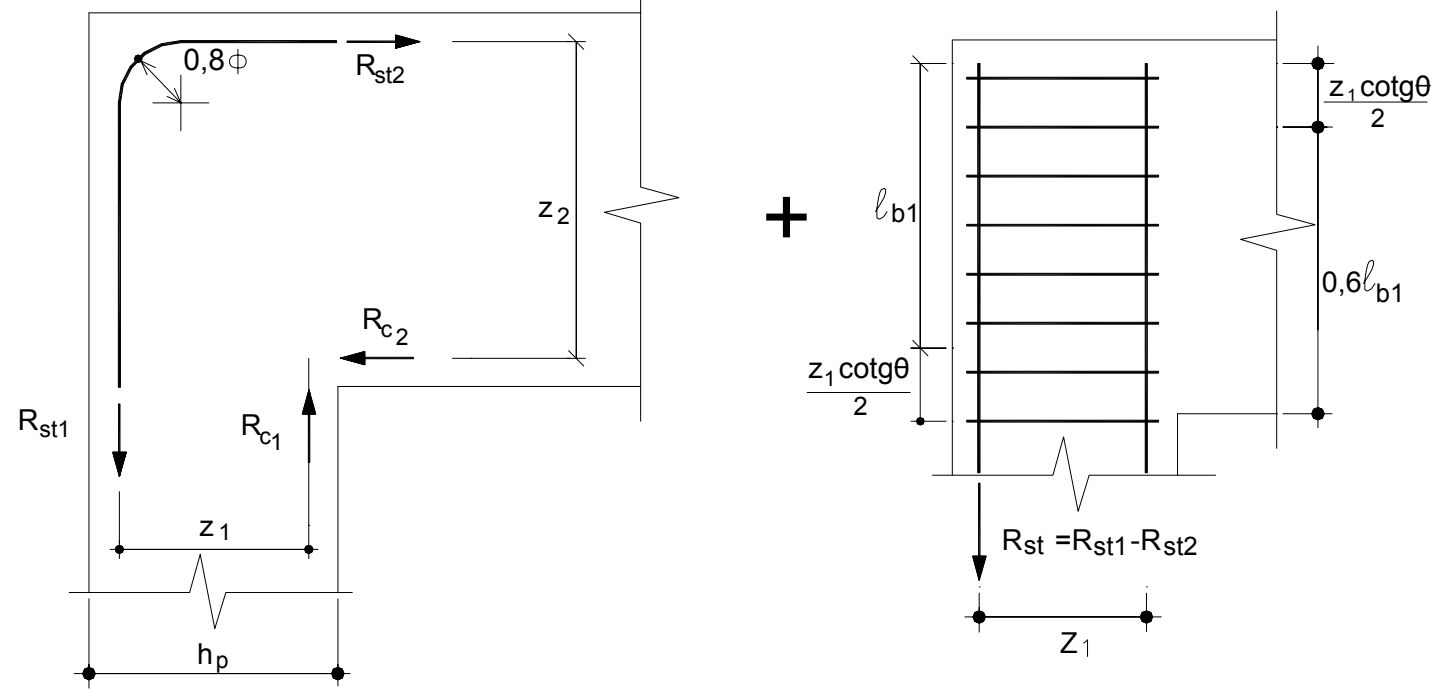

Figura 3.16 - Arranjo de armaduras proposto para $h_{v}>1,5 h_{p}-$ MC CEB-FIP 1990. 


\subsubsection{Ligação viga de cobertura-pilar intermediário}

A trajetória das tensões elásticas é apresentada na Figura 3.17. Conforme Leonhardt e Mönnig (1978) a ancoragem reta das barras do pilar, partindo do bordo inferior da viga, só deve ser adotada quando o momento fletor no topo pilar for pequeno em relação ao da viga, pois as tensões de compressão provenientes da flexão, transversais à barra, colaboram com uma ancoragem segura. Caso o momento fletor atuante no topo do pilar seja grande, recomenda-se prolongar as barras a ancorar do pilar até o banzo tracionado da viga e emendá-las por traspasse nas barras da viga.

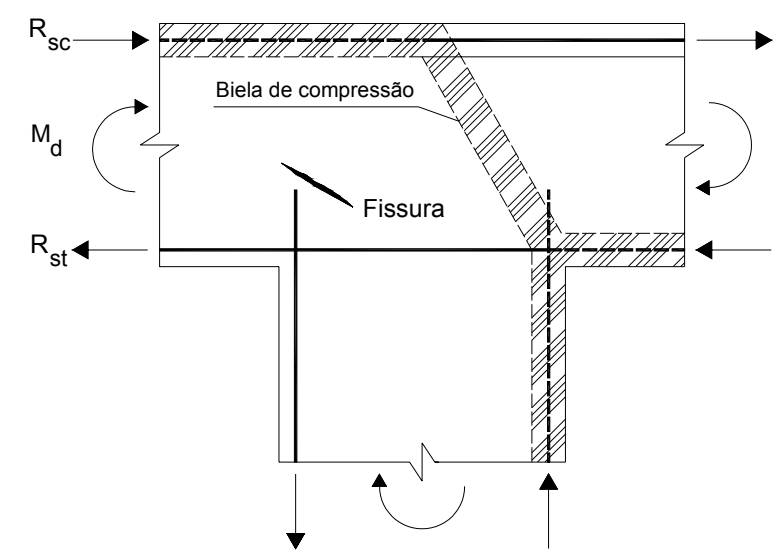

Fluxo de tensões idealizado para nós do tipo T

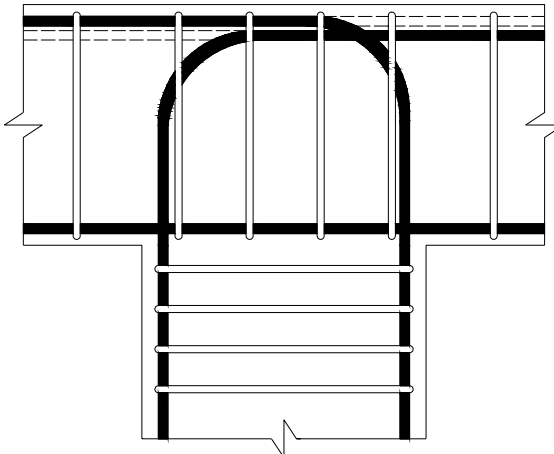

Arranjo de armadura indicado para grandes momentos no topo do pilar

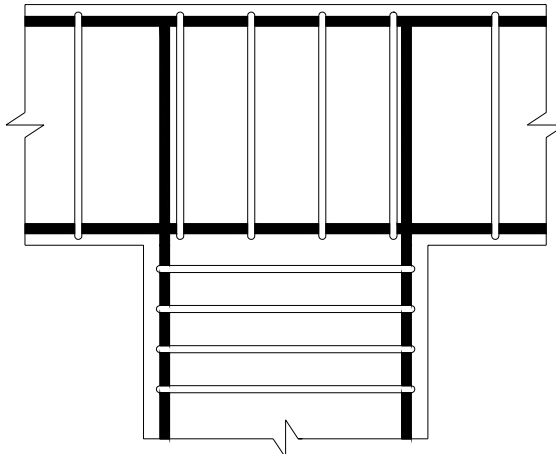

Arranjo de armadura indicado para pequenos momentos no topo do pilar

Figura 3.17 - Panorama do fluxo de tensões elásticas na ligação viga de cobertura pilar intermediário e detalhamento recomendado - LEONHARDT e MÖNNIG (1978). 


\subsubsection{Ligação viga intermediária-pilar de extremidade}

Conforme Leonhardt e Mönnig (1978), o comportamento da ligação viga intermediária - pilar de extremidade é caracterizado por dois efeitos preponderantes na capacidade resistente do nó: surgimento de tensões de tração diagonal provocada pela transmissão do momento fletor da viga para o pilar e a ocorrência de elevadas tensões de aderência na armadura do elemento de apoio causada pela alternância de tensões ao longo da região delimitada pela altura da viga (ver Figura 3.18). Em vigas de pequena altura, as tensões de aderência atingem facilmente sua resistência última e as fissuras provocam diminuição da resistência da zona comprimida do pilar.

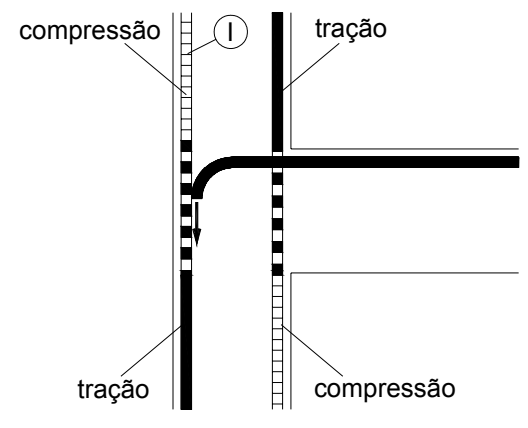

solicitação nas armaduras

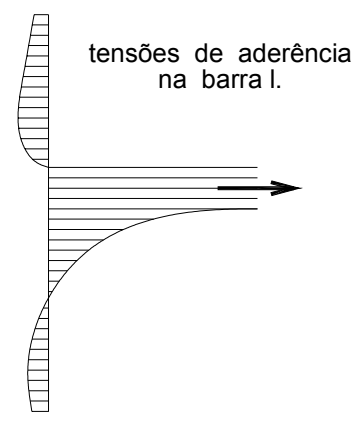

distribuição de tensões

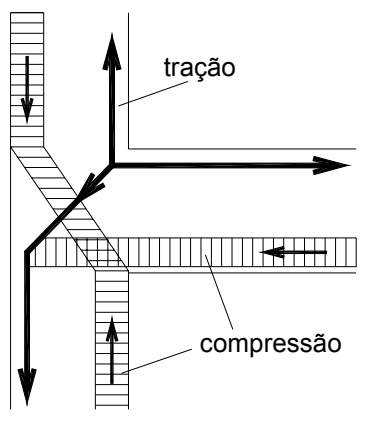

caminhos de tensões

Figura 3.18 - Viga engastada elasticamente em pilar de extremidade - Modificado de LEONHARDT e MÖNNIG (1978).

Ortiz (1993) avaliou experimentalmente este tipo de ligação sob ações monotônicas, utilizando diferentes arranjos de armadura e de carregamentos, com a finalidade de entender melhor o mecanismo interno de transferência de tensões descrito mediante a análise do equilíbrio de forças.

O equilíbrio das forças verticais deve ser analisado em cada lado do nó, onde as barras da armadura longitudinal do pilar alternam de tração para compressão mediante a ação da aderência. Quando a região nodal é solicitada, as barras da armadura do pilar, no lado seu interno, transferem tensões por meio de forças diagonais entre o pilar e as barras da armadura da viga posicionadas no interior do pilar e as bielas inclinadas vindas da viga. As forças oriundas das bielas secundárias não são consideradas como parte da biela diagonal principal. Entretanto, as fissuras que surgem nos vértices da ligação podem se prolongar ao longo das barras e perturbar a ação da aderência, principalmente se não houver estribos no trecho. Dessa maneira, as tensões de aderência 
são direcionadas para a parte inferior do nó onde o concreto está altamente comprimido (ver detalhe 01 da Figura 3.19).

O lado externo do nó apresenta uma situação mais complexa. A ancoragem das barras da viga se dá pela ponta reta após o gancho por emenda nas barras da armadura do pilar, entretanto, parte dessa ancoragem é garantida pelo cobrimento das barras (ver detalhe 2 da Figura 3.19), onde as forças de arrancamento causadas pela aderência são equilibradas pela resistência à tração do concreto.

No detalhe 03 da Figura 3.19 é mostrado como as forças nas bielas agem nas barras da armadura do pilar. O núcleo da ligação é mais rígido que o cobrimento e promove tensões de aderência mais altas nesse lado das barras, principalmente quando a taxa apropriada de estribos é colocada. A presença de estribos permite que o lado externo do nó trabalhe em toda sua altura, amarrando as barras verticais e auxiliando na ação da aderência.

Já o equilíbrio horizontal é garantido pela interação da biela diagonal com as barras da armadura da viga e a força cortante do pilar. Os estribos colaboram levando as forças horizontais de parte externa mais baixa da biela para o lado interno do nó e de lá, a biela (ou as bielas secundárias) leva essas forças para a região superior. Na região superior da ligação, os estribos trabalham da mesma maneira, elevando a aderência das barras da armadura do pilar e prevenindo a abertura de fissuras.

Sem os estribos, as barras verticais não são suportadas e as forças horizontais tendem a empurrar as barras para fora do cobrimento. As forças de tração no cobrimento de concreto superam a resistência do material e, conseqüentemente, ocorre o surgimento de fissuras que fragilizam a ligação que, em seguida, rompe-se.

Os testes mostraram que a presença dos estribos não influencia a resistência a fissuração do nó que é uma função da resistência do concreto e do fluxo de tensões. Todavia, a capacidade última é consideravelmente dependente do efeito de confinamento estabelecido pelos estribos. Este confinamento depende da taxa e do arranjo da armadura de cisalhamento na ligação. 

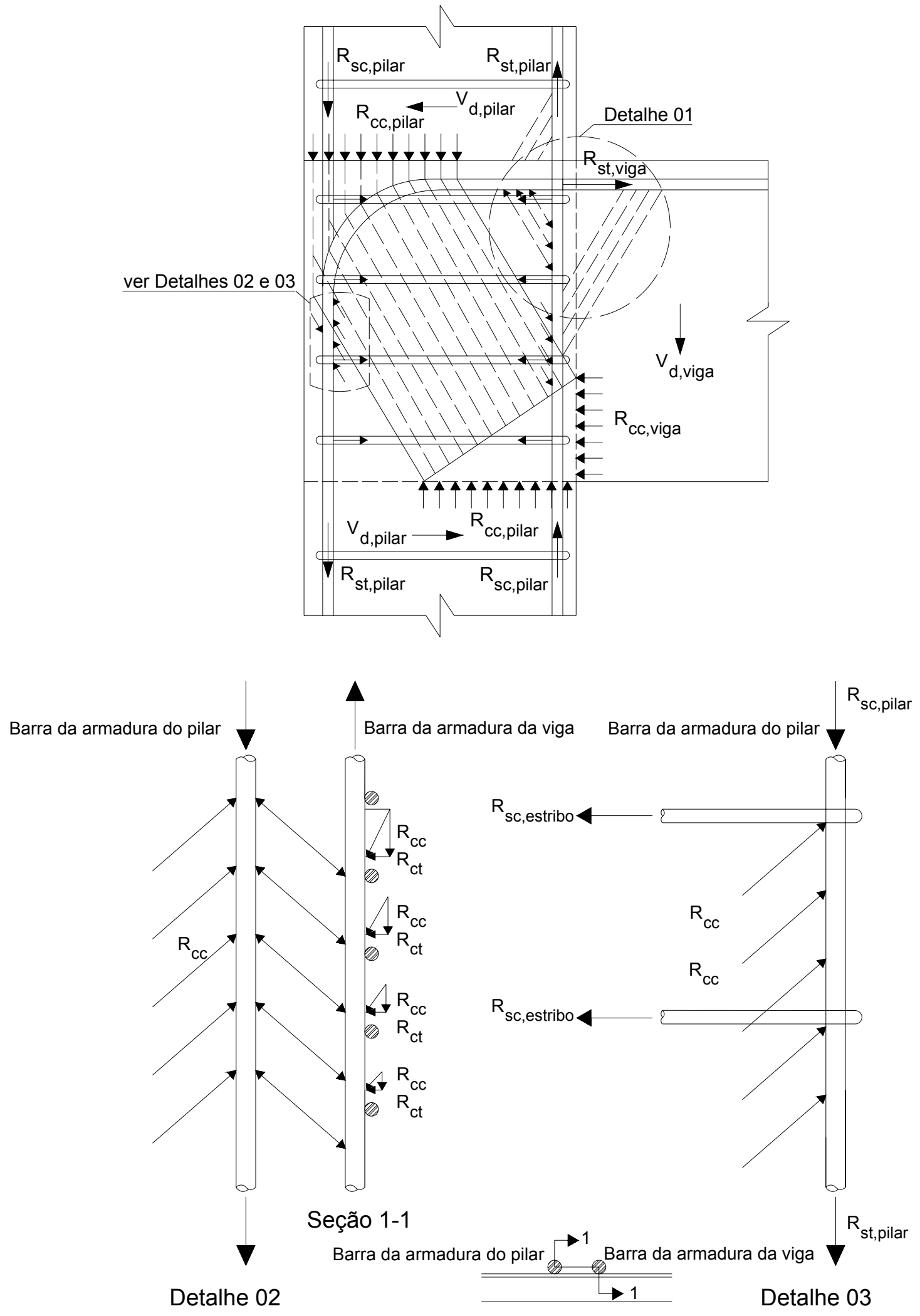

Figura 3.19 - Mecanismos de transferência de tensões - Adaptado de ORTIZ (1993).

Os detalhamentos apresentados para esse tipo de ligação estão expostos na Figura 3.20. De acordo com Leonhardt e Mönnig (1978), as barras inclinadas, as quais 
não são usualmente adotadas, devem ter uma área igual a 50\% da área da armadura a ancorar e o diâmetro das barras deve ser igual a 70\% do diâmetro das barras daquela armadura.

No que tange ao posicionamento dos estribos do pilar, eles devem ter o espaçamento reduzido para no máximo $100 \mathrm{~mm}$ e a distribuição desses deve ser no mínimo em um trecho de comprimento igual a duas vezes a largura do pilar, medido na direção da viga, acrescido da altura da viga $\left(2 h_{p}+h_{v}\right)$.

Para a disposição da armadura apresentada na Figura 3.20 a, a eficiência total foi atingida somente com a taxa de armadura $(\rho)$ inferior a $0,6 \%$. Para taxas maiores, essa eficiência caiu para $80 \%$. Recomenda-se que o diâmetro interno da curvatura das barras deve ser maior ou igual a $8 \phi$ e comprimento reto após a curvatura da barra da ancorada dentro do pilar deve ser no mínimo igual a $35 \phi$ e deve ser emendada na barra tracionada do pilar.

Em ligações submetidas a altas forças normais (nos pavimentos mais baixos de um edifício), se for constatado que a seção do pilar esteja toda comprimida (pouca influência do momento fletor transmitido pela viga), as barras da armadura superior da viga podem ser ancoradas de maneira reta na largura do pilar conforme a Figura $3.20 \mathrm{~b}$ (GIONGO, 2004).

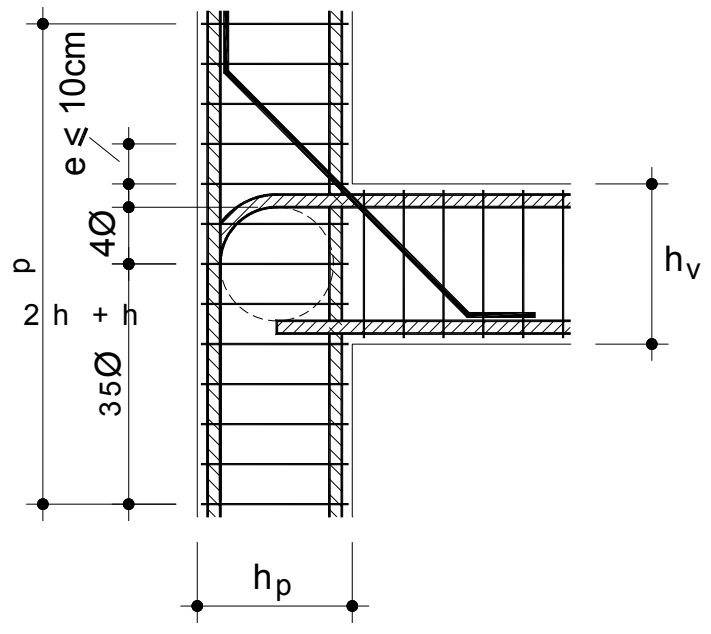

(a)

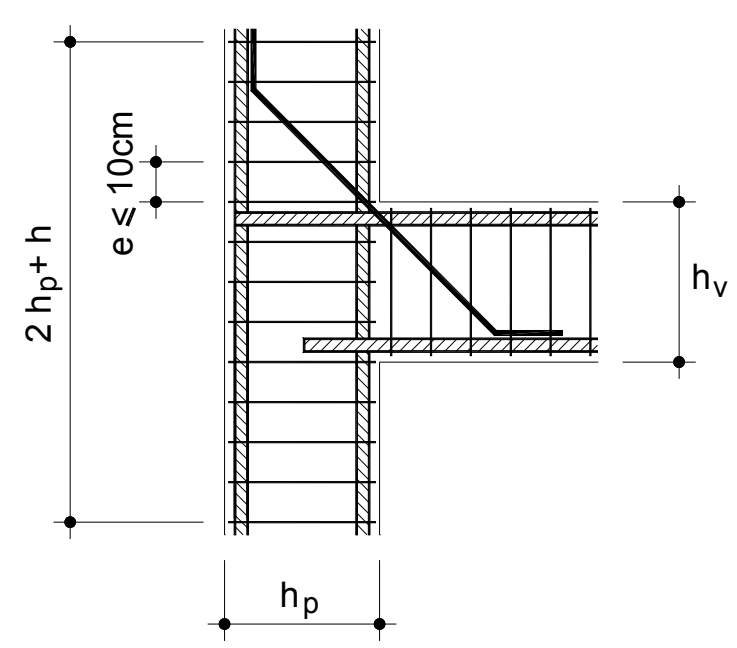

(b)

Figura 3.20 - Arranjos de armaduras propostos para a ligação viga intermediária - pilar de extremidade - Modificado de LEONHARDT e MÖNNIG (1978). 


\subsubsection{Ligação viga intermediária-pilar intermediário}

As ligações do tipo cruz são arranjadas por analogia das linhas de tensões representadas nas ligações do tipo T. A Figura 3.21 apresenta o comportamento da ligação mediante as ações dos esforços solicitantes. As disposições de armaduras são equivalentes ao esforço predominante ao qual o nó é submetido. De acordo com a seqüência apresentada, o primeiro é recomendado quando se tem alternância de esforços no domínio da ligação. Já o segundo, é adequado quando as ações verticais são predominantes.

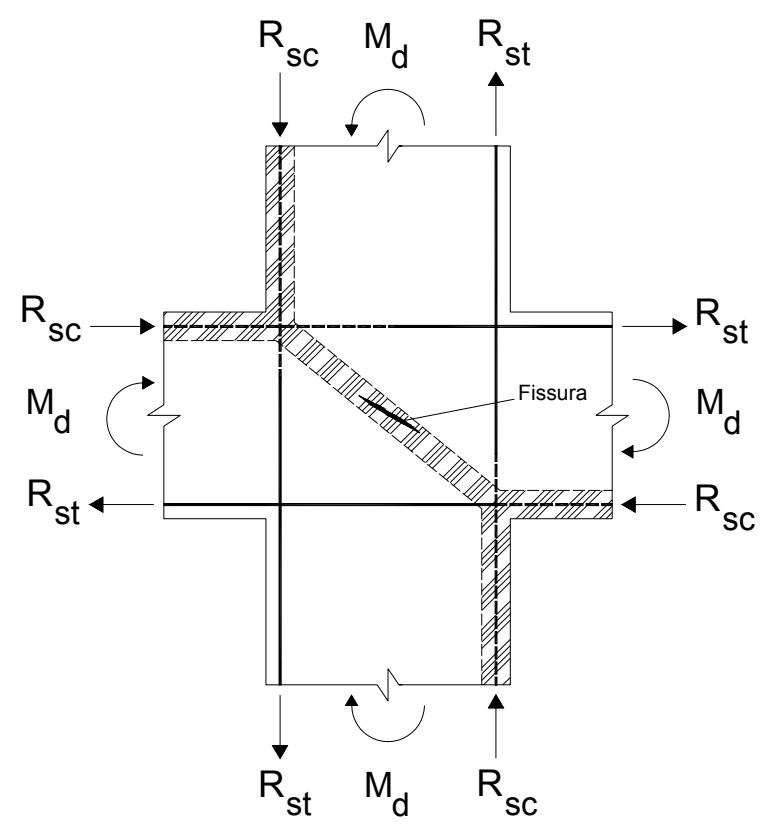

Fluxo de tensões idealizado para nós do tipo cruz

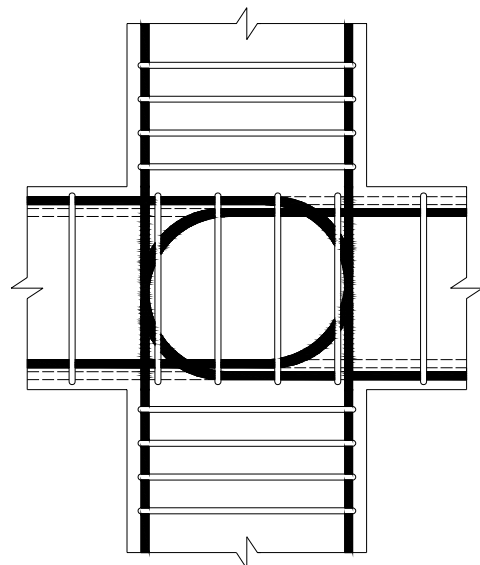

(a)

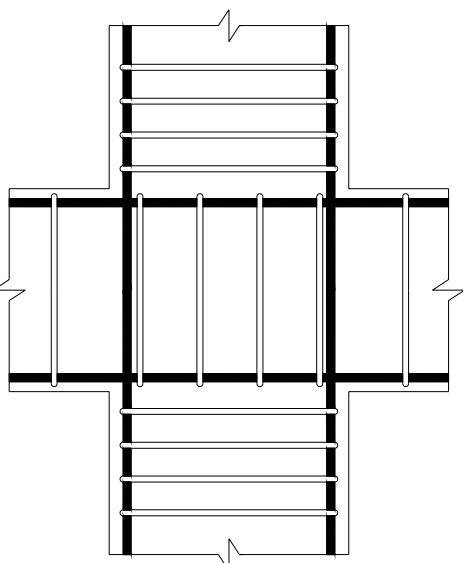

(b)

Figura 3.21 - Modelos e arranjos de armaduras para ligação viga intermediária - pilar intermediário - Modificado de LEONHARDT e MÖNNIG (1978). 


\subsubsection{Ligação viga-viga}

A ancoragem na ligação viga-viga é assegurada pela transmissão da reação de apoio da viga suportada para a viga suporte mediante armadura de suspensão que, assim como o próprio nome sugere, tem como função "suspender" a força oriunda da biela de compressão para a região comprimida da viga de apoio, conforme a Figura 3.22.

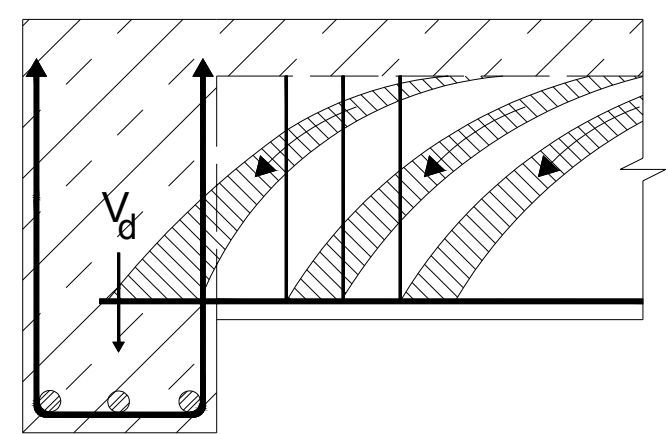

Figura 3.22 - Fluxo de tensões na ligação viga-viga - LEONHARDT e MÖNNIG (1978).

A armadura de suspensão é constituída por estribos que envolvem a armadura longitudinal da viga e devem ser bem ancorados na parte de cima. Caso a força a ancorar seja elevada ou haja congestionamento de armaduras na região da ligação, a armadura de suspensão deve ser distribuída nas regiões adjacentes ao nó (ver Figura $3.23)$.

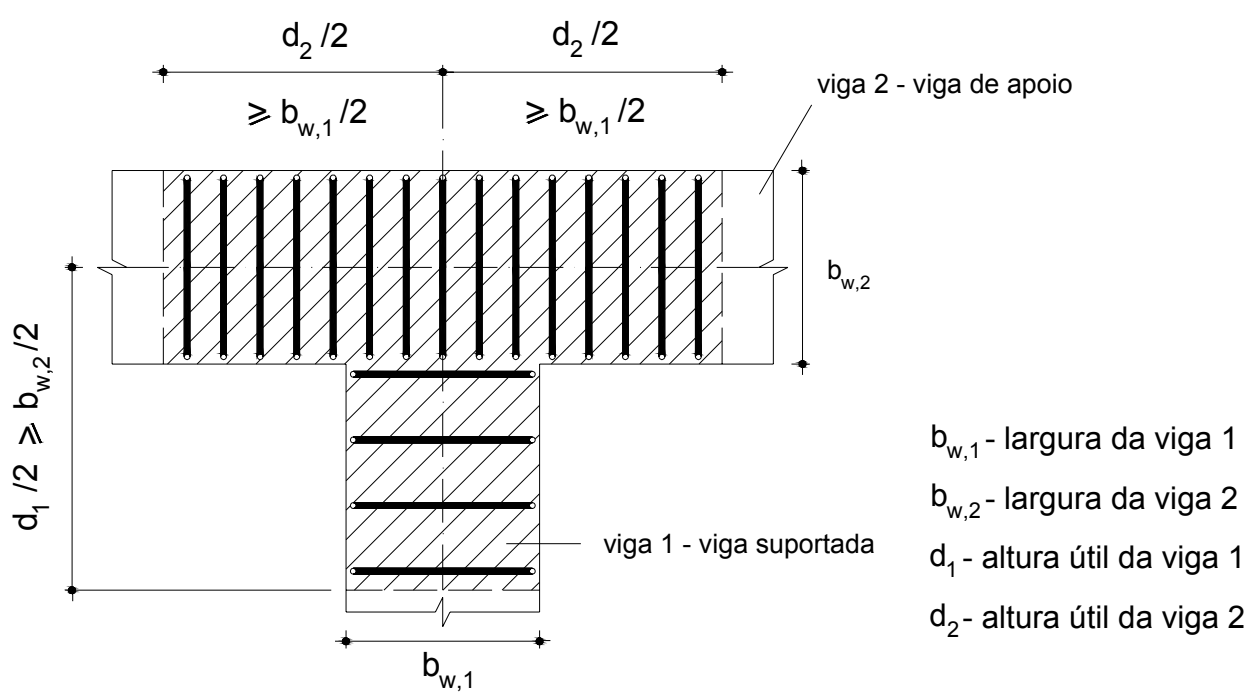

Figura 3.23 - Zona de distribuição da armadura de suspensão - Adaptado de LEONHARDT e MÖNNIG (1978). 
De acordo com Leonhardt e Mönnig (1978), com base na analogia de treliça, não é necessário armadura de cisalhamento adicional no local, entretanto, a armadura de suspensão não pode ser inferior à armadura de cisalhamento necessária. Numa outra observação desses pesquisadores, se os comprimentos de ancoragem reta das barras da armadura de tração proveniente da viga suportada forem insuficientes, deve-se adotar ganchos deitados ou inclinados em vez de verticais, pois, há tendência à formação de fissuras de flexão na viga suportada.

Segundo Fusco (1995), a força de suspensão $\left(R_{t t}\right)$ só pode ser considerada inferior a reação de apoio quando as duas vigas tiverem suas faces superiores no mesmo nível. Nesse caso, a força de suspensão pode ser calculada pela eq.(3.12).

$$
R_{s t w, s u s p}=R_{\text {apoio }} \cdot \frac{h_{1}}{h_{2}}
$$

Onde $h_{1} \leq h_{2}$, sendo $h_{1}$ a altura da viga suportada e $h_{2}$ a altura da viga suporte.

\subsubsection{Ligação viga-laje}

Na ligação viga-laje, a diferença de rigidezes entre os elementos estruturais componentes pode comprometer a segurança desta região. No estado elástico, a ação das lajes nas vigas ocorre por intermédio de um carregamento variável e não uniforme ao longo do seu comprimento, dependente das condições de apoio e da relação entre os vãos, que acarreta na dificuldade do cálculo dos esforços nas vigas.

Nos modelos de cálculos simplificados, os quais são adotados pelas normas em geral, os esforços nas lajes são verificados em separado das vigas que as sustentam, admitindo-se que esses apoios sejam rígidos. Essa consideração não contabiliza a influência da deslocabilidade das vigas de sustentação, que caso seja significativa, eleva o valor dos esforços nas peças e, conseqüentemente, a intensidade das tensões.

Segundo Leonhardt e Mönnig (1978), o arranjo das armaduras nessa região é função das condições de vínculo entre a laje e a viga. No que se refere à ligação da laje em vigas de bordo, para um engastamento parcial, pode-se adotar uma malha construtiva contra fissura na parte superior ou, se a armadura da laje for composta por barras, pelo menos $1 / 3$ da armadura positiva do vão deve ser dobrada na região próxima 
ao apoio (ver Figura 3.24). Essa condição é a mais corriqueira, pois, as vigas quase sempre apresentam pequena altura e, portanto, pouca rigidez à torção.

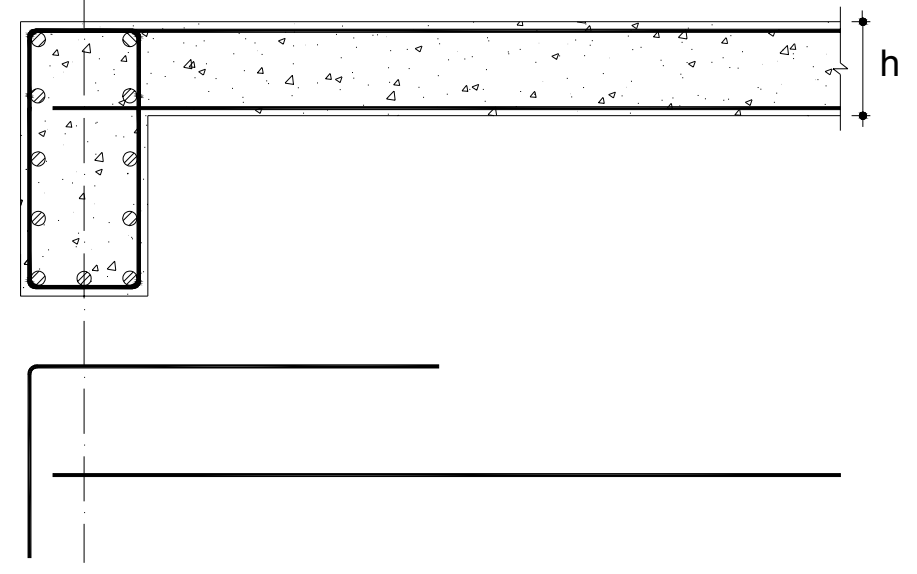

Figura 3.24 - Engastamento parcial da ligação viga-laje - Modificado de LEONHARDT e MÖNNIG (1978).

Assumindo um engastamento perfeito, é conveniente dobrar as barras da armadura em dois locais para o escalonamento da armadura principal. Para que o engastamento seja obtido, é necessário que o ramo horizontal superior do estribo da viga de apoio se estenda cerca de $0,20 \ell$ na laje para evitar o aparecimento de fissuras de flexão na face superior da laje (ver Figura 3.25). Tem-se uma situação de engastamento prefeito na ligação entre laje isolada e a viga suporte.

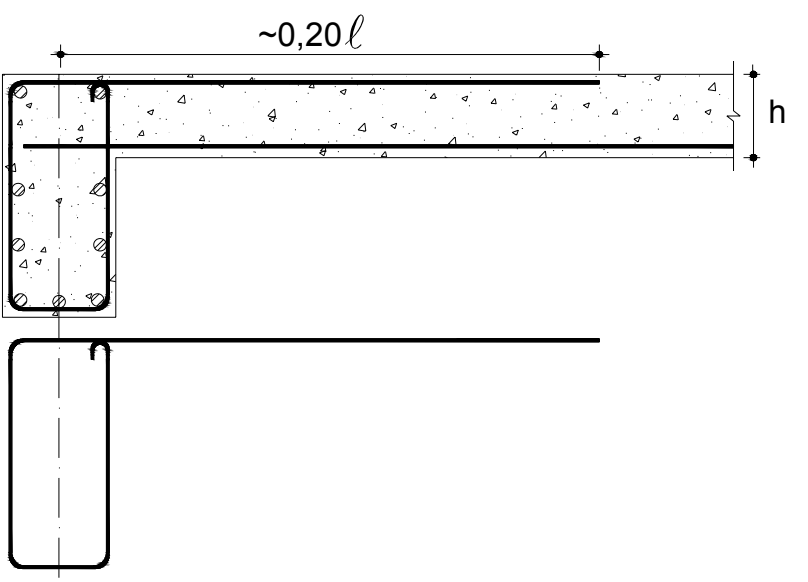

Figura 3.25 - Engastamento na viga de apoio - Modificado de LEONHARDT e MÖNNIG (1978). 
O grau de engastamento entre a laje e a viga é proporcional ao estado de fissuração dos elementos na região do apoio. Com isso, o engastamento é tão maior quanto à rigidez da viga à torção, desde que a peça se apresente no estádio I.

Portanto, quando as vigas não forem suficientemente rígidas, não ocorre o engastamento e o momento fletor no meio do vão da laje não pode ser reduzido em virtude da parcela absorvida pelo engastamento.

Nos casos usuais de edifícios, nos quais as larguras das vigas são limitadas a valores da ordem de $10 \mathrm{~cm}$ a $20 \mathrm{~cm}$, é inadequado considerar lajes engastadas nas vigas por falta de inércia à torção. Assim, é conveniente adotar uma armadura constituída por barras junto à face superior da laje afim de que se limitem às aberturas das fissuras.

Nas vigas invertidas, as lajes devem ser tratadas como forças aplicadas, indicando o uso de armaduras de suspensão na parte inferior da viga (ver Figura 3.26).
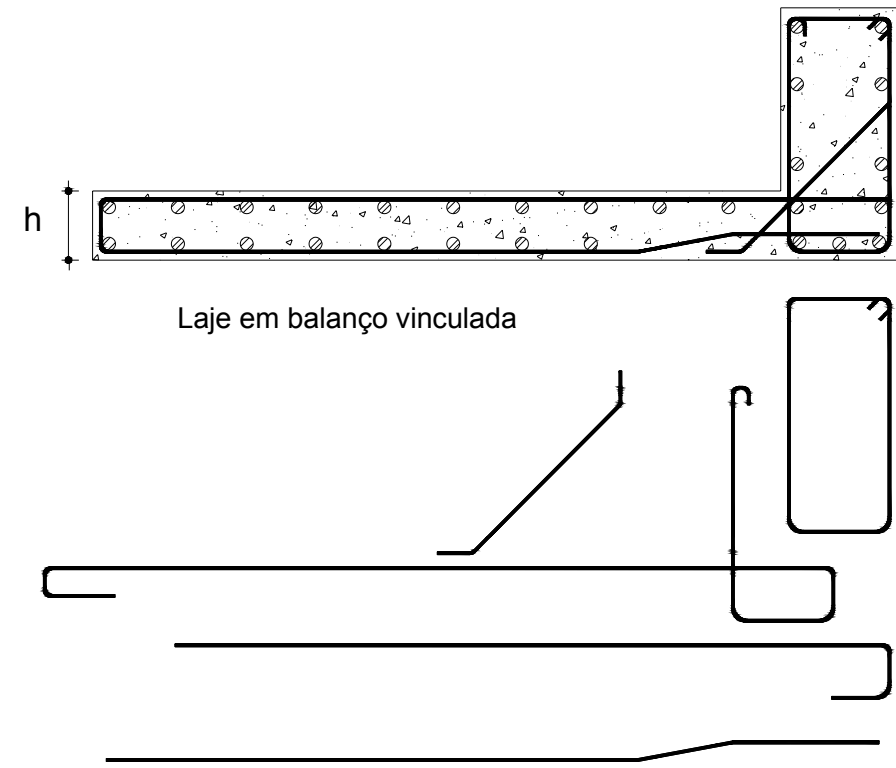

Figura 3.26 - Laje em balanço pendurada em uma viga invertida - LEONHARDT e MÖNNIG (1978).

Quanto à ligação entre vigas e lajes contínuas de vários vãos, é recomendável prolongar pelos menos um terço da armadura positiva do vão até os apoios intermediários.

Caso seja considerada a redistribuição de momentos, podem-se estender todas as barras da armadura principal. A armadura deve ser prolongada para ambos os lados, sem redução, com um comprimento $\ell_{b, \text { nec }} \geq 3 h$, (LEONHARDT e MÖNNIG, 1978). 
A adoção de barras dobradas para armaduras de lajes é incomum na prática da construção de obras comuns. Essa solução se apresenta como uma alternativa que, embora seja econômica com relação à racionalização dos materiais, torna-se onerosa sob o aspecto de custo de produção. Sendo assim, para esse tipo de ligação, costumeiramente, adotam-se os arranjos apresentados na Figura 3.9.

\subsubsection{Ligação laje-laje}

As ligações laje-laje podem ser verificadas nos reservatórios em geral, piscinas e muros de arrimo. Na prática, essas estruturas são projetadas como um conjunto de lajes, embora as paredes possam ser dimensionadas como vigas ou como viga-parede, adotando ambos os tipos de armadura (de laje e de viga ou de viga-parede).

Dada à complexidade das estruturas em questão, existem vários processos de cálculo aproximados (Marcus, Barès, Nadai, Czerny, Stiglat/Wippel, entre outros) que auxiliam na verificação dos esforços solicitantes atuantes nas peças estruturais que compõem os reservatórios.

Um aspecto relevante nessas ligações é que a reação de apoio de uma laje ocasiona o surgimento de forças de tração nas lajes de suporte. Em conseqüência, as lajes componentes do reservatório devem ser dimensionadas à flexão composta, pois nelas atuam força de tração, força cortante e momento fletor (ver Figura 3.27).

Esses esforços podem ser determinados mediante regras empíricas de distribuição das cargas ou por meio de coeficiente tabelados existentes na literatura a respeito da distribuição das reações de apoio das lajes (CUNHA e SOUZA, 1994; FUSCO, 1995).

Para Fusco (1995), o modelo de cálculo mais simples é aquele no qual cada parede é considerada como uma laje engastada em três bordas e simplesmente apoiada na borda superior ligada à laje da tampa e submetida ao carregamento correspondente à altura interna total da caixa.

A laje de fundo é calculada como placa com as quatro bordas engastadas, submetidas ao peso próprio acrescido do peso total da água no interior do reservatório. Já a laje da tampa é calculada como laje contínua simplesmente apoiada, submetida à ação do peso próprio e de uma ação variável normal. Para todos os elementos, devem-se considerar as forças de tração aplicadas, embora na prática sejam desprezados quando são de pequena intensidade. 

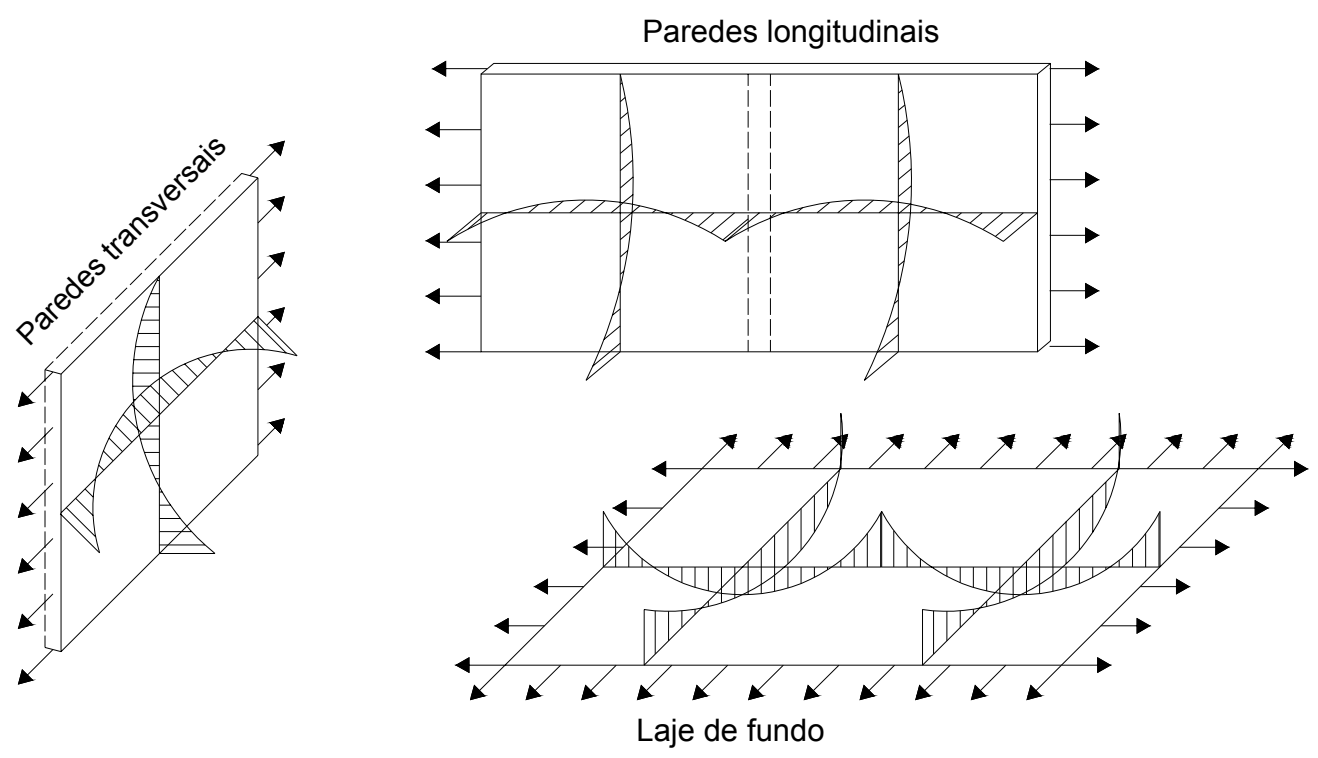

Figura 3.27 - Momentos fletores e forças normais de tração - Modificado de FUSCO (1995).

Quanto às disposições construtivas, as ligações parede-parede e parede-fundo podem ser chanfradas para melhorar a estanqueidade das arestas e reduzir os riscos de fissuração.

Conforme Cunha e Souza (1994), os pilares devem se estender por toda a altura do reservatório para que se evite o esmagamento das paredes nos pontos de apoios (região crítica nas vigas-parede). Quanto às dimensões das lajes, em especial das paredes e o fundo, é recomendável que a espessura mínima não seja inferior a $12 \mathrm{~cm}$, afim de que sejam facilitados os serviços de armação e concretagem.

Os arranjos típicos das armaduras, bem como das ligações são mostrados na Figura 3.28 e na Figura 3.29. A presença da armadura de reforço na ligação é justificada, pelo procedimento de divisão do reservatório em faixas com carregamentos de intensidades diferentes cujo objetivo é a economia em armadura. Assim, podem ser adotadas diferentes quantidades de armadura em cada faixa (armadura mais densa nas faixas inferiores, e mais reduzidas nas superiores). 


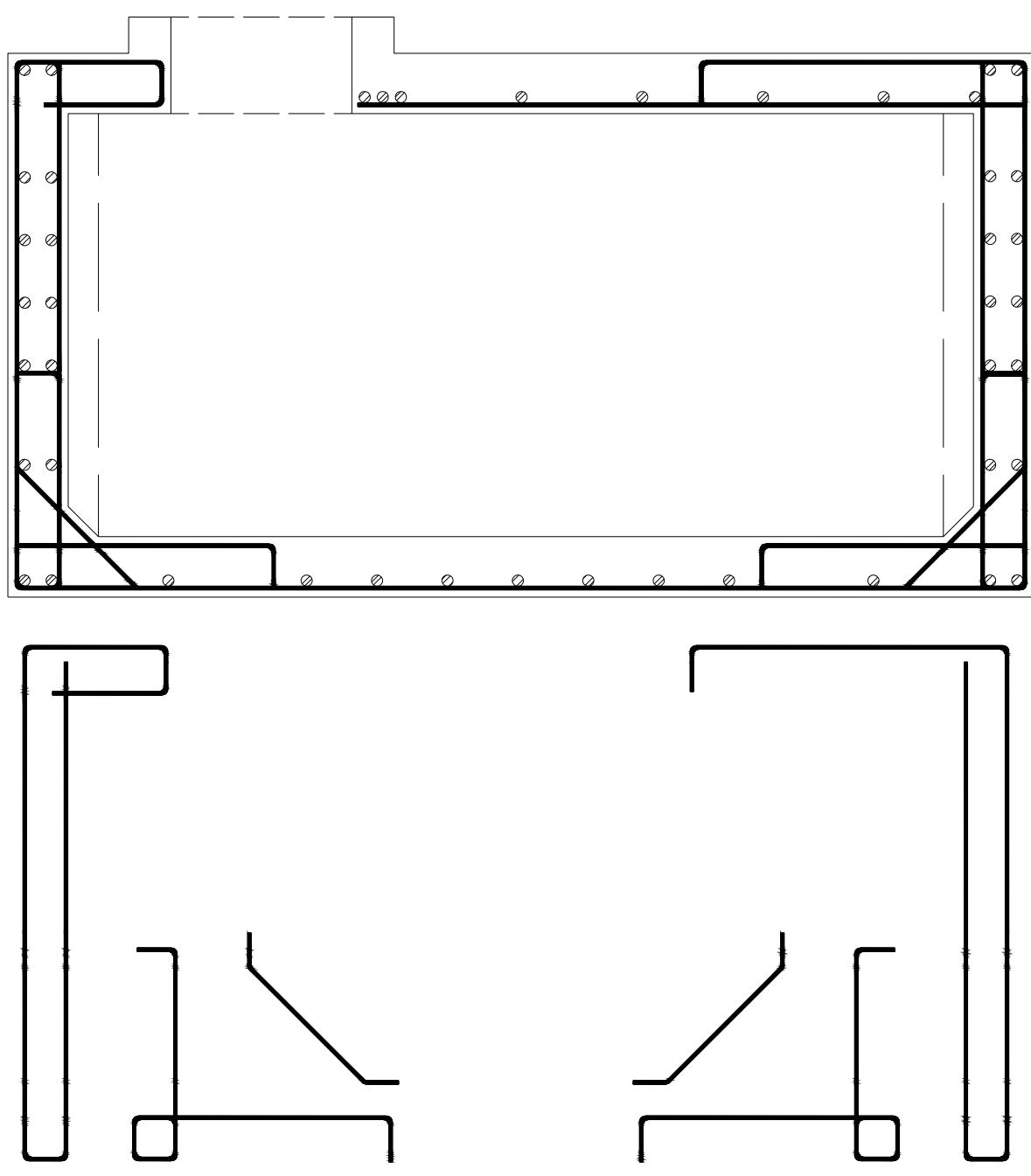

Figura 3.28 - Arranjos típicos das armaduras para reservatório elevado - CUNHA e SOUZA (1994). 

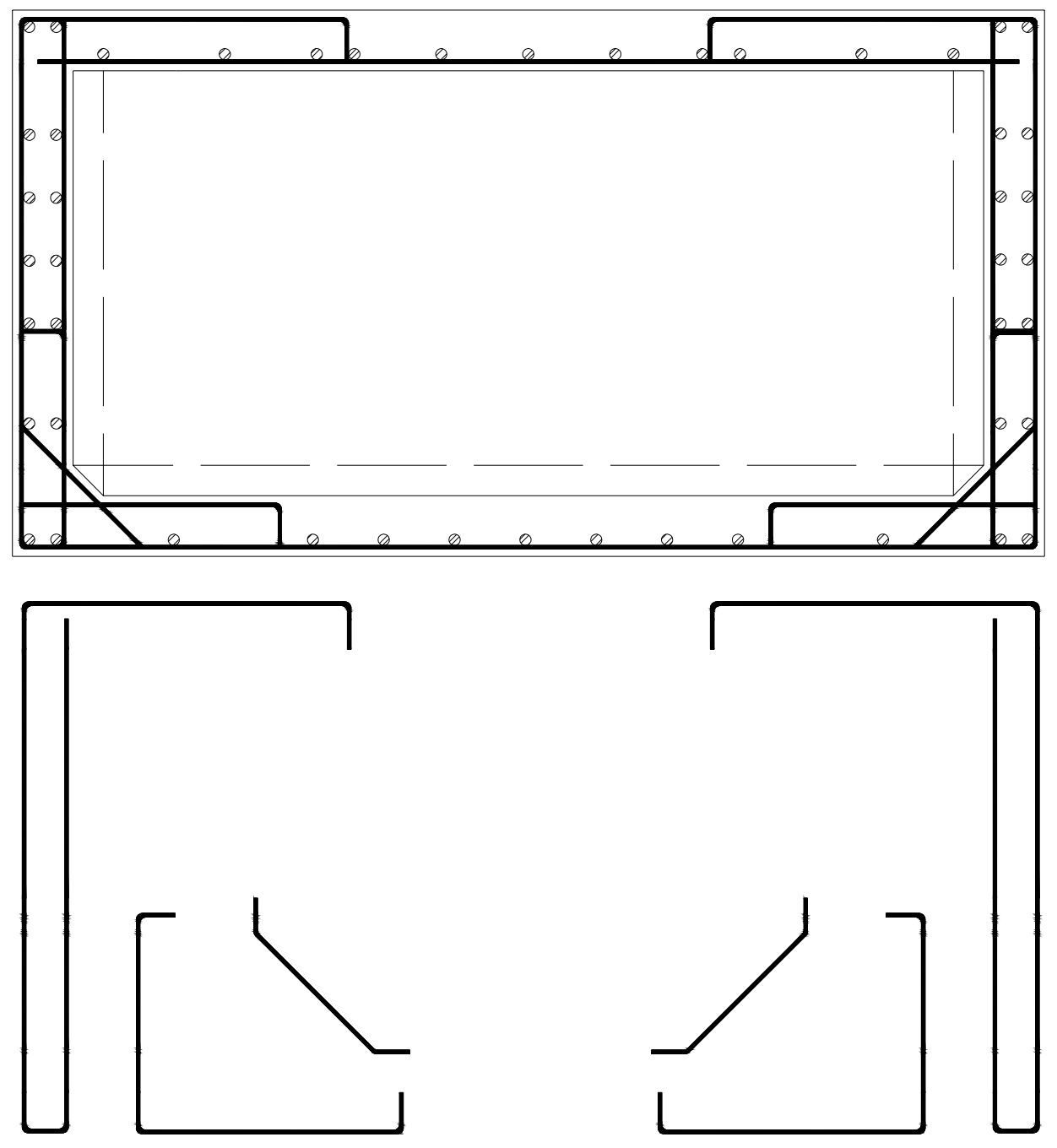

Figura 3.29 - Arranjos típicos das armaduras para reservatório enterrado - CUNHA e SOUZA (1994). 


\section{Critérios adotados na avaliação numérica das ancoragens nas ligações}

\subsection{Considerações iniciais}

A proposta para o desenvolvimento do presente estudo consiste na avaliação, via análise numérica, das ligações em edifícios do tipo viga-pilar que enfocam o comportamento das ancoragens das armaduras longitudinais junto às faces superior e inferior e da adequação dos arranjos das armaduras, sob o efeito de ações monotônicas.

A priori, neste capítulo são apresentados os critérios referentes às aproximações e hipóteses de comportamento físico e discretização na modelagem numérica e, em seguida, são conduzidas análises comparativas para aferição entre uma ligação do tipo viga-pilar de extremidade analisada experimentalmente por Ortiz (1993) e o modelo numérico produzido no programa ADINA (2002).

Embora haja diferenças entre os resultados experimentais e numéricos, as hipóteses assumidas parecem razoáveis para uma abordagem inicial da análise numérica da ancoragem em ligações viga-pilar representadas por modelos bidimensionais. 


\subsection{Procedimentos de modelagem}

\subsubsection{Modelos constitutivos dos materiais}

\subsubsection{Concreto}

O comportamento mecânico do concreto obedeceu ao modelo não-linear apresentado na Figura 4.1 o qual é baseado na relação tensão versus deformação uniaxial, generalizada para se obter em tensões biaxiais e triaxiais.

Essa relação tem propriedades peculiares, como, o enfraquecimento do material sob acréscimos das tensões de compressão, envoltórias de ruína que definem a ruptura na tração e o esmagamento na compressão e uma estratégia para modelagem do comportamento do material na pós-fissuração e esmagamento (ADINA, 2002).

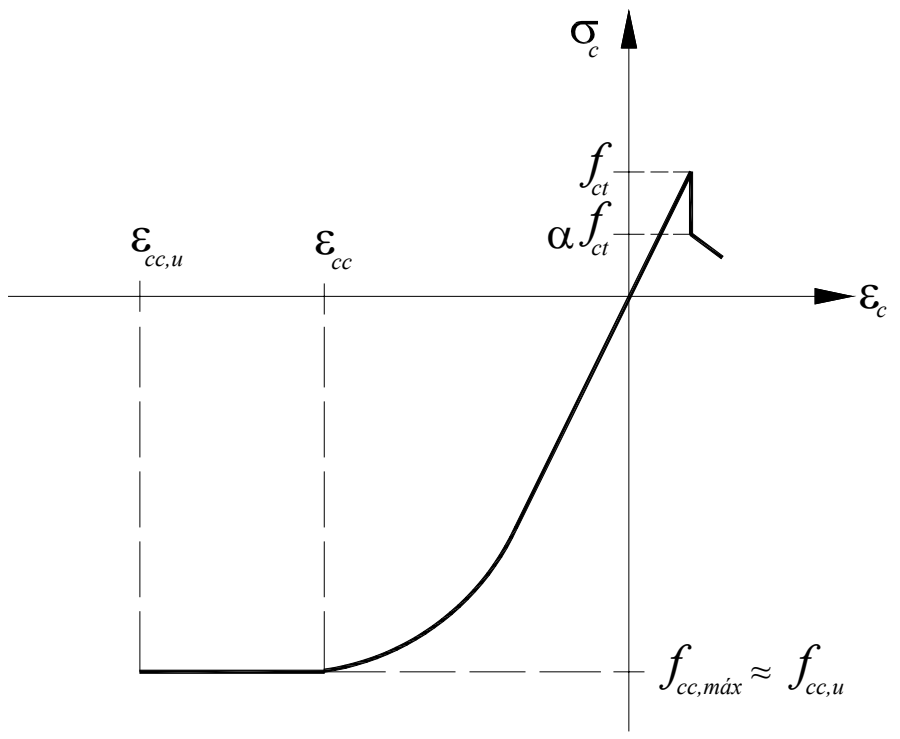

Figura 4.1 - Relação uniaxial tensão-deformação do concreto - Adaptado de ADINA (2002).

Para a geração da curva mostrada na Figura 4.1 é necessário que se tenha um conhecimento prévio em relação ao comportamento do concreto por meio de valores experimentais e/ou estimados. Esses valores são representados pelas tensões e deformações explicitadas no gráfico que funcionam como dados de entrada os quais devem ser fornecidos pelo usuário.

Neste caso, foi conveniente adotar os parâmetros de cálculo estabelecidos pela NBR 6118:2003, com algumas exceções, uma vez que a idéia central é a análise da ancoragem em situações usuais de projeto. 
No ramo negativo da curva que representa o estado do concreto comprimido, há quatro parâmetros, a saber:

$f_{c c, \text { máx }}$ : resistência máxima à compressão do concreto;

$f_{c c, u}$ : resistência última à compressão do concreto;

$\varepsilon_{c c}$ : deformação específica à compressão do concreto referente à $f_{c c, \text { máx }}$;

$\varepsilon_{c c, u}$ : deformação específica última à compressão do concreto.

Para a resistência máxima à compressão do concreto $\left(f_{c c, \text { máx }}\right)$ foi conferido o valor de $85 \%$ da resistência de cálculo à compressão do concreto $\left(f_{c d}\right)$. Entretanto, a resistência última à compressão do concreto $\left(f_{c c, u}\right)$ foi determinada como sendo aproximadamente igual à resistência máxima à compressão do concreto, já que esses valores têm que ser obrigatoriamente diferentes no modelo de concreto disponível no programa ADINA (2002).

Quanto às deformações, foram adotados os valores de 0,002 e 0,0035 para $\varepsilon_{c c}$ e $\varepsilon_{c c, u}$, respectivamente.

Para o trecho da curva referente ao comportamento do concreto à tração, é preciso fornecer a resistência à tração do concreto $\left(f_{c t}\right)$ que, nesta situação, adotou-se como sendo igual à resistência à tração de cálculo do concreto determinada de acordo com eq.(4.1):

$$
\begin{aligned}
f_{c t d} & =\frac{f_{c t k, \mathrm{inf}}}{\gamma_{c}} \leftrightarrow f_{c t k, \mathrm{inf}}=0,7 \cdot f_{c t, m}\left(=0,3 \cdot f_{c k}^{2 / 3}\right) \\
f_{c t d} & =0,15 \cdot f_{c k}^{2 / 3} \leftrightarrow f_{c k}=\gamma_{c} \cdot f_{c d} \\
f_{c t d} & =0,19 \cdot f_{c d}^{2 / 3}
\end{aligned}
$$

Após a ruptura do concreto tracionado, admitiu-se que, em função dos efeitos da resistência de aderência, o concreto íntegro entre as fissuras contribui para a resistência a qual decresce gradativamente até atingir a resistência $\left(\alpha \cdot f_{c t d}\right)$ em que o mesmo não seja capaz de absorver tensões de tração.

No que se refere ao coeficiente $\alpha$, esse foi determinado conforme o modelo proposto por Figueiras (1983) para o comportamento do concreto tracionado, pois se 
assemelha ao modelo conferido pelo programa, cujo valor é tal que $0,5 \leq \alpha \leq 0,7$. Para este trabalho, estabeleceu-se $\alpha=0,7$.

Além dos parâmetros acima indicados, foi necessário fornecer o coeficiente de Poisson, $v=0,20$, a massa específica do concreto armado, $\gamma_{c}=2,5 \cdot 10^{-5} \mathrm{kN} / \mathrm{cm}^{3}$, o módulo de elasticidade do concreto e a energia de fraturamento $\left(G_{F}\right)$.

O módulo de elasticidade do concreto foi admitido como sendo o módulo de elasticidade tangente inicial do concreto $\left(E_{c i}\right)$ nas análises não-lineares, expresso pela eq.(4.2), conforme a NBR 6118:2003:

$$
E_{c i}=5600 \cdot f_{c k}^{1 / 2}
$$

Sendo $E_{c i}$ e $f_{c k}$ dados em MPa.

Por definição, a energia de fraturamento $\left(G_{F}\right)$ é a energia necessária para a propagação de fissuras por unidade de área no concreto tracionado que pode ser estimada pela eq.(4.3), segundo prescrição do MC CEB-FIP 1990:

$$
G_{F}=\alpha_{F} \cdot\left(f_{c j} / f_{c o}\right)^{0,7}
$$

Onde $f_{c j}$ é a resistência média do concreto à compressão e $f_{c o}=10 M P a$.

De acordo com a NBR 12655:1996, na ausência de valores experimentais, a resistência média do concreto à compressão $\left(f_{c j}\right)$ pode ser estimada pela eq.(4.4):

$$
f_{c j}=f_{c k}+1,65 \cdot S_{d}
$$

Em que $S_{d}$ é o desvio-padrão da dosagem, em $M P a$. Para as análises deste estudo, considerou-se $S_{d}=4,0 M P a$ em concordância com os critérios da NBR 12655:1996.

O coeficiente $\alpha_{F}$ depende do diâmetro máximo do agregado $\left(\phi_{\max }\right)$ como é mostrado na Tabela 4.1, seguindo os padrões de MC CEB-FIP 1990. 
Tabela 4.1 - Valores do coeficiente $\alpha_{F}$ (MC CEB-FIP 1990).

\begin{tabular}{c|c}
\hline$\phi_{\text {máx }}(\mathrm{mm})$ & $\alpha_{F}\left(\mathrm{Nmm} / \mathrm{mm}^{2}\right)$ \\
\hline 8 & 0,02 \\
16 & 0,03 \\
32 & 0,05 \\
\hline
\end{tabular}

Ressalta-se que foi utilizado o método de Kupfer para a geração da curva triaxial de ruptura, conforme os exemplos de aprendizagem contidos no programa em uso.

\subsubsection{Aço}

Para a descrição do comportamento mecânico das barras de aço utilizadas no concreto armado, atribuiu-se um modelo elasto-plástico perfeito conforme se apresenta na Figura 4.2. O critério de ruptura que rege esse tipo de material foi o de von Mises.

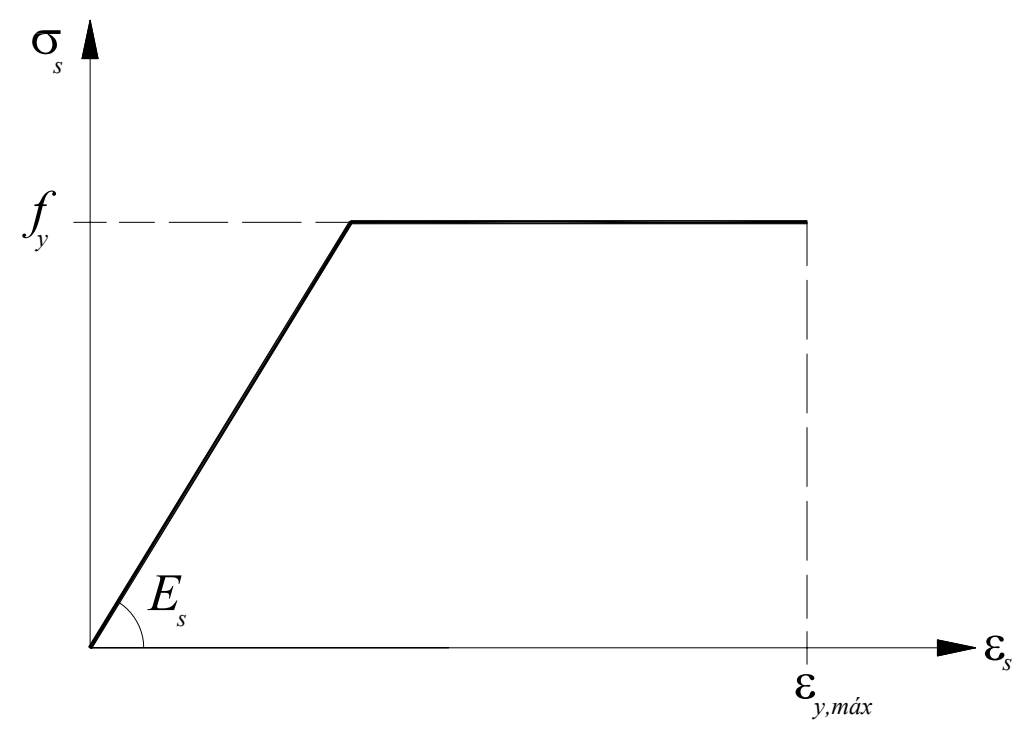

Figura 4.2 - Relação uniaxial tensão-deformação do aço.

Assim como no modelo adotado para o concreto, foram conferidos valores de cálculo para a concepção do diagrama tensão versus deformação do aço, conforme os dados fornecidos pela NBR 6118:2003.

Como se percebe, deve-se informar a deformação específica máxima de escoamento do aço $\left(\varepsilon_{y, \text { máx }}\right)$ que no caso foi adotada igual a 0,01 , o módulo de elasticidade do aço de armadura passiva $\left(E_{s}\right)$ que para fins de projeto pode ser admitido igual a $210 G P a$ e a resistência de escoamento do aço $\left(f_{y}\right)$ cujo valor de 
cálculo para o aço categoria CA-50, o mais empregado na construção civil no Brasil, é de $f_{y d}=435 M P a$.

Além dos dados discutidos, algumas informações complementares são pertinentes:

Coeficiente de Poisson: $v=0,30$;

Massa específica do aço: $\gamma_{\mathrm{s}}=7,85 \cdot 10^{-5} \mathrm{kN} / \mathrm{cm}^{3}$.

\subsubsection{Discretização dos objetos de análise}

\subsubsection{Seleção dos elementos}

Para a descrição do comportamento do concreto em modelos planos, foi utilizado o elemento de superfície 2-D solid que pode ser definido por elementos quadrilaterais e/ou triangulares, conforme apresentados na Figura 4.3, com dois graus de liberdade por nó (translações nodais nos eixos pertencentes ao plano).

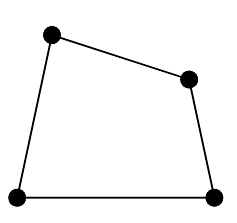

4 nós quadrilateral

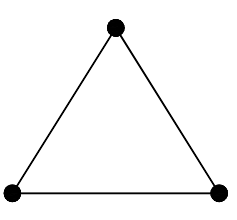

3 nós triangular

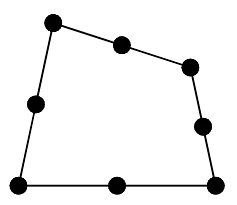

8 nós quadrilateral

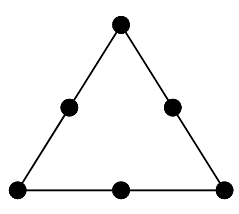

6 nós triangular

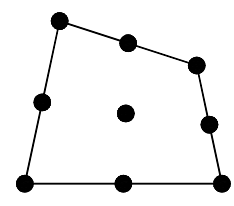

9 nós quadrilateral

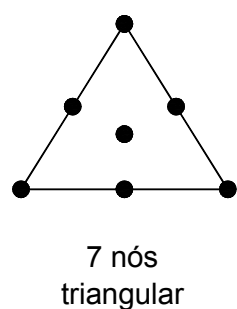

Figura 4.3 - Elemento finito 2-D SOLID - Modificado de ADINA 8.0 (2002).

Já as barras de aço que compunham a armadura foram discretizadas por meio de elementos de barra ("truss”) definidos quanto aos possíveis números de nós por elemento segundo a Figura 4.4. Como se trata de elementos constituintes de estruturas de concreto armado é sugerido que se opte por elementos de barra com 3 ou 4 nós cujo grau de liberdade implica apenas no deslocamento ao longo do eixo longitudinal. 

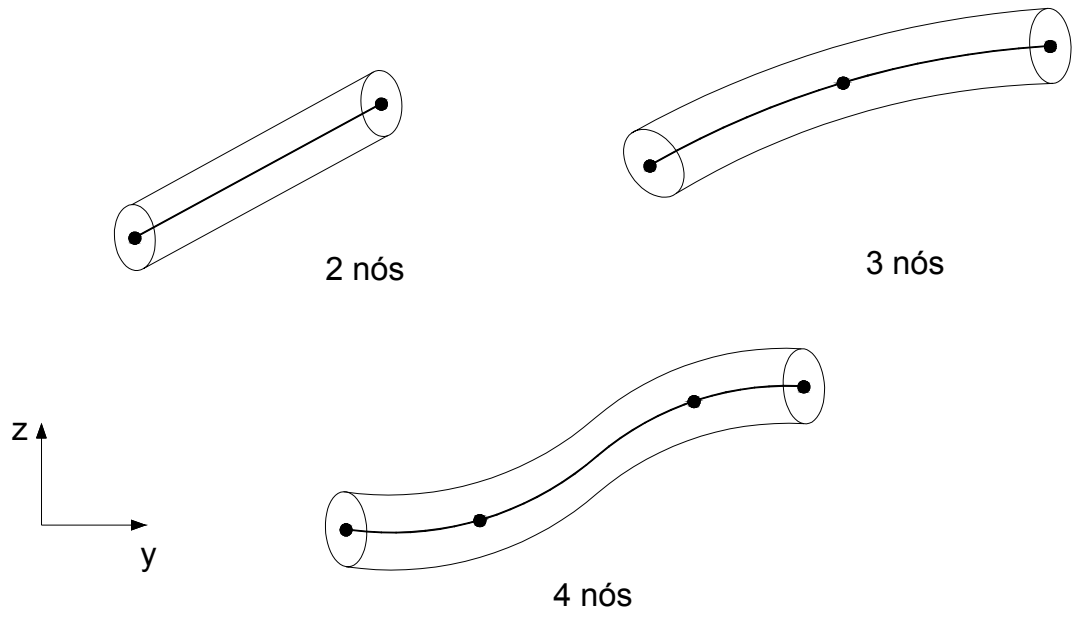

Figura 4.4 - Elemento finito TRUSS - Modificado de ADINA 8.0 (2002).

\subsection{Simulação preliminar para aferição do programa ADINA (2002)}

Em vistas a analisar a eficácia do programa e a coerência das respostas fornecidas, nesta etapa foi realizada a simulação numérica de uma ligação viga-pilar de extremidade analisada experimentalmente por Ortiz (1993), escolhida por razões de comodidade já que o arranjo das barras não oferece grandes dificuldades sob o aspecto da modelagem.

\subsubsection{Descrição do modelo experimental de Ortiz (1993)}

O programa experimental realizado por Ortiz (1993) consistiu na avaliação de sete ligações do tipo viga intermediária-pilar de extremidade para as quais foram utilizados diferentes detalhamentos de armadura e de cargas atuantes.

Os modelos experimentais em escala real foram construídos com a finalidade de reproduzir uma situação de ligação de viga contínua com pilar de extremidade de pórtico de edifício. Para isso, os elementos estruturais do modelo de ligação, viga e pilar, tiveram as dimensões escolhidas de tal modo a representar uma estrutura real.

Neste contexto, são apresentadas apenas as particularidades da ligação BCJ2, a qual foi modelada e os seus resultados serviram como parâmetro para calibragem dos modelos constitutivos dos materiais na simulação numérica. Os detalhes geométricos deste pórtico são apresentados na Figura 4.5. 


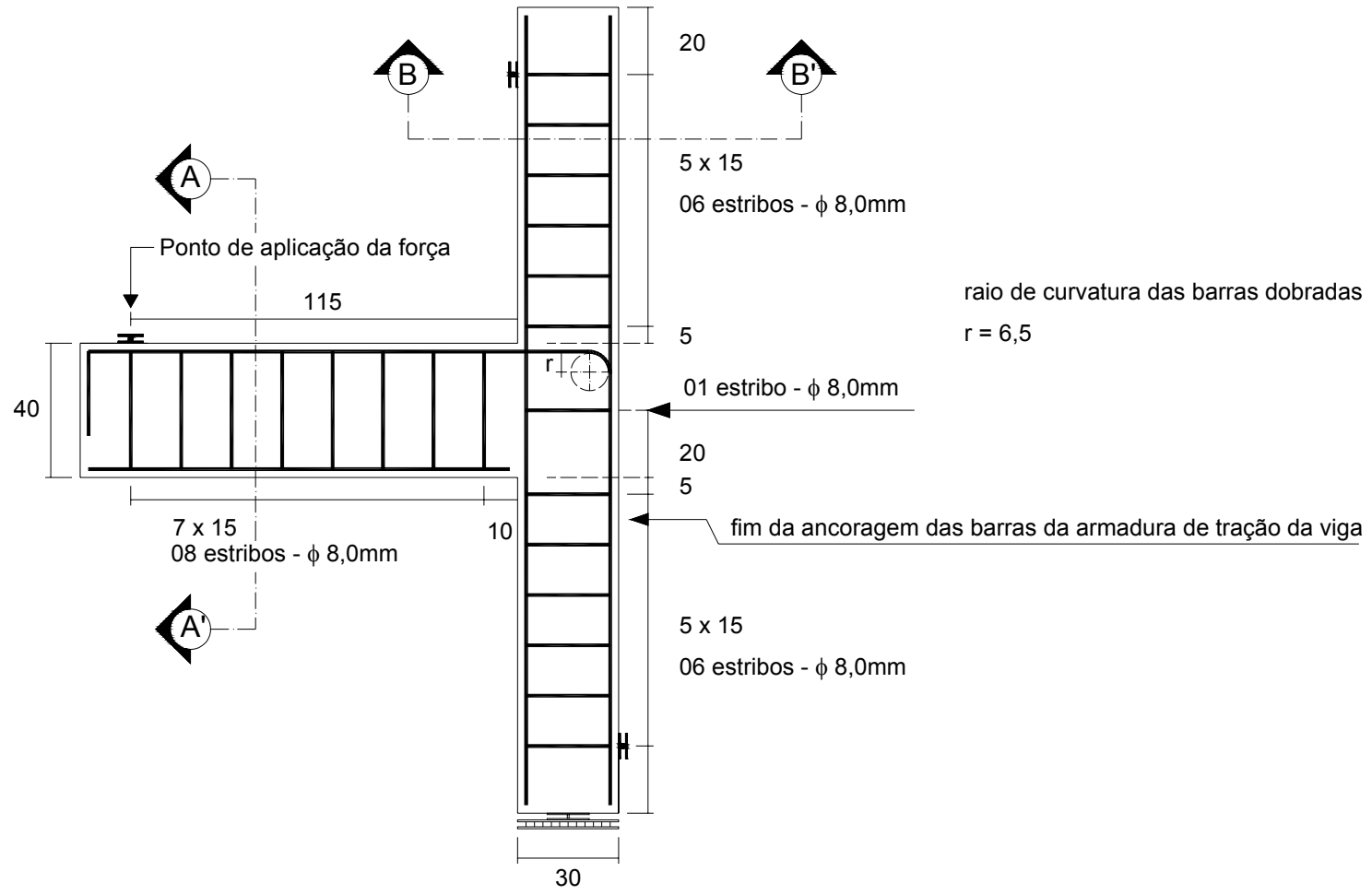

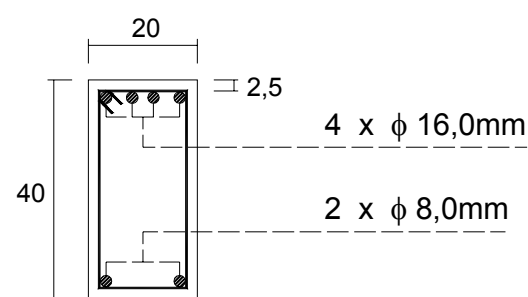

CORTE A - A'

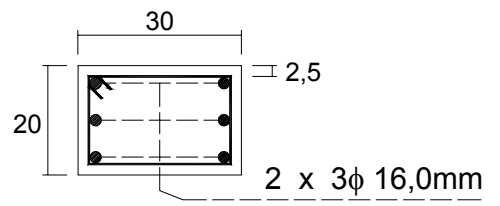

CORTE B -B'

Medidas em centímetros (cm).

Figura 4.5 - Ligação viga-pilar BCJ2 (Dados geométricos) - Adaptado de ORTIZ (1993).

Quanto às propriedades dos materiais, a resistência média do concreto à compressão aos 28 dias $\left(f_{c, 28}\right)$ e a resistência média do concreto à tração $\left(f_{c t}\right)$ foram de, $38 \mathrm{MPa}$ e $3,7 \mathrm{MPa}$, respectivamente.

Já as armaduras da viga e do pilar foram compostas por dois tipos de aço. Nas barras das armaduras longitudinais dos dois elementos foi utilizado o aço Swedish Kam Ks60 de resistência ao escoamento igual a $720 \mathrm{MPa}$ e para os estribos e as barras da armadura inferior da viga, foi utilizado o aço $B S 4449$ cuja resistência ao escoamento é de $571 M P a$. 
Quanto à ancoragem, foram verificadas as deformações em alguns pontos da armadura longitudinal superior da viga. Para tanto, uma barra dessa armadura foi instrumentada com strain-gauges nos locais indicados na Figura 4.6.

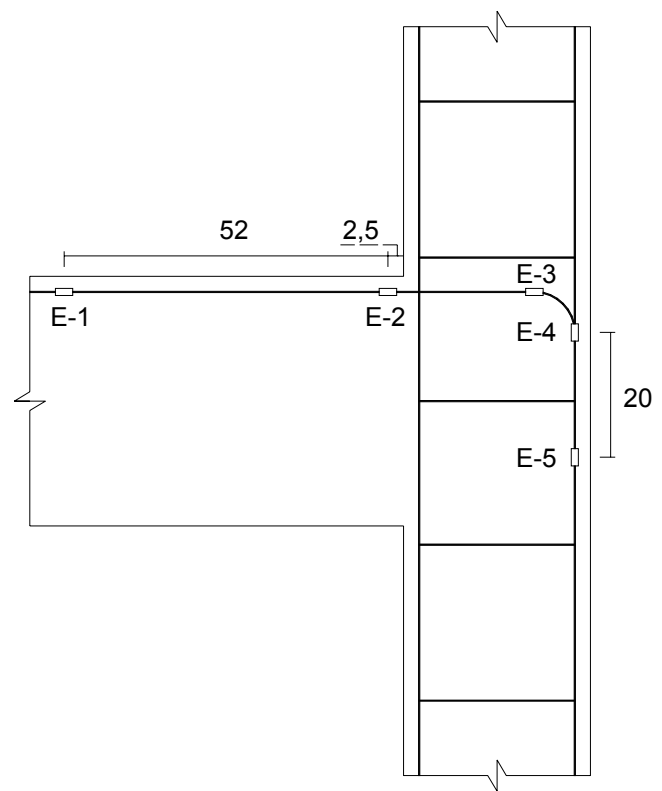

Medidas em centímetros (cm).

Figura 4.6 - Instrumentação da barra da armadura longitudinal da viga - Adaptado de ORTIZ (1993).

Como a ação do momento fletor é preponderante, as barras da armadura longitudinal superior da viga foram emendadas por traspasse nas barras longitudinais do pilar conforme se mostra na Figura 4.7.

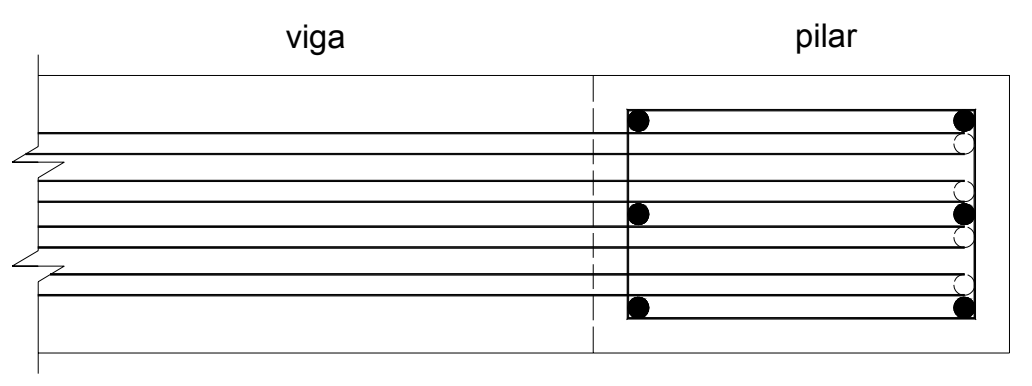

- Barra da armadura longitudinal do pilar

Barra da armadura longitudinal superior da viga

Figura 4.7 - Detalhe das barras da armadura longitudinal superior da viga na região do nó - Adaptado de ORTIZ (1993). 


\subsubsection{Simulação numérica}

A simulação numérica se fundamentou na modelagem da ligação contemplando a não-linearidade física dos materiais e calibrando o modelo com dados provenientes dos resultados experimentais, ou seja, valores médios, salvo exceções.

A concepção geométrica de modelos bidimensionais se resume na definição de pontos, retas e superfícies. Para isso, é imprescindível atentar para alguns aspectos relativos ao lançamento do objeto de análise, pois, uma adequada disposição do modelo geométrico melhora as condições para a discretização da malha de elementos finitos e, conseqüentemente, um possível refinamento até que se atinja uma plausível acurácia dos resultados.

A disposição da geometria do modelo é apresentada na Figura 4.8. No que se refere à discretização da malha, Figura 4.9, para a representação do material concreto, admitindo um estado plano de tensões, foi escolhido o elemento 2-D solid com oito nós e para o aço, o elemento truss com três nós. Essa escolha é justificada pela busca de uma compatibilidade de deslocamentos na interface entre os dois materiais.

Vale salientar que outra hipótese aqui considerada é a de que o concreto e o aço são perfeitamente aderentes, não sendo considerado o atrito entre ambos.

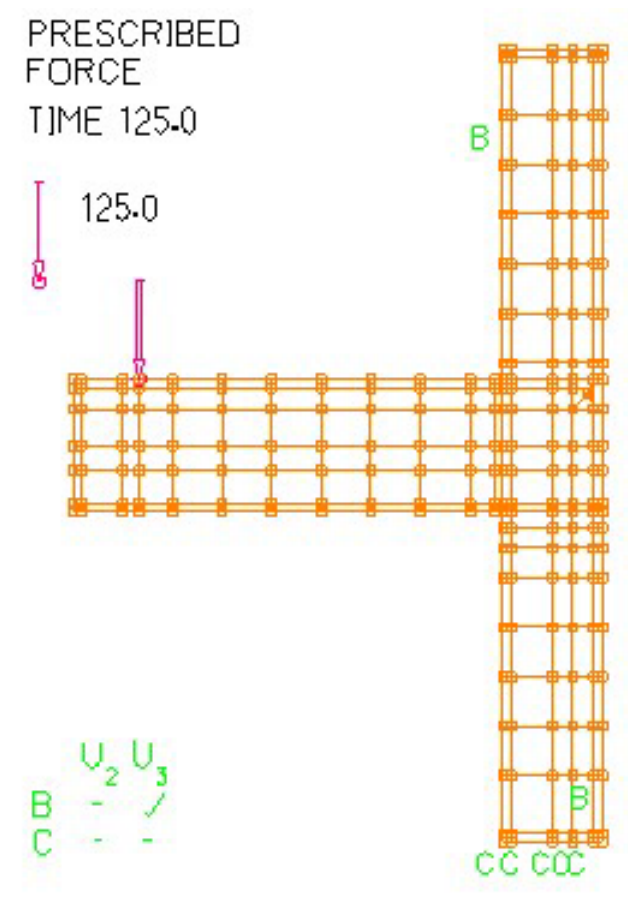

Figura 4.8 - Disposição geométrica do modelo numérico da ligação BCJ2. 


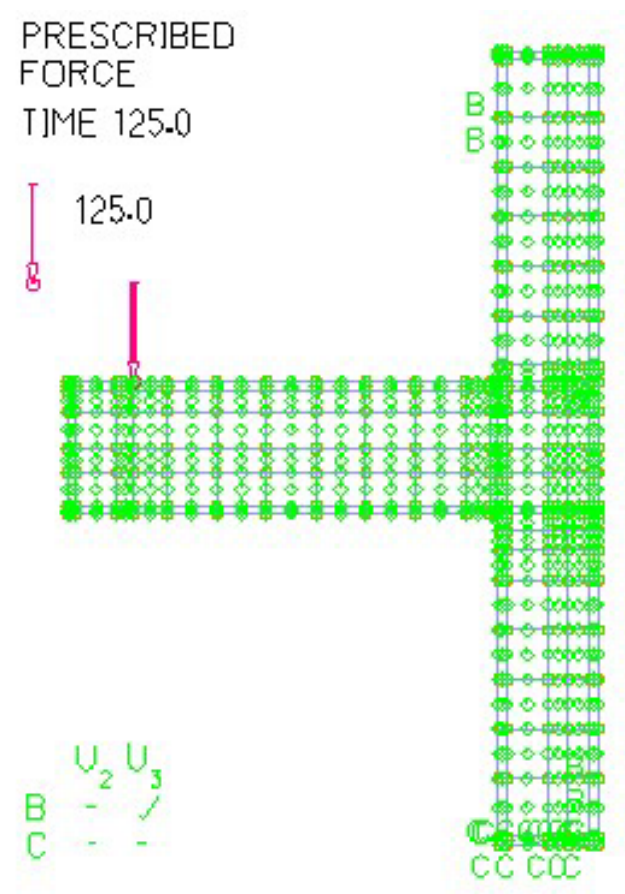

Figura 4.9 - Disposição da malha de elementos finitos da ligação BCJ2.

As letras B e C são as condições de contorno que representam o tipo e a posição dos apoios no pórtico. A letra B indica um apoio com restrição de translação na direção horizontal. Já a letra $\mathrm{C}$ significa que há restrição de translação nas duas direções concernentes ao plano.

As propriedades dos materiais são mostradas na Tabela 4.2. Experimentalmente, foram avaliadas apenas a resistência média do concreto à compressão $\left(f_{c, 28}\right), 38 M P a$, e a resistência média do concreto à tração $\left(f_{c t}\right), 3,7 \mathrm{MPa}$. O módulo de elasticidade do concreto foi determinado por eq.(4.2), substituindo $f_{c k}$ por $f_{c, 28}$. Os demais parâmetros para aferição do modelo de concreto foram assumidos como foi exposto no item 4.2.1.1. Quanto às propriedades dos aços, a resistência ao escoamento e o módulo de elasticidade de ambos foram definidos na análise experimental. As variáveis restantes foram adotadas conforme apresentado no item 4.2.1.2.

Dada a geometria, a disposição da malha e os atributos relativos ao concreto e o aço, iniciou-se o procedimento de análise cujo objetivo foi atingir a mesma força de ruína que foi alcançada no estudo experimental.

Conseguiu-se tal propósito aplicando a força em 125 passos de carga, mediante o método iterativo completo de Newton (Full Newton Method), com o comando line 
searches ativado e o número máximo de iterações por passo. Além disso, foi adotado o critério de deslocamento como o critério de convergência, com a tolerância de $5 \%$.

Tabela 4.2 - Propriedades dos materiais do pórtico BCJ2.

\begin{tabular}{|c|c|c|}
\hline Material & Propriedade & Valor médio \\
\hline Concreto & $\begin{array}{l}f_{c c, \text { máx }} \rightarrow \text { resistência máxima à compressão do concreto } \\
\left(\mathrm{kN} / \mathrm{cm}^{2}\right) \\
f_{c c, u} \rightarrow \text { resistência última à compressão do concreto } \\
\left(\mathrm{kN} / \mathrm{cm}^{2}\right) \\
\varepsilon_{c c} \rightarrow \text { deformação específica à compressão do concreto } \\
\text { referente à } f_{c c, \text { maxx }} \\
\varepsilon_{c c, u} \rightarrow \text { deformação específica última à compressão do } \\
\text { concreto } \\
f_{c t} \rightarrow \text { resistência à tração do concreto }\left(\mathrm{kN} / \mathrm{cm}^{2}\right) \\
\alpha \cdot f_{c t d} \rightarrow \text { resistência à tração do concreto pós-fissurado } \\
\left(\mathrm{kN} / \mathrm{cm}^{2}\right) \\
\nu \rightarrow \text { coeficiente de Poisson } \\
\gamma_{c} \rightarrow \text { massa específica do concreto armado }\left(\mathrm{kN} / \mathrm{cm}^{3}\right) \\
G_{F} \rightarrow \text { energia de fraturamento }\left(\mathrm{kN} \cdot \mathrm{cm} / \mathrm{cm}^{2}\right) \\
E_{c i} \rightarrow \text { módulo de elasticidade tangente inicial do } \\
\text { concreto }\left(\mathrm{kN} / \mathrm{cm}^{2}\right)\end{array}$ & $\begin{array}{c}-3,79 \\
-0,0035 \\
-0,002 \\
0,37 \\
0,22 \\
0,20 \\
2,5 \cdot 10^{-5} \\
7,64 \cdot 10^{-4} \\
3452,07\end{array}$ \\
\hline $\begin{array}{c}\text { Aço } \\
\text { Swedish } \\
\text { Kam } \\
\text { Ks60 }\end{array}$ & $\begin{array}{l}f_{y} \rightarrow \text { resistência ao escoamento do aço }\left(\mathrm{kN} / \mathrm{cm}^{2}\right) \\
\varepsilon_{y, \text { máx }} \rightarrow \text { deformação específica máxima de escoamento } \\
\text { do aço } \\
\nu \rightarrow \text { coeficiente de Poisson } \\
\gamma_{s} \rightarrow \text { massa específica do aço }\left(\mathrm{kN} / \mathrm{cm}^{3}\right) \\
E_{s} \rightarrow \text { módulo de elasticidade do aço }\left(\mathrm{kN} / \mathrm{cm}^{2}\right)\end{array}$ & $\begin{array}{c}72,00 \\
0,01 \\
0,30 \\
7,85 \cdot 10^{-5} \\
18000\end{array}$ \\
\hline $\begin{array}{c}\text { Aço } B S \\
4449\end{array}$ & $\begin{array}{l}f_{y} \rightarrow \text { resistência ao escoamento do aço }\left(\mathrm{kN} / \mathrm{cm}^{2}\right) \\
\varepsilon_{y, \text { máx }} \rightarrow \text { deformação específica máxima de escoamento } \\
\text { do aço } \\
\nu \rightarrow \text { coeficiente de Poisson } \\
\gamma_{s} \rightarrow \text { massa específica do aço }\left(\mathrm{kN} / \mathrm{cm}^{3}\right) \\
E_{s} \rightarrow \text { módulo de elasticidade do aço }\left(\mathrm{kN} / \mathrm{cm}^{2}\right)\end{array}$ & $\begin{array}{c}57,10 \\
0,01 \\
0,30 \\
7,85 \cdot 10^{-5} \\
22840\end{array}$ \\
\hline
\end{tabular}




\subsubsection{Resultados e discussões}

Os parâmetros comparativos estabelecidos foram a relação força aplicada versus deformação das barras da armadura longitudinal da viga, a intensidade máxima de solicitação das barras nos pontos analisados, em termos das tensões e deformações, e a força tração à medida que as seções transversais se afastam da face do pilar.

De acordo com a descrição da análise experimental feita por Ortiz (1993), as primeiras fissuras surgiram no canto superior da ligação entre a viga e o pilar no instante em que a força aplicada na extremidade da viga foi de $27 k N$, e a primeira fissura diagonal no nó ocorreu quando a força foi de $50 \mathrm{kN}$, a qual foi definida como sendo a força de fissuração do nó. Para esse valor da força, o momento de fissuração foi $M_{r}=6250 \mathrm{kN} \cdot \mathrm{cm}$. Na ruína do pórtico, a força última foi de $125 \mathrm{kN}$ e o momento correspondente foi $M_{u}=15625 \mathrm{kN} \cdot \mathrm{cm}$.

Para tal verificação, foi fornecida a evolução das deformações nas barras da viga ao longo da aplicação da força nos cinco pontos mencionados na Figura 4.6 (ver Figura 4.10, Figura 4.11, Figura 4.12, Figura 4.13 e Figura 4.14).

Os resultados experimentais foram apresentados mediante valores pontuais, ou seja, a deformação foi registrada em alguns estágios de força, ao passo que, pela análise numérica, puderam-se apreciar os acréscimos de deformações ao longo da história do carregamento.

No âmbito geral, a aproximação entre os resultados experimentais e os numéricos melhorou à proporção que se verificou a deformação nas barras nos pontos mais internos da região nodal, com exceção do ponto E-4.

É notável que o modelo numérico mostrou-se com um comportamento mais rígido no nó até o instante em que força aplicada foi a de $50 \mathrm{kN}$. A partir daí, a deformação das barras da viga se elevaram substancialmente. Uma possível justificativa para tal fato se deve a limitação do modelo quanto à desconsideração do contato entre a armadura e o concreto.

Tal hipótese se traduz na completa absorção das tensões de tração pelas barras da armadura no instante em que o concreto atinge sua capacidade de resistência à tração. Na realidade, o atrito entre os elementos constituintes do concreto armado no estágio de pós-fissuração do concreto reduz as tensões nas barras e, conseqüentemente, as deformações. 
Em quase todos os pontos de análise, a perda de rigidez se deu num intervalo aproximado ao instante de força aplicada igual a $50 \mathrm{kN}$. Isso significa que o momento de fissuração obtido numericamente se aproxima do avaliado na análise experimental.

Entretanto, é conveniente perceber que, no ponto E-2 (o mais próximo da seção mais solicitada da viga) a perda de rigidez se iniciou quando a força na extremidade da viga foi um valor tal que $30 k N \leq F \leq 35 k N$, o que está razoável, visto que as primeiras fissuras apareceram no modelo experimental e nessa região, quando a força aplicada foi de $27 \mathrm{kN}$.

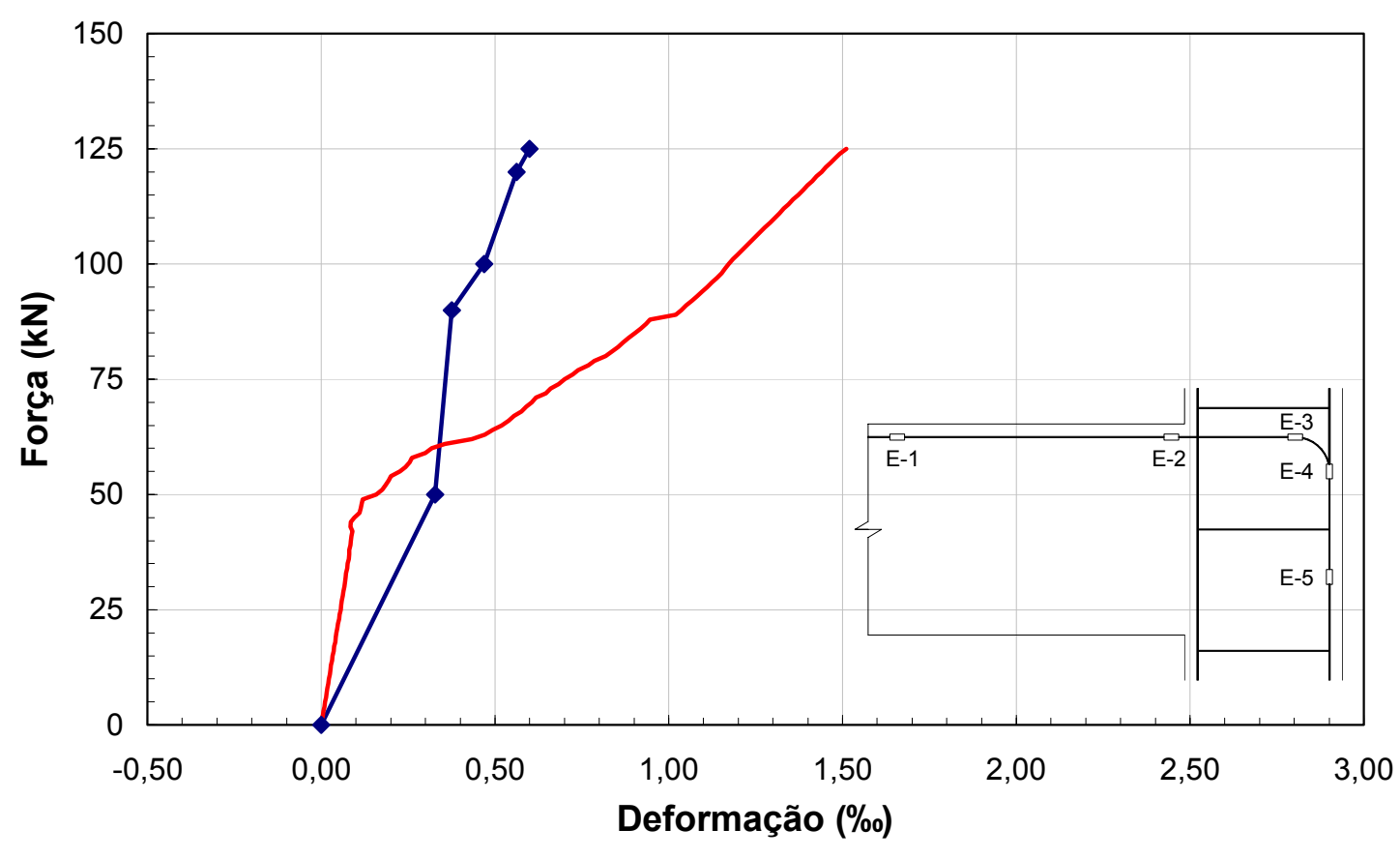

Valores experimentais de Ortiz (1993)

—Valores numéricos - ADINA

Figura 4.10 - Diagrama força aplicada versus deformação no ponto E-1. 


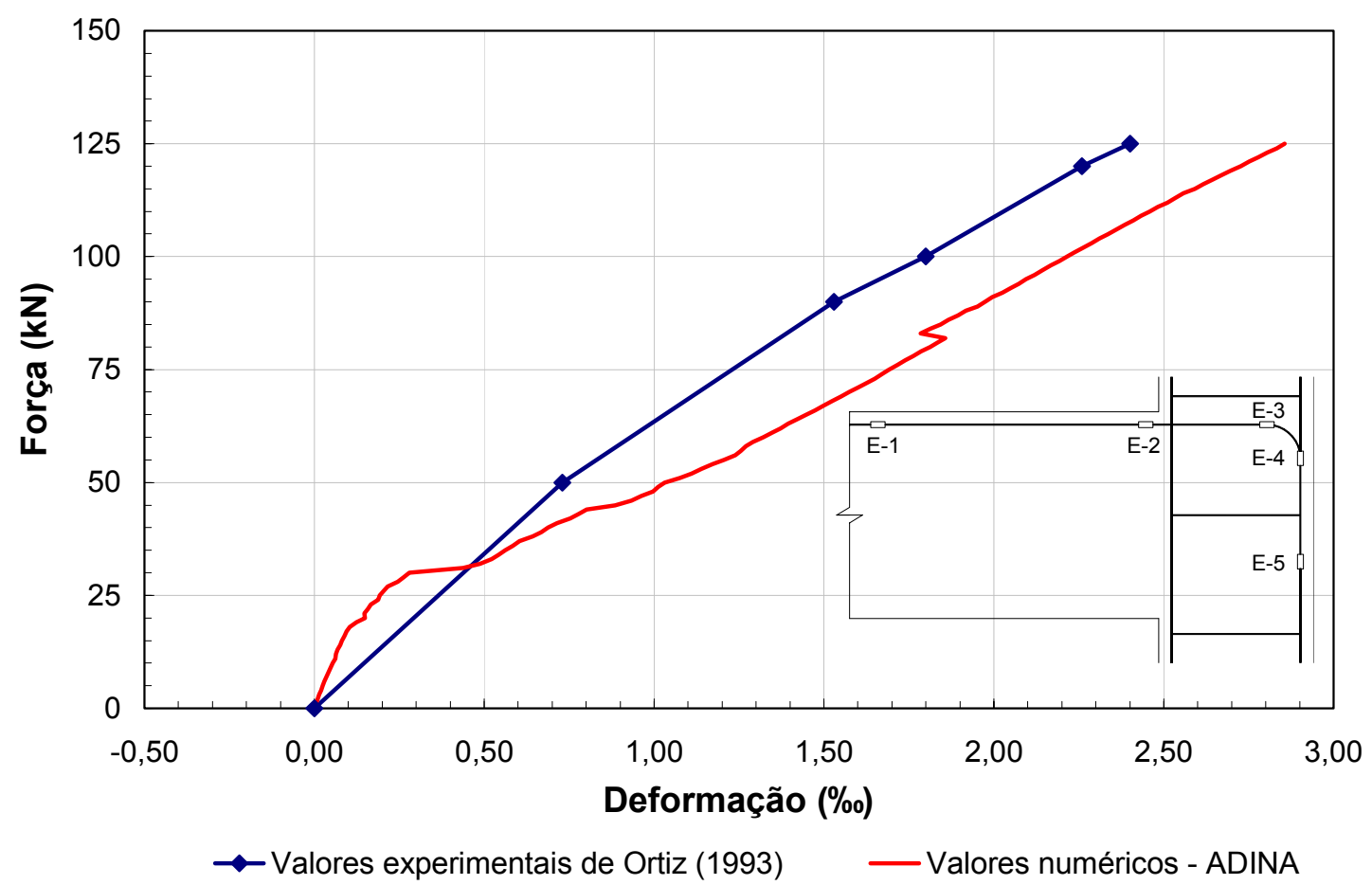

Figura 4.11 - Diagrama força aplicada versus deformação no ponto E-2.

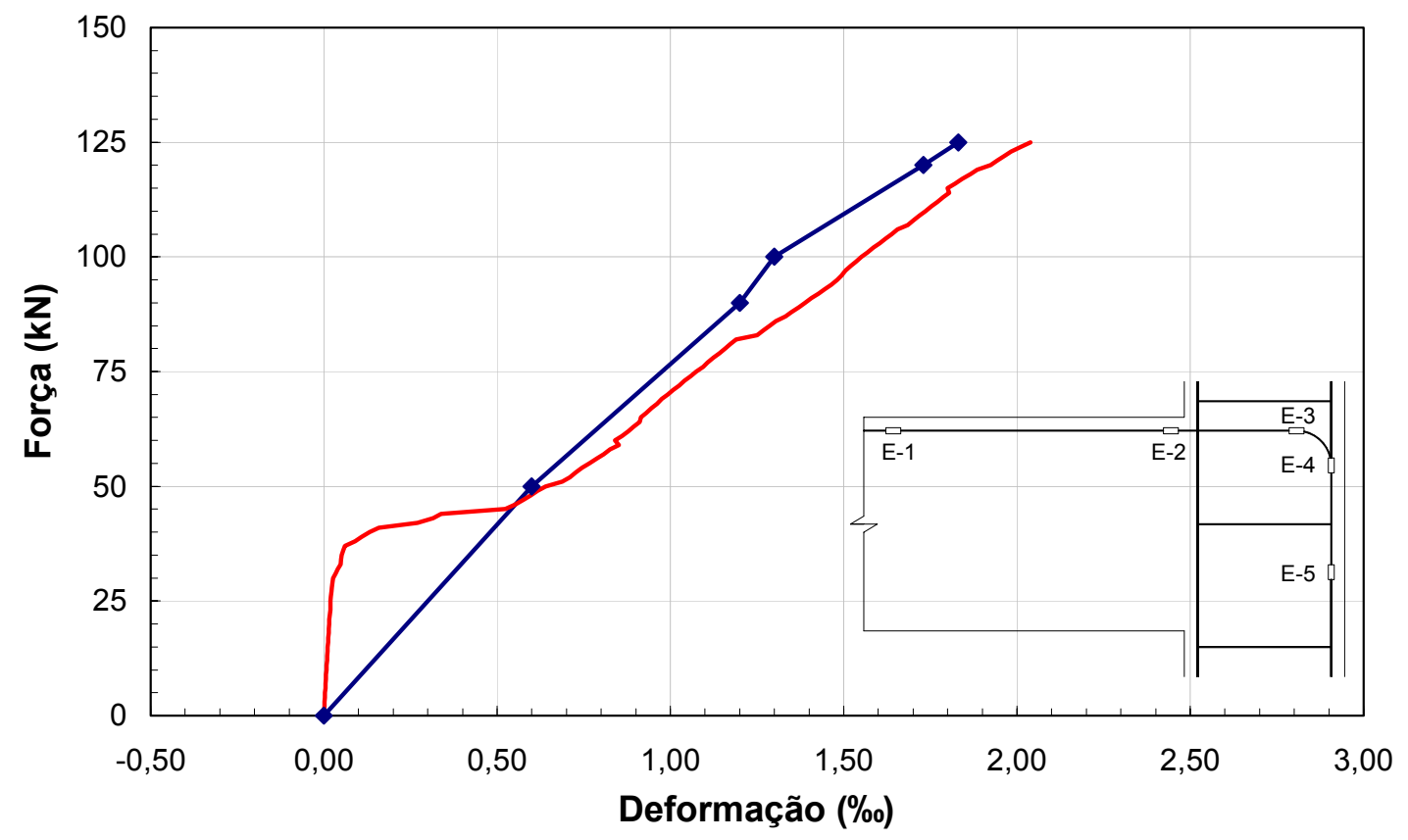

$\multimap$ - Valores experimentais de Ortiz (1993) — — Valores numéricos - ADINA

Figura 4.12 - Diagrama força aplicada versus deformação no ponto E-3. 


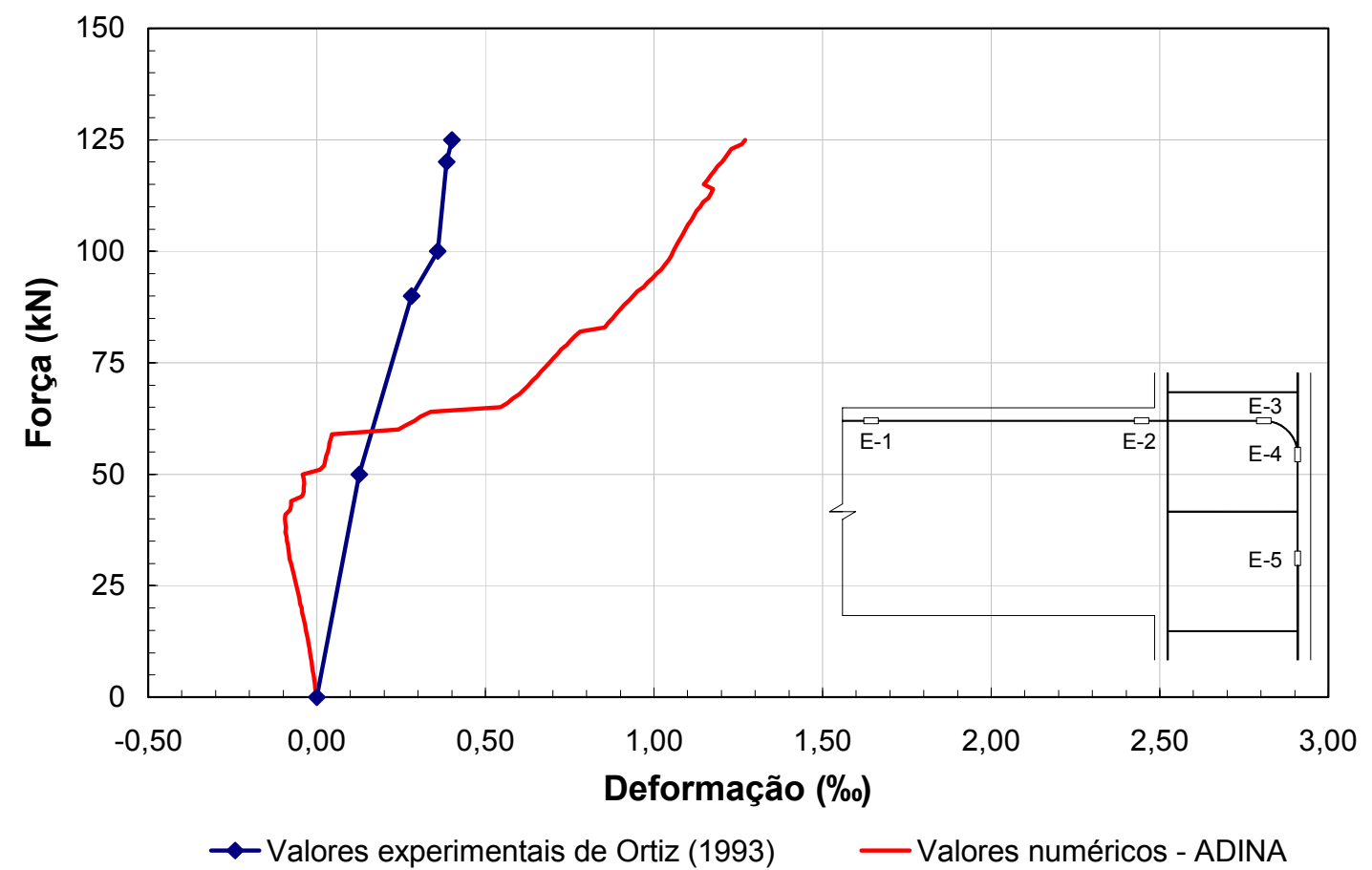

Figura 4.13 - Diagrama força aplicada versus deformação no ponto E-4.

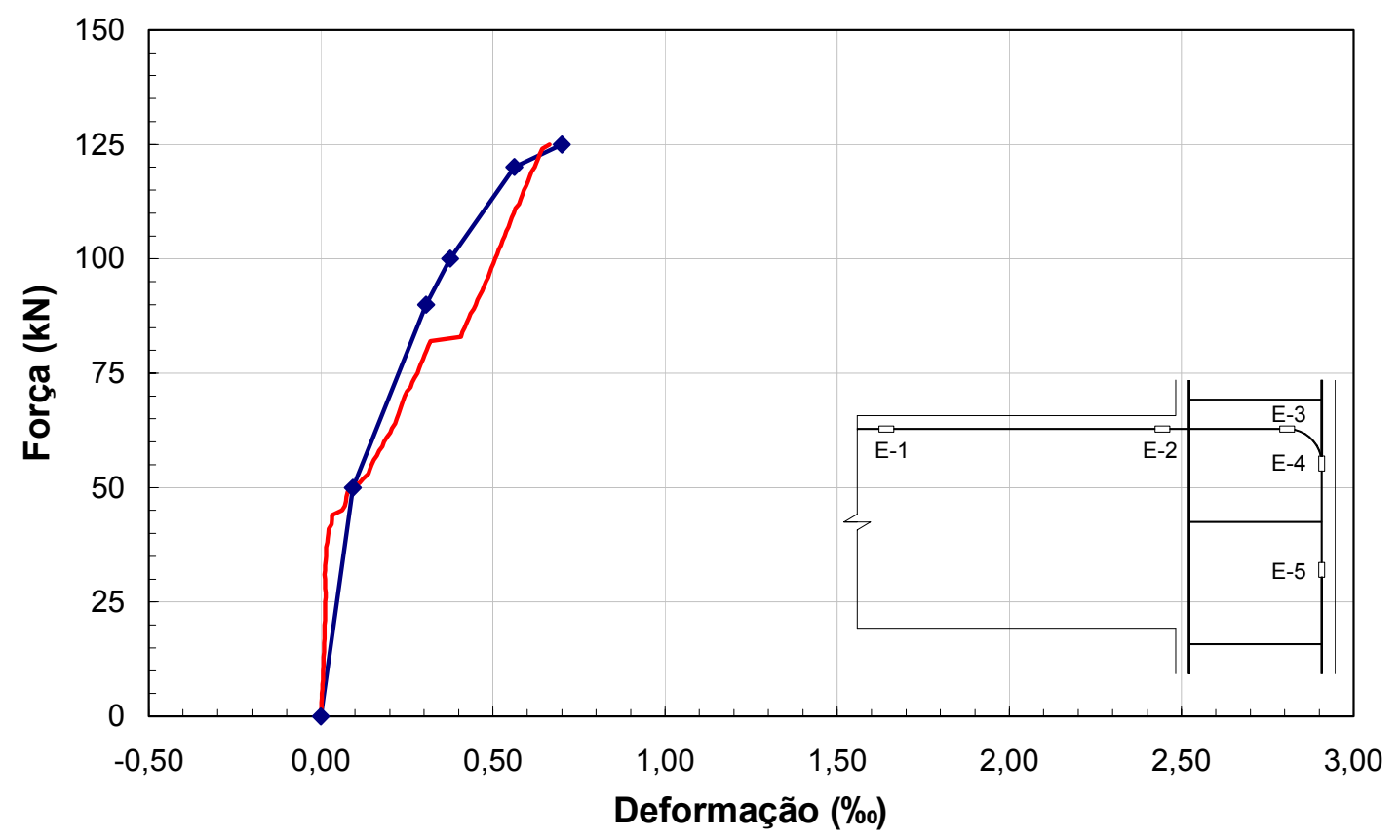

Valores experimentais de Ortiz (1993) — - Valores numéricos - ADINA

Figura 4.14 - Diagrama força aplicada versus deformação no ponto E-5. 
De acordo com os dados obtidos no instante de ruína da ligação, a Tabela 4.3 apresenta os valores das tensões máximas alcançadas e as respectivas deformações nos pontos da barra da armadura superior da viga em estudo tanto na análise do modelo numérico como no experimental. Além disso, é mostrada a razão entre os valores fornecidos, a qual chega à ordem de 3,18 no ponto E-4.

É interessante observar que, para o modelo experimental, houve um acréscimo de deformação no trecho ancorado entre o fim do gancho (ponto E-4) e o ponto situado na emenda por traspasse (E-5). No modelo numérico, a deformação nas barras diminuiu à proporção que o trecho ancorado adentrou no apoio.

Tabela 4.3 - Valores máximos das tensões e deformações nos pontos verificados.

\begin{tabular}{c|c|c|c|c|c|c}
\hline \multirow{2}{*}{ Posição } & \multicolumn{3}{|c|}{$\sigma_{s}\left(\mathrm{kN} / \mathrm{cm}^{2}\right)$} & \multicolumn{3}{c}{$\varepsilon_{s}(\%$ o } \\
\cline { 2 - 7 } & $\mathrm{N}^{*}$ & $\mathrm{E}^{\dagger}$ & $\mathrm{N} / \mathrm{E}$ & $\mathrm{N}$ & $\mathrm{E}$ & $\mathrm{N} / \mathrm{E}$ \\
\hline $\mathrm{E}-1$ & 27,20 & 10,80 & 2,52 & 1,51 & 0,60 & 2,52 \\
$\mathrm{E}-2$ & 51,41 & 43,20 & 1,19 & 2,86 & 2,40 & 1,19 \\
$\mathrm{E}-3$ & 36,70 & 32,94 & 1,11 & 2,04 & 1,83 & 1,11 \\
E-4 & 22,87 & 7,20 & 3,18 & 1,27 & 0,40 & 3,18 \\
E-5 & 11,96 & 12,60 & 0,95 & 0,67 & 0,70 & 0,95 \\
\hline
\end{tabular}

* Resultado da análise numérica realizada no programa ADINA;

$†$ Resultado experimental aproximado verificado por Ortiz (1993).

No que diz respeito à força de tração por barra, essa grandeza foi medida em apenas dois pontos correspondentes a E-2 e E-3. A correlação entre os valores numérico e experimental se mostrou satisfatória (ver Tabela 4.4).

Tabela 4.4 - Valores da força de tração por barra nos pontos E-2 e E-3.

\begin{tabular}{c|c|c|c}
\hline Posição & $R_{\text {st, numérico }}(k N)$ & $R_{\text {st, experimental }}(k N)$ & $R_{\text {st, numérico }} / R_{\text {st, experimental }}$ \\
\hline E-2 & 103,34 & 96,00 & 1,08 \\
E-3 & 73,77 & 72,00 & 1,03 \\
\hline
\end{tabular}

Mediante os resultados ora apresentados, pode-se afirmar que, dos cinco pontos analisados, em apenas dois pontos (E-1 e E-4) houve diferenças significativas entre os resultados produzidos pelo modelo numérico e pelo modelo experimental. Contudo, neste instante, faz-se necessário ressaltar as prováveis razões que ocasionam tais desigualdades. 
É importante enfatizar que o modelo numérico se trata de uma representação simplificada de um modelo real para o qual são admitidas hipóteses que, indubitavelmente, já proporciona alteração nos resultados.

A ausência de parâmetros fundamentais para aferição dos modelos constitutivos dos materiais, como o módulo de elasticidade do concreto, dentre outros e que neste caso, foram estimados a partir de equações normativas, também dificultam uma melhor performance do modelo. Além disso, a desconsideração do atrito entre o concreto e o aço é um fator relevante que promove distorção na resposta por motivos que outrora já foi comentado.

Por outro lado, ainda existem os problemas provenientes da construção do modelo experimental, tais como, os erros nas avaliações das propriedades dos materiais, realização do ensaio e instrumentação, os quais não são contabilizados na análise numérica.

Mesmo com esses pormenores, o estudo comparativo mostrou a viabilidade da análise numérica com o programa ADINA (2002) para a avaliação da ancoragem de barras da armadura longitudinal de viga em ligações do tipo viga - pilar para as quais ficam restritas as demais análises na seqüência do trabalho. 


\section{Estudo de caso}

\subsection{Considerações iniciais}

Neste capítulo é apresentado um estudo de caso acerca da verificação da ancoragem das barras da armadura longitudinal de uma viga numa típica ligação do tipo viga-pilar de extremidade de um edifício residencial em concreto armado.

As ligações utilizadas no presente trabalho fazem parte do sistema estrutural que compõe o edifício residencial Wassily Kandinsky em São Carlos (SP), cujo projeto estrutural foi feito pela empresa AEOLUS Engenharia e Consultoria Ltda.

Nas investigações aqui desenvolvidas são empregadas as mesmas idealizações e considerações que foram utilizadas na modelagem numérica da ligação viga-pilar de extremidade BCJ2 analisada experimentalmente por Ortiz (1993) e apresentada no capítulo 4.

O momento de fissuração e a força de tração a ancorar na seção de transição entre a viga e o pilar, as tensões e deformações máximas em alguns pontos ao longo do trecho ancorado das armaduras de longitudinais da viga e a influência da força normal aplicada no pilar são os parâmetros de análise obtidos nos modelos numéricos e comparados aos valores determinados pelos métodos analíticos e/ou por expressões sugeridas pela NBR 6118:2003. 


\subsection{Apresentação}

O edifício residencial Wassily Kandinsky é composto por pavimento térreo, oito pavimentos-tipo, dois pavimentos duplex e cobertura. Na Figura 5.1 é mostrada a quarta parte da forma estrutural do pavimento tipo para o qual ficaram restritas as análises já que as ligações foram verificadas na altura do primeiro, quarto e sexto pavimentos-tipo.

As referidas ligações foram os encontros entre o pilar P31 e as vigas V325 e V341. Como as análises se limitam a modelos bidimensionais, esses nós foram avaliados em separado, desprezando os efeitos de um em relação ao outro.

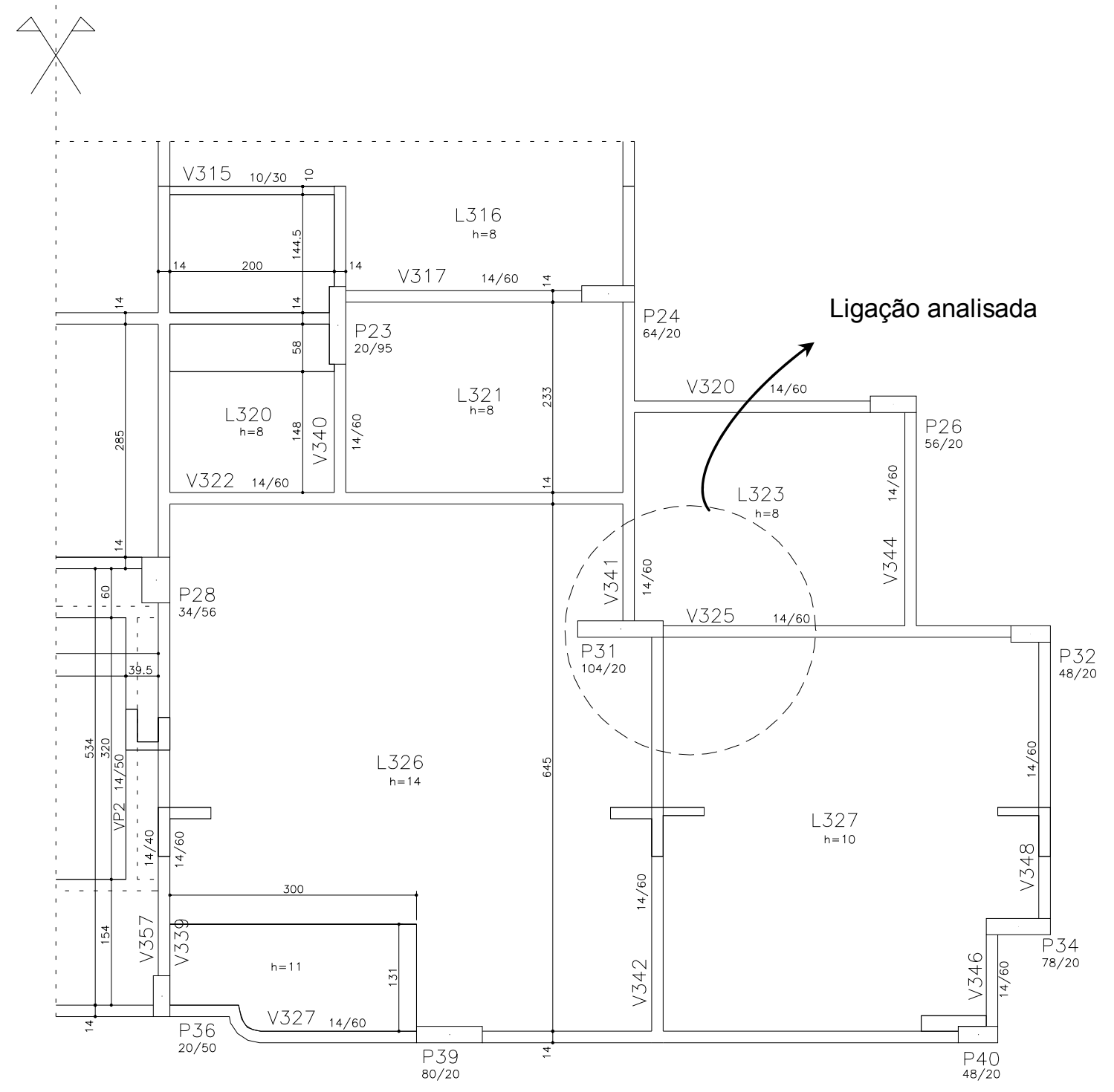

Medidas em centímetros $(\mathrm{cm})$.

Figura 5.1 - Quarta parte da forma estrutural do pavimento-tipo. 


\subsection{Descrição dos modelos físicos das ligações viga-pilar}

A definição da geometria dos modelos físicos das ligações foi baseada nas mesmas hipóteses admitidas por Ortiz (1993).

Sendo assim, consideraram-se nessas seções apoios que restringiam a translação horizontal do pórtico no pilar e o ponto de aplicação de forças concentradas na viga. Para garantir o equilíbrio da ligação em análise e reproduzir o efeito de compressão da força normal no pilar, foi colocado um apoio na extremidade inferior desse elemento de modo a impedir apenas o deslocamento vertical.

Os detalhamentos das armaduras longitudinais e transversais das vigas V325 e V341 na região de ligação com o pilar P31 são apresentados na Figura 5.2.

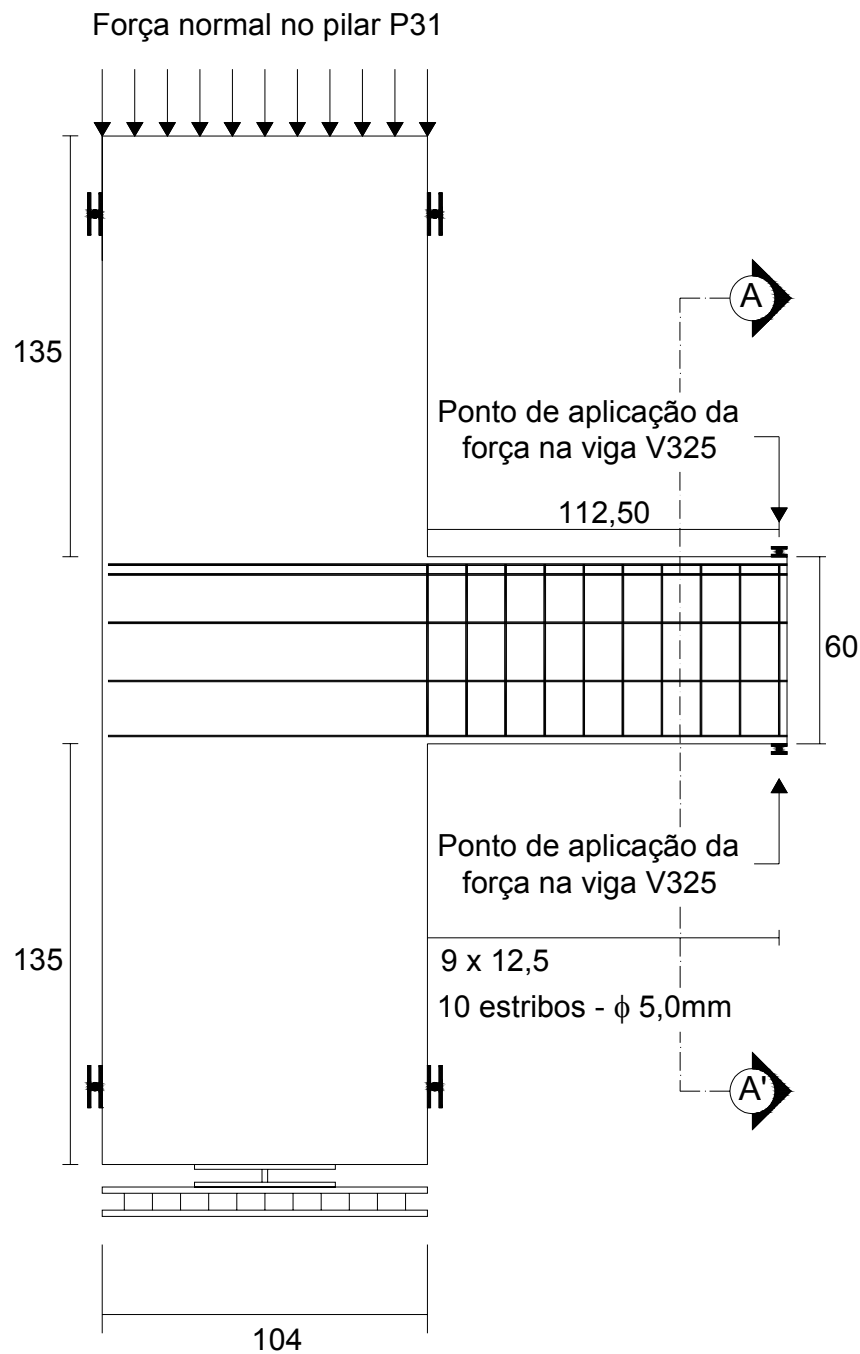

(a) 
Força normal no pilar P31

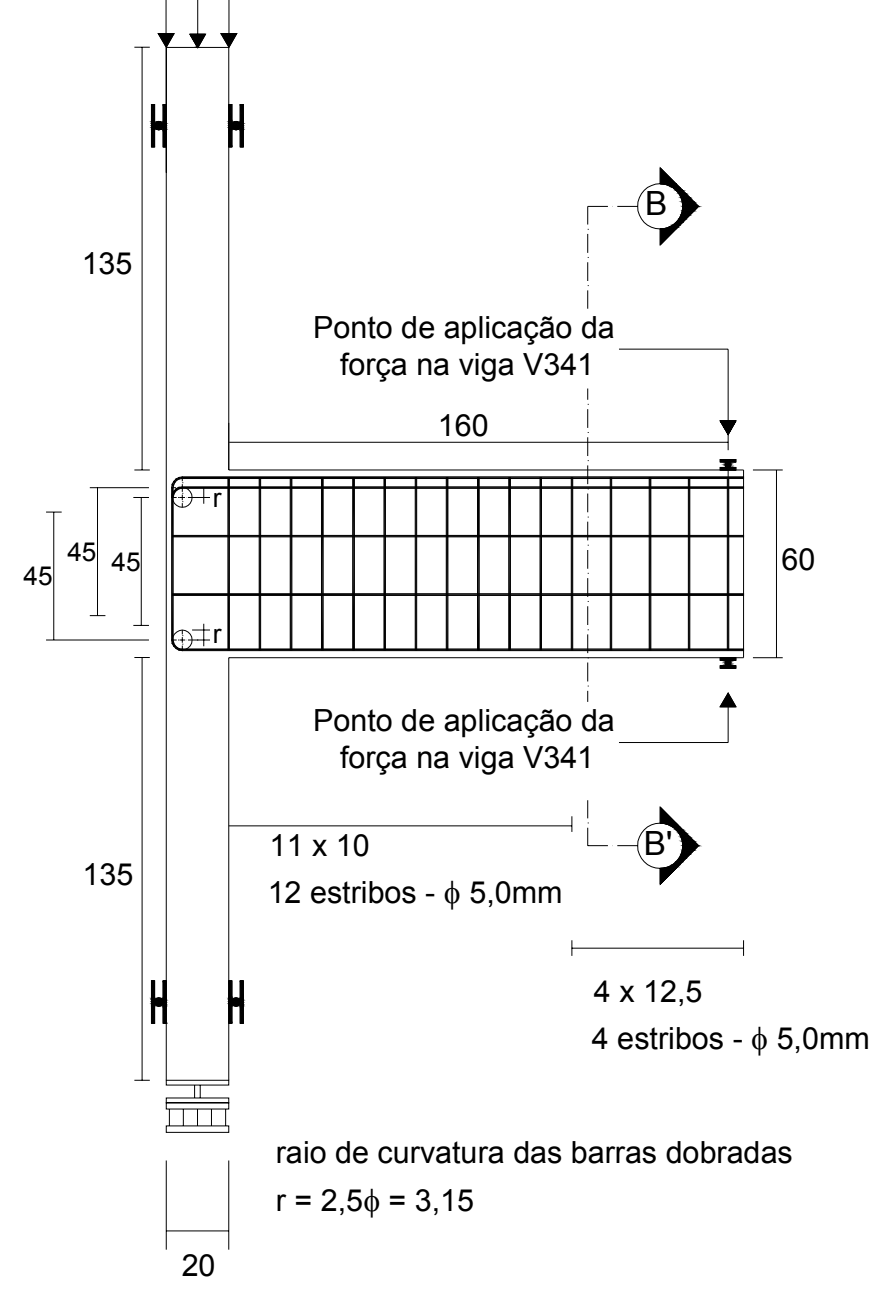

(b)

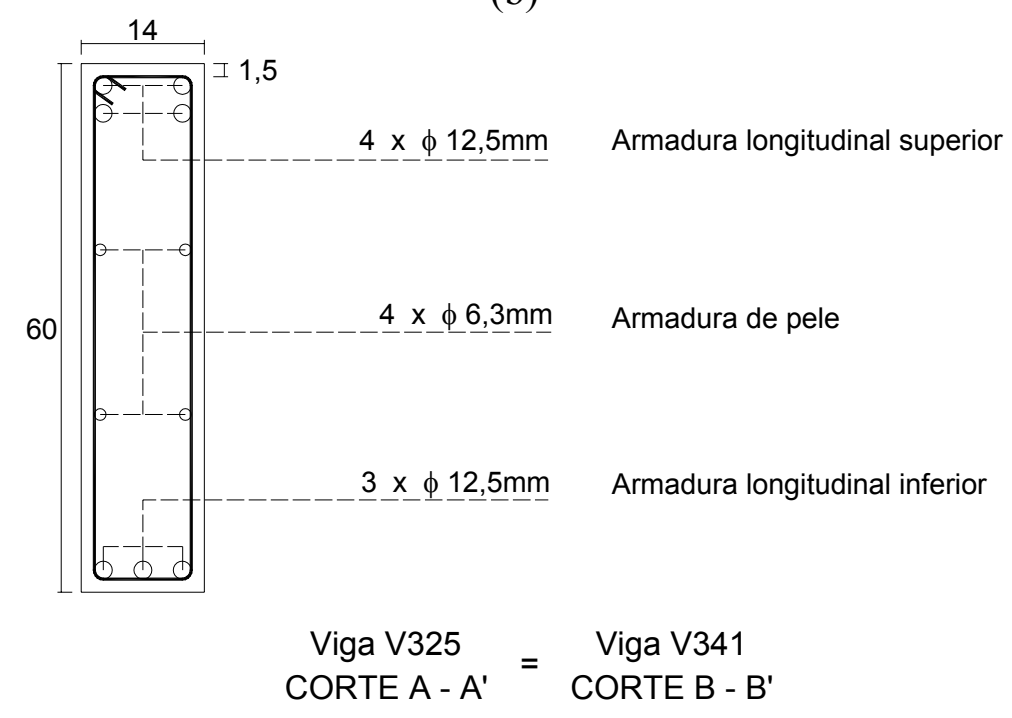

Medidas em centímetros $(\mathrm{cm})$.

(c)

Figura 5.2 - Detalhamento das armaduras longitudinais e transversais das vigas na ligação com o pilar P31: (a) V325; (b) V341; (c) Seção transversal. 
Conforme é percebido, as vigas são idênticas quanto à geometria da seção e a disposição das armaduras longitudinais. Contudo, as taxas das armaduras transversais e o tipo de ancoragem adotada se diferem em virtude da disponibilidade dimensional do apoio.

A viga V325 se une ao pilar P31 na sua maior dimensão e, portanto, foi suficiente adotar barras com ancoragem de ponta reta para as armaduras superior e inferior. A verificação da adequação do comprimento de ancoragem $\left(\ell_{b}\right)$ foi feita em comparação com a prescrição da NBR 6118:2003 referente a esse aspecto.

Conforme foi esmiuçado no item 3.1, o comprimento de ancoragem das barras é determinado pela expressão abaixo:

$$
\ell_{b}=\frac{\phi}{4} \cdot \frac{f_{y d}}{f_{b d}}
$$

Substituindo os dados inerentes às propriedades das armaduras longitudinais da viga V325, tem-se que:

$$
\ell_{b}=\frac{\phi}{4} \cdot \frac{f_{y d}}{f_{b d}}=\frac{\phi}{4} \cdot \frac{f_{y d}}{\eta_{1} \cdot \eta_{2} \cdot \eta_{3} \cdot 0,19 \cdot f_{c d}^{2 / 3}}=\frac{1,25}{4} \cdot \frac{43,50}{2,25 \cdot 0,7 \cdot 1 \cdot \frac{0,19 \cdot 14,3^{2 / 3}}{10}}=77,11 \mathrm{~cm}
$$

Esse resultado revela que o comprimento adotado para a ancoragem das barras de ambas as armaduras favorecem a segurança, já que o valor do comprimento de ancoragem adotado é cerca de $30 \%$ maior que o comprimento determinado pela recomendação normativa.

Como as barras das armaduras longitudinais da viga V341 possuem as mesmas propriedades das barras que compõem as armaduras longitudinais da viga V325, o comprimento de ancoragem é o mesmo $\left(\ell_{b}=77,11 \mathrm{~cm}\right)$. Porém, pela limitação de espaço no apoio, as barras das armaduras longitudinais foram ancoradas com gancho de extremidade ou emendadas por traspasse nas barras da armadura longitudinal do pilar.

O comprimento de ancoragem total das barras, considerando os trechos retos e a parte curva, adotado no projeto foi:

$$
\ell_{b, \text { projeto }}=64,80 \mathrm{~cm}
$$


Assim, admitindo as barras ancoradas com gancho de extremidade, o comprimento de ancoragem passa a ser $70 \%$ do valor calculado de $\ell_{b}$. Logo:

$$
\ell_{b, \text { nec }}=0,70 \cdot \ell_{b}=0,70 \cdot 77,11 \cong 54 \mathrm{~cm}
$$

Pela determinação do comprimento de ancoragem efetivo definido pela geometria do apoio e recomendações normativas quanto o diâmetro de dobramento $(5 \phi)$ e a ponta reta após o gancho $(\geq 8 \phi)$, verificou-se que:

$$
\ell_{b, e f, \text { gancho }} \geq 26,65 \mathrm{~cm}
$$

Assumindo as barras emendadas por traspasse, há também a redução de $30 \%$ do comprimento de ancoragem. Avaliando o comprimento de ancoragem efetivo cujo diâmetro de dobramento e a ponta reta após o gancho são $8 \phi$ e $\geq 35 \phi$, respectivamente, tem-se que:

$$
\ell_{b, e f, \text { emenda }} \geq 60,75 \mathrm{~cm}
$$

Essas respostas atestam que, embora ambos atendam aos critérios exigidos por norma, a emenda por traspasse se aproxima mais do valor apresentado no projeto.

É oportuno relatar que, a presença dos pontos de aplicação de força nas faces do topo e da base das vigas deveu-se a necessidade de verificação da ancoragem nas barras da armadura superior e inferior, respectivamente. Além da função de absorver as tensões ocasionadas pelas ações permanentes e acidentais, a existência dessas armaduras também se justifica pela consideração em projeto do efeito do vento sob esses elementos estruturais.

No que tange a armadura de pele, a mesma atende às prescrições da NBR 6118:2003 uma vez que as vigas têm altura $(h)$ igual a $60 \mathrm{~cm}$.

No projeto estrutural do pilar P31, o detalhamento das armaduras longitudinal e transversal possui três variações ao longo dos andares correspondentes ao pavimentotipo (ver Figura 5.3). Mediante esse fato, foram escolhidos nós entre os andares que permitissem analisar a ancoragem das barras das armaduras das vigas nessas transições. 
Em relação aos esforços solicitantes no pilar em questão, admitiu-se apenas a ação da força normal sobre o elemento para a análise da ancoragem. A composição desse esforço considerou, além das ações habituais para o dimensionamento de pilares, a ação do vento nas duas direções da seção transversal.

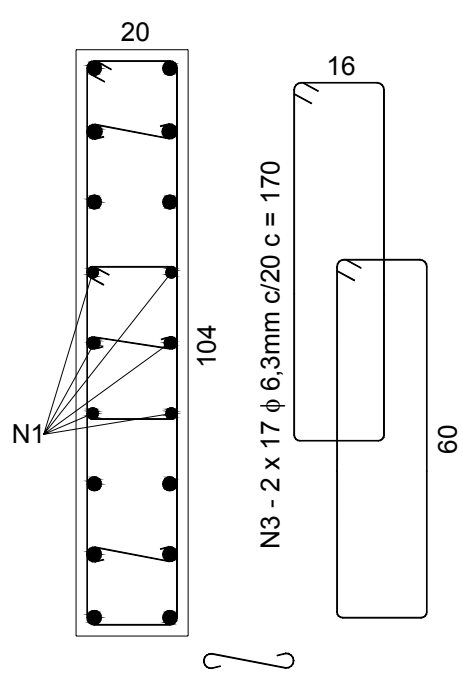

$\mathrm{N} 4-3 \times 17 \phi 6,3 \mathrm{~mm} \mathrm{c} / 20 \mathrm{c}=35$

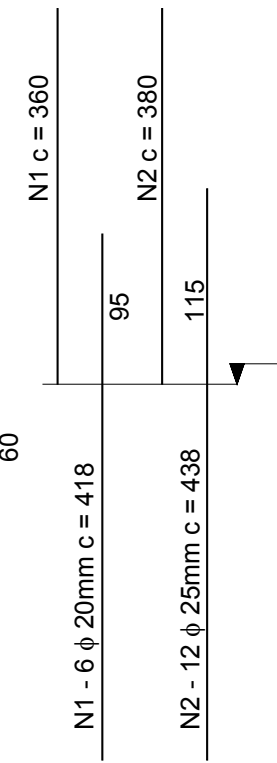

(a)

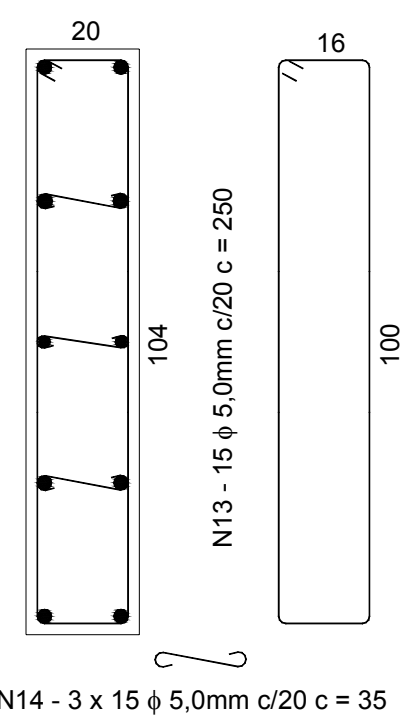

(c)

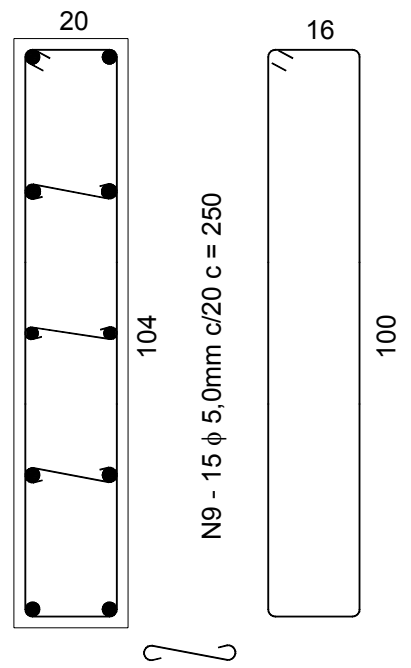

$\mathrm{N} 10-3 \times 15 \phi 5,0 \mathrm{~mm} \mathrm{c} / 20 \mathrm{c}=35$

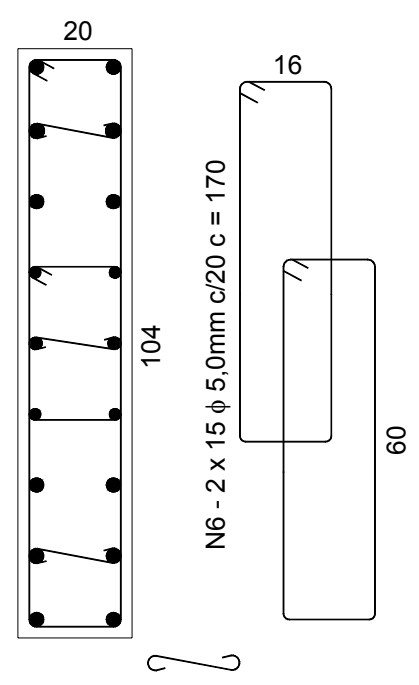

$\mathrm{N} 7-3 \times 15 \phi 5,0 \mathrm{~mm} \mathrm{c} / 20 \mathrm{c}=35$

(b)

$\checkmark$ Face superior da viga;

Medidas em centímetros ( $\mathrm{cm})$.

Figura 5.3 - Disposição das armaduras longitudinal e transversal do pilar P31:

(a) Ligação entre o $1^{\circ}$ e $2^{\circ}$ pavimento-tipo; (b) Ligação entre o $4^{\circ}$ e $5^{\circ}$ pavimento-tipo;

(c) Ligação entre o $6^{\circ}$ e $7^{\circ}$ pavimento-tipo. 


\subsection{Procedimentos de concepção e análise dos modelos numéricos}

Em linhas gerais, a ancoragem das barras das armaduras longitudinais da viga foi verificada considerando as vigas solicitadas até o mais próximo do estado limite último, mantendo o pilar submetido à ação da força normal solicitante de cálculo.

Os elementos de análise foram o momento de fissuração e a força de tração $\left(R_{s t}\right)$ na seção da face de ligação da viga com o pilar, o comportamento das armaduras longitudinais da viga ao longo do trecho das barras ancoradas discutido também em função das tensões e deformações máximas em determinados pontos e a influência da força normal advinda do pilar.

Para possibilitar uma análise comparativa com os métodos analíticos de cálculo dos parâmetros avaliados, as vigas V341 e V325 foram admitidas como sendo duplamente armadas, no sentido de armadas duas vezes. Isso significa que a determinação da área da armadura longitudinal superior e inferior é independente uma da outra.

Logo, em vistas a obter respostas mais representativas, os modelos numéricos foram concebidos com algumas simplificações que de certa maneira alteraram a configuração original dos modelos físicos, mas que não comprometeram a melhor performance desses. Essas simplificações estão relacionadas à disposição das barras da armadura longitudinal da viga segundo a Figura 5.4.

Como se mostra na Figura 5.4, consideraram-se a armadura longitudinal superior disposta em apenas uma camada, a influência da armadura de pele foi desconsiderada porquanto sua função estrutural é de evitar fissuração exagerada em condições de serviço e apenas a armadura tracionada foi ancorada no pilar, tendo a armadura comprimida a função de porta-estribos.

O ponto de aplicação da força $(F)$ foi estabelecido em função da armadura tracionada. Assim, sendo a armadura tracionada a superior, a força foi aplicada de cima para baixo no topo da viga. No caso contrário, em que a armadura tracionada foi a inferior, a força foi aplicada de baixo para cima na base da viga.

Quanto aos apoios laterais do pilar que restringem o deslocamento horizontal, esses foram combinados, conforme consta na Figura 5.4, com a finalidade de gerar um binário nas extremidades do pilar que garantissem o equilíbrio do nó. 


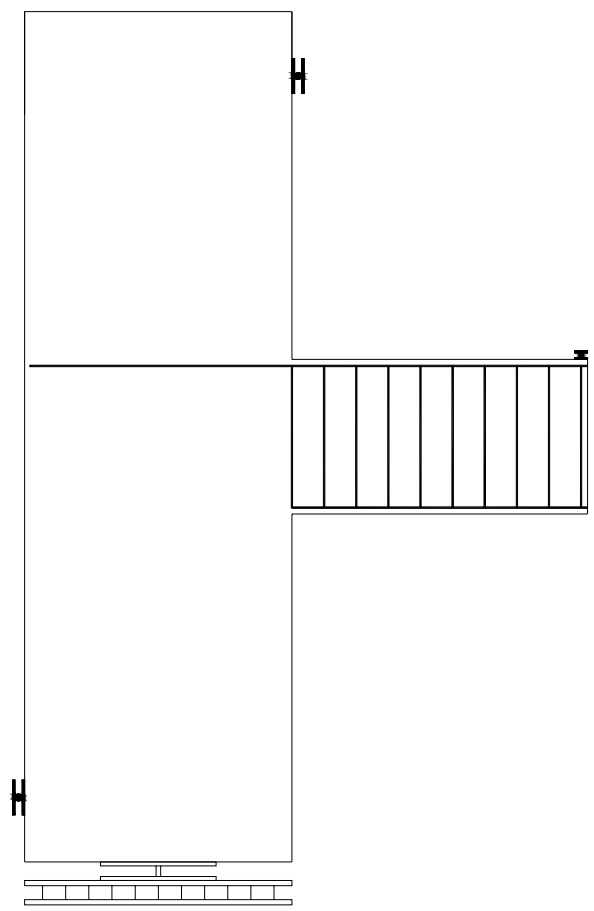

(a)

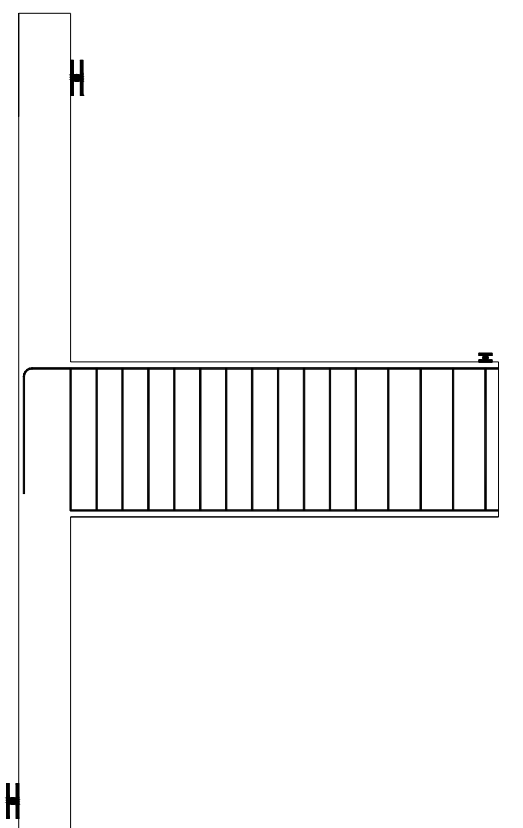

(c)

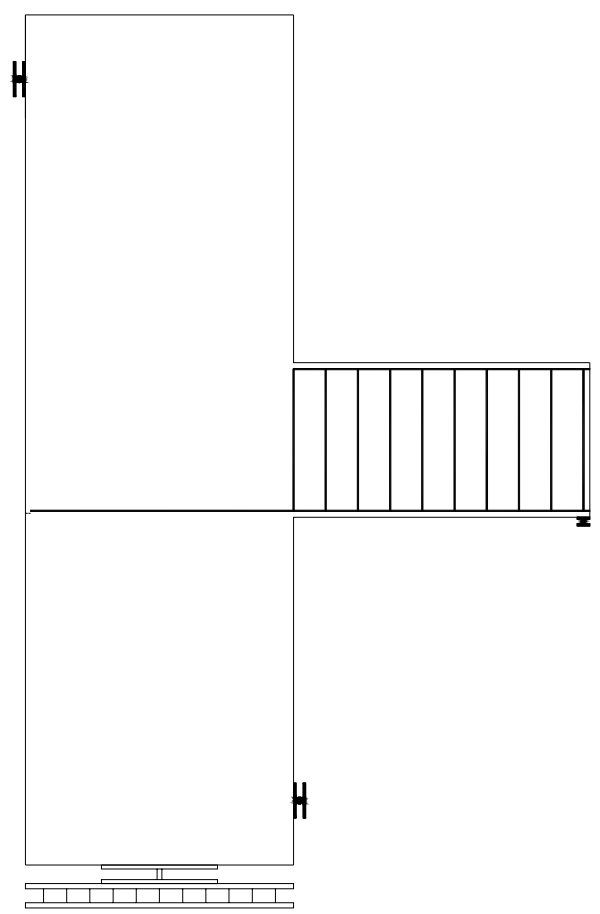

(b)

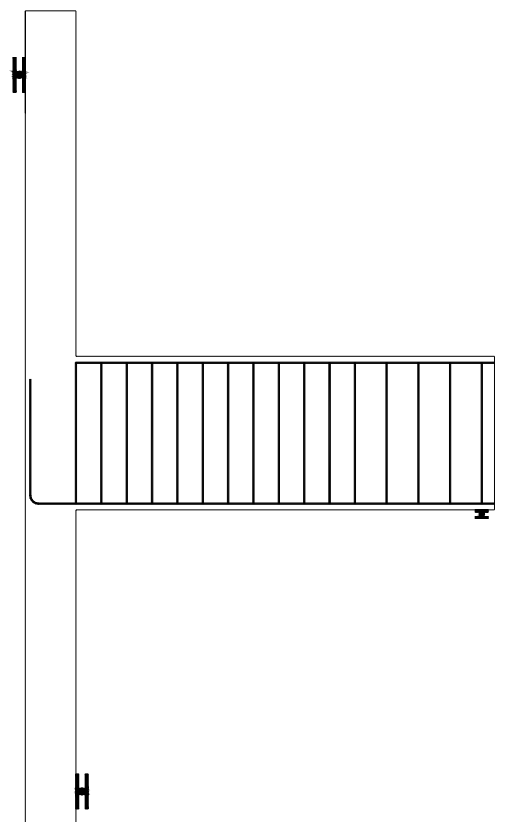

(d)

Figura 5.4 - Simplificações quanto à disposição das armaduras longitudinais das vigas.

Mediante as condições de equilíbrio e compatibilidade, foram verificados os momentos resistentes de cálculo para cada situação e, por meio destes, foram estimadas as forças concentradas últimas na extremidade das vigas. Assumiram-se, nos modelos numéricos, forças a aplicar menores que as forças últimas (ver Tabela 5.1). 
Tabela 5.1 - Momento resistente de cálculo, força última correspondente e força aplicada nas vigas.

\begin{tabular}{c|c|c|c|c}
\hline Viga & Armadura & $\begin{array}{c}M_{R d} \\
(\mathrm{kN} \cdot \mathrm{cm})\end{array}$ & $\begin{array}{c}F_{\text {ultima }} \\
(\mathrm{kN})\end{array}$ & $\begin{array}{c}F_{\text {aplicada }} \\
(\mathrm{kN})\end{array}$ \\
\hline 325 & $L S$ & 10521,60 & 61,47 & 61,00 \\
325 & $L I$ & 8392,10 & 53,51 & 53,00 \\
341 & $L S$ & 10521,60 & 59,24 & 59,00 \\
341 & $L I$ & 8392,10 & 52,01 & 52,00 \\
\hline
\end{tabular}

$L S$ é armadura longitudinal superior;

$L I$ é armadura longitudinal inferior.

No que diz respeito à força normal atuante no pilar P31, essa foi definida em três intensidades já que foram avaliados três modelos para cada ligação. Por questões do programa em uso, a força normal foi substituída por uma pressão equivalente distribuída na face superior do pilar e calculada pela razão entre a força normal e a área bruta da seção transversal do elemento (ver Tabela 5.2).

A força normal atuante no pilar foi determinada pela análise de esforços da estrutura contabilizando as ações convenientemente cabíveis, inclusive a ação do vento, e a interação entre os pórticos.

É importante esclarecer que as pressões aplicadas nos modelos foram uniformizadas porque as diferenças não são significativas e também não havia sentido admitir o pilar submetido a duas forças normais. Assim como no caso da força concentrada nas vigas, optou-se por adotar menores valores por questões de convergência nas simulações.

Tabela 5.2 - Valores da força normal e da pressão aplicada nos modelos das ligações.

\begin{tabular}{c|c|c|c|c}
\hline Modelo & Ligação & $\begin{array}{c}\text { Força normal de cálculo } \\
(\mathrm{kN})\end{array}$ & $\begin{array}{c}\text { Pressão de cálculo } \\
\left(\mathrm{kN} / \mathrm{cm}^{2}\right)\end{array}$ & $\begin{array}{c}\text { Pressão aplicada } \\
\left(\mathrm{kN} / \mathrm{cm}^{2}\right)\end{array}$ \\
\hline 1 & \multirow{2}{*}{ V325-P31 } & 3018 & 1,45 & 1,45 \\
2 & 2080 & 1,00 & 1,00 \\
3 & & 1449 & 0,70 & 0,70 \\
\hline 1 & \multirow{2}{*}{ V341-P31 } & 3082 & 1,48 & 1,45 \\
2 & & 2107 & 1,01 & 1,00 \\
3 & & 1458 & 0,70 & 0,70 \\
\hline
\end{tabular}

Modelo 1 é a ligação entre $1^{\circ} \mathrm{e} 2^{\circ}$ pavimento-tipo;

Modelo 2 é a ligação entre $4^{\circ} \mathrm{e} 5^{\circ}$ pavimento-tipo;

Modelo 3 é a ligação entre $6^{\circ} \mathrm{e} 7^{\circ}$ pavimento-tipo.

Na Tabela 5.3 segue os parâmetros relativos às propriedades dos materiais utilizados nas análises de acordo com os dados fornecidos no projeto estrutural. 
Tabela 5.3 - Propriedades dos materiais das ligações V325-P31 e V341-P31.

\begin{tabular}{c|c|c|c}
\hline Material & Propriedade & Unidade & Valor \\
\hline & $f_{c c, \text { máx }}$ & $\mathrm{kN} / \mathrm{cm}^{2}$ & $-1,22$ \\
& $f_{c c, u}$ & $\mathrm{kN} / \mathrm{cm}^{2}$ & $-1,21$ \\
& $\varepsilon_{c c}$ & - & $-0,0035$ \\
& $\varepsilon_{c c, u}$ & - & $-0,002$ \\
Concreto & $f_{c t}$ & $\mathrm{kN} / \mathrm{cm}^{2}$ & 0,11 \\
C-20 & $\alpha \cdot f_{c t d}$ & $\mathrm{kN} / \mathrm{cm}^{2}$ & 0,08 \\
& $v$ & - & 0,20 \\
& $\gamma_{c}$ & $\mathrm{kN} / \mathrm{cm}^{3}$ & $2,5 \cdot 10^{-5}$ \\
& $G_{F}$ & $\mathrm{kN} \cdot \mathrm{cm}^{2} / \mathrm{cm}^{2}$ & $5,95 \cdot 10^{-4}$ \\
& $E_{c i}$ & $\mathrm{kN} / \mathrm{cm}^{2}$ & 2504,40 \\
\hline Aço & $f_{y}$ & $\mathrm{kN} / \mathrm{cm}^{2}$ & 43,50 \\
CA-50 & $\varepsilon_{y, \max }$ & - & 0,01 \\
& $v$ & - & 0,30 \\
& $\gamma_{s}$ & $\mathrm{kN} / \mathrm{cm}^{3}$ & $7,85 \cdot 10^{-5}$ \\
& $E_{s}$ & $\mathrm{kN} / \mathrm{cm}^{2}$ & 21000 \\
\hline
\end{tabular}

Em relação à definição da malha e discretização das superfícies de concreto e das barras de aço, foram adotados os elementos 2-D solid com oito nós e truss com três nós, respectivamente. As razões que motivaram a escolha de tais elementos, bem como outras hipóteses essenciais para a geração adequada dos modelos são semelhantes àquelas que foram assumidas e explanadas na simulação numérica apresentada no capítulo anterior.

Para a avaliação do trecho ancorado das barras das armaduras longitudinais da viga, foram escolhidos alguns pontos conforme exposto na Figura 5.5. Neles, foi coletada a evolução da tensão, deformação e força de tração na direção do eixo das barras ao longo de toda história do carregamento.

Observando a Figura $5.5 \mathrm{~b}$, optou-se por manter as emendas das barras traspassadas justapostas às barras da armadura longitudinais do pilar da mesma maneira que na ligação viga-pilar BCJ2 feita por Ortiz (1993), visto que os resultados obtidos na simulação numérica foram plausíveis conforme foi discutido.

Essa opção foi adotada porque no projeto estrutural não havia uma indicação ou detalhamento das armaduras na região da ligação entre o pilar e a viga. 


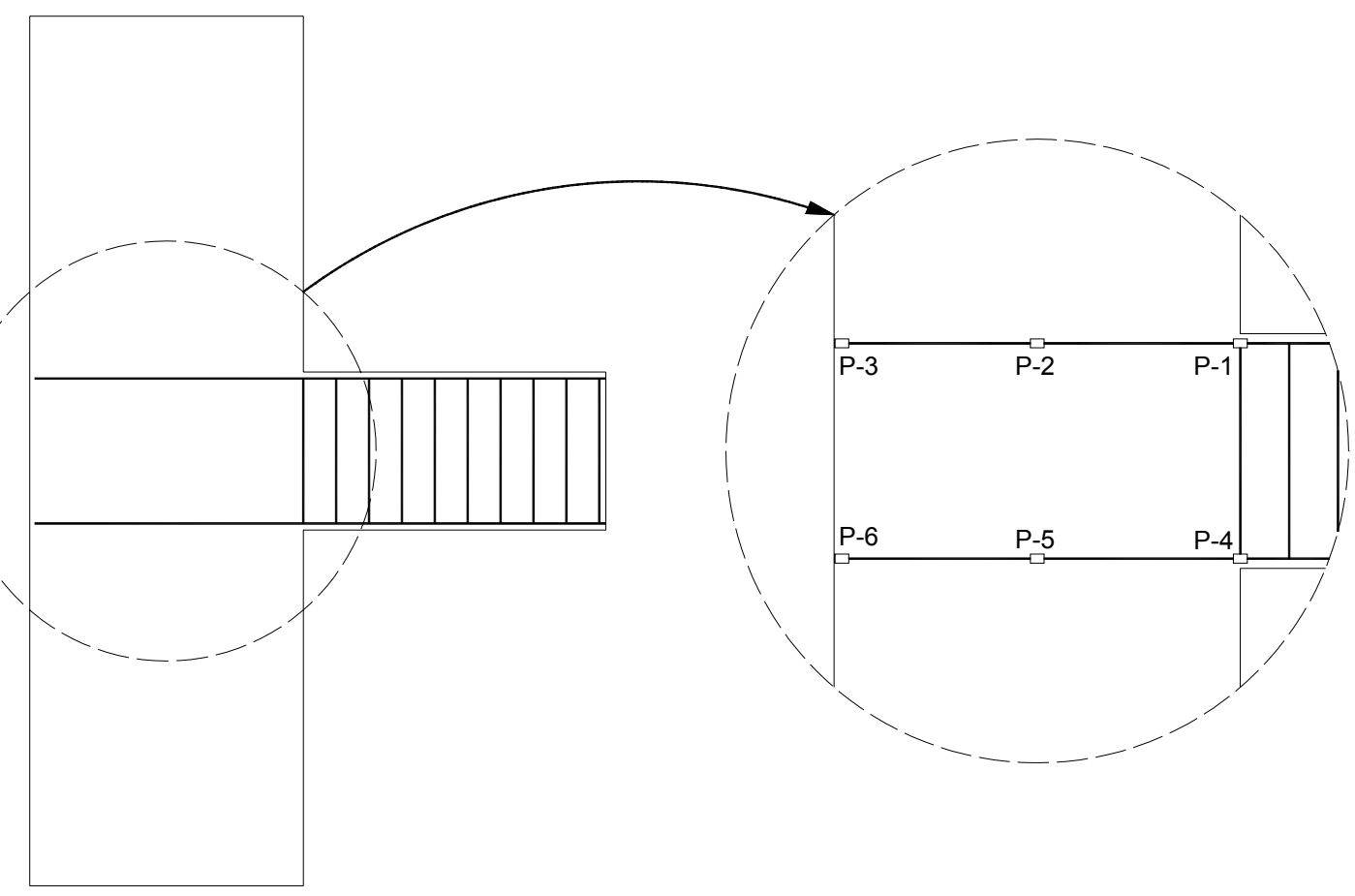

(a)

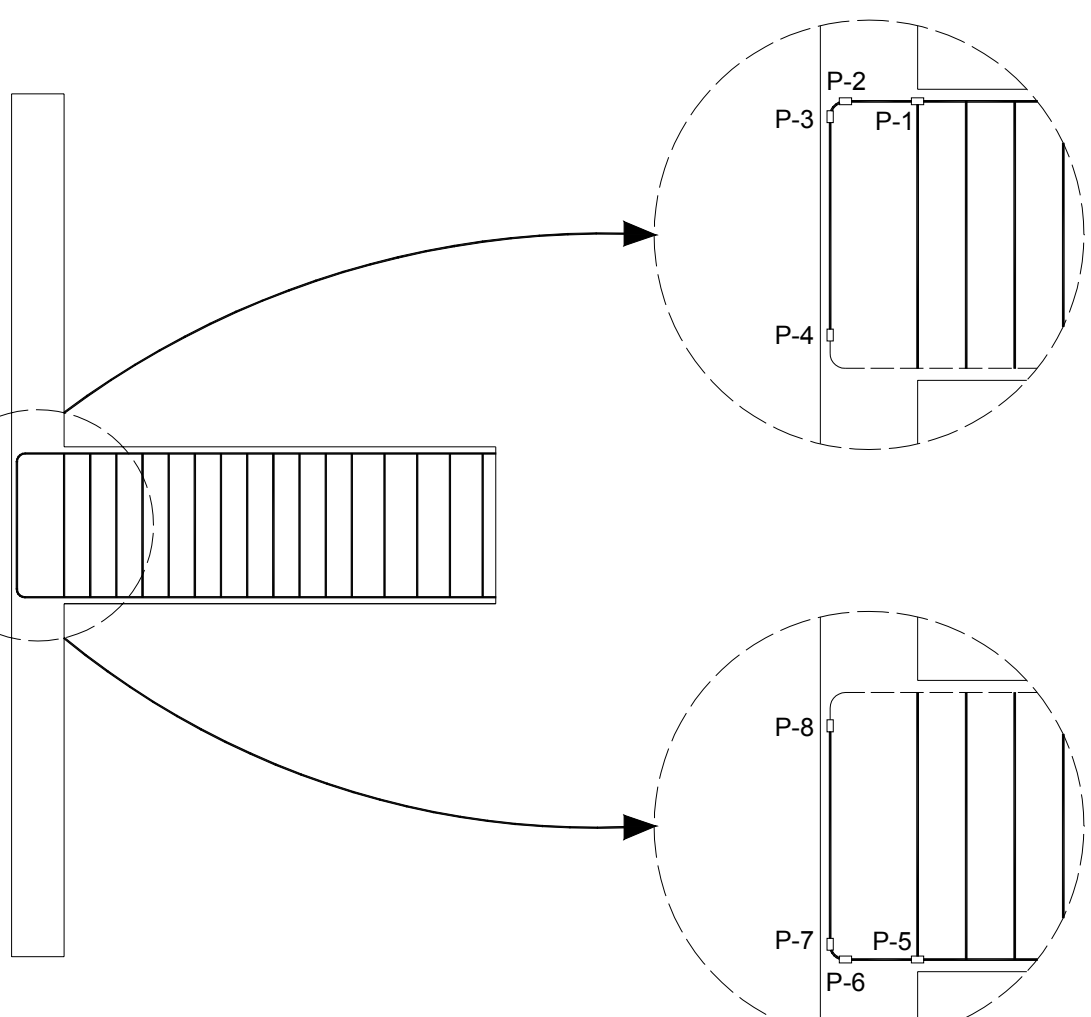

(b)

Figura 5.5 - Pontos de medição na armadura longitudinal da viga:

(a) Ligação V325-P31; (b) Ligação V341-P31. 


\subsection{Resultados e discussões}

\subsubsection{Ligação V325-P31}

\subsubsection{Armadura superior}

Para a simulação dos três modelos da ligação V325-P31 foram adotados os mesmos critérios de convergência e de aplicação de carga. $O$ critério de convergência foi o de deslocamento, com a tolerância de $5 \%$, utilizando o método iterativo completo de Newton.

$\mathrm{Na}$ avaliação da armadura superior, o modelo I atingiu a total convergência com 61 passos de carga, enquanto que os modelos II e III só alcançaram tal propósito com 70 passos de carga.

A discussão se inicia com a análise do comportamento das barras na região nodal para a qual foram concebidos diagramas que relacionam o momento de cálculo na viga versus deformação durante a aplicação dos carregamentos nos pontos P-1, P-2 e P3 (ver Figura 5.6, Figura 5.7 e Figura 5.8, respectivamente).

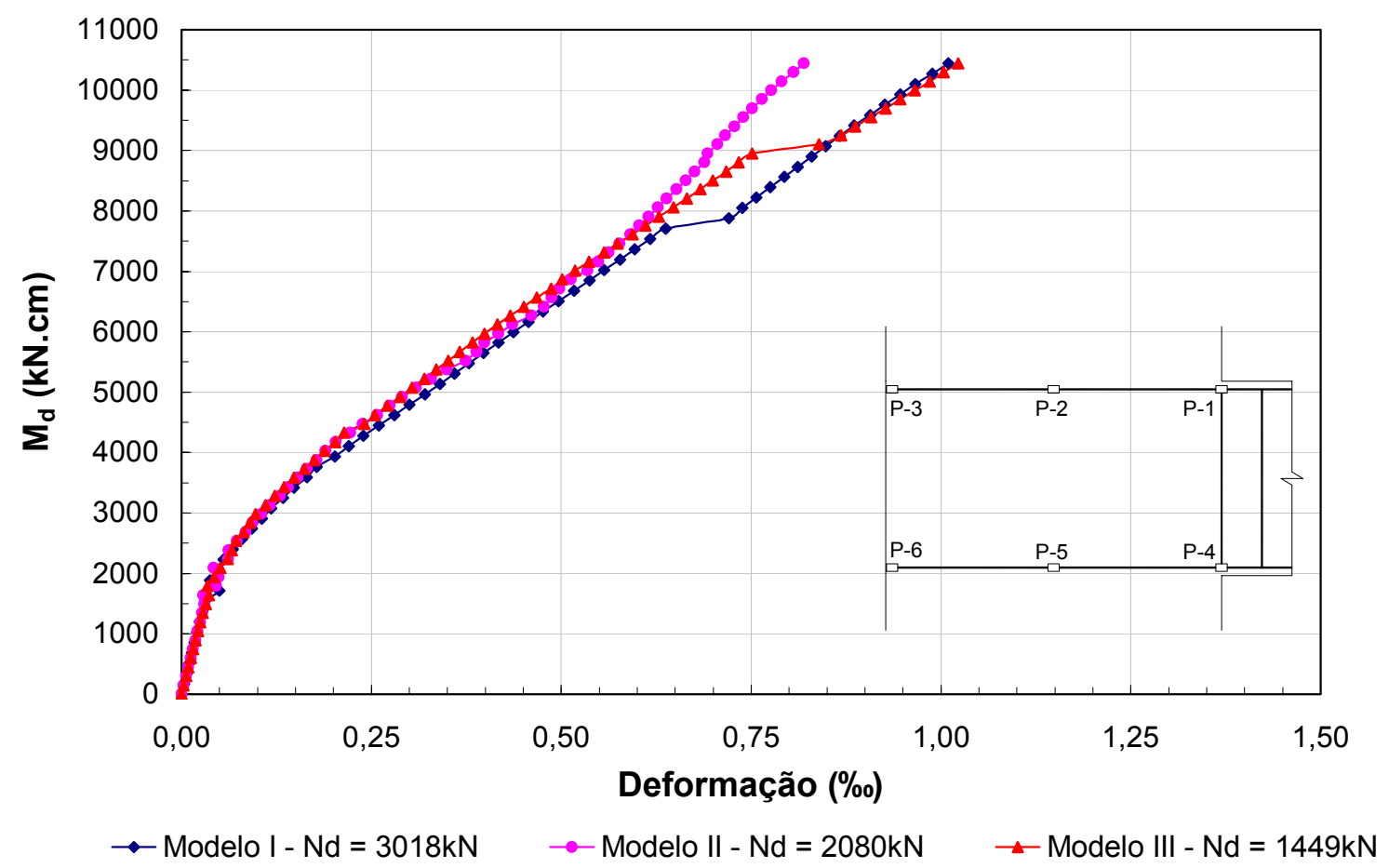

Figura 5.6 - Diagrama momento fletor no eixo do apoio da viga V325 versus deformação no ponto P-1. 


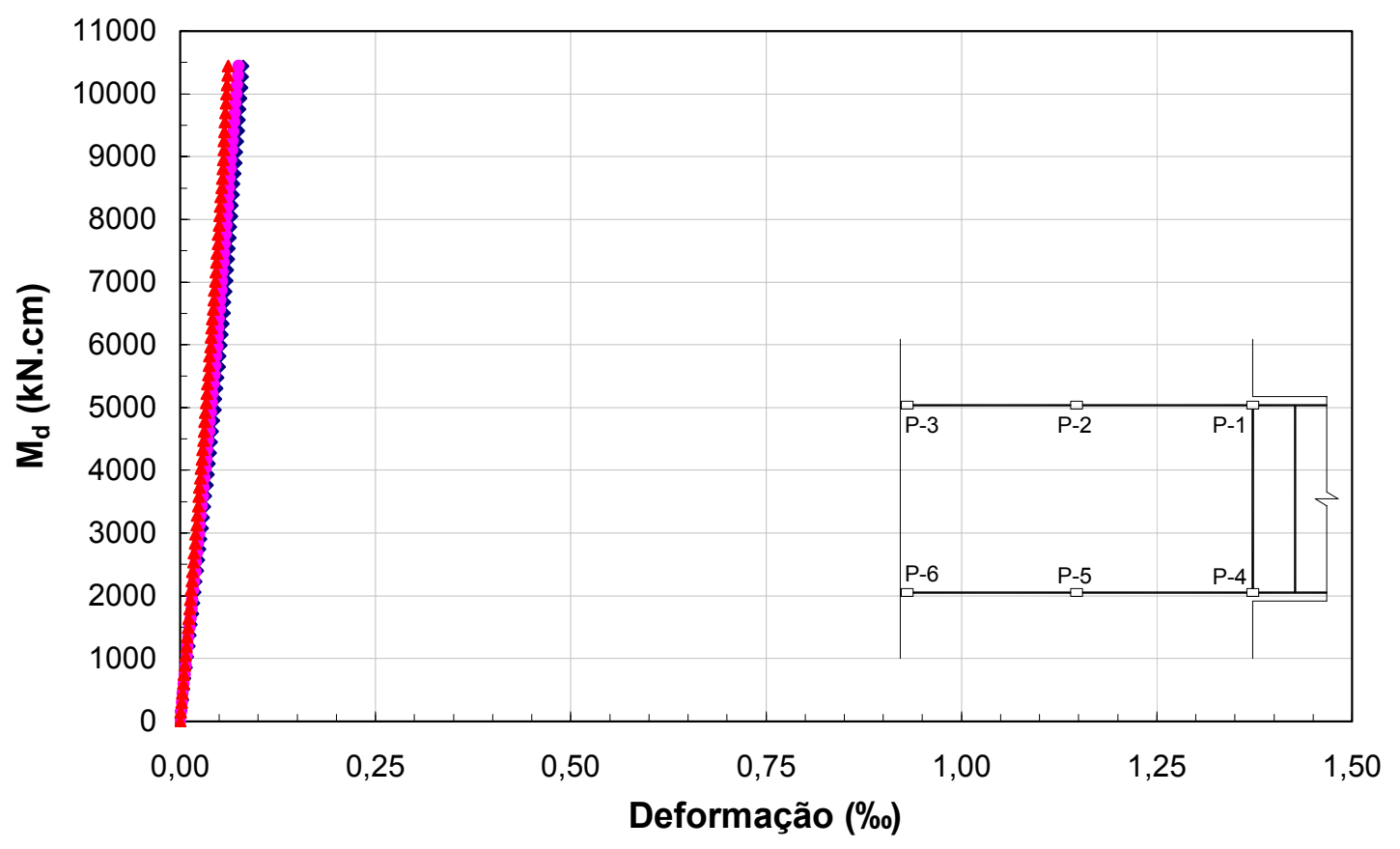

$\rightarrow-$ Modelo I - Nd $=3018 \mathrm{kN} \quad \rightarrow$ Modelo II $-\mathrm{Nd}=2080 \mathrm{kN} \quad \neg$ Modelo III $-\mathrm{Nd}=1449 \mathrm{kN}$

Figura 5.7 - Diagrama momento fletor no eixo do apoio da viga V325 versus deformação no ponto P-2.

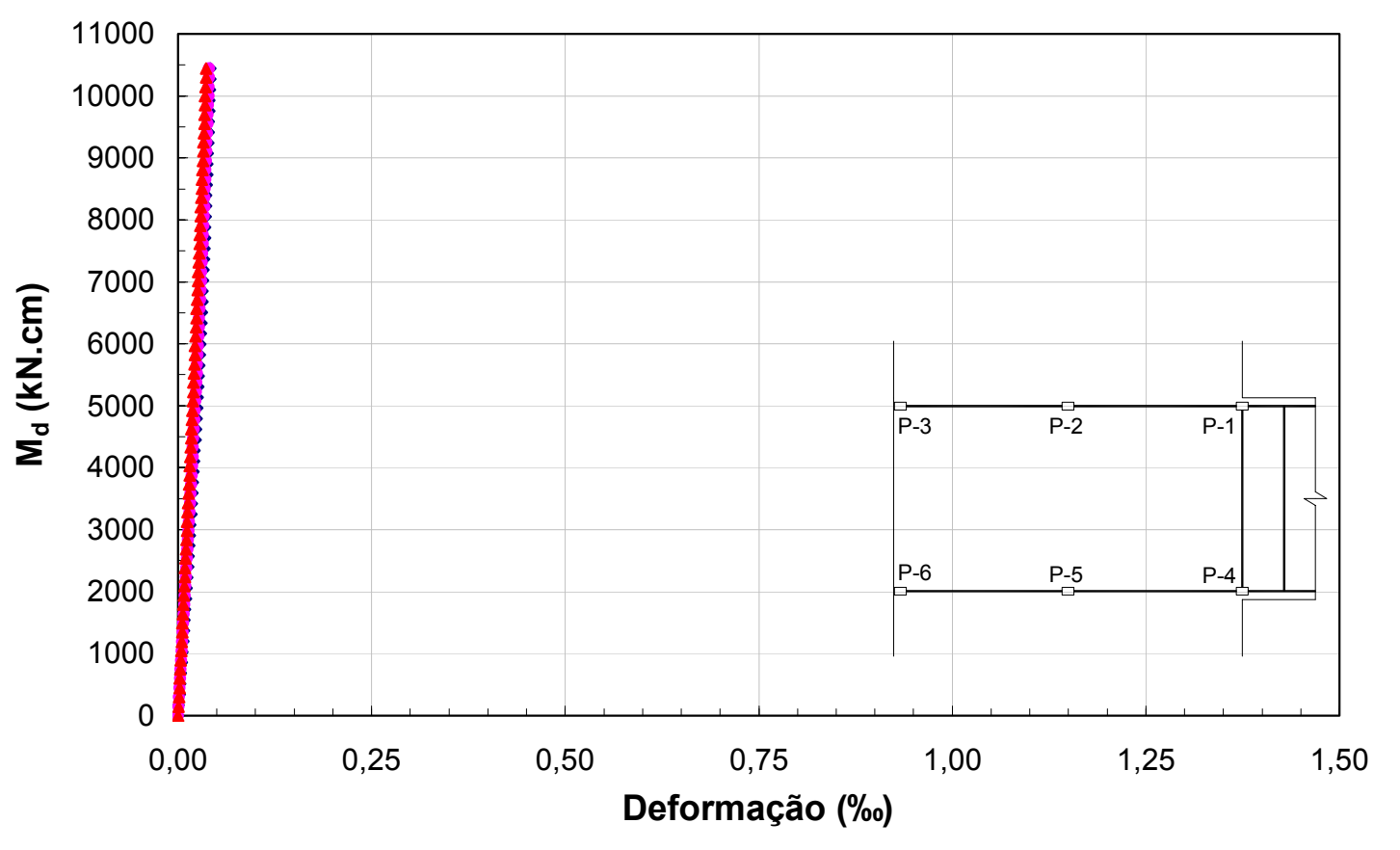

$\rightarrow$ Modelo I - Nd $=3018 \mathrm{kN} \quad \rightarrow$ Modelo II $-\mathrm{Nd}=2080 \mathrm{kN} \quad \rightarrow$ Modelo III $-\mathrm{Nd}=1449 \mathrm{kN}$

Figura 5.8 - Diagrama momento fletor no eixo do apoio da viga V325 versus deformação no ponto P-3. 
De acordo com o que se mostra na Figura 5.6, o momento de fissuração, verificado na seção na qual a viga é mais solicitada, está compreendido no intervalo $2000 \mathrm{kN} \cdot \mathrm{cm} \leq M_{r} \leq 2500 \mathrm{kN} \cdot \mathrm{cm}$ para os três modelos. A ratificação dessa resposta é feita por meio da sua comparação com a expressão aproximada sugerida pela NBR 6118:2003 para o cálculo desse parâmetro.

A norma brasileira prescreve que o momento de fissuração pode ser estimado segundo a eq.(5.1):

$$
M_{r}=\frac{\alpha \cdot f_{c t} \cdot I_{c}}{y_{t}}
$$

Em que, neste caso:

$\alpha$ é o fator que correlaciona aproximadamente a resistência à tração na flexão com a resistência à tração direta. Para as peças de seções retangulares, $\alpha=1,5$;

$y_{t}$ é a distância do centro de gravidade da seção bruta à fibra mais tracionada;

$I_{c}$ é o momento de inércia da seção bruta de concerto.

$f_{c t}$ é a resistência direta do concreto. Para determinação do momento de fissuração deve ser usado o $f_{c t k \text {,inf }}\left(0,21 \cdot f_{c k}^{2 / 3}\right)$ no estado limite de formação de fissura.

Com base nessas informações, o momento de fissuração da viga V325 é:

$$
M_{r}=\frac{\alpha \cdot f_{c t} \cdot I_{c}}{y_{t}}=\frac{1,5 \cdot \frac{0,21 \cdot 20^{2 / 3}}{10} \cdot \frac{14 \cdot 60^{3}}{12}}{\frac{60}{2}}=1949,59 \mathrm{kN} \cdot \mathrm{cm}
$$

No que se refere à transferência de tensão do aço para o concreto, os resultados foram bastante razoáveis visto que as deformações reduziram significativamente à medida que as seções transversais das barras da viga se afastaram da face pilar.

Quanto à força normal, embora não seja tanto expressiva nas situações analisadas, é perceptível que sua influência elevou as tensões e, conseqüentemente, as deformações nas barras.

No ponto P-1, ponto na seção do apoio, a evolução das deformações foi quase idêntica nos três modelos até grande parte do carregamento. Próximo à ruína da ligação, 
houve certa dispersão das curvas que descaracterizaram o efeito majorante da força normal.

Todavia, os pontos P-2 e P-3, que apresentaram um comportamento praticamente linear ao longo de toda solicitação, foram mais deformáveis com a elevação da força normal.

$\mathrm{Na}$ avaliação das tensões e deformações no instante da ruína, a Tabela 5.4 contém essas variáveis registradas nos pontos de análise.

De uma maneira geral, os resultados encontrados foram consistentes apesar de apresentar algumas incoerências sob o ponto de vista comparativo.

Tabela 5.4 - Valores máximos das tensões e deformações nos pontos analisados na armadura superior da viga V325.

\begin{tabular}{c|c|c|c}
\hline Modelo & Posição & $\sigma_{s}\left(k N / \mathrm{cm}^{2}\right)$ & $\varepsilon_{s}(\%)$ \\
\hline \multirow{3}{*}{ I } & P-1 & 21,21 & 1,01 \\
& P-2 & 1,69 & 0,08 \\
& P-3 & 0,87 & 0,04 \\
\hline \multirow{2}{*}{ II } & P-1 & 17,21 & 0,82 \\
& P-2 & 1,58 & 0,08 \\
& P-3 & 0,85 & 0,04 \\
\hline \multirow{3}{*}{ III } & P-1 & 21,48 & 1,02 \\
& P-2 & 1,29 & 0,06 \\
& P-3 & 0,77 & 0,04 \\
\hline
\end{tabular}

Na Tabela 5.5 consta a análise entre a força de tração nas barras da armadura longitudinal superior da viga determinada nos modelos numéricos e pelo método analítico.

A força de tração foi calculada analiticamente segundo a eq.(5.2):

$$
R_{\text {st }, \text { sup }}=\frac{M_{S d, \text { face }}}{z}
$$

Em que $M_{S d, f a c e}$ é o momento solicitante de cálculo na face do apoio.

Nesta situação, o momento solicitante se confunde com o momento resistente $M_{R d, f a c e} . \operatorname{Logo}, M_{S d, f a c e}=M_{R d, f a c e}=7245,41 \mathrm{kN} \cdot \mathrm{cm}$. 
O braço de alavanca $(z)$ foi estimado como sendo $z=d-0,4 \cdot x$, onde $d$ é a altura útil da viga e $x$ é a posição da linha neutra. Neste caso, $x=15,51 \mathrm{~cm}$ e $d=55,75 \mathrm{~cm}$, e, por conseguinte, $z=49,55 \mathrm{~cm}$. Então, a força de tração a ancorar foi:

$$
R_{s t, \text { sup }}=\frac{M_{S d, \text { face }}}{z}=\frac{M_{R d, f a c e}}{z}=\frac{7245,41}{49,55}=146,22 \mathrm{kN}
$$

Dividindo pelo número barras que compõe a armadura longitudinal superior, tem-se:

$$
R_{s t, \text { sup }}=\frac{146,22}{4}=36,56 \mathrm{kN}
$$

Tabela 5.5 - Valores últimos da força de tração por barra da armadura superior da viga V325 na seção na face do apoio.

\begin{tabular}{c|c|c|c|c}
\hline \multirow{2}{*}{ Modelo } & Posição & $\begin{array}{c}R_{\text {st, sup, } \text { numérico }}(k N) \\
(1)\end{array}$ & $\begin{array}{c}R_{\text {st, sup, analitico }}(k N) \\
(2)\end{array}$ & $\frac{(1)}{(2)}$ \\
\hline I & \multirow{2}{*}{$\mathrm{P}-1$} & 26,04 & \multirow{2}{*}{36,56} & 0,71 \\
II & 21,12 & & 0,58 \\
III & & 26,37 & & 0,72 \\
\hline
\end{tabular}

Os resultados verificados para a força de tração determinada nos modelos numéricos variaram de $58 \%$ a $72 \%$ da força de tração calculada pelo método analítico. 


\subsubsection{Armadura inferior}

A verificação da ancoragem das barras da armadura longitudinal inferior da viga V325 seguiu os mesmos moldes que a da armadura superior. Nesses modelos, utilizouse o mesmo critério de convergência que o da análise da armadura superior. Os modelos I e II convergiram com as forças aplicadas em 60 passos de carga, enquanto que o modelo III com 53 passos de carga.

Em resumo, observando os diagramas momento fletor no eixo do apoio versus deformação nos pontos P-4, P-5 e P-6 (Figura 5.9, Figura 5.10 e Figura 5.11), vê-se que o comportamento da armadura inferior é bastante semelhante ao da armadura superior durante toda aplicação das cargas.

O que difere a armadura superior da inferior é apenas o número de barras que as compõem. Portanto, o momento de fissuração determinado pela recomendação da NBR 6118:2003, segundo a eq.(5.1), é igual, pois, esse parâmetro depende de variáveis que não se alteram com tal divergência. $\mathrm{O}$ momento de fissuração constatado numericamente foi satisfatório uma vez que seu valor se encontrou no mesmo intervalo que o da armadura superior $\left(2000 \mathrm{kN} \cdot \mathrm{cm} \leq M_{r} \leq 2500 \mathrm{kN} \cdot \mathrm{cm}\right)$ como se verifica na

Figura 5.9 que se refere ao ponto situado na seção de ligação com o pilar.

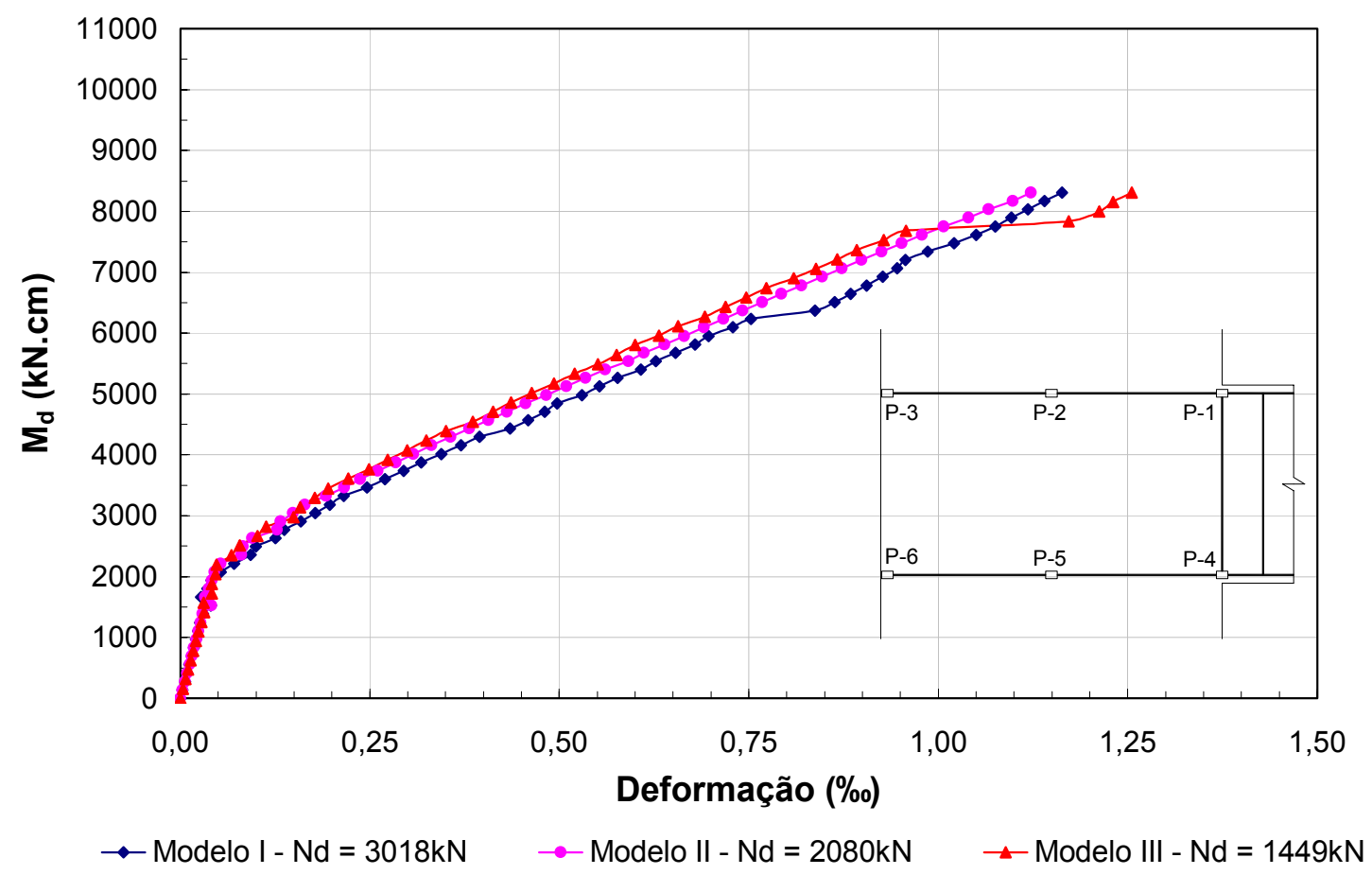

Figura 5.9 - Diagrama momento fletor no eixo do apoio da viga V325 versus deformação no ponto P-4. 


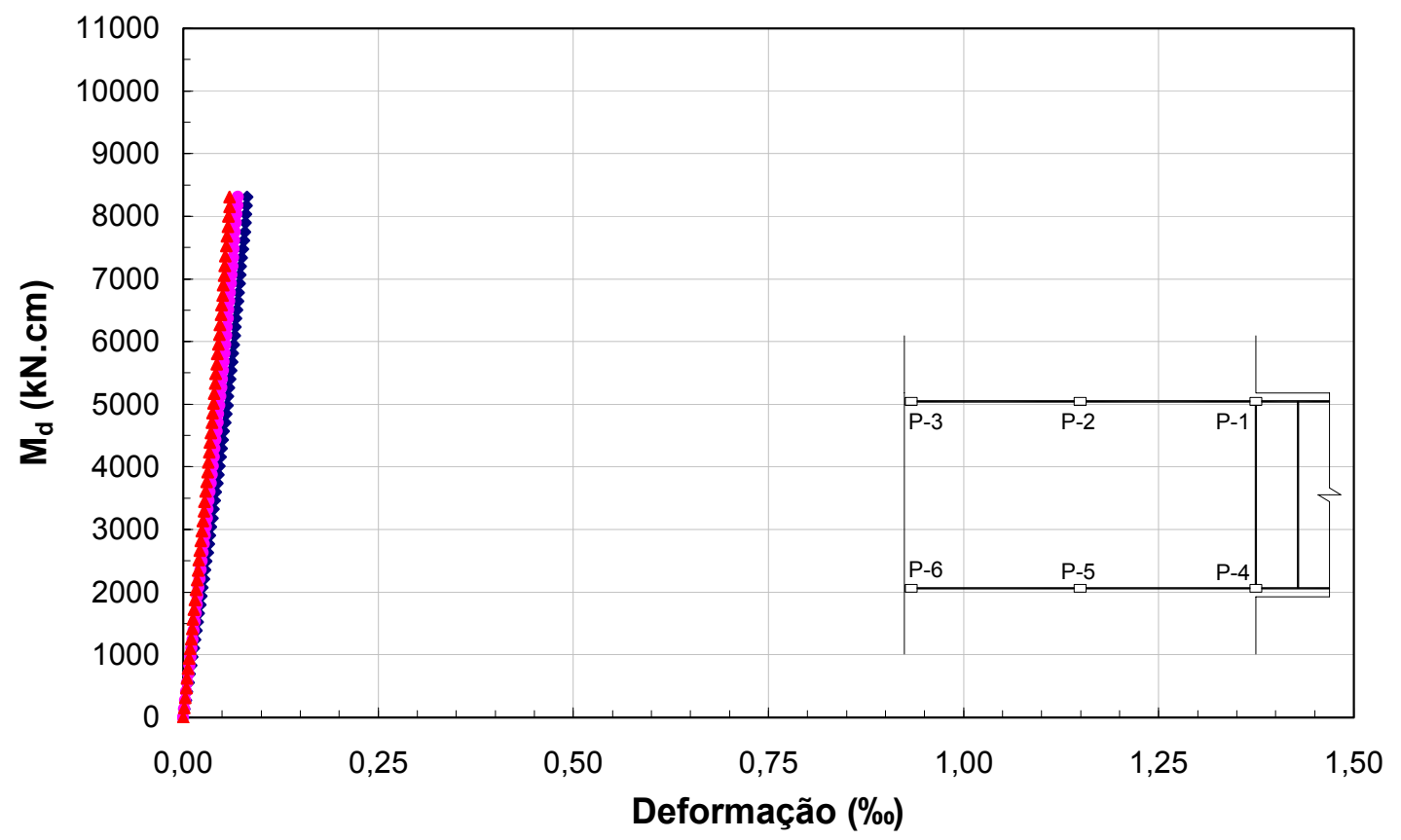

$\rightarrow$ Modelo I - Nd $=3018 \mathrm{kN} \rightarrow-$ Modelo II $-\mathrm{Nd}=2080 \mathrm{kN} \rightarrow$ Modelo III $-\mathrm{Nd}=1449 \mathrm{kN}$

Figura 5.10 - Diagrama momento fletor no eixo do apoio da viga V325 versus deformação no ponto P-5.

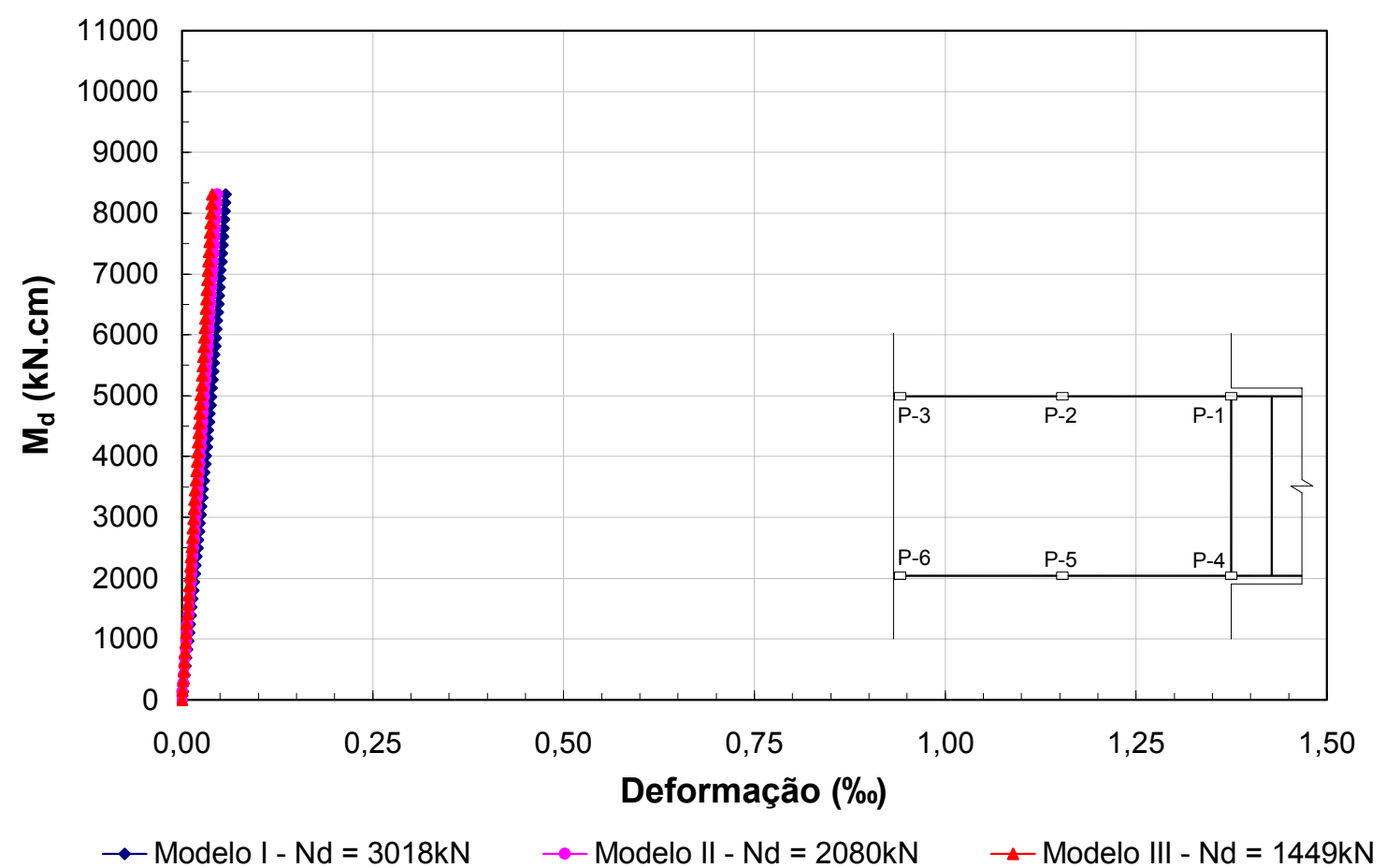

Figura 5.11 - Diagrama momento fletor no eixo do apoio da viga V325 versus deformação no ponto P-6. 
Os diagramas revelam de maneira clarividente a tendência de minoração das tensões e deformações nos pontos ao longo do trecho do ancorado da armadura longitudinal.

A pouca significância da força normal prevaleceu assim como na armadura superior. Sua presença foi mais contundente na seção mais próxima da face do apoio que coincide com a viga quando essa passou do estádio I para o II, ou seja, atingiu o momento de fissuração. Essa influência decaiu continuadamente ao passo que as seções adentraram no pilar.

As tensões e deformações máximas nos pontos P-4, P-5 e P-6 avaliadas nos três modelos são apresentados na Tabela 5.6.

Tabela 5.6 - Valores máximos das tensões e deformações nos pontos analisados na armadura inferior da viga V325.

\begin{tabular}{c|c|c|c}
\hline Modelo & Posição & $\sigma_{s}\left(k N / \mathrm{cm}^{2}\right)$ & $\varepsilon_{s}(\%)$ \\
\hline \multirow{2}{*}{ I } & P-4 & 24,43 & 1,16 \\
& P-5 & 1,73 & 0,08 \\
& P-6 & 1,20 & 0,06 \\
\hline \multirow{2}{*}{ II } & P-4 & 23,58 & 1,12 \\
& P-5 & 1,47 & 0,07 \\
& P-6 & 0,98 & 0,05 \\
\hline \multirow{3}{*}{ III } & P-4 & 26,36 & 1,26 \\
& P-5 & 1,25 & 0,06 \\
& P-6 & 0,84 & 0,04 \\
\hline
\end{tabular}

A comparação entre a força de tração a ancorar obtida pelo método analítico e os modelos numéricos está exibida na Tabela 5.7. Utilizando a eq.(5.2), a força de tração a ancorar da armadura longitudinal inferior $\left(R_{s t \text {,inf,analitico }}\right)$ foi determinada de acordo com os dados a seguir:

- $\quad M_{S d, f a c e}=M_{R d, f a c e}=5778,99 \mathrm{kN} \cdot \mathrm{cm}$;

$-\quad d=57,38 \mathrm{~cm}$

$-\quad x=12,41 \mathrm{~cm}$

- $\quad z=52,42 \mathrm{~cm}$. 
Logo, a força de tração a ancorar foi:

$$
R_{s t, \text { inf }}=\frac{M_{S d, \text { face }}}{z}=\frac{M_{R d, \text { face }}}{z}=\frac{5778,99}{52,42}=110,24 \mathrm{kN}
$$

Dividindo pelo número barras da armadura longitudinal inferior, tem-se:

$$
R_{s t, \text { inf }}=\frac{110,24}{3}=36,75 \mathrm{kN}
$$

Tabela 5.7 - Valores últimos da força de tração por barra da armadura inferior da viga

\begin{tabular}{|c|c|c|c|c|}
\hline Modelo & Posição & $\begin{array}{c}R_{s t, \text { inf }, \text { numérico }}(k N) \\
\text { (1) }\end{array}$ & $\begin{array}{c}R_{\text {st, inf, } \text {,analitico }}(k N) \\
\text { (2) }\end{array}$ & $\frac{(1)}{(2)}$ \\
\hline $\begin{array}{l}\text { I } \\
\text { II } \\
\text { III }\end{array}$ & P-4 & $\begin{array}{l}30,05 \\
29,00 \\
32,42\end{array}$ & 36,75 & $\begin{array}{l}0,82 \\
0,79 \\
0,88\end{array}$ \\
\hline
\end{tabular}
V325 na seção na face do apoio.

Os valores da força de tração alcançados por simulação numérica ficaram entre $79 \%$ e $88 \%$ daquele determinado pelo método analítico. Os resultados da armadura inferior referente a essa questão foram melhores que os da armadura superior. 


\subsubsection{Ligação V341-P31}

\subsubsection{Armadura superior}

Os modelos da ligação V341-P31 para a análise da armadura superior foram simulados obedecendo ao mesmo critério de convergência e tolerância que foram estabelecidos para os modelos da ligação V325-P31.

Entretanto, para o modelo I, que corresponde à ligação entre o $1^{\circ}$ e $2^{\circ}$ pavimento-tipo, conseguiu-se atingir aproximadamente 95,58\% das ações atuantes cuja intensidade foi conferida em 65 passos de carga. Para os modelos II e III, obteve-se êxito na aplicação plena das ações, com as cargas aplicadas em 65 passos para ambos.

Para os pontos $\mathrm{P}-1, \mathrm{P}-2, \mathrm{P}-3$ e $\mathrm{P}-4$ foram concebidos gráficos que relacionam o acréscimo de deformação durante a solicitação do pórtico e o momento fletor no eixo do pilar (ver Figura 5.12, Figura 5.13, Figura 5.14 e Figura 5.15).

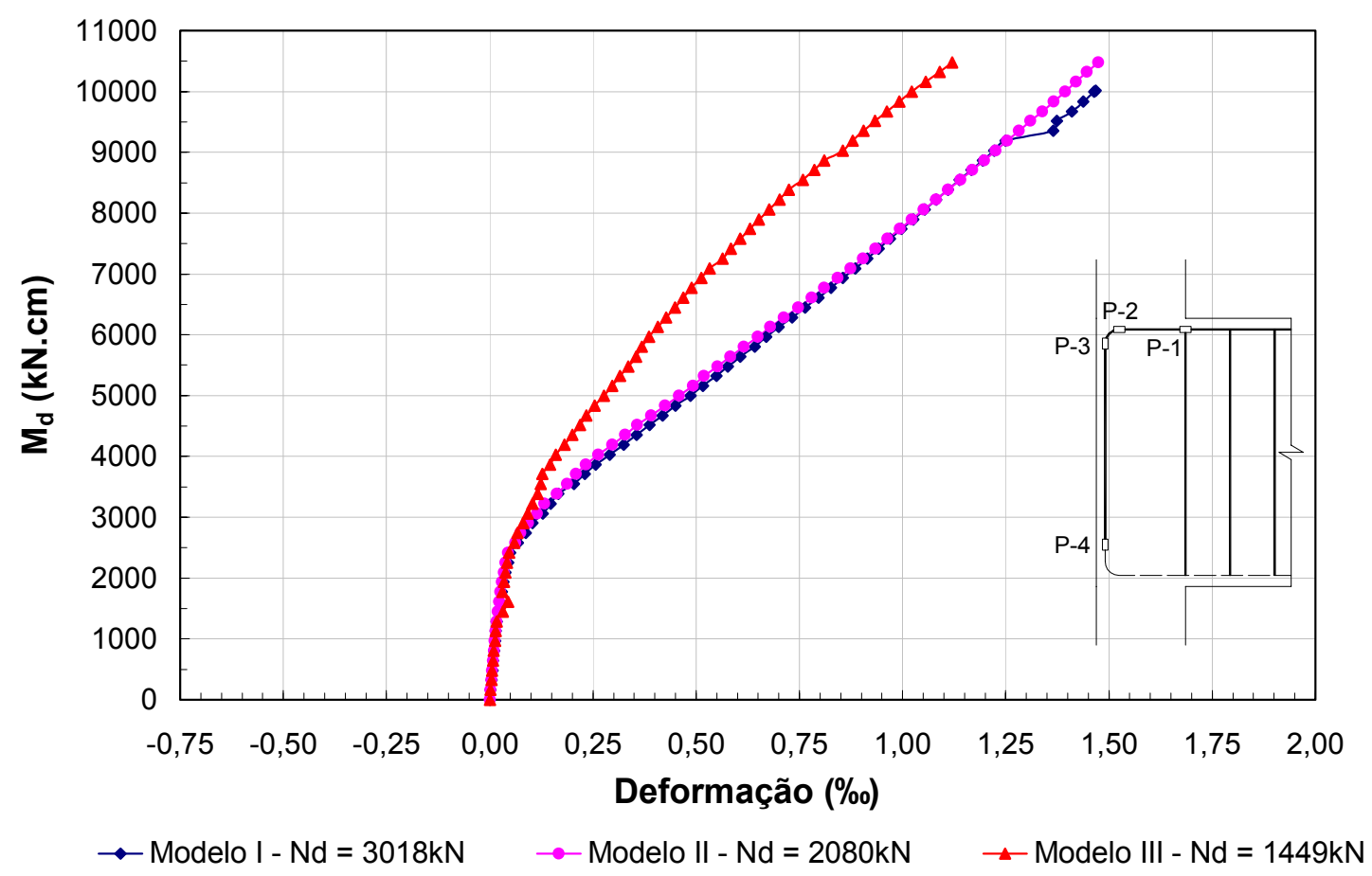

Figura 5.12 - Diagrama momento fletor no eixo do apoio da viga V341 versus deformação no ponto P-1. 


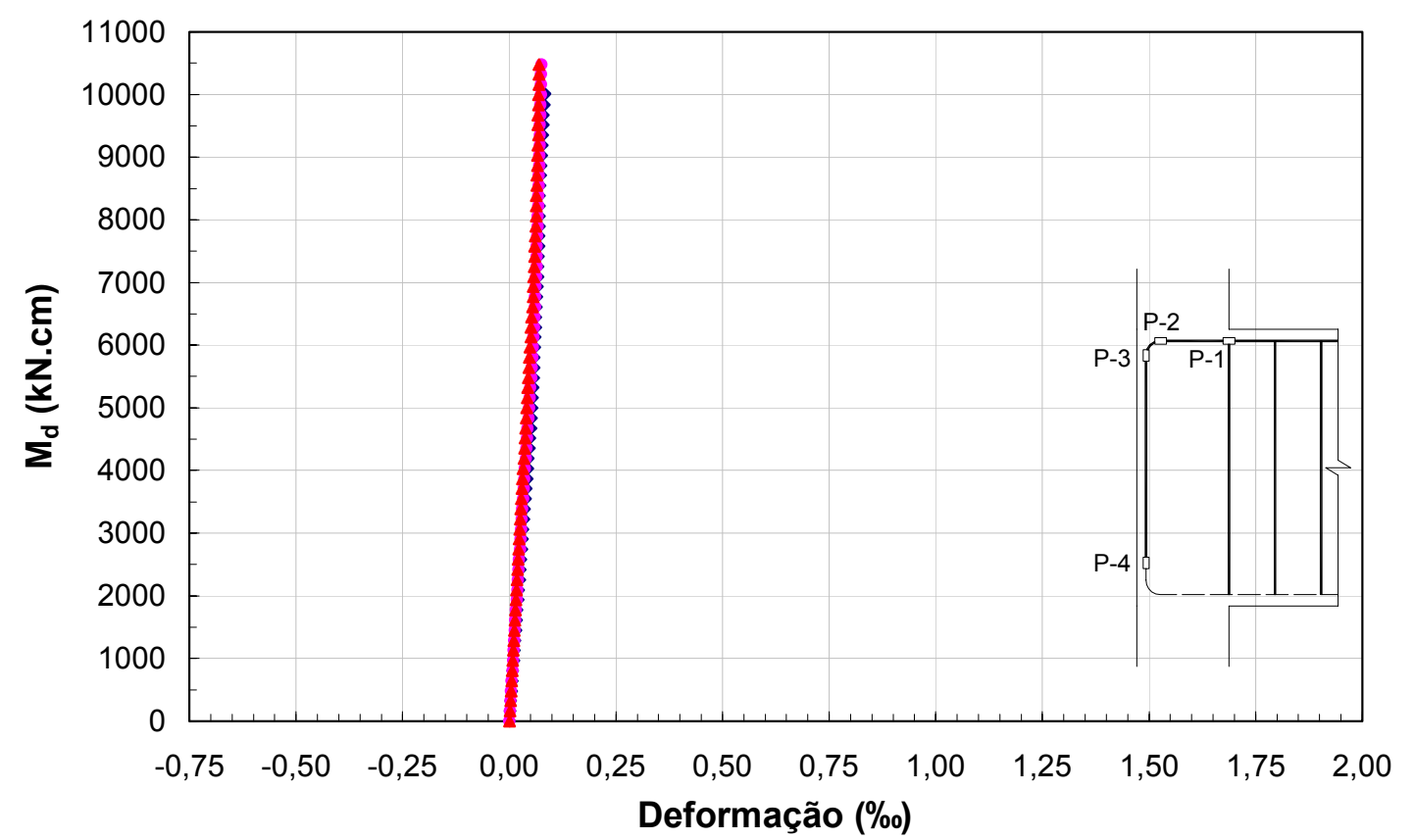

$\rightarrow-$ Modelo I - Nd $=3018 \mathrm{kN}$

$\rightarrow-$ Modelo II - Nd $=2080 \mathrm{kN}$

$\neg$ Modelo III $-\mathrm{Nd}=1449 \mathrm{kN}$

Figura 5.13 - Diagrama momento fletor no eixo do apoio da viga V341 versus deformação no ponto P-2.

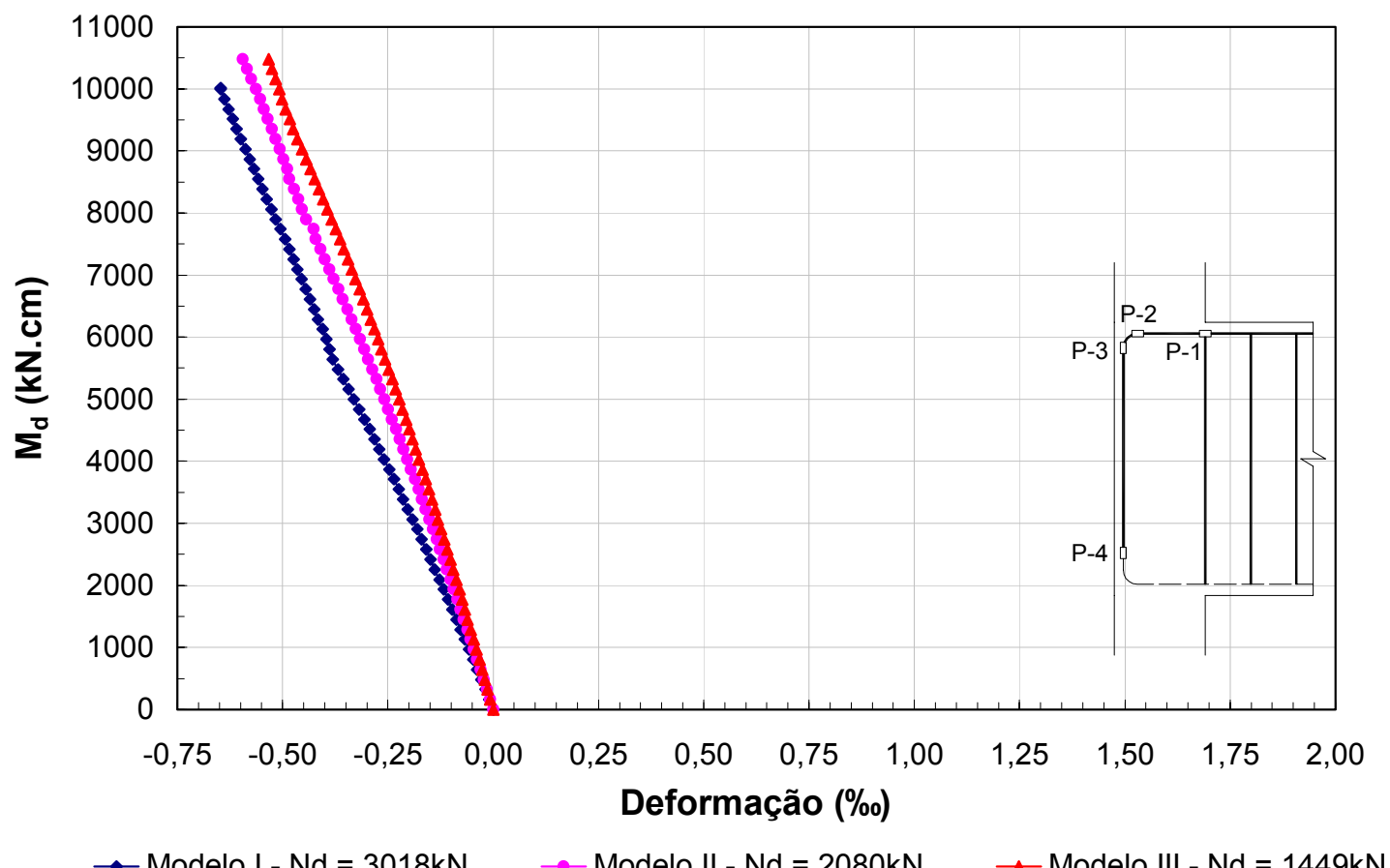

Figura 5.14 - Diagrama momento fletor no eixo do apoio da viga V341 versus deformação no ponto P-3. 


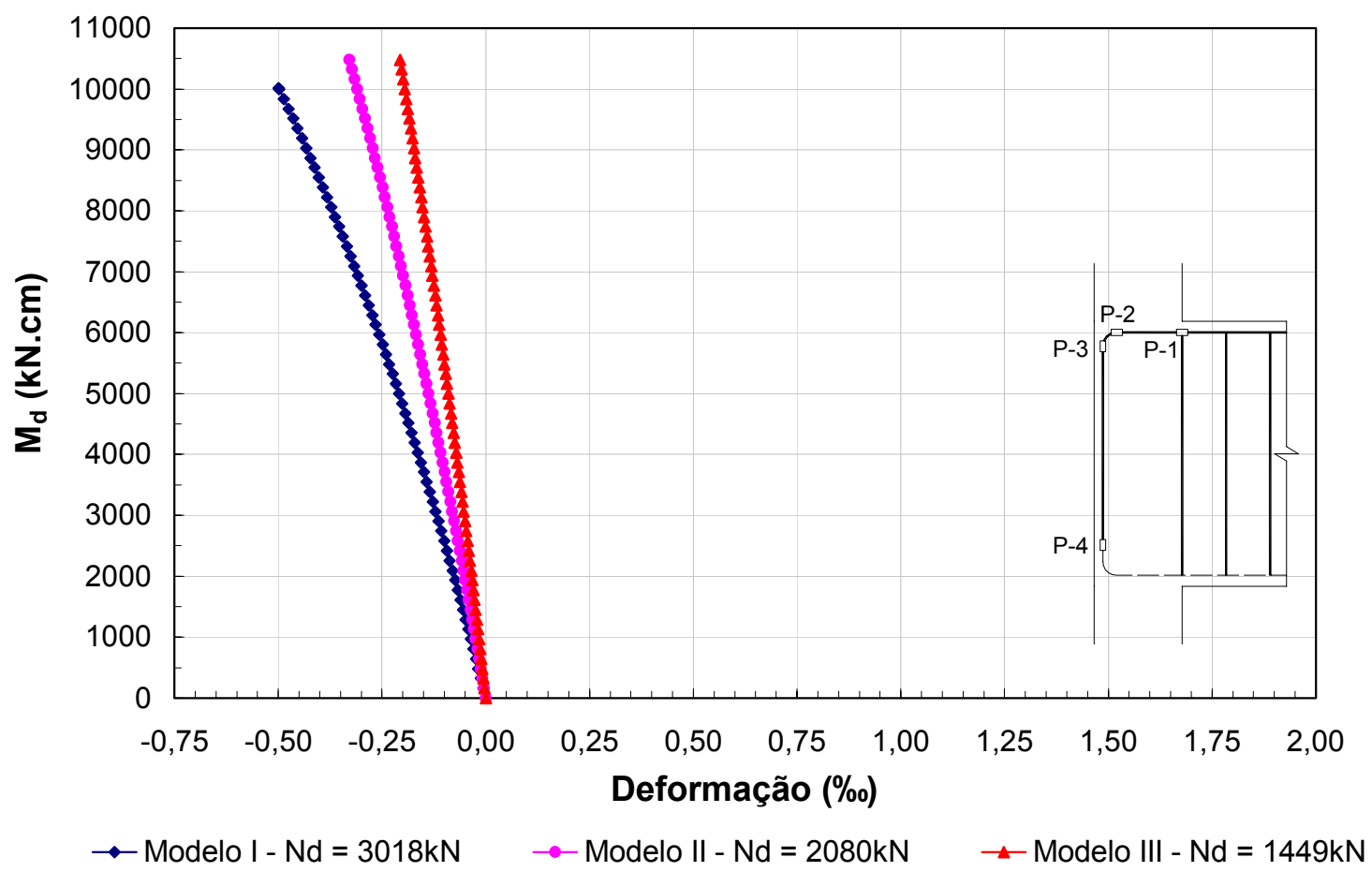

Figura 5.15 - Diagrama momento fletor no eixo do apoio da viga V341 versus deformação no ponto P-4.

O momento de fissuração previsto para a viga V341 segundo a NBR 6118:2003, expresso pela eq.(5.1), é igual aquele estimado para a viga V325, pois, elas são semelhantes em todos os aspectos. Sendo assim, $M_{r}=1949,59 \mathrm{kN} \cdot \mathrm{cm}$.

De acordo com a Figura 5.12, o momento fissuração se dá nos três modelos numéricos em torno de $M_{r}=2500,00 \mathrm{kN} \cdot \mathrm{cm}$. A razão entre o momento de fissuração determinada pela norma brasileira e o encontrado pelos modelos numéricos é tal que, $M_{r, \text { analitico }} / M_{r, \text { numérico }} \cong 0,78$, o que indica que a prescrição normativa está favorável a segurança neste caso e os modelos forneceram resultados convincentes.

Com exceção do ponto na face do pilar (P-1), nos demais pontos, as deformações evoluíram linearmente em todos os estágios de carregamento e foram tão maiores quanto à força normal.

Para o trecho reto horizontal do trecho ancorado das barras da armadura superior, a interferência da força normal foi mais evidente na seção mais solicitada da viga após a fissuração do concreto. No ponto P-2 (final do trecho horizontal reto Figura 5.13) é notável que esta influência praticamente inexista.

Pela avaliação dos pontos P-3 e P-4, as barras nos trechos da região da dobra e do segmento reto vertical ficaram comprimidas no decorrer de todo o carregamento dos 
modelos. No ponto P-3 (no fim da dobra), as deformações foram maiores que as registradas no final da emenda (ponto P-4) e, em ambos, as deformações foram superiores, em módulo, aquelas verificadas no ponto P-2.

Esse comportamento verificado tanto na dobra quanto na ponta reta vertical é justificável, pois, a ponta reta vertical na região do nó colabora na absorção de parte das tensões de compressão advindas das barras da armadura longitudinal do pilar nas quais as barras da armadura longitudinal da viga estão emendadas.

$\mathrm{Na}$ etapa última de carga para cada modelo, foram averiguadas as tensões e deformações máximas encontradas nos pontos de análise que estão apresentadas na Tabela 5.8. Essa verificação confirma os comentários feitos nos parágrafos anteriores a respeito dos resultados encontrados nos pontos de estudo.

Tabela 5.8 - Valores máximos das tensões e deformações nos pontos analisados na armadura superior da viga V341.

\begin{tabular}{c|c|c|c}
\hline Modelo & Posição & $\sigma_{s}\left(\mathrm{kN} / \mathrm{cm}^{2}\right)$ & $\varepsilon_{s}(\%$ o $)$ \\
\hline \multirow{3}{*}{ I } & P-1 & 30,82 & 1,47 \\
& P-2 & 1,74 & 0,08 \\
& P-3 & $-13,60$ & $-0,65$ \\
& P-4 & $-10,48$ & $-0,50$ \\
\hline \multirow{3}{*}{ II } & P-1 & 30,95 & 1,47 \\
& P-2 & 1,59 & 0,08 \\
& P-3 & $-12,48$ & $-0,59$ \\
& P-4 & $-6,89$ & $-0,33$ \\
\hline \multirow{3}{*}{ III } & P-1 & 23,52 & 1,12 \\
& P-2 & 1,46 & 0,07 \\
& P-3 & $-11,20$ & $-0,53$ \\
& P-4 & $-4,34$ & $-0,21$ \\
\hline
\end{tabular}

A força de tração a ancorar obtida para a armadura superior da viga V341 por meio das simulações numéricas, bem como a calculada pelo método analítico, consta na Tabela 5.9. Como a dimensão do apoio paralela ao comprimento da viga é menor, o momento fletor é superior ao determinado para a viga V325.

Os dados necessários para a determinação da força de tração analiticamente estão expostos a seguir:

- $\quad M_{S d, f a c e}=M_{R d, f a c e}=9920,37 \mathrm{kN} \cdot \mathrm{cm}$;

$-\quad d=55,75 \mathrm{~cm}$ 
$\begin{aligned}-\quad x & =15,51 \mathrm{~cm} ; \\ -\quad z & =49,55 \mathrm{~cm} .\end{aligned}$

Substituindo na eq.(5.2), tem-se que a força de tração a ancorar foi:

$$
R_{s t, \text { sup }}=\frac{M_{S d, \text { face }}}{z}=\frac{M_{R d, \text { face }}}{z}=\frac{9920,57}{49,55}=200,21 \mathrm{kN}
$$

Como o número barras da armadura longitudinal superior é quatro, tem-se:

$$
R_{s t, \text { sup }}=\frac{200,21}{4}=50,06 k N
$$

Em termos comparativos, os valores numéricos variaram de $58 \%$ a $76 \%$ da força de tração calculada pelo método analítico.

Tabela 5.9 - Valores últimos da força de tração por barra da armadura superior da viga V341 na seção na face do apoio.

\begin{tabular}{c|c|c|c|c}
\hline \multirow{2}{*}{ Modelo } & Posição & $\begin{array}{c}R_{\text {st,sup, } \text {,umérico }}(k N) \\
(1)\end{array}$ & $\begin{array}{c}R_{\text {st,sup, } \text {,nalitico }}(k N) \\
(2)\end{array}$ & $\frac{(1)}{(2)}$ \\
\hline I & \multirow{2}{*}{$\mathrm{P}-1$} & 37,83 & \multirow{2}{*}{50,06} & 0,76 \\
II & & 38,00 & & 0,76 \\
III & & 28,87 & & 0,58 \\
\hline
\end{tabular}




\subsubsection{Armadura inferior}

Assim como nos modelos utilizados na avaliação da armadura superior, houve problema de convergência no modelo não-linear I. Para tal, as ações foram aplicadas em 65 passos de carga e o percentual máximo atingido foi de $95,48 \%$.

Nos modelos II e III, alcançou-se a convergência total da força concentrada e a pressão no topo do pilar aplicados em 65 e 52 passos, respectivamente. O critério de convergência e a tolerância aceitável foram idênticos aos demais modelos das ligações anteriores.

Para os pontos P-5, P-6, P-7 e P-8 assumidos para a avaliação da armadura longitudinal inferior foram concebidos diagramas que confrontam o momento fletor no eixo do apoio e o aumento progressivo das deformações no decorrer da história do carregamento (ver Figura 5.16, Figura 5.17, Figura 5.18 e Figura 5.19).

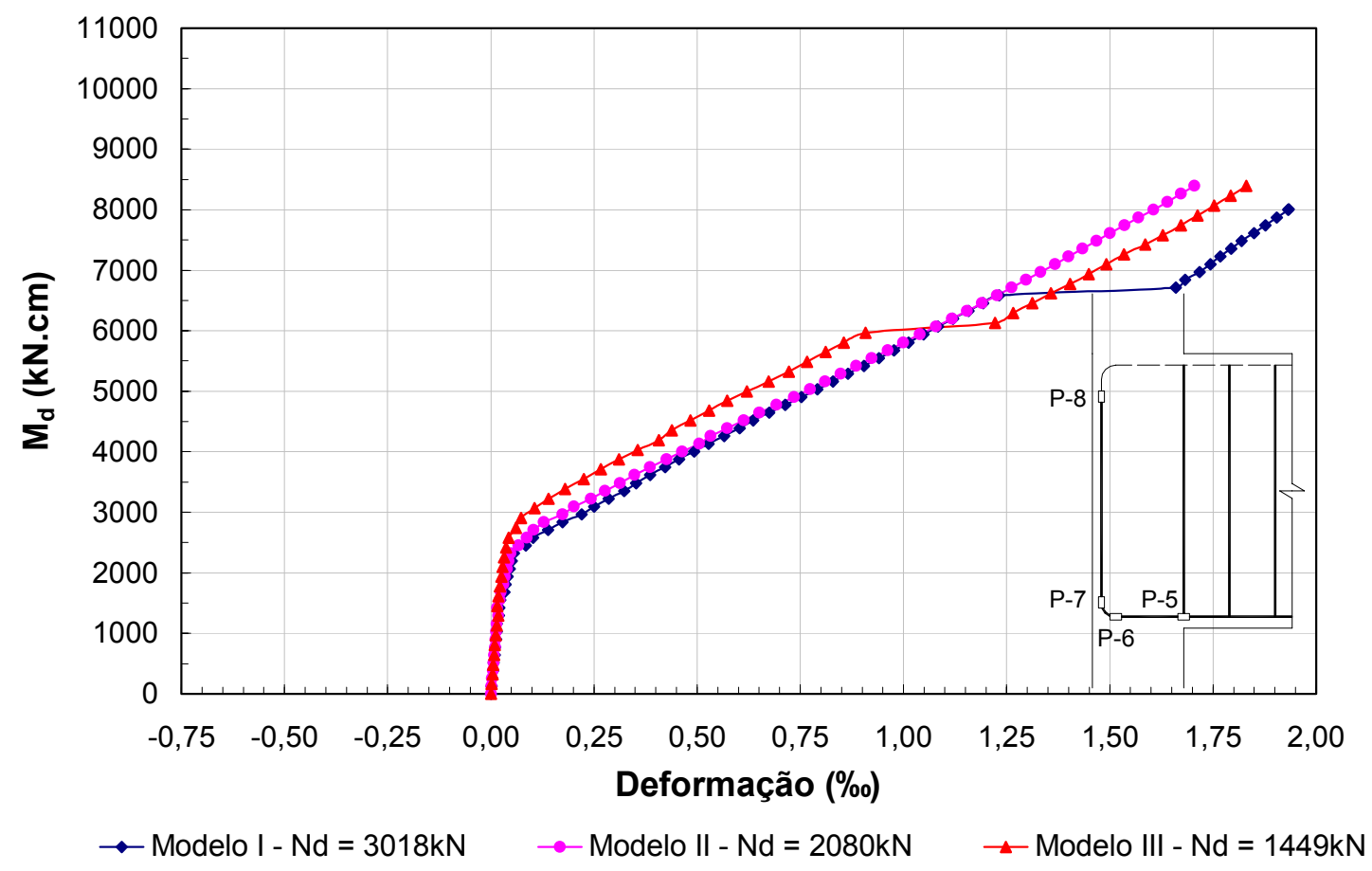

Figura 5.16 - Diagrama momento fletor no eixo do apoio da viga V341 versus deformação no ponto P-5. 


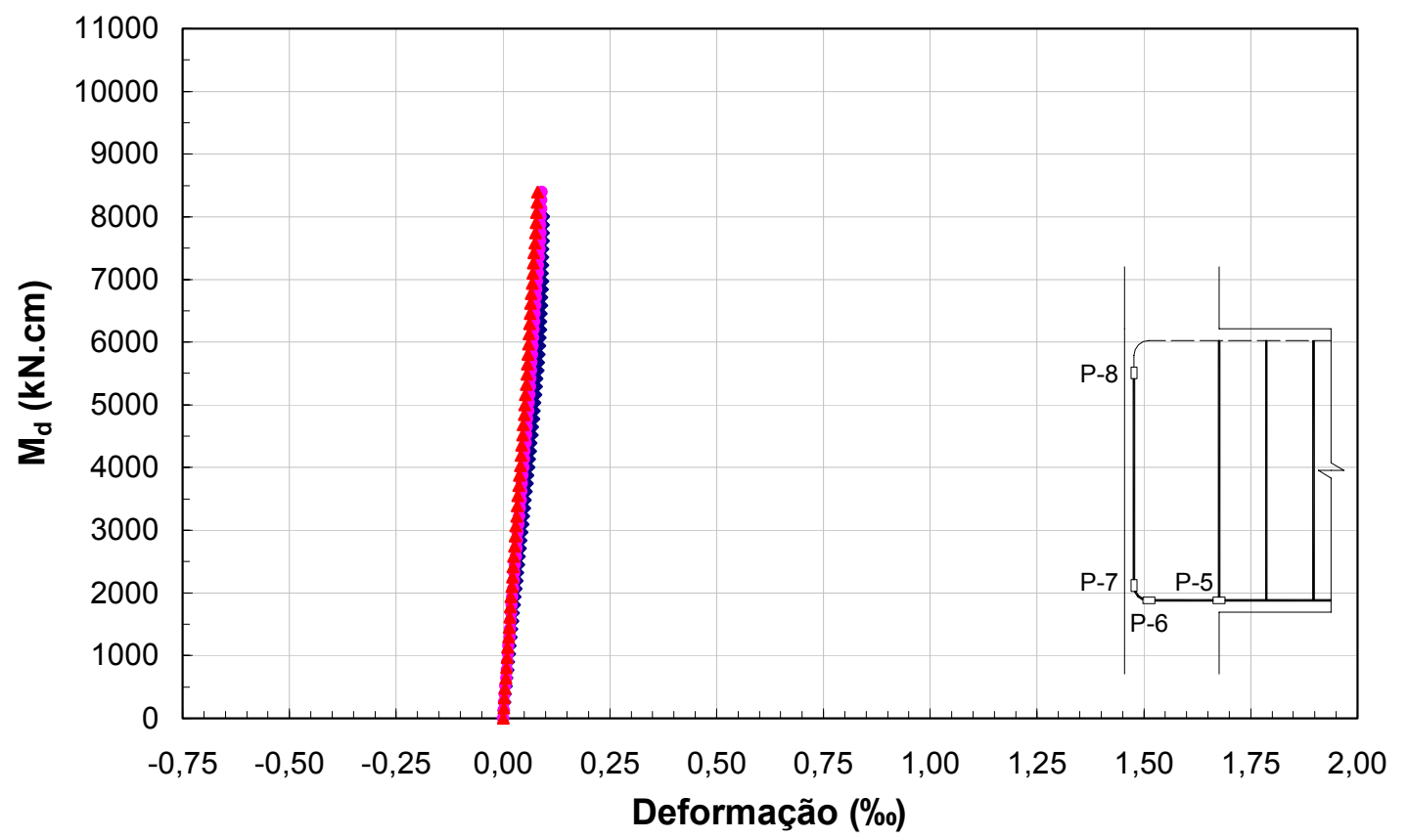

$\rightarrow$ Modelo I - Nd $=3018 \mathrm{kN} \rightarrow$ Modelo II $-\mathrm{Nd}=2080 \mathrm{kN} \rightarrow$ Modelo III $-\mathrm{Nd}=1449 \mathrm{kN}$

Figura 5.17 - Diagrama momento fletor no eixo do apoio da viga V341 versus deformação no ponto P-6.

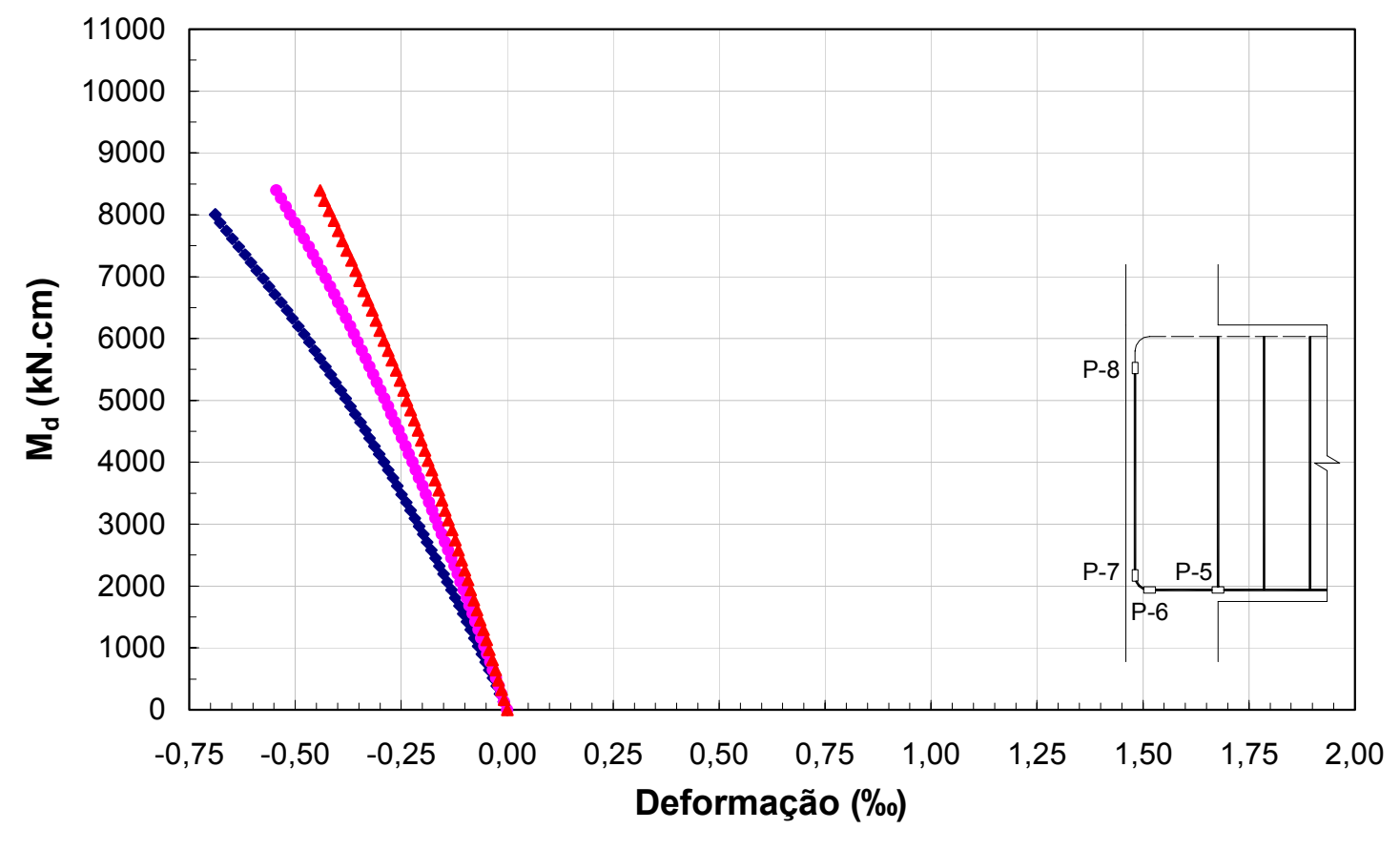

Figura 5.18 - Diagrama momento fletor no eixo do apoio da viga V341 versus deformação no ponto P-7. 


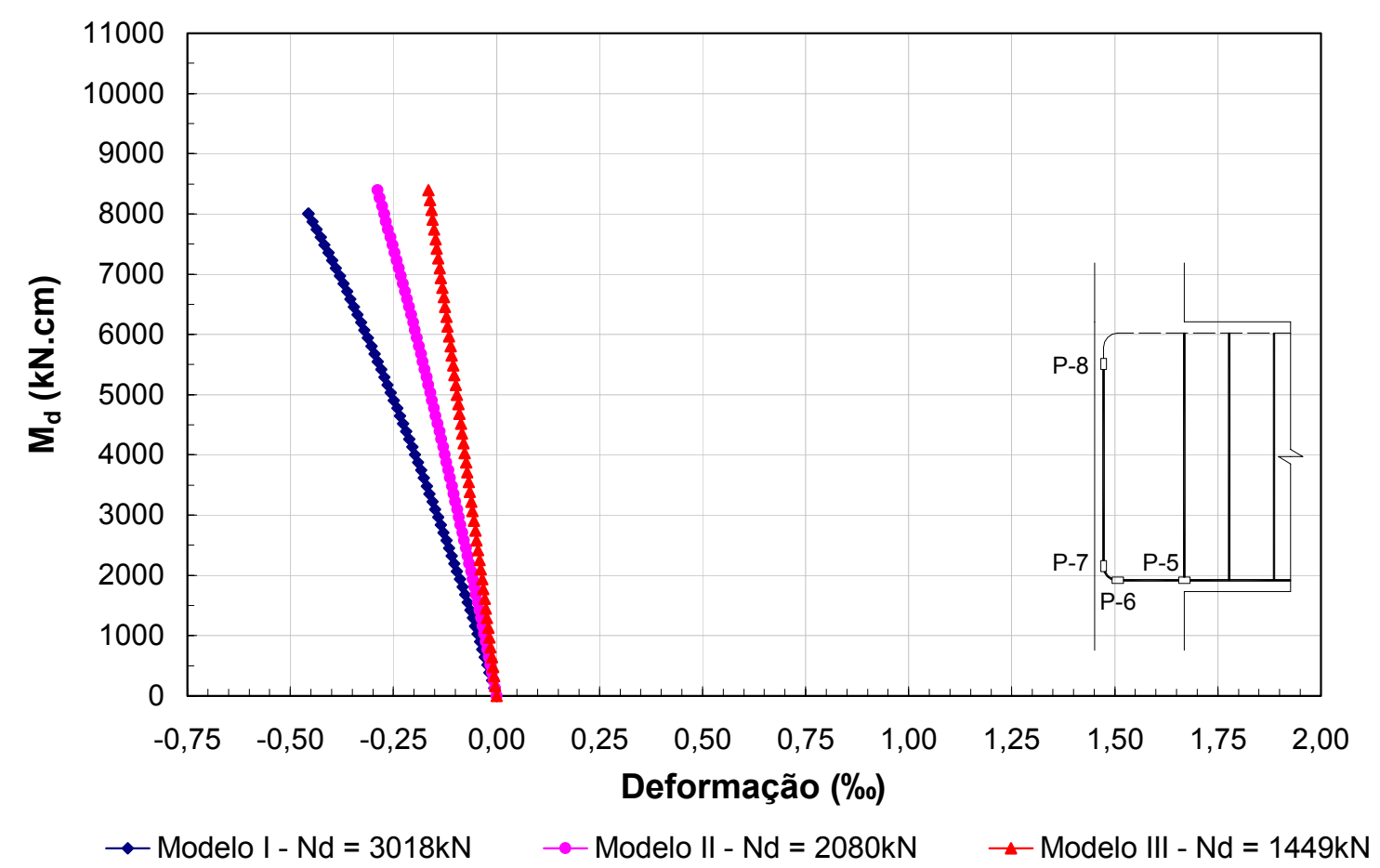

Figura 5.19 - Diagrama momento fletor no eixo do apoio da viga V341 versus deformação no ponto P-8.

A questão do momento de fissuração definido segundo a NBR 6118:2003 recai na mesma situação que ocorreu para a ligação V325-P31. Por esse motivo, assumiu-se esse parâmetro como sendo igual ao determinado para a armadura superior. Logo, o momento de fissuração da viga V341 para o estudo da armadura inferior é $M_{r}=1949,59 \mathrm{kN} \cdot \mathrm{cm}$. De acordo com a Figura 5.16, o momento de fissuração da viga nos três modelos foi caracterizado em $M_{r}=2500,00 \mathrm{kN} \cdot \mathrm{cm}$, que satisfaz a verificação desse parâmetro.

No geral, o comportamento da armadura inferior, no que se refere à evolução das deformações nos pontos estudados, foi semelhante ao da armadura superior. Houve um decréscimo da intensidade de tensão nas seções mais afastadas da face interna do pilar e na região da dobra e da emenda, e as barras trabalharam comprimidas durante toda solicitação.

Os motivos que justificam tal comportamento são os mesmos que foram apresentados na análise da armadura superior. A Tabela 5.10 mostra as tensões e deformações máximas nos pontos P-5, P-6, P-7 e P-8. Os resultados foram satisfatórios no âmbito geral, embora tenha havido certa inconsistência nos resultados do ponto P-5. Esperava-se que no modelo II o resultado fosse superior ao do modelo III. 
Tabela 5.10 - Valores máximos das tensões e deformações nos pontos analisados na armadura inferior da viga V341.

\begin{tabular}{c|c|c|c}
\hline Modelo & Posição & $\sigma_{s}\left(k N / \mathrm{cm}^{2}\right)$ & $\varepsilon_{s}(\%$ o $)$ \\
\hline \multirow{3}{*}{ I } & P-5 & 40,60 & 1,93 \\
& P-6 & 1,99 & 0,10 \\
& P-7 & $-14,47$ & $-0,69$ \\
& P-8 & $-9,59$ & $-0,46$ \\
\hline \multirow{3}{*}{ II } & P-5 & 35,81 & 1,71 \\
& P-6 & 1,91 & 0,09 \\
& P-7 & $-11,43$ & $-0,54$ \\
& P-8 & $-6,06$ & $-0,29$ \\
\hline \multirow{3}{*}{ III } & P-5 & 38,45 & 1,83 \\
& P-6 & 1,70 & 0,08 \\
& P-7 & $-9,28$ & $-0,44$ \\
& P-8 & $-3,46$ & $-0,17$ \\
\hline
\end{tabular}

A Tabela 5.11 apresenta os valores da força de tração obtidos mediante os modelos numéricos e pelo método analítico. Para o cálculo da força de tração analiticamente, os dados utilizados foram os seguintes:

$$
\begin{aligned}
& -\quad M_{S d, f a c e}=M_{R d, f a c e}=7912,55 \mathrm{kN} \cdot \mathrm{cm} ; \\
& -\quad d=57,38 \mathrm{~cm} ; \\
& -\quad x=12,41 \mathrm{~cm} ; \\
& -\quad z=52,41 \mathrm{~cm} .
\end{aligned}
$$

Esses valores foram substituídos na eq.(5.2) e, em seguida, o resultado foi dividido pelo número de barras que compõem a armadura longitudinal inferior da viga V341 do mesmo modo que foi demonstrado em outras ocasiões.

Os resultados numéricos encontrados possuem uma variação entre $87 \%$ e 99\% do valor analítico e, conforme ocorreu na ligação V325-P31, esses valores foram

\begin{tabular}{|c|c|c|c|c|}
\hline Modelo & Posição & $\begin{array}{c}R_{\text {st,inf, } \text {,numérico }}(k N) \\
\text { (1) }\end{array}$ & $\begin{array}{c}R_{s t, \text { inf }, \text { analitico }}(k N) \\
\text { (2) }\end{array}$ & $\frac{(1)}{(2)}$ \\
\hline $\begin{array}{c}\text { I } \\
\text { II } \\
\text { III }\end{array}$ & P-5 & $\begin{array}{l}49,80 \\
43,93 \\
47,17\end{array}$ & 50,32 & $\begin{array}{l}0,99 \\
0,87 \\
0,94\end{array}$ \\
\hline
\end{tabular}
melhores do que aqueles encontrados para a armadura superior.

Tabela 5.11 - Valores últimos da força de tração por barra da armadura inferior da viga V341 na seção na face do apoio. 


\section{Conclusão}

\subsection{Considerações finais}

Nesta dissertação, o enfoque primordial foi a busca do melhor entendimento da ancoragem em ligações de elementos fletidos. Para tanto, foi desenvolvida uma revisão bibliográfica que buscou compilar importantes estudos desenvolvidos ao longo de décadas a respeito do tema.

Como complemento e contribuição ao estudo, foi desenvolvido um método com o qual foi possível reproduzir modelos numéricos bidimensionais de ligações. Por motivos excepcionais, realizaram-se apenas análises restritas as ligações do tipo vigapilar de extremidade. No geral, os exemplos realizados mostraram resultados plausíveis.

\subsubsection{Quanto à análise numérica}

O programa ADINA (2002) se mostrou um procedimento eficaz para a investigação da ancoragem dentro do propósito que foi adotado no desenvolvimento do trabalho.

É óbvio que não se esperava alcançar resultados iguais aqueles determinados por experimentos ou por métodos analíticos de cálculo em virtude das hipóteses admitidas para a viabilização das análises numéricas que de certa maneira distorcem os resultados a obter.

Além disso, tratou-se aqui da modelagem numérica de ligações de concreto armado que é outro agravante. Como o concreto é um material heterogêneo e de diferente comportamento quando submetido à tração e à compressão, sua avaliação se torna mais difícil e penosa. 
Acredita-se que os modelos constitutivos dos materiais tenham sido razoavelmente calibrados e a não consideração do atrito entre o aço e o concreto foi o fator mais relevante em relação à obtenção de melhores respostas.

Como foi um estudo inicial sobre o tema, para a discretização das barras das armaduras e das superfícies de concreto buscou-se utilizar o meio mais simples ao invés do melhor para a geração da malha de elementos finitos, o que não comprometeu os resultados.

\subsubsection{Quanto aos parâmetros de análise}

Como a proposta foi analisar ligações de projeto reais, a aferição desses só foi possível mediante comparação entre os resultados numéricos e as expressões analíticas e prescrições normativas que são habitualmente utilizadas no projeto e dimensionamento de edificações.

Assim, os parâmetros-chave para aferição dos modelos reproduzidos no estudo de caso foram o momento de fissuração e a força de tração a ancorar na seção mais solicitada das vigas. Essas variáveis também serviram para a verificação dos valores experimentais do modelo concebido por Ortiz (1993), porém, havia o registro da relação deformação em alguns pontos da armadura longitudinal e força concentrada aplicada na extremidade da viga os quais foram de grande valia.

Em síntese, os resultados referentes ao momento de fissuração e à força de tração a ancorar foram satisfatórios. Na comparação entre os valores obtidos pelos modelos numéricos e aqueles determinados pelo método analítico as respostas se apresentaram favoráveis à segurança.

Em todos os modelos avaliados, verificou-se que a seção transversal em comum entre o pilar e a viga é a mais crítica e que as deformações e, por conseqüência, as tensões nas barras pertencentes às armaduras longitudinais da viga decresceram à proporção que as seções das barras se afastaram da face interna do pilar.

Nos modelos cuja ancoragem das barras foi de ponta reta, as barras trabalharam somente a tração durante toda a aplicação das solicitações.

Já nas ligações com as barras ancoradas com dobra e ponta reta vertical emendada por traspasse nas barras da armadura longitudinal do pilar, ao passo que as seções das barras foram se afastando da seção de transição entre a viga e o pilar, a tensão foi decaindo até o fim do trecho horizontal reto. Na parte curva, as barras 
passaram a trabalhar comprimidas em virtude das tensões de compressão provenientes da ação da força normal atuante no pilar.

Na ligação viga-pilar BCJ2 experimentalmente desenvolvido por Ortiz (1993) e simulado numericamente neste trabalho, no qual o pilar foi submetido apenas pelo seu peso próprio, constatou-se que, no modelo numérico, na seção final da dobra, as barras permaneceram comprimidas até o surgimento da primeira fissura diagonal no nó e, em seguida, essas barras passaram a estar tracionadas até o instante final de carregamento.

A participação da força normal foi avaliada apenas nos exemplos apresentados no estudo de caso. Neles, percebeu-se que a sua influência é mais significativa no instante pós-fissuração do concreto. Sua atuação tende a provocar a flambagem do pilar ocasionando o alargamento da seção do elemento estrutural. Esse efeito provoca o surgimento de um incremento de tensão o qual é adicionado à tensão que provém da flexão da viga. Por essa razão, observou-se nos modelos que as barras das armaduras longitudinais da viga foram mais solicitadas na proporção que se elevou a força normal.

Para a ancoragem das barras tracionadas, sua atuação é benéfica até certa intensidade por causa da sua contribuição para o aumento do confinamento na região nodal que, por sua vez, melhora as condições de aderência. Todavia, como a força normal eleva as tensões longitudinais de tração nas barras, essas podem provocar fissuração do concreto adjacente e, conseqüentemente, reduzir a capacidade de ancoragem.

\subsection{Sugestões para próximos trabalhos}

Mediante as idéias e conclusões observadas, seguem-se alguns tópicos de cunho sugestivo para possíveis extensões da pesquisa:

- Reprodução de protótipos de ligações de estruturas reais para comparação e aferição de modelos numéricos;

- Estudo da influência das armaduras transversais (estribos) e de combate ao fendilhamento, conforme consta na literatura, no comportamento da ancoragem das armaduras longitudinais;

- Verificação experimental e numérica de outros tipos de ligações (viga-viga, viga-laje e laje-laje); 
- Simulação numérica em modelos bidimensionais para análise da ancoragem em ligações viga-pilar de extremidade considerando o contato entre o aço e o concreto;

- Avaliação do refinamento da malha de elementos finitos na região nodal para a melhoria dos resultados a cerca do comportamento das barras na região ancorada;

- Investigação da ancoragem em modelos tridimensionais. 


\section{Referências}

ADINA (2002). Automatic Dynamic Incremental Nonlinear Analysis. Watertown: ADINA R \& D. 1 CD-ROM.

ALLWOOD, R.J.; BAJARWAN, A.A. (1996). Modeling nonlinear bond-slip behavior for finite element analyses of reinforced concrete structures. ACI Structural Journal, Detroit, v.93, n.5, p.538-544, Sept,/Oct.

ALVA, G.M.S. (2004). Estudo teórico-experimental do comportamento de nós de pórtico de concreto armado submetidos a ações cíclicas. 218p. Tese (Doutorado)Escola de Engenharia de São Carlos, Universidade de São Paulo, São Carlos, 2004.

ALVA, G.M.S.; EL DEBS, A.L.H. (2002). Análise numérica do comportamento de ligações viga-pilar de concreto armado submetidas a ações cíclicas. In: JORNADAS SUL-AMERICANAS DE ENGENHARIA ESTRUTURAL, 30., 2002, Brasília. Anais... Brasília: UnB. 1 CD-ROM.

AMERICAN CONCRETE INSTITUTE (2002). ACI 318/02 - Código de construcción para el hormigón estructural y discusiones. Farmington Hills.

ANDREASEN, B.S. (1991). Anchorage of multilayered reinforcement at supports. Nordic Concrete Research, Oslo, n.10, p.6-23.

ASSOCIAÇÃO BRASILEIRA DE NORMAS TÉCNICAS (1982). NBR 7477 Determinação do coeficiente de conformação superficial das barras e fios de aço destinados a armaduras de concreto armado. Rio de Janeiro.

. (1996). NBR 7480 - Barras e fios de aço destinados a armaduras para concreto armado. Rio de Janeiro.

Janeiro.

(1996). NBR 12655 - Concreto - preparo, controle e recebimento. Rio de

(2003). NBR 6118 - Projeto de estruturas de concreto - procedimento. Rio de $\overline{\text { Janeiro. }}$ 
ATTA, A.EL-N. et al. (2003). Behaviour of reinforced high-strength concrete beamcolumn joint. Part I: experimental investigation. Structural Concrete, Lausanne, v.4, n.4, p.175-183, Dec.

(2004). Behaviour of reinforced high-strength concrete beam-column joint. Part II: numerical simulation. Structural Concrete, Lausanne, v.5, n.3, p.101-112, Sept.

AZIZINAMINI, A.; CHISALA, M.; GHOSH, S.K. (1995). Tension development length of reinforcing bars embedded in high-strength concrete. Engineering Structures, Guildford, v.17, n.7, p.512-522, Aug.

BARBOSA, L.A.G.; ALMEIDA, P.A.O. (2001). Nós de pórtico em estruturas de concreto armado. In: CONGRESSO BRASILEIRO DO CONCRETO, 43., 2001, Foz do Iguaçu. Anais... São Paulo: IBRACON. 1 CD-ROM.

(2003). Comportamento das armaduras longitudinais dos nós de pórtico em $\mathrm{T}$ submetidos a ensaios estáticos e dinâmicos de baixo cíclico. In: CONGRESSO BRASILEIRO DO CONCRETO, 45., 2003, Vitória. Anais... São Paulo: IBRACON. 1 CD-ROM.

BARBOSA, M.T. (2003). Aderência aço-concreto: resultados experimentais x normalização brasileira. In: CONGRESSO BRASILEIRO DO CONCRETO, 45., 2003, Vitória. Anais... São Paulo: IBRACON. 1 CD-ROM.

BARBOSA, M.T.; OLIVEIRA, T.M.; ALBUQUERQUE, R. (2000). Estudo da influência da resistência à compressão do concreto na determinação do coeficiente de conformação superficial das barras. In: JORNADAS SUDAMERICANAS DE INGENIERÍA ESTRUCTURAL, 29., 2000, Punta del Este. Memórias... Montevideo: Instituto de Estructuras y Transporte/Faculdad de Ingenieria/Universidad de la Republica, 2000. 1 CD-ROM.

. (2000a). Teoria da plasticidade aplicada ao estudo da aderência aço-concreto para os aços brasileiros. In: JORNADAS SUDAMERICANAS DE INGENIERÍA ESTRUCTURAL, 29., 2000, Punta del Este. Memórias... Montevideo: Instituto de Estructuras y Transporte/Faculdad de Ingenieria/Universidad de la Republica, 2000. 1 CD-ROM.

CANADIAN STANDARDS ASSOCIATION (1994). CSA standard - A23.3-94 design of concrete structures. Rexdale.

CARVALHO, R.C.; FIGUEIREDO FILHO, J.R. (2004). Cálculo e detalhamento de estruturas usuais de concreto armado segundo a NBR 6118:2003. 2.ed. São Carlos: EDUFSCar.

CASTRO, C.M. (2002). Concreto de alto desempenho: estudo da aderência com a armadura sob ações repetidas. 194p. Dissertação (Mestrado) - Escola de Engenharia de São Carlos, Universidade de São Paulo, São Carlos, 2002. 
CEB-FIB model code 1990: final draft. (1991). CEB Bulletin D'Information, Paris, n.203-205, July.

CUNHA, A.J.P.; SOUZA, V.C.M. (1994). Lajes em concreto armado e protendido. Niterói: EDUFF.

FERNANDES, R.M. (2000). A influência das ações repetidas na aderência açoconcreto. 155p. Dissertação (Mestrado) - Escola de Engenharia de São Carlos, Universidade de São Paulo, São Carlos, 2000.

FERNANDES, R.M.; DEBS, A.L.H. (2000). A influência das ações repetidas na aderência aço-concreto. In: JORNADAS SUDAMERICANAS DE INGENIERÍA ESTRUCTURAL, 29., 2000, Punta del Este. Memórias... Montevideo: Instituto de Estructuras y Transporte/Faculdad de Ingenieria/Universidad de la Republica, 2000. 1 CD-ROM.

FIGUEIRAS, J.A. (1983). Ultimate load analysis of anisotropic and reinforced concrete plates and shells. Ph.D.Thesis - Department of Civil Engineering, University of College of Swansea, Swansea, 1983.

FIORIN, E. (1998). Arranjos de armaduras em estruturas de concreto armado. 248p. Dissertação (Mestrado) - Escola de Engenharia de São Carlos, Universidade de São Paulo, São Carlos, 1998.

FUSCO, P.B. (1995). Técnica de armar as estruturas de concreto. São Paulo: Pini.

GIONGO, J.S. (2004). Concreto armado: ancoragem por aderência. São Carlos: EESC-USP. Apostila.

GIONGO, J.S.; TOTTI JR., F. (1994). Concreto armado: resistência de elementos fletidos submetidos à força cortante. São Carlos: EESC-USP.

GOTO, Y. (1971). Cracks formed in concrete around deformed tension bars. Journal of the American Concrete Institute, New York, v.68, n.4, p.244-251, Apr.

HEGGER, J.; SHERIF, A.; ROESER, W. (2003). Nonseismic design of beam-column joints. ACI Structural Journal, Detroit, v.100, n.5, p.654-664, Sept./Oct.

INSTITUTO BRASILEIRO DO CONCRETO (2003). Prática recomendada IBRACON: comentários técnicos NB-1. NBR 6118:2003 - Projeto de estruturas de concreto - procedimento. São Paulo. (Comitê Técnico - CT 301)

HRIBAR, J.A.; VASKO, R.C. (1969). End anchorage of high strength steel reinforcing bars. Journal of the American Concrete Institute, Detroit, v.66, n.11, p.875-883, Nov.

KUCHMA, D.A.; TJHIN, T.N. (2002). Designing discontinuity regions in structural concrete with computer-based strut-and-tie methodology. Transportation Research Record, Washington, n.1814, p.72-82. 
LEON, R.T. (1989). Interior joints with variable anchorage lengths. Journal of Structural Engineering, v.115, n.9, p.2261-2275, Sept.

LEONHARDT, F.; MÖNNIG, E. (1977). Construções de concreto: princípios básicos do dimensionamento de estruturas de concreto armado. Rio de Janeiro: Interciência. v.1.

(1978). Construções de concreto: princípios básicos sobre a armação de estruturas de concreto armado. 2.ed. Rio de Janeiro: Interciência. v.3.

. (1978a). Construções de concreto: Princípios básicos sobre a armação de estruturas de concreto armado. 2.ed. Rio de Janeiro: Interciência. v.2.

LUNDGREN, K. (2002). FE analyses and tests of lap splices in frame corners. Structural Concrete, Lausanne, v.5, n.3, p.47-57, June.

LUNDGREN, K.; MAGNUSSON, J. (2001). Three-dimensional modeling of anchorage zones in reinforced concrete. Journal of Engineering Mechanics, New York, v.127, n.7, p.693-699, July.

LUO, Y.H. et al. (1994). Study of reinforcing detail of tension bars in frame corner connections. ACI Structural Journal, Detroit, v.91, n.4, p.486-496, July/Aug.

MACGREGOR, J.G. (1988). Reinforced concrete: mechanics and design. Englewood Cliffs; New Jersey: Prentice-Hall.

MARQUES, J.L.G.; JIRSA, J.O. (1975). A study of hooked bar anchorages in beamcolumn joints. Journal of the American Concrete Institute, Detroit, v.72, n.5, p.198209, May.

MARTINS, M.M.; FAKURY, R.H.; PAULA, F.A. (2001). Estudo de pilares metálicos pelo método dos elementos finitos. In: CONGRESSO INTERNACIONAL DA CONSTRUÇÃO METÁLICA/SEMINÁRIO INTERNACIONAL DE ESTRUTURAS METÁlICAS NA CONSTRUÇÃO CIVIL., 4., 2001, São Paulo. Anais... Belo Horizonte: SME/SCI/AM/CEM, 2001.

MINOR, J.; JIRSA, J.O. (1975). Behavior of bent bar anchorages. Journal of the American Concrete Institute, Detroit, v.72, n.4, p.141-149, Apr.

MOEHLE, J.P.; WALLACE, J.W.; HWANG, S.J. (1991). Anchorage lengths for straight bars in tension. ACI Structural Journal, Detroit, v.88, n.5, p.531-537, Sept./Oct.

MONTOYA, P.J.; MESEGUER, A.; CABRE, M. (2000). Hormigón armado. $14^{\text {th }} \mathrm{ed}$. Barcelona: Gustavo Gili.

MORENO JR., A.L.; ROSSI, N. (2002). Resistência de aderência da armadura passiva no concreto de alto desempenho. In: JORNADAS SUL-AMERICANAS DE

ENGENHARIA ESTRUTURAL, 30., 2002, Brasília. Anais... Brasília: UnB. 1 CDROM. 
NILSSON, I.H.E.; LOSBERG, A. (1976). Reinforced concrete corners and joints subjected to bending moment. Journal of the Structural Division, New York, v.102, n.6, p.1229-1254, June.

ORANGUN, C.O.; JIRSA, J.O.; BREEN, J.E. (1977). A reevaluation of test data on development length and splices. ACI Journal Proceedings, Detroit, v.74, n.3, p.114122, Mar.

ORTIZ, I.R. (1993). Strut-and-tie modelling of reinforced concrete short beams and beam-column joints. 208p. Ph.D.Thesis - University of Westminster, London, 1993.

PINTO, R.S. (2002). Análise não-linear das estruturas de contraventamento de edifícios em concreto armado. 155p. Tese (Doutorado) - Escola de Engenharia de São Carlos, Universidade de São Paulo, São Carlos, 2002.

PLIZZARI, G.A.; DELDOSSI, M.A.; MASSINO, S. (1998). Transverse reinforcement effects on anchored deformed bars. Magazine of Concrete Research, London, v.50, n.2, p.161-177, June.

PROENÇA, S.P.B. (2004). Análise não-linear de estruturas. São Carlos: EESC-USP. Notas de aula.

PROMON ENGENHARIA (1976). Tabelas para dimensionamento de concreto armado: segundo a NB-1/76. São Paulo: McGraw-Hill do Brasil.

SCHLAICH, M.; ANAGNOSTOU, G. (1990). Stress fields for nodes of struts-and-tie models. Journal of Structural Engineering, New York, v.116, n.1, p.13-23, Jan.

SILVA, D.M. (1986). Análise experimental sobre o concreto, a aderência e a ancoragem de barras de aço para concreto armado. 2v. Dissertação (Mestrado) Universidade Federal do Rio Grande do Sul, Porto Alegre, 1986.

SILVA, R.C.; GIONGO, J.S. (2000). Modelos de bielas e tirantes aplicados a estruturas de concreto armado. São Carlos: EESC-USP.

. (2002). Ancoragem no apoio extremo em vigas de concreto armado: análises teórica e experimental. In: CONGRESSO BRASILEIRO DO CONCRETO, 44., 2002, Belo Horizonte. Anais... São Paulo: IBRACON.

SHIOHARA, H. (2001). New model for shear failure of RC interior beam-column connections. Journal of Structural Engineering, New York, v.127, n.2, p.152-160, Feb.

SORIANO, H.L. (2003). Métodos de elementos finitos em análise de estruturas. São Paulo: EDUSP.

SOROUSHIAN, P.; CHOI, KI-B. (1989). Local bond of deformed bars with different diameters in confined concrete. ACI Structural Journal, Detroit, v.86, n.2, p.217-222, Mar./Apr. 
. (1991). Analytical evaluation of straight bar anchorage design in exterior joints. ACI Structural Journal, Detroit, v.88, n.2, p.161-168, Mar./Apr.

SOROUSHIAN, P. et al. (1988). Pullout behavior of hooked bars in exterior beamcolumn connections. ACI Structural Journal, Detroit, v.85, n.3, p.269-276, May/June.

SOUZA, R.A. (2001). Análise de fraturamento em estruturas de concreto utilizando programas de análise estrutural. 237p. Dissertação (Mestrado) - Faculdade de Engenharia Civil, Universidade de Estadual de Campinas, Campinas, 2001.

SÜSSEKIND, J.C. (1981). Curso de concreto: concreto armado. 2.ed. Rio de Janeiro: Globo. v.1.

TAYLOR, H.P.J.; CLARKE, J.L. (1976). Some detailing problems in concrete frame structures. The Structural Engineer, London, v.54, n.1, p.19-32, Jan.

TJHIN, T.N.; KUCHMA, D.A. (2002). Computer-based tools for design by strut-andtie method: advances and challenges. ACI Structural Journal, Detroit, v.99, n.5, p.586594, Sept./Oct.

UEDA, T.; LIN, I.; HAWKINS, N.M. (1986). Beam bar anchorage in exterior columnbeam connections. Journal of the American Concrete Institute, Detroit, v.83, n.3, p.412-422, May/June.

UNTRAUER, R.E.; WARREN, G.E. (1977). Stress development of tension steel in beams. ACI Journal Proceedings, Detroit, v.74, n.8, p.368-372, Aug.

YUN, Y.M. (2000). Computer graphics for nonlinear strut-tie model approach. Journal of Computing in Civil Engineering, New York, v.14, n.2, p.127-133, Apr.

. (2000a). Nonlinear strut-tie model approach for structural concrete. $A C I$ Structural Journal, New York, v.97, n.4, p.581-590, July/Aug.

YUN, Y.M.; RAMIREZ, J.A. (1996). Strength of struts and nodes in strut-tie model. Journal of Structural Engineering, New York, v.122, n.1, p.20-29, Jan.

ZIELINSKI, Z.A.; RIGOTTI, M. (1995). Tests on shear capacity of reinforced concrete. Journal of Structural Engineering, New York, v.121, n.11, p.1660-1666, Nov. 